ROSICLER APARECIDA VIEGAS DI LORENZO

\title{
Caracterização da implantação das equipes de saúde da família no Estado de São Paulo: limites e possibilidades
}

\footnotetext{
Dissertação apresentada à Faculdade de Medicina da Universidade de São Paulo para obtenção do título de Mestre em Ciências
}

São Paulo

2006 
ROSICLER APARECIDA VIEGAS DI LORENZO

\title{
Caracterização da implantação das equipes de saúde da família no Estado de São Paulo: limites e possibilidades
}

\author{
Dissertação apresentada à Faculdade de \\ Medicina da Universidade de São Paulo \\ para obtenção do título de Mestre em \\ Ciências
}

Área de concentração: Medicina

Preventiva

Orientador: Prof. Dr. Paulo Eduardo Mangeon Elias

São Paulo 
Agradecimentos

Aos meus pais, irmãos, marido, filhos e aos que se juntaram a nós nesta estrada,

Aos amigos que se reconhecerão neste agradecimento,

Às queridas pessoas que tenho tido o privilégio de confecer e aprender com elas nestes caminhos do PSF. 
“... Pode afirmar-se. Sem lugar para dúvidas, que não é possivel tratar realmente nenhuma pessoa que se olfe a si mesma apenas como um 'caso', e que nenhum médico pode, por seu turno, ajudar um indivíduo a superar uma doença grave ou mais ou menos leve aplicando-lhe apenas o poder rotineiro da sua especialidade. Em ambas as perspectivas somos partícipes de um mundo da vida que nos suporta. $\mathcal{E}$ a tarefa que se nos impõe como seres humanos consiste em encontrar o nosso caminho nesse mundo vital e em aceitar os nossos condicionamentos. Tal caminho implica, para o médico, a dupla obrigação de unir a sua competência altamente especializada à sua participação no mundo da vida [Lebeswelt]." (GADAMER 1997. p.100) 


\section{RESUMO}

DI LORENZO, RAV. Caracterização da Implantação das equipes de saúde da família no Estado de São Paulo: limites e possibilidades. São Paulo. 2006. 245f. Dissertação (Mestrado). Faculdade de Medicina da Universidade de São Paulo.

Este estudo tem como objetivo caracterizar o processo de implantação das equipes de saúde da família (ESF) no Estado de São Paulo (ESP) no período de 1996 a 2001. Foram utilizados dados secundários referentes ao Estado, produzidos por uma pesquisa nacional realizada pelo Ministério da Saúde em 2001 e 2002. Esta pesquisa foi ampliada com questões específicas desenvolvidas pela Coordenação Estadual do Programa Saúde da Familia (PSF). Estes dados referem-se às 1058 ESF implantadas em $54 \%$ dos municípios do Estado, e foram estruturados abrangendo os seguintes aspectos: 1. caracterização das ESF; 2. infraestrutura (área física, equipamentos disponíveis e recursos humanos); 3. ações desenvolvidas pelas ESF; 4 . instrumentos de planejamento e organização do atendimento do trabalho das ESF; 5. capacitações das ESF. As variáveis utilizadas no plano de análise foram o tempo de implantação das equipes e o porte dos municípios. Também foi desenvolvida uma classificação de adequação das caracteristicas estudadas que objetivou verificar maior ou menor aproximação com a situação ideal preconizada pelas diretrizes do PSF. Os resultados do presente estudo fornecem elementos que podem contribuir para implantação de novas ESF e servir como linha de base para estudos futuros. 


\begin{abstract}
DI LORENZO, RAV. Characterization of the implantation of the family heath team in the São Paulo State; limits and possibilities. São Paulo. 2006. 245f. Dissertação (Mestrado). Faculdade de Medicina da Universidade de São Paulo.
\end{abstract}

The objective of this study is to evaluate the implantation of family health teams (FHTs) in the State of São Paulo (SSP), Brazil, during the period 1996-2001. Secondary data from the SSP obtained through a national survey carried out by the Ministry of Health in 2001-2202 were utilized. This survey was expanded by the State Coordination of the Family Health Program (PSF) to include specific questions. These data refer to $1058 \mathrm{FHTs}$ implemented in $54 \%$ of the municipalities of the SSS, and were structured to encompass the following aspects: 1 . characterization of the FHTs; 2. infrastructure (physical area, available equipment and human resources); 3. actions developed by the FHTs; 4 . planning instruments and organization of the work of the FHTs; 5 . FHTs training. The variables used for the analysis included time of implementation of the FHTs and size of the municipalities. An adequateness scoring classification for the studied characteristics was developed in order to assess greater or smaller approximation to the ideal situation envisioned by the Family Heath Program (PSF) of guidelines. The results of this study provide elements that may contribute to the implementation of new FHTs and serve as baseline data for future studies. 


\section{SUMÁRIO}

\section{RESUMO \\ SUMMARY}

1 INTRODUÇÃO

2 PROGRAMA DE SAÚDE DA FAMÍLIA: UMA ESTRATÉGIA DA

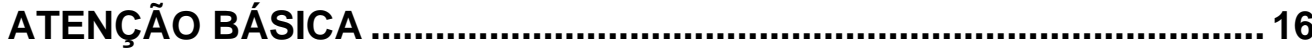

2.1 Da exclusão à proposta de universalidade da atenção à doença à proposta de atenção à saúde ........................................................... 16

2.2 Princípios e diretrizes do Programa Saúde da Família....................... 30

2.3 Uma visão geral da implantação do Programa Saúde da Família no Brasil

2.4 Uma visão geral da implantação do Programa Saúde da Família no Estado de São Paulo.

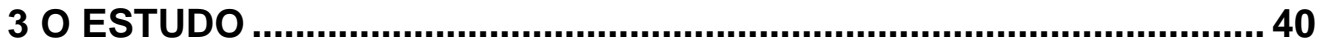

4 OBJETIVOS

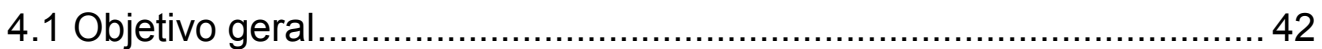

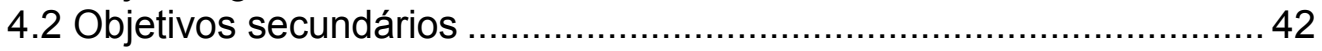

5 PROCEDIMENTOS DA PESQUISA .................................................... 43

6 RESULTADOS E DISCUSSÃO ........................................................... 47

6.1 Caracterização das ESF no estado de São Paulo ..............................4 47

6.1.1 Descrição geral da caracterização da implantação das equipes de saúde da família no Estado de São Paulo (ESP) ............ 47

6.1.1.1 Tempo de implantação, porte dos municípios com PSF implantado e cobertura populacional pelas ESF ............................4 47

6.1.1.2 Área de atuação das ESF ............................................. 50

6.1.1.3 População adstrita às ESF .............................................. 51

6.1.2 Caracterização dos municípios com PSF implantado no

Estado de São Paulo.

6.1.2.1 Caracterização - tempo de implantação, porte dos

municípios com PSF implantado e cobertura populacional

pelas ESF

6.1.2.2 Caracterização - Área de atuação das ESF.....

6.1.2.3 Caracterização - População adstrita às equipes de

saúde a família.

6.2 Infra-estrutura (áreas física, equipamentos e pessoal)........................59

6.2.1 Infra-estrutura da Unidade Básica de Saúde (UBS) .................. 59

6.2.1.1 Número de equipes e dependências de área física por UBS

6.2.2 Infra-estrutura da Unidade Básica de Saúde (UBS) 
6.2.2.1 Número de equipes por UBS e dependências de área física das UBS

6.2.3 Existência de equipamentos disponíveis para o trabalho das ESF

6.2.3.1 Existência do conjunto básico de equipamentos para o trabalho das ESF

6.2.3.2 Existência de "kit" básico de equipamentos para o

atendimento de adultos e crianças

6.2.3.3 Existência de "kit" básico de equipamentos para o

atendimento de mulheres pelas ESF

6.2.3.4 Existência de equipamentos para aumentar a

resolubilidade das ESF

6.2.4 Existência de equipamentos para o trabalho das ESF .............. 73

6.2.4.1 Equipamentos disponíveis para o trabalho das equipes.....73

6.2.4.2 Existência do conjunto básico de equipamentos

disponível para o trabalho das equipes

6.2.4.3 Existência de "kit" básico de equipamentos para o

atendimento de adultos e crianças

6.2.4.4 Existência de "kit" básico de equipamentos para o

atendimento de mulheres

6.2.4.5 Existência de equipamentos para aumentar a

resolubilidade das equipes

6.2.5 Caracterização dos recursos humanos das ESF.....................78

6.2.5.1 Caracterização dos médicos das ESF .............................. 78

6.2.5.1.1 Número de médicos por ESF..................................... 78

6.2.5.1.2 Tempo de atuação dos médicos nas ESF.....

79

6.2.5.1.3 Carga horária trabalhada, cumprida e vinculação

trabalhista dos médicos das ESF 80

6.2.5.1.4 Faixa salarial dos médicos das ESF

6.2.5.2 Caracterização dos Médicos das ESF

6.2.5.2.1 Número de médicos por equipe de saúde da família ... 85

6.2.5.2.2 Tempo de atuação dos médicos nas ESF.

6.2.5.2.3 Carga horária trabalhada, cumprida e vinculação

trabalhista dos médicos das ESF

6.2.5.2.4 Faixa salarial dos médicos das ESF ........................... 89

6.2.5.3 Caracterização dos enfermeiros das ESF .........................90 90

6.2.5.3.1 Número de enfermeiros por ESF

6.2.5.3.2 Tempo de atuação dos enfermeiros das ESF

.90

6.2.5.3.3 Carga horária contratada, cumprida e vinculação trabalhista dos enfermeiros das ESF

6.2.5.3.4 Faixa salarial dos enfermeiros das ESF ..................... 95

6.2.5.4 Caracterização dos enfermeiros das ESF ....................... 96

6.2.5.4.1 Número de enfermeiros por ESF ..............................96

6.2.5.4.2 Tempo de atuação dos enfermeiros nas ESF ..............99

6.2.5.4.3 Carga horária trabalhada, cumprida e vinculação

trabalhista dos enfermeiros das ESF

6.2.5.4.4 Faixa salarial dos enfermeiros das ESF 
6.2.5.5 Caracterização dos auxiliares de enfermagem das ESF ....100

6.2.5.5.1 Número de auxiliares de enfermagem nas ESF.......... 100

6.2.5.5.2 Tempo de atuação dos auxiliares de enfermagem nas ESF. 101

6.2.5.5.3 Carga horária contratada, cumprida e vinculação trabalhista dos auxiliares de enfermagem das ESF ................... 101

6.2.5.6 Caracterização dos auxiliares de enfermagem das ESF .... 107

6.2.5.6.1 Número de auxiliares de enfermagem por ESF ........... 107

6.2.5.6.2 Tempo de atuação dos auxiliares de enfermagem nas ESF 108

6.2.5.6.3 Carga horária trabalhada, cumprida e vinculação trabalhista dos auxiliares de enfermagem das ESF 109

6.2.5.6.4 Faixa salarial dos auxiliares de enfermagem das ESF.

6.2.5.7 Caracterização dos agentes comunitários de saúde

(ACS) das ESF 111

6.2.5.7.1 Número de ACS por ESF.... 111

6.2.5.7.2 Carga horária contratada, cumprida e vinculação trabalhista dos ACS das ESF. 113

6.2.5.7.3 Faixa salarial dos ACS das ESF 115

6.2.5.8 Caracterização dos ACS das ESF 117

6.2.5.8.1 Número de ACS por ESF 117

6.2.5.8.2 Carga horária trabalhada, cumprida e vinculação trabalhista dos ACS das ESF. 118

6.2.5.8.3 Faixa salarial dos ACS das ESF.

6.3 Ações desenvolvidas pelos profissionais das ESF 121

6.3.1 Atividades realizadas pelos médicos dentre as previstas para as ESF

6.3.1.1 Atividades realizadas pelos médicos das ESF... 121

6.3.1.2 Atendimentos clínicos realizados pelos médicos das ESF

6.3.2 Atividades realizadas pelos médicos dentre as previstas para as ESF - considerações

6.3.2.1 Atividades realizadas pelos médicos das ESF. 125

6.3.2.2 Atendimentos clínicos realizados pelos médicos das ESF 126

6.3.3 Atividades realizadas pelos enfermeiros dentre as previstas para as ESF

6.3.3.1 Atividades realizadas pelos enfermeiros das ESF .............. 128

6.3.3.2 Atendimentos clínicos realizados pelos enfermeiros das ESF 130

6.3.4 Atividades realizadas pelos enfermeiros dentre as previstas para as ESF - considerações

6.3.4.1 Atividades realizadas pelos enfermeiros das ESF 132

6.3.4.2 Atendimentos clínicos realizados pelos enfermeiros das ESF 
6.3.5 Atividades realizadas pelos auxiliares de enfermagem dentre as previstas para as ESF.

6.3.6 Atividades realizadas pelos auxiliares de enfermagem

dentre as previstas para as ESF - considerações

6.3.7 Atividades realizadas pelos ACS dentre as previstas para as

ESF

6.3.8 Atividades realizadas pelos ACS dentre as previstas para as

ESF - considerações

6.3.9 Ações das ESF por área de atenção à saúde

6.3.9.1 Ações das ESF na saúde da mulher

6.3.9.2 Ações das ESF na saúde da criança

6.3.9.3 Ações das ESF na saúde do adulto (controle da hipertensão arterial e diabetes)

6.3.9.4 Ações das ESF na eliminação da hanseníase e no

controle da tuberculose

6.3.9.5 Ações das ESF na realização das ações de vigilância

epidemiológica

6.3.9.6 Ações das ESF na realização das ações de investigação

de óbitos

6.3.9.7 Ações das ESF na realização das ações de investigação

de internações hospitalares

6.3.9.8 Ações das ESF na realização das ações de

acompanhamento em saúde mental

6.3.9.9 Ações das ESF na realização das ações de doenças de

transmissão sexual

6.3.10 Realização de atividades educativas continuadas em grupos populacionais.

6.3.11 Ações das ESF por área de atenção à saúde

6.3.11.1 Ações das ESF na saúde da mulher

6.3.11.2 Ações das ESF na saúde da criança

6.3.11.3 Ações das ESF na saúde do adulto (controle da hipertensão arterial e diabetes)

6.3.11.4 Ações das ESF na eliminação da hanseníase e no controle da tuberculose

6.3.11.5 Ações das ESF na realização das ações de vigilância epidemiológica

6.3.11.6 Ações das ESF na realização das ações de investigação de óbitos

6.3.11.7 Ações das ESF na realização das ações de investigação de internações hospitalares.

6.3.11.8 Ações das ESF na realização das ações de acompanhamento em saúde mental

6.3.11.9 Ações das ESF na realização das ações de doenças de 
6.3.12 Realização de atividades educativas continuadas em grupos populacionais.

6.4 Instrumentos de planejamento e organização do trabalho das ESF ... 162 6.4.1 Existência dos Instrumentos de planejamento do trabalho das equipes de ESF

6.4.2 Existência de área de abrangência definida e de mapa da área de abrangência para as ESF

6.4.3 Utilização das informações do SIAB para planejamento das atividades das ESF

6.4.4 Existência de cronograma semanal de atividades para os profissionais das ESF

6.4.5 Utilização de prontuário pelas ESF e tipos existentes nas UBS

6.4.6 Atendimento a pacientes não agendados.

6.5 Existência de vagas diárias para pacientes não agendados pelas

ESF

6.5.1 Participação dos profissionais nas reuniões de equipe.

6.6 Instrumentos de planejamento e organização do trabalho das ESF ... 172

6.6.1 Existência dos Instrumentos de planejamento do trabalho das equipes de ESF

6.6.2 Existência de área de abrangência definida e de mapa da área de abrangência para as ESF

6.6.3 Utilização das informações do SIAB para planejamento das atividades das ESF.

6.6.4 Existência de cronograma semanal de atividades para os profissionais das ESF.....

6.6.5 Utilização de prontuário pelas ESF e tipo de prontuário existentes nas UBS

6.6.6 Atendimento a pacientes não agendados............................... 178

6.6.7 Participação dos profissionais nas reuniões de equipe .............. 179

6.7 Capacitação das ESF....

6.7.1 Capacitação geral das ESF. 180

6.7.2 Existência de programa sistemático de educação continuada para os profissionais das equipes

6.8.1 Capacitação geral das ESF

6.8.1.1 Capacitação das ESF em treinamento introdutório e preenchimento do Sistema de Informação da Atenção Básica

6.8.1.2 Capacitação das ESF em saúde da criança

6.8.1.3 Capacitação das ESF em saúde da mulher

6.8.1.4 Capacitação das ESF em diabetes e hipertensão arterial .. 187 6.8.1.5 Capacitação as ESF em hanseníase, tuberculose e DST/ AIDS 
6.8.2 Existência e programa sistemático de educação continuada para os profissionais das equipes

6.8.2.1 Participação e controle social por profissionais das ESF ... 189

7 CONSIDERAÇÕES FINAIS .................................................................. 190

REFERÊNCIAS BIBLIOGRÁFICAS..................................................... 207

ANEXO I - QUESTIONÁRIO DA PESQUISA ........................................ 213 


\section{INTRODUÇÃO}

O Programa Saúde da Família (PSF) tem sido apontado como estratégia prioritária de implementação da atenção básica no Brasil. (BRASIL, MS, 1998; PNS, 2004).

No Estado de São Paulo, a exemplo do que ocorre no Brasil, o PSF vem se expandindo regularmente desde a sua implantação, com aumento da participação dos municípios na sua implementação e com graus variados de cobertura populacional.

Entretanto, uma questão que se coloca é - em que medida as diretrizes propostas para o PSF estão sendo incorporadas e viabilizadas pelos municípios e em que medida os pressupostos do desenvolvimento do trabalho das equipes de saúde da família (ESF) podem ser verificados?

Assim, com essa perspectiva, este estudo visa descrever alguns aspectos selecionados do Banco de Dados relativo à pesquisa realizada com as equipes de saúde da família implantadas no Estado de São Paulo no ano de 2001.

Mesmo considerando-se possíveis restrições de se trabalhar com dados secundários, este estudo trata da possibilidade de sistematizar um conjunto de informações verificadas em cada equipe, UBS e cidade do Estado de São Paulo. Essas informações retratam as várias dimensões da 
situação de implantação do PSF em cada um dos locais visitados no momento da pesquisa, bem como propiciam uma visão geral da implantação do PSF no Estado.

Muitos dados encontrados podem não refletir aspectos qualitativos mais acurados, sendo necessário agregar outras verificações para isso. Entretanto, a ausência e/ou deficiência de respostas previstas na realização do PSF, relativas a recursos humanos, área física, materiais e equipamentos, capacitação e realização de ações, podem dar uma noção das correções necessárias para que se atinja os objetivos e resultados esperados nessa forma de prestação de atenção à saúde das pessoas.

Assim sendo, a descrição desse Banco de Dados possibilitará uma visão da estratégia saúde da família nos seus seis primeiros anos de implantação, e pode servir de "linha de base" para futuros olhares na implementação dessa estratégia no Estado de São Paulo.

Este estudo descritivo procurou também verificar se o tempo de implantação e o tamanho do município influenciaram os itens pesquisados.

Cabe informar, ainda, que a Coordenação Estadual da implantação do PSF, função exercida pela autora na época, teve a oportunidade de agregar ao questionário original do Ministério da Saúde (MS) algumas questões consideradas importantes de serem verificadas para o Estado, o que faz com que o Banco de dados relativo ao Estado de São Paulo possua diferenças em relação ao do MS para a pesquisa em nível nacional. Entre 
essas questões estão, por exemplo, as relativas aos salários recebidos pelos profissionais das equipes, a existência de cronograma semanal de atividades para esses profissionais, vinculação dos profissionais a programas de educação continuada, além da realização de atendimento clínico nas três clínicas básicas individualizadas para os médicos e enfermeiros (Vide Anexo I - Questionário da Pesquisa).

O Estado de São Paulo fez parte, juntamente com alguns estados, da primeira fase da pesquisa nacional que ocorreu no ano de 2001. Para a segunda fase da pesquisa, que ocorreu no ano de 2002, o MS adotou algumas das questões formuladas no Estado de São Paulo.

Os dados relativos às questões formuladas pelo Estado de São Paulo não fazem parte, no entanto, dos relatórios nacionais da pesquisa elaborados e apresentados pelo MS. Assim, este estudo descritivo, possibilitará também o conhecimento e explicitação das informações relativas às questões formuladas no Estado de São Paulo para a pesquisa avaliativa. 


\section{PROGRAMA DE SAÚDE DA FAMÍLIA: UMA ESTRATÉGIA DA ATENÇÃO BÁSICA}

\subsection{Da exclusão à proposta de universalidade da atenção à doença à proposta de atenção à saúde}

Qualquer consideração ou pensamento que se queira elaborar em saúde pública deve-se levar em conta alguns aspectos fundamentais que antecederam a própria instituição do Sistema Único de Saúde (SUS), bem como os acontecimentos que vem se sucedendo desde então.

Assim, entre outros aspectos, é importante relembrar que antes da instituição do SUS, o sistema de saúde funcionava com restrições e com exclusões graves de segmentos populacionais em relação ao atendimento à saúde, reconhecendo apenas o direito à saúde dos trabalhadores com carteira assinada, caracterizando uma forma regulada de cidadania $(\mathrm{COHN}$; ELIAS, 1996). Aqueles que não estivessem vinculados ao mercado formal de trabalho não tinham acesso aos serviços de saúde e, se não pudessem pagar pelos mesmos, estavam sujeitos à caridade. (PAIM, 2002)

Essa forma de exclusão das pessoas das ações de saúde, principalmente enquanto direito inerente aos cidadãos, pode ser verificada desde o século XIX, quando a política de saúde privilegiava o saneamento dos espaços de circulação de mercadorias, visando o controle ou a 
erradicação de doenças que poderiam prejudicar a exportação das mesmas. (VILAÇA, 1995)

Posteriormente, as ações de saúde passaram a ser dirigidas ao trabalhador no sentido de manter suas condições para o trabalho e de "Ihe assegurar forças mínimas de sobrevivência ante os acidentes e as conseqüências do esgotamento de sua capacidade para o trabalho" (COHN; ELIAS, 1996). Para atender essa população, nos anos 1920, é criada a Previdência Social com a função de atender apenas os trabalhadores assalariados, principalmente na forma de benefícios como aposentadorias e pensões, estando a assistência médica condicionada à disponibilidade de recursos. (DONNANGELO, 1975)

Essa assistência era prestada principalmente nos centros urbanos por médicos em prática privada, estando a assistência hospitalar concentrada nas misericórdias, pertencentes a instituições religiosas ou filantrópicas. (VILAÇA, 1995)

A industrialização ocorrida nos anos 1950 promove um aumento de demanda por serviços médicos, principalmente devido às precárias condições de trabalho e de saúde das populações, sendo que a assistência médica se torna efetivamente uma reivindicação dos trabalhadores.

Nos anos 1960, a assistência médica individual passa a fazer parte da Previdência sendo que os Institutos de Aposentadoria e Pensão (IAPs) são substituídos, em 1966, por um único e poderoso Instituto Nacional da 
Previdência Social (INPS), cujas características são um aprofundamento do caráter assistencialista da Previdência Social e a ausência de controle por parte dos trabalhadores, ganhando destaque à assistência médica. (COHN; ELIAS, 1996)

O que pode ser verificado é que desde o começo do século passado as ações de saúde têm deixado de ter como foco principal a manutenção dos ambientes de trabalho, passando a ter como maior preocupação o trabalhador, enquanto força de trabalho fundamental para a produção, ação que cabia à Previdência Social. Ao MS cabia a realização de ações na forma de campanhas sanitárias, de programas especiais: materno-infantil, tuberculose, hanseníase, endemias, entre outras, além de ações complementares como internações em psiquiatria, tisiologia, etc. A medicina previdenciária baseava-se na oferta de consultas médicas, serviços de diagnose e terapia, e internações hospitalares compradas do setor privado (serviços médicos de empresas, setor filantrópico, clínicas e hospitais privados, etc). (PAIM, 2002)

As ações de saúde pública eram, de maneira geral, dirigidas a determinadas ações ou grupos populacionais, os quais se acreditava serem incapazes de adquirir uma consciência sanitária por eles mesmos, fase em que preponderaram as atividades de educação sanitária, com o fortalecimento da divisão entre saúde pública e saúde individual. 
Coincide com a transição das fases das campanhas e da polícia sanitária para a de Educação Sanitária o início da institucionalização da assistência médica individual vinculada à Previdência Social [...] a Saúde Pública irá assumindo cada vez mais um papel complementar e subordinado, desde o nível das dotações orçamentárias até o das representações ideológicas, em que vai sendo identificada à imunização e ao saneamento básico. (MENDES-GONÇALVES, 1994, p. 116)

No início dos anos 1970, com a crise social decorrente do final do milagre econômico, verifica-se a persistência de uma grande diferença no acesso das pessoas aos serviços e ações de saúde, principalmente daqueles que dependiam do setor público. Essa diferença, todavia, também era evidenciada para a população previdenciária, apesar de ocorrerem algumas ações de extensão de cobertura e a inclusão de determinados grupos sociais como os destacados na análise realizada por Cohn e Elias (1996, p. 21):

[...] maiores de 70 e inválidos que tenham em algum período contribuído para Previdência Social ou exercido qualquer atividade a ela vinculada, mesmo sem terem contribuído, a concessão de benefícios aos trabalhadores rurais acidentados no trabalho; a inclusão do salário maternidade, até então sob responsabilidade da empresa; a extensão dos benefícios previdenciários às empregadas domésticas e trabalhadores autônomos, trabalhadores rurais, salário maternidade, empregados domésticos e trabalhadores autônomos.

Apesar dessa inclusão, Vilaça (1995, p.23) ressalta: "entretanto, ao mesmo tempo em que se ampliava o âmbito de ação da Previdência Social, desnudava-se o caráter discriminatório da política de saúde, na medida em 
que ficavam claras as desigualdades no acesso quantitativo e qualitativo entre as diferentes clientelas urbanas e entre estas e as rurais".

Ao mesmo tempo vão se fortalecendo as atividades de saúde ligadas ao setor privado em detrimento do fortalecimento das ações de saúde pública, permitindo que o sistema de saúde se organizasse com base na procura espontânea, na prática médica curativa, individual, assistencialista, além de favorecer os produtores privados de saúde e de excluir parcelas significativas da população:

De um lado, se notava a dominância da medicina altamente diferenciada, de custo elevado e intenso consumo por parte da população: de outro, um elevado número de pessoas que tinham necessidades básicas de saúde sem atendimento. (SILVA; DALMASO, 2002, p. 21)

Era necessário ampliar as ações de saúde para as populações não atendidas pela previdência social, uma vez que era inviável estender o modelo de medicina privada para todos, tornando imprescindíveis ações voltadas à diminuição da exclusão e que oferecessem também a estas populações marginalizadas, além das ações de saúde pública, assistência médica individual. É neste contexto que surgem os Programas de Extensão de Cobertura (PECs), como o Programa de Interiorização das Ações de Saúde e Saneamento (PIASS), dirigidos às populações rurais e marginalizadas das áreas urbanas. Esses programas, em geral, de acordo com Paim (2002, p. 297), eram baseados no movimento da Medicina Comunitária, "que se pautava pelo princípio da integralidade da atenção, 
associadas a propostas racionalizadoras tais como: regionalização, hierarquização de serviços, tecnologias simplificadas, utilização de pessoal auxiliar, participação da comunidade, etc".

Essas propostas também eram respaldadas pela Declaração de Alma-Ata, de 1978. Entretanto, cabe ressaltar que há uma apropriação reducionista da proposta de atenção primária, acordada em Alma-Ata, em 1978, como salienta Vilaça (1995 p. 26):

[...] Assim começa a desenvolver-se no Brasil, uma proposta de atenção primária seletiva, concebida na sua concepção estreita de um programa, executado com recurso marginal, dirigido às populações marginalizadas de regiões marginalizadas através da oferta de tecnologias simples e baratas, providas por pessoal de baixa qualificação profissional, sem possibilidades de referência a níveis de maior complexidade tecnológica, incluindo a retórica da participação comunitária.

\section{Nesse período vai se conformando o Movimento da Reforma}

\section{Sanitária.}

\footnotetext{
Em oposição a essa modalidade de intervenção estatal nas condições de saúde da população e a essa organização institucional 'hegemonizada' pelos interesses privados, o movimento sanitário articulou-se durante os 'anos Geisel', ao fim dos quais apresentou-se como um movimento propriamente dito, com órgãos de representação, propostas de transformação, mecanismos de formação de agentes e de divulgação de seu pensamento. (ESCOREL,1998, p. 63)
} 
Com a promulgação da Constituição Federal (CF) em 1988, fica instituído o Sistema Único de Saúde (SUS), reafirmando os conceitos fundamentais do movimento sanitário, como explicitados no texto da CF:

Saúde é direito de todos e o dever do Estado, garantido mediante políticas sociais e econômicas que visem à redução do risco das doenças e de outros agravos e ao acesso universal e igualitário às ações e serviços para sua promoção, proteção e recuperação. (BRASIL, CF, 1988, art.196)

Com a criação do SUS, são definidos aspectos fundamentais de responsabilização, abrangência e visão sobre a questão da saúde, trazendo com isso a necessidade, entre outras questões, de rever como estavam organizados os serviços de saúde, qual a lógica que orientava a constituição dos sistemas de saúde e a atuação dos mesmos, e propor as mudanças necessárias para adequá-los ao proposto nas determinações do SUS.

Essas mudanças deveriam considerar, entre outras, a dimensão tanto da ampliação do direito à saúde como a dimensão do conceito ampliado de saúde. Com a universalização do direito à saúde, tornou-se fundamental pensar em quantidade sem esquecer de qualidade. Da mesma forma, definiu-se que ter saúde não era simplesmente ausência de doença, dependendo além do componente biológico de cada um, do modo de viver das pessoas, segundo as condições de vida a que estavam expostas, ou "o conceito de saúde entendido numa perspectiva de uma articulação de políticas sociais e econômicas" (VILAÇA, 1995, p. 47). Portanto, era necessário transformar o pensamento hegemônico que determinava as 
ações no setor saúde, passando a incluir os determinantes sociais do processo saúde-doença no pensar e realizar essas ações.

As ações de saúde deveriam voltar-se para as pessoas e as comunidades, e também para a manutenção de ambientes de vida saudáveis, tanto no sentido de curar e recuperar os indivíduos doentes como estabelecer ações de diagnóstico precoce e prevenção, garantindo o acesso de todos e em todos os níveis de atenção. Também como definido no SUS, essas ações deveriam ser intersetoriais para efetivar a proteção e a promoção da saúde.

Várias iniciativas institucionais e legais foram criando condições jurídicas para a efetivação do SUS, e ao longo desses quinze anos muitos avanços já ocorreram, cabendo destacar os seguintes:

- Lei 8080, de 19 de setembro de 1990, que dispõe sobre as condições para a promoção, proteção e recuperação da saúde, a organização e o funcionamento dos serviços de saúde, incluindo a ampliação do conceito de saúde como referido no seu art. $2^{\circ}$, parágrafo $3^{\circ}$ - a saúde tem como fatores determinantes e condicionantes, entre outros, a alimentação, a moradia, o saneamento básico, o meio ambiente, o trabalho, a renda, a educação, o transporte, o lazer e o acesso a bens e serviços essenciais; os níveis de saúde expressam a organização social e econômica do País. 
- Lei 8142, de 28 de dezembro de 1990, que dispõe sobre a participação da comunidade na gestão do SUS e sobre as transferências governamentais de recursos financeiros na área de saúde criando os Conselhos de Saúde as Conferências de Saúde e também os Fundos de Saúde.

- Norma Operacional Básica - SUS 01/93, que definiu critérios para habilitação dos municípios, segundo condições de gestão: incipiente, parcial e semiplena com pactuação de recursos segundo critérios definidos nas comissões - intergestores tripartite e bipartite - e início das transferências do Fundo Nacional de Saúde aos Fundos Municipais de Saúde.

- Norma Operacional Básica - SUS 01/96, que redefine as condições de gestão.

- Norma Operacional da Assistência a Saúde (NOAS/SUS/2001), que estabelece critérios e estratégias de regionalização nos estados, atribuindo maiores poderes às secretarias estaduais de saúde.

Sem pretender revisar aqui todas as iniciativas já realizadas para a consolidação do SUS, para o que se pretende relatar neste trabalho é importante destacar a Norma Operacional Básica 01/96 (NOB-01/96) que, entre outras questões, aprimorou a efetiva descentralização da gestão para estados e municípios ao estabelecer apenas duas formas de gestão: Plena da Atenção Básica e Plena do Sistema. 
A NOB 01/96 tem, por finalidade primordial, promover e consolidar o pleno exercício, por parte do poder público municipal e do Distrito Federal, da função de gestor à saúde de seus municípios, com a conseqüente redefinição de responsabilidades dos Estados, Distrito Federal e da União, avançando na consolidação do SUS. (BRASIL, MS - NOB 01/96, item 2, §1)

A NOB 01/96 define, ainda, a responsabilização do município pela gestão e execução direta da atenção básica, com a determinação de financiamento fundo a fundo, para custear essas ações. Esse financiamento, denominado Piso de Atenção Básica (PAB) deve ser transferido mensalmente de forma regular. O PAB é composto por uma parte fixa (PAB Fixo), com valor calculado por habitante/ano e uma parte variável (PAB Variável). O PAB Variável é formado de recursos para o incentivo de ações voltadas para a reorganização da atenção básica e do modelo de atenção, entre elas, dos Programas de Saúde da Família (PSF) e de Agentes Comunitários de Saúde (PACS).

Apesar dos recursos ainda serem insuficientes para custear as ações de saúde, essa forma de transferência de recursos vem possibilitando aos gestores avançarem no planejamento e na elaboração de políticas de saúde mais adequadas às reais necessidades das suas populações.

A descentralização da gestão trouxe para os gestores, além de responsabilização e conquistas, vários desafios que ainda precisam ser superados, em especial aqueles vinculados à forma como os serviços de saúde devem ser organizados. Provavelmente a prática de pagamento por 
serviços prestados, que possibilita aos municípios a captação de recursos para a saúde de suas populações por procedimento realizado e receberem como prestadores de serviços, favorecendo a manutenção da "Política de Serviços" já instalados na concepção dos sistemas de saúde municipais. Essas práticas têm dificultado a elaboração de propostas que rompam com a determinação na qual as necessidades de saúde da população são ajustadas aos serviços ofertados, não sendo os serviços organizados conforme as necessidades das populações onde estão implantados.

Tem-se verificado que os avanços ocorridos com a descentralização da gestão e de parte do financiamento ainda precisam ser acompanhados de mudanças nas práticas de saúde, para que estas se aproximem cada vez mais dos preceitos do SUS. Essa questão pode ser bem evidenciada na mesa de abertura da VII Conferência Estadual de Saúde de São Paulo, em 2003, como referido nas palavras do Presidente do COSEMS-SP, "[...] nós temos o sistema de saúde de formulação mais ousada que se conhece, estamos precisando ousar na execução" e nas palavras complementares da representante dos usuários: "[...] precisamos praticar o discurso.” (José Ênio, presidente do COSEMS; Roseli, representante dos usuários do CES).

Fica evidente que falar em "sistema de saúde", no sentido de maior proximidade com a proposição do SUS, ainda é um desafio a ser superado.

[...] a menção ao Sistema de Saúde, no caso brasileiro, implica muito mais o enunciado de um discurso sobre o que deveria ser, ou sobre aquilo que se pretende estruturar, portanto no domínio das idéias, do que propriamente sobre aquilo que realmente é, 
dado que a atual forma de organização dos serviços de saúde no país encontra-se bem distante de merecer a qualificação de sistema. De fato, a análise do funcionamento desses serviços não fornece qualquer base empírica para configurá-los sequer como partes articuladas de um conjunto objetivando atender às necessidades socialmente demandadas em relação à saúde, sendo que desta situação não escapam sequer os serviços governamentais, que em seu conjunto ainda carecem de articulação e organização. (ELIAS, 1997, p. 206)

Infelizmente, quase dez anos depois dessas considerações acerca da consolidação do SUS terem sido formuladas, muitas das questões ainda não foram equacionadas na sua totalidade, persistindo lacunas a preencher e soluções a encontrar. Torna-se cada vez mais evidente a necessidade de se desenvolver modelos de atenção capazes de implementar o SUS. Portanto, é preciso pensar qual a lógica em que se deve basear a organização dos serviços de saúde para que eles dêem conta de responder satisfatoriamente aos indivíduos e comunidades.

Sobre a necessidade de rever e propor mudanças na lógica que orienta os sistemas de saúde é importante considerar que as práticas de saúde ou a forma de prestar atendimento aos indivíduos devem estar dirigidas no sentido de "reorientar as ações de saúde no sentido da integralidade da atenção, da qualidade da ética e da efetividade" (PAIM, 2002, p. 327). Ainda segundo o autor:

[...] modelos assistenciais ou modelo de atenção à saúde podem ser compreendidos como combinações tecnológicas estruturadas em função de problemas de saúde (danos e riscos) que compõem o perfil epidemiológico de uma dada população e das 
necessidades de saúde historicamente definidas [...]. Dai a pertinência de reforçar a questão dos modelos de atenção à saúde ou dos modelos assistenciais. (PAIM, 2002, p. 337)

Dai a pertinência de reforçar a questão dos modelos de atenção à saúde ou dos modelos assistenciais.

Outro aspecto que deve ser considerado quando se fala em modelo de atenção à saúde, refere-se à orientação que os mesmos devem ter para alcançarem seus objetivos. Segundo Viana e Dal Poz (1998, p. 13), o que se tem observado é que esta é uma das questões que se coloca dentre os problemas que o SUS tem enfrentado para a sua consolidação, além das questões referentes ao:

[...] financiamento das ações de saúde; definição clara de funções para os três entes de governamentais (federal, estadual e municipal); as formas de articulação entre o público e o privado; e a resistência do antigo modelo assistencial - baseado na doença e em ações curativas individuais - a uma mudança mais substantiva nas práticas assistenciais.

Após 25 anos, cuidados primários em saúde é outro ponto da Declaração de Alma-Ata que vem sendo "reapropriado" no Brasil, sem a conotação de medicina pobre para os pobres como aconteceu anteriormente aqui e também em muitos outros países, como pode ser verificado nas palavras do Dr. David Tejada de Rivero - subdiretor da OMS, presidente da Academia Peruana da Saúde, e um dos organizadores do Seminário de Alma-Ata, O não cumprimento das metas acordadas há 25 anos deve-se, 
principalmente, à falta de um entendimento claro sobre os termos da conferência.

A questão saúde não foi analisada em toda a sua complexidade sócio-econômica. Faltou, por exemplo, observar como outras áreas, entre elas, educação e trabalho, estão relacionadas à saúde. A atenção primária também foi uma expressão subestimada na visão de Tejada, por ser relacionada com atenção básica, rural, sem especialização. (OPAS, $\operatorname{dez} / 2003)$

[...] a saúde de um indivíduo ou de uma população é determinada por sua combinação genética, mas grandemente modificada pelo meio físico e social, por comportamentos que são cultural ou socialmente determinados e pela natureza da atenção á saúde oferecida. (STARFIELD, 2004, p. 22)

Ainda segundo a autora, quanto mais socialmente desfavorecidas forem as populações, maior será a desigualdade na saúde. Entretanto, a organização dos serviços de saúde pode ser um fator de diminuição das desvantagens desses grupos em relação à saúde.

Buscando demonstrar a premissa anterior de que a organização dos serviços é um dos fatores que podem aumentar a equidade em saúde, Starfield realizou um estudo em vários países, no qual pôde verificar que aqueles onde os sistemas de saúde têm suas ações de saúde mais fortemente orientadas para a atenção primária, possuem maior probabilidade de terem melhores níveis de saúde e custos mais baixos. Faz parte dos 
achados deste estudo a observação de que quanto mais médicos generalistas por população e quanto menor o número de outros especialistas, melhores as chances de vida, independente do efeito de outros fatores de influência, como a renda per capita. (STARFIELD, 2004)

No Brasil, com a denominação preferencial de atenção básica, a atenção primária vem sendo colocada como foco das ações para o setor saúde com a proposta de priorização pelo MS, do Programa Saúde da Família (PSF), como evidenciada na entrevista do secretário-executivo do Ministério da Saúde.

Queremos que $70 \%$ das famílias do Brasil estejam inscritas em programas de saúde da família. Se esquecermos esta meta, a tendência dos custos crescentes em Saúde continuará. A 'porta de entrada' do sistema continuará sendo a emergência, o especialista e o hospital, que encarecem a assistência, sem benefícios à população. (apud OPAS, dez./2003)

\subsection{Princípios e diretrizes do Programa Saúde da Família}

A implantação do PSF se constitui num grande desafio, pois envolve mudanças importantes nas práticas de saúde com a inclusão, entre outros aspectos, de trabalho em equipe, da intervenção envolvendo intersetorialidade e ações na comunidade. Nesse sentido, se propõe mudanças na forma de prestar assistência à saúde, resgatando ou determinando novas ações baseadas nas concepções de território, vinculação, responsabilização, resolubilidade, integralidade e participação 
comunitária, que são objetivos e diretrizes do PSF. (BRASIL, MS, 1998; PNS, 2004)

Sem dúvida uma das diretrizes principais do PSF é a abrangência territorial, a partir da qual vão se concretizar as possibilidades de inteiração e intervenção da equipe de saúde da família. O território é entendido aqui não somente enquanto um espaço geográfico, onde residem as famílias acompanhadas pelas equipes, ele deve ser entendido como espaço com características próprias que o identifica.

Para atingir esses objetivos, faz parte da diretriz do PSF conhecer a realidade de vida da população adstrita e, juntamente com a comunidade, planejar as ações a serem executadas para o enfrentamento dos problemas priorizados. O "conhecer a realidade" é iniciado pelo cadastramento das famílias e dos equipamentos sociais presentes no território onde as equipes irão atuar. Essa ação deverá fornecer informações sobre a situação de vida da população e suas principais relações, possibilitando a elaboração do diagnóstico de saúde da comunidade. O cadastramento é um instrumento extremamente dinâmico, pois permite uma atualização constante dos dados através de contato direto com as famílias adstritas as ESF. Isso significa saber onde as condições sanitárias são mais deficitárias, quais são e onde estão os grupos e situações mais vulneráveis, propiciando o planejamento de ações para o enfrentamento de problemas prioritários, incorporando assim às suas proposições a lógica da vigilância à saúde. 
As equipes de saúde da família devem ser constituídas por médico generalista, enfermeiro, 1 a 2 auxiliares de enfermagem e 4 a 6 agentes comunitários de saúde (ACS), que devem se responsabilizar por aproximadamente 1000 famílias em um dado território. É importante lembrar que os ACS devem ser moradores da comunidade onde irão atuar, sendo o elo das ESF com a comunidade, proporcionando, desta forma, a aproximação do serviço de saúde e a população. (BRASIL, MS, 1998; BRASIL, MS / PNS, 2004; BRASIL MS-Manual ACS, 2000)

A equipe de saúde deve ter como base para suas atividades a Unidade de Saúde da Família (UBSF) que, além de possuir equipamentos e insumos adequados para responder aos problemas de atenção básica da comunidade de sua área de abrangência, deve ser o que se convencionou chamar de uma unidade ativa, isto é, sem muros e que atende as pessoas que a procuram, também contemplando a busca dos doentes. As equipes também devem realizar, atividades na casa das pessoas e nos espaços sociais e comunitários.

Ao delimitar sua área de abrangência, a unidade de saúde passa a interrelacionar-se com a mesma, conhecendo suas características, as de seus habitantes, seus problemas de saúde. A partir daí a unidade passará a adequar as ações de saúde oferecidas à realidade detectada. (UNGLERT, 1995, p. 36)

Outro pressuposto do PSF é a integralidade da atenção, mediante a qual deve-se buscar superar a fragmentação dos cuidados, tendo sempre presente a necessidade de desenvolver ações de prevenção e promoção da 
saúde juntamente com as ações de cura e recuperação. As equipes deverão propor planos de atenção à saúde para o indivíduo e para a comunidade que contemplem estes aspectos. (BRASIL, CF, 1988, artigo 196; Lei n. 8080, 19/09/1990)

Além disso, para se garantir a qualidade e resolubilidade da atenção, é fundamental a vinculação destes profissionais a um programa de educação permanente para que possam adquirir as habilidades necessárias para um desempenho satisfatório das ESF, conforme comentário de Filiberto P. Ares, adido da Embaixada de CUBA no Brasil, no Seminário de Experiências Internacionais, 1999: “[...] somente se obtém um serviço com qualidade quando os recursos humanos estão qualificados."

Também é importante destacar que as ações de saúde não se esgotam na atenção básica, sendo que a estratégia - saúde da família - é o primeiro nível de assistência. Isto não significa que essa é a unidade que oferecerá todas as ações de saúde àquela população, mas que essa é a unidade que conhecerá e tomará as providências necessárias para que todas as ações de saúde àquela população sejam garantidas. (UNGLERT, 1995)

Dessa maneira, ao mesmo tempo em que a estratégia saúde da família pode se configurar enquanto a "porta de entrada" principal dos sistemas de saúde, é fundamental que se determine a "porta de saída", ou seja, a referência aos níveis de maior complexidade de atenção, com fluxo e 
mecanismos claros de referência e contra-referência entre eles, bem como a "porta de retorno". Garantindo-se assim, atenção integral à saúde e o direito de acesso das pessoas aos vários níveis de atenção, bem como os retornos dessas pessoas para a continuidade da atenção nos locais aonde moram, interagem, vivem e sobrevivem. (BRASIL, CF, 1988; BRASIL Lei, nº 8080, de 19 set 1990)

\subsection{Uma visão geral da implantação do Programa Saúde da Família no Brasil}

A história da implantação do PSF começa com a implantação de Agentes Comunitários da Saúde em 1991, como Programa Nacional de Agentes Comunitários de Saúde (PACS). A experiência de se trabalhar com agentes de saúde escolhidos na comunidade começa anteriormente com o Programa de Interiorização de Ações de Saúde e Saneamento (PIASS), realizado inicialmente no nordeste, entre 1976 e 1979, e numa segunda fase para a região do Vale do Ribeira, no Estado de São Paulo, no período de 1980 a 1985, também conhecido como Projeto Devale. Esses programas tinham, entre outras, a característica de extensão de cobertura, com ênfase na prevenção, utilização de pessoal auxiliar recrutado na comunidade, participação popular, desenvolvimento de ações de saúde de baixo custo e alta efetividade. (SILVA; DALMASO, 2002)

Em 1987 inicia-se o PACS no Ceará, em princípio como frente de trabalho "em situação crítica de seca", com recursos federais do fundo 
emergencial. Em 1988 o programa continua com o objetivo de que as comunidades pudessem cuidar melhor de sua saúde e assim contribuir para a diminuição da mortalidade materna infantil. Em 1991, o MS dá inicio ao Plano Nacional de Agentes Comunitários de Saúde, enfocando não apenas o indivíduo, mas também a família e a comunidade. (SILVA; DALMASO, 2002; e VIANA; DAL POZ, 1998). Em 1993 o MS formula o PSF, baseado na experiência positiva dos agentes comunitários de saúde (ACS). Segundo Viana e Dal Poz (1998, p. 19), esta iniciativa se deu em:

[...] resposta a uma demanda de secretários municipais de saúde que queriam apoio financeiro para efetuar as mudanças na forma de operação da rede básica (expansão do programa de agentes com outros tipos de profissionais). [...] Contribuiu também para essa formulação a experiência do médico de família de Niterói.

Em 1994 o PSF é oficializado, sendo de setembro de 1994 o primeiro documento oficial que prioriza, para o início de suas ações, os municípios pertencentes ao Mapa da Fome do IPEA (VIANA; DAL POZ, 1998)

Nessa primeira fase de implantação do PSF, o mecanismo de repasse de recursos para os municípios prioritários ocorria na forma convenial, pelo qual os municípios receberiam um recurso inicial para aquisição de equipamentos de trinta mil reais e verba para três meses de custeio das atividades das equipes. Para continuidade das atividades, os recursos deveriam ser captados através do SIA-SUS, onde as atividades desenvolvidas pelas Equipes de Saúde da Família (ESF) teriam um valor 
diferenciado, o que, em tese, possibilitaria a continuidade das atividades pelos municípios. Para essas ações foi destinado um teto especial para os municípios. A forma convenial, entretanto, mostrou-se inadequada para o pretendido. (VIANA; DAL POZ, 1998)

A partir da NOB/96, e com a regulamentação do financiamento da atenção básica, fica definido o financiamento do PACS e PSF, pagamento per capita e fundo a fundo, para que os municípios realizem essas atividades. A NOB/96 só entra em vigor com a edição da Portaria MS n. 157, de 19 de fevereiro de 1998 (BRASÍLIA, MS, 1998), que fixa os valores a serem transferidos para os programas PACS e PSF.

Desde então, pode se dizer que o PSF é a estratégia prioritária para a reorganização da Atenção Básica no Brasil (BRASIL, MS, 1997), o que pode ser verificado pelo número de Portarias Ministeriais que foram editadas desde a implantação do PSF para regulamentar a implantação, aumentar a destinação de recursos ou incluir populações marginalizadas (BRASIL, MS, Portarias n. 1886 de 18/12/97; 3925 de 13/09/98; 347 de 27/03/03; 396 de 04/04/03; 1432 de 14/06/04; 2023 de 23/09/04; 2513 de 23/11/04; 2084 de 26/10/05; 648 e 649 e 650 de 28/03/06 e, Brasil, Lei n 10507, de 10/07/02)

Em julho de 2005, estavam implantadas 23.097 ESF em 4.868 municípios, e 200.139 ACS implantados em 5.198 municípios, representando, respectivamente, $39,1 \%$ e 55,6\% de cobertura populacional. 


\subsection{Uma visão geral da implantação do Programa Saúde da Família no Estado de São Paulo}

No Estado de São Paulo, o PSF vem sendo implantado desde 1995, por iniciativa de alguns municípios que aderiram a essa proposta. Esses municípios perceberam que precisavam fazer algo na área da saúde, pois se gastava muito recurso e os resultados nem sempre eram os melhores. São dessa época as importantes e fundamentais experiências dos municípios de Amparo, Assis, Piraju, Santa Fé do Sul, entre outras. Esses municípios não contavam com propostas claras relativas ao funcionamento do programa, nem recursos humanos ou financiamento adequados para a implantação do PSF, uma vez que a proposta de teto diferenciado para cobrir esses valores pouco foi discutida no Estado de São Paulo. Por esta razão, alguns projetos municipais nunca chegaram a ser efetivados, outros receberam os recursos iniciais e desistiram de implementar o programa, por outro lado, outros o mantém até hoje.

Cabe ressaltar que no município de São Paulo, no final dos anos 1980, por iniciativa do governo estadual, foi implantado o Programa de Consultórios de Médicos de Família em co-gestão entre o Estado e a Casa de Saúde Santa Marcelina (CSSM), na Zona Leste do município. Era uma proposta baseada no modelo cubano, com o médico de família trabalhando com um auxiliar de enfermagem, responsável por um dado território e que deveria morar na área de abrangência (SILVA; DALMASO, 2002). A proposta estava na base do PSF que foi implantado em 1996, na capital, denominado 
Projeto Qualidade Integral em saúde (QUALIS/PSF), com o aproveitamento de alguns consultórios, médicos de família e da experiência de participação da comunidade.

Naquela época, as ações de saúde não estavam municipalizadas. Nesta condição, para atender inicialmente na Zona Leste, áreas com várias unidades de saúde muito periféricas, com dificuldade de se fixar profissionais (principalmente médicos), com populações recém-chegadas em áreas de invasão e que se encontravam, portanto, completamente descobertas, o Governo do Estado de São Paulo juntamente com o Governo Federal e a CSSM decidem implantar o primeiro QUALIS na capital, sob a coordenação da Doutora Rosa Barros e em parceria com a Casa de Saúde Santa Marcelina.

O primeiro QUALIS inicia suas atividades em abril de 1996. Devido ao êxito dessa experiência, tanto do ponto de vista de que era possível implantar o PSF em áreas periféricas de grandes metrópoles, como pela forte adesão e aceitação da proposta pela comunidade, a expansão do programa começa a ser solicitada. Em 1998, o Doutor Davi Capistrano é convidado pelo Governo Estadual para coordenar a ampliação do QUALIS em parceria com a Fundação Zerbini. Posteriormente, a expansão continua com a realização de parcerias com a UNISA e Associação Congregação Catarina. Essa situação persiste até a entrada do município de São Paulo para o SUS, em 2001, com a municipalização das 215 ESF do projeto QUALIS/PSF. 
Dos resultados positivos do Projeto QUALIS/PSF-Capital, o governo estadual expandiu o PSF, final de 1999 / início de 2000, para os municípios considerados prioritários para o governo. O projeto foi estendido para o interior do Estado, passando a ser conhecido como QUALIS/PSF-Interior. O projeto consistia em implantar a estratégia de saúde da família em municípios com baixo Índice de Valorização Humana (IDH), em município com população assentada e em municípios com populações remanescentes de quilombos, mediante o repasse de recursos estaduais no valor aproximado de 8 mil reais por mês para custeio das equipes, tendo sido implantadas até agosto de 2002 - 269 equipes de saúde da família, em 177 municípios. (SÃO PAULO, SECRETARIA ESTADUAL DA SAÚDE, 2002)

Paralelamente, o PSF se expande no Estado como um todo, após a regulamentação da NOB/96, no início de 1998. Em março de 2004, estavam implantadas 2.329 ESF em 436 municípios, significando uma cobertura populacional de cerca de $20 \%$, correspondendo a mais de 7 milhões de pessoas. Com a implantação do Projeto de Expansão da Saúde da Família (PROESF) para municípios acima de 100 mil habitantes (BRASIL, MS, 2003), pretende-se que essa cobertura se amplie consideravelmente até 2008, com uma previsão de ampliar a cobertura para $50 \%$ da população do estado de São Paulo. (BRASIL, MS, 2003 - Portaria n. 347 de 27/03/03). Os dados anteriores demonstram também a importância quantitativa que o PSF de São Paulo representa para o Estado e para o país. 


\section{O ESTUDO}

Descrever e caracterizar a implantação do PSF no Estado de São Paulo se constitui num desafio e também motivação para o estudo que se pretende realizar, por sua dimensão populacional e por ser o pólo de maior desenvolvimento tecnológico em saúde, com práticas de saúde diversa e consolidada nos seus vários municípios. Junte-se a isso a oportunidade da existência de um Banco de Dados com informações referentes à grande maioria das equipes de saúde da família implantadas no Estado, onde foram entrevistadas 1058 ESF - 91\% das equipes implantadas na época da pesquisa, distribuídas em 349 municípios de porte variado. (Vide Anexo I Questionário da Pesquisa).

O programa de saúde da família no Estado de São Paulo, a exemplo do que ocorre no Brasil, vem se expandindo regularmente, aumentando a cobertura populacional desde o seu início (SÃO PAULO, SECRETARIA ESTADUAL DA SAÚDE, 2001). Entretanto, são enormes os desafios que precisam ser superados, existindo vários pontos que necessitam ser equacionados na implantação das equipes de saúde da família, pelos municípios.

Os problemas ou limites dessa implantação são de várias naturezas, sendo os principais: aqueles relacionados ao vínculo trabalhista nas equipes, apontado como "precarização" do trabalho; o desenvolvimento do trabalho 
dos profissionais da equipe, sobretudo no que se refere às habilidades clínicas. Neste caso apresenta-se o médico das equipes de saúde da família que deve prestar atenção coletiva e individual e realizar atendimento clínico a crianças, adultos e mulheres, incluindo o atendimento às urgências e os aspectos relacionados à integralidade da atenção. (BRASIL, MS, 1999; DAL POZ, 2000; e CAMPOS; AGUIAR, 2005)

Também é necessário observar aspectos relacionados às condições de infra-estrutura, utilização de instrumentos de planejamento, capacitação e vinculação empregatícia dos recursos humanos, verificando-se as condições que as ESF têm para o trabalho e em que medida essa situação pode ser verificada. (BRASIL, MS, 2001)

Assim, busca-se caracterizar a implantação das equipes de saúde da família no Estado de São Paulo, no período de 1996 a 2001, objetivando identificar os limites e possibilidades dessa implantação. Este estudo também pretende subsidiar o planejamento desta política pública no Estado. 


\section{OBJETIVOS}

\subsection{Objetivo geral}

Caracterizar a implantação das equipes de saúde da família no Estado de São Paulo, no período de 1996 a 2001.

\subsection{Objetivos secundários}

1) Caracterizar o PSF no Estado de São Paulo, considerando tempo de implantação, cobertura populacional por equipe de saúde da família, infra-estrutura física e material.

2) Caracterizar as ações desenvolvidas pelas equipes de saúde da família e a organização do atendimento clínico.

3) Caracterizar os recursos humanos das equipes da saúde da família, abrangendo o processo de capacitação.

4) Caracterizar a organização do trabalho das equipes de saúde da família e o planejamento de atividades. 


\section{PROCEDIMENTOS DA PESQUISA}

A presente pesquisa utiliza-se de dados secundários, referentes ao Estado de São Paulo, produzidos pela Pesquisa de Avaliação da Implantação das Equipes de Saúde da Família no Brasil, realizada pelo Ministério de Saúde no ano de 2001, em cooperação com a Coordenação Estadual do PACS/PSF da SES/SP. Ao instrumento original de pesquisa foi incorporado um outro específico desenvolvido pela Coordenação estadual do PACS/PSF. As informações resultantes foram organizadas em um Banco de Dados.

O Banco contém dados referentes às 1.058 ESF do ESP cadastradas no MS até setembro de 2001. Os entrevistadores foram selecionados pelo MS, vindo de diversas partes do Brasil e com experiência na estratégia saúde da família, geralmente indicados pelas coordenações estaduais de PACS/PSF, pelo DAB/MS ou pelos Pólos de Capacitação em Saúde da Família. Estes entrevistadores foram acompanhados pelos interlocutores regionais do PSF no Estado. Todos os profissionais envolvidos são de nível universitário.

O MS disponibilizou um técnico que trabalhou junto com a coordenação estadual do PACS/PSF e ficou responsável para operacionalizar e apoiar os participantes da pesquisa. 
Os entrevistadores receberam um treinamento prévio de cerca de 8 horas sobre a aplicação dos questionários, onde era discutido o Manual de Preenchimento do Roteiro de Observações, o roteiro de visitas de cada um, retiradas as dúvidas e informados de como fazer contato com os responsáveis de apoio (MS e SES) aos entrevistadores. A pesquisa foi composta de questões de observação direta nas UBS e da entrevista que deveria ser realizada preferencialmente com o profissional médico e/ou enfermeiro.

A partir do Banco, os dados foram estruturados abrangendo os seguintes tópicos:

- Caracterização das ESF.

- Infra-estrutura (área física, insumos, equipamentos e pessoal).

- Ações desenvolvidas pelas ESF.

- Instrumentos para o planejamento e organização do trabalho das ESF.

- Capacitação das ESF.

O procedimento para análise segue um plano que contempla como variáveis o porte do município e o tempo de implantação das ESF.

Para fins deste trabalho foi estabelecida uma classificação de adequação da disponibilidade dos itens pesquisados - sejam de infra- 
estrutura ou relacionados ao processo de trabalho das equipes, incluindo recursos humanos, ações e capacitações, com a finalidade de se estabelecer uma maior ou menor aproximação com a situação ideal.

A classificação foi a seguinte:

- Adequada: quando for verificado $100 \%$ dos itens pesquisados.

- Suficiente: quando for verificado de $80 \%$ a $99 \%$ dos itens pesquisados.

- Mínimo: quando for verificado de $50 \%$ a $79 \%$ dos itens pesquisados.

- Insuficiente: quando for verificado menos que $50 \%$ dos itens pesquisados.

Entretanto, cabe ressaltar que a classificação proposta apresenta restrições de abordagem, uma vez que não qualifica os itens pesquisados, dando valores iguais para todos eles.

Também vale apontar que neste estudo o $\mathbf{n}$ é igual a 1043, mas em algumas questões ocorreram perdas, as quais estão referidas no rodapé das tabelas.

Além disso, a fim de situar a condição da implantação do PSF no Estado de São Paulo em relação aos demais Estados que compõem a região Sudeste, e a média nacional dos mesmos, para alguns aspectos 
desta pesquisa foram utilizados dados da Avaliação Normativa do Programa Saúde da Família no Brasil: monitoramento da implantação e funcionamento das equipes de saúde da família: 2001-2202. Durante este trabalho a mesma será referida como Avaliação Normativa - MS. 


\section{RESULTADOS E DISCUSSÃO}

\subsection{Caracterização das ESF no estado de São Paulo}

6.1.1 Descrição geral da caracterização da implantação das equipes de saúde da família no Estado de São Paulo (ESP)

6.1.1.1 Tempo de implantação, porte dos municípios com PSF implantado e cobertura populacional pelas ESF

Tabela 6.1 - Municípios do ESP e municípios com ESF implantadas por porte populacional

\begin{tabular}{|c|c|c|c|}
\hline \multirow{2}{*}{ Porte dos municípios } & \multicolumn{2}{|c|}{ Municípios ESP } & \multirow{2}{*}{$\begin{array}{l}\text { \% municípios do } \\
\text { ESP com PSF }\end{array}$} \\
\hline & $\mathbf{N}^{\circ}$ & $\%$ & \\
\hline$<20 \mathrm{mil}$ & 408 & 63,3 & 48,8 \\
\hline 20 a 50 mil & 119 & 18,4 & 51,3 \\
\hline 50 a $100 \mathrm{mil}$ & 56 & 8,7 & 64,3 \\
\hline$>100 \mathrm{mil}$ & 62 & 9,6 & 53,2 \\
\hline Total & 645 & 100 & 51 \\
\hline
\end{tabular}

Cerca de $2 / 3$ dos municípios de porte entre 50 a 100 mil habitantes aderiram ao PSF. Nos demais, o PSF teve adesão de $50 \%$, indicando uma boa penetração do programa no Estado de São Paulo.

Cabe ressaltar que os municípios de 50 a 100 mil habitantes representam aproximadamente $9 \%$ do Estado. $O$ menor percentual de adesão foi observado nos municípios de porte menor que 20 mil habitantes, que correspondem a $49 \%$ do total de ESF e $63 \%$ dos municípios do Estado. 
Tabela 6.2 - Municípios do ESP com ESF e número de ESF nos municípios por porte populacional

\begin{tabular}{l|r|r|r|r}
\hline \multirow{2}{*}{ Porte dos municípios } & \multicolumn{2}{|c|}{ Municípios com PSF } & \multicolumn{2}{c}{$\mathbf{N}^{\circ}$ de ESF implantadas } \\
\cline { 2 - 5 } & \multicolumn{1}{|c}{$\mathbf{N}^{\circ}$} & \multicolumn{1}{|c}{ \% } & \multicolumn{1}{c}{$\%$} \\
\hline$<20$ mil & 199 & 60.5 & 318 & 30.5 \\
20 a 50 mil & 61 & 18.5 & 179 & 17.2 \\
50 a 100 mil & 36 & 10.9 & 137 & 13.1 \\
$>100$ mil & 33 & 10.0 & 409 & 39.2 \\
\hline Total & 329 & 100.0 & 1043 & 100.0 \\
\hline
\end{tabular}

Dos municípios com ESF implantadas, a maior parte possui menos de 20 mil habitantes (cerca de 60\%). Entretanto, do total de equipes implantadas, 39\% encontram-se nos municípios de porte maior que 100 mil habitantes, seguindo-se os de porte menor que 20 mil habitantes com $31 \%$ das equipes.

Tabela 6.3 - População do ESP por porte populacional e cobertura de ESF

\begin{tabular}{l|r|r|r}
\hline Porte dos municípios & População & \% População & \% Cobertura PSF \\
\hline$<20$ mil & 3.033 .510 & 7,9 & 36,7 \\
$20-50$ mil & 3.743 .233 & 9,8 & 18,8 \\
$50-100$ mil & 4.087 .460 & 10,7 & 12,9 \\
$>100$ mil & 27.313 .531 & 71,5 & 6,3 \\
\hline Total & 38.177 .734 & 100,0 & 10,6 \\
\hline
\end{tabular}

A maior cobertura populacional pode ser observada nos municípios com menos de 20 mil habitantes, com $37 \%$ de cobertura de população deste porte. Esta cobertura é cerca de 6 vezes maior que a existente para a população dos municípios de mais de 100 mil habitantes. Vale notar que apenas $11 \%$ da população do Estado de São Paulo estão cobertos pelas ESF. 
Tabela 6.4 - Tempo de implantação das ESF por porte populacional

\begin{tabular}{|c|c|c|c|c|c|}
\hline \multirow{2}{*}{ Porte dos municípios } & \multicolumn{5}{|c|}{ Tempo de implantação das ESF } \\
\hline & 5 anos ou + & 3-5 anos & 1-3 anos & $<1$ ano & Total \\
\hline \multirow[t]{2}{*}{$<20$ mil } & 2 & 25 & 168 & 122 & 317 \\
\hline & $0.6 \%$ & $7.9 \%$ & $53.0 \%$ & $38.5 \%$ & $100 \%$ \\
\hline \multirow[t]{2}{*}{20 a 50 mil } & & 18 & 107 & 49 & 179 \\
\hline & $2.8 \%$ & $10.1 \%$ & $59.8 \%$ & $27.4 \%$ & $100 \%$ \\
\hline \multirow[t]{2}{*}{50 a $100 \mathrm{mil}$} & 12 & 13 & 66 & 42 & 133 \\
\hline & $9.0 \%$ & $9.8 \%$ & $49.6 \%$ & $31.6 \%$ & $100 \%$ \\
\hline \multirow[t]{2}{*}{$>100 \mathrm{mil}$} & 26 & 81 & 174 & 125 & 406 \\
\hline & $6.4 \%$ & $20.0 \%$ & $42.9 \%$ & $30.8 \%$ & $100 \%$ \\
\hline Total & $\begin{array}{r}45 \\
4.3 \%\end{array}$ & $\begin{array}{r}137 \\
13.2 \%\end{array}$ & $\begin{array}{r}515 \\
49.8 \%\end{array}$ & $\begin{array}{r}338 \\
32.7 \%\end{array}$ & $\begin{array}{r}1035 \\
100 \%\end{array}$ \\
\hline
\end{tabular}

Evidencia-se que a implantação inicial do PSF ocorre preferencialmente nos municípios de maior porte, sendo que cerca de $35 \%$ das ESF encontram-se nos municípios acima de 100 mil habitantes, e 34\% das equipes estão nos municípios de menos de 20 mil habitantes. A grande expansão do PSF ocorre nas equipes implantadas entre 1 e 3 anos, e principalmente nos municípios de menor porte.

Dentre as ESF com tempo de implantação superior a 3 anos, o maior percentual se encontra nos municípios com mais de 100 mil habitantes (59\%), seguindo-se os demais portes com 14\%-15\%. À época da pesquisa, a maioria das ESF implantadas no Estado de São Paulo (83\%) era recente (menos de 3 anos), sendo 1/3 delas há menos de 1 ano. Dentre as ESF com mais de 3 anos, o maior percentual se encontra nos municípios com mais de 100 mil habitantes, seguindo-se os demais com percentual entre $13 \%-15 \%$. 


\subsubsection{2 Área de atuação das ESF}

Tabela 6.5 - Área de atuação das ESF

\begin{tabular}{l|r|r}
\hline \multicolumn{1}{c|}{ Área de atuação das ESF } & $\mathbf{N}^{\circ}$ & $\%$ \\
\hline Urbana & 677 & 64.91 \\
Rural & 101 & 9.68 \\
Ambas & 259 & 24.83 \\
Sem informação & 6 & 0.58 \\
\hline Total & 1043 & 100 \\
\hline
\end{tabular}

O levantamento mostra que cerca de $65 \%$ das ESF atua em zona urbana e apenas $9.6 \%$ em áreas exclusivamente rurais.

Tabela 6.6 - Tempo de implantação e área de atuação das ESF

\begin{tabular}{|c|c|c|c|c|}
\hline \multirow{2}{*}{ Tempo implantação } & \multicolumn{4}{|c|}{ Área de atuação } \\
\hline & Urbana & Rural & Ambas & Total \\
\hline \multirow[t]{2}{*}{5 anos ou +} & 40 & 1 & 4 & 45 \\
\hline & $88.9 \%$ & $2.2 \%$ & $8.9 \%$ & $100 \%$ \\
\hline \multirow[t]{2}{*}{3 a 5 anos } & 105 & 10 & 22 & 137 \\
\hline & $76.6 \%$ & $7.3 \%$ & $16.1 \%$ & $100 \%$ \\
\hline \multirow[t]{2}{*}{1 a 3 anos } & 312 & 53 & 153 & 518 \\
\hline & $60.2 \%$ & $10.2 \%$ & $29.5 \%$ & $100 \%$ \\
\hline \multirow[t]{2}{*}{$<1$ ano } & 220 & 37 & 80 & 337 \\
\hline & $65.3 \%$ & $11.0 \%$ & $23.7 \%$ & $100 \%$ \\
\hline Total & $\begin{array}{r}677 \\
\end{array}$ & $\begin{array}{r}101 \\
97 \%\end{array}$ & 259 & 1037 \\
\hline
\end{tabular}

$\mathrm{n}=1043$

Os dados demonstram uma expansão recente da atuação das equipes de saúde da família em áreas exclusivamente rurais e em ambas, sendo que cerca de $89 \%$ das equipes de atuação exclusivamente rurais e 90\% das equipes com atuação em áreas urbano-rural estão implantadas há menos de 3 anos. Nota-se um aumento da atuação em área rural e em ambas nos municípios com PSF implantado entre 1 e 3 anos, quase $40 \%$ das equipes atuam nestas áreas. 
Tabela 6.7 - Porte dos municípios e área de atuação das ESF

\begin{tabular}{l|r|r|r|r}
\hline \multicolumn{1}{c}{$\begin{array}{r}\text { Área de Atuação } \\
\text { Porte dos } \\
\text { municípios }\end{array}$} & \multicolumn{1}{c}{ Urbana } & \multicolumn{1}{c}{ Rural } & Ambas & \multicolumn{1}{c}{ Total } \\
\hline$<20$ mil & 108 & 39 & 171 & 318 \\
& $34.0 \%$ & $12.3 \%$ & $53.8 \%$ & $100 \%$ \\
& 113 & 27 & 36 & 176 \\
50 a 100 mil & $64.2 \%$ & $15.3 \%$ & $20.5 \%$ & $100 \%$ \\
& 95 & 17 & 25 & 137 \\
$>100$ mil & $69.3 \%$ & $12.4 \%$ & $18.2 \%$ & $100 \%$ \\
& 361 & 18 & 27 & 406 \\
Total & $88.9 \%$ & $4.4 \%$ & $6.7 \%$ & $100 \%$ \\
& 677 & 101 & 259 & 1037 \\
\hline
\end{tabular}

$\mathrm{n}=1043$

Verifica-se o predomínio de atuação em área urbana nas equipes dos municípios de porte maior que 100 mil habitantes, concentrando $90 \%$ das equipes deste porte populacional em contraponto aos municípios menores de 20 mil habitantes, que concentram apenas $34 \%$ das ESF em área exclusivamente urbana. No entanto, nos municípios de menor porte, cerca de 2/3 das equipes mostram atuação em área rural e urbano-rural em contraste com os $11 \%$ das equipes dos municípios de maior porte.

\subsubsection{População adstrita às ESF}

Tabela 6.8 - Distribuição da população adstrita às ESF

\begin{tabular}{l|r|r}
\multicolumn{1}{c|}{ População adstrita às ESF } & $\mathbf{N}^{\mathbf{2}}$ & $\%$ \\
\hline Menos de 2400 pessoas & 137 & 13.14 \\
De 2400 a 4500 pessoas & 727 & 69.7 \\
Mais de 4500 pessoas & 151 & 14.48 \\
Não sabe & 18 & 1.73 \\
Sem informação & 10 & 0.96 \\
\hline Total & 1043 & 100.0 \\
\hline
\end{tabular}

Encontra-se maior freqüência, quase $70 \%$, de equipes que acompanham de 2.400 a 4.500 pessoas. Nota-se que $14 \%$ das ESF têm população adstrita acima de 4.500 pessoas e $2 \%$ delas referem não saber o número de pessoas que acompanham. 
Tabela 6.9 - Tempo de implantação e população adstrita por ESF

\begin{tabular}{|c|c|c|c|c|c|}
\hline \multirow[b]{2}{*}{ Tempo implantação } & \multicolumn{5}{|c|}{ População adstrita } \\
\hline & $<2.400$ & $\begin{array}{c}2.400 \mathrm{a} \\
4.500\end{array}$ & $>4.500$ & Não sabe & Total \\
\hline 5 anos ou + & 6 & 32 & 7 & 0 & 45 \\
\hline & $13.3 \%$ & $71.1 \%$ & $15.6 \%$ & $0.0 \%$ & $100 \%$ \\
\hline 3 a 5 anos & 13 & 75 & 45 & 1 & 134 \\
\hline & $9.7 \%$ & $56.0 \%$ & $33.6 \%$ & $0.7 \%$ & $100 \%$ \\
\hline 1 a 3 anos & 65 & 378 & 67 & 8 & 518 \\
\hline & $12.5 \%$ & $73.0 \%$ & $12.9 \%$ & $1.5 \%$ & $100 \%$ \\
\hline$<1$ ano & 53 & 242 & 32 & 9 & 336 \\
\hline & $15.8 \%$ & $72.0 \%$ & $9.5 \%$ & $2.7 \%$ & $100 \%$ \\
\hline Total & $\begin{array}{r}137 \\
131 \%\end{array}$ & $\begin{array}{r}727 \\
707 \%\end{array}$ & $\begin{array}{r}151 \\
146 \%\end{array}$ & $\begin{array}{r}18 \\
17 \%\end{array}$ & $\begin{array}{r}1033 \\
100 \%\end{array}$ \\
\hline
\end{tabular}

$\mathrm{n}=1043$

Em relação ao tempo de implantação, nota-se uma distribuição uniforme de equipes com população adstrita entre 2.400 a 4.500 pessoas (variando de $71 \%$ a $73 \%$ ), exceto nas equipes implantadas entre 3 e 5 anos, que apresentam cerca de $33 \%$ das equipes com mais de 4.500 pessoas adstritas.

Tabela 6.10 - Porte dos municípios e população adstrita por ESF

\begin{tabular}{|c|c|c|c|c|c|}
\hline \multirow[b]{2}{*}{ Porte dos municípios } & \multicolumn{5}{|c|}{ População adstrita } \\
\hline & $<2.400$ & $\begin{array}{c}2.400 \mathrm{a} \\
4.500\end{array}$ & $>4.500$ & Não sabe & Total \\
\hline$<20$ mil & 61 & 224 & 26 & 4 & 315 \\
\hline & $19.4 \%$ & $71.1 \%$ & $8.3 \%$ & $1.3 \%$ & $100 \%$ \\
\hline 20 a $50 \mathrm{mil}$ & 32 & 120 & 23 & 3 & 178 \\
\hline & $18.0 \%$ & $67.4 \%$ & $12.9 \%$ & $1.7 \%$ & $100 \%$ \\
\hline 50 a $100 \mathrm{mil}$ & 19 & 83 & 24 & 9 & 135 \\
\hline & $14.1 \%$ & $61.5 \%$ & $17.8 \%$ & $6.7 \%$ & $100 \%$ \\
\hline$>100 \mathrm{mil}$ & 25 & 300 & 78 & 2 & 405 \\
\hline & $6.2 \%$ & $74.1 \%$ & $19.3 \%$ & $0.5 \%$ & $100 \%$ \\
\hline Total & $\begin{array}{r}137 \\
13.3 \%\end{array}$ & $\begin{array}{r}727 \\
70.4 \%\end{array}$ & $\begin{array}{r}151 \\
146 \%\end{array}$ & $\begin{array}{r}18 \\
17 \%\end{array}$ & $\begin{array}{r}1033 \\
100 \%\end{array}$ \\
\hline
\end{tabular}

$\mathrm{n}=1043$

Evidencia-se que quanto maior o porte do município, maior o percentual de equipes implantadas com mais de 4.500 pessoas adstritas, sugerindo uma relação entre ambos. Sendo que $52 \%$ das equipes com mais de 4.500 pessoas adstritas ocorrem nos municípios acima de 100 mil habitantes. 
6.1.2 Caracterização dos municípios com PSF implantado no Estado de São Paulo

6.1.2.1 Caracterização - tempo de implantação, porte dos municípios com PSF implantado e cobertura populacional pelas ESF

Evidencia-se que a implantação inicial do PSF ocorre preferencialmente nos municípios de maior porte, sendo que cerca de $59 \%$ das equipes implantadas há mais de 3 anos podem ser observadas nestes municípios (Tabela 6.4). Contudo, a grande expansão do PSF ocorre principalmente nos municípios de menor porte e nas equipes implantadas entre 1 e 3 anos (Tabela 6.4).

Observa-se ainda que os municípios de menor porte apresentam um aumento 7 vezes maior nas equipes implantadas há menos de 3 anos em relação às implantadas há mais de 3 anos (Tabela 6.4). Esta relação decresce com o aumento do porte dos municípios, sendo quase 2 vezes para os municípios de maior porte. De maneira geral, aproximadamente $82 \%$ das equipes do Estado estão implantadas há menos de 3 anos, e destas, mais de $30 \%$ há menos de 1 ano (Tabela 6.4), demonstrando a pouca maturidade do PSF no Estado de São Paulo, principalmente ao se considerar a magnitude das mudanças propostas na implantação do PSF, notadamente as relacionadas a financiamento, insumos e recursos humanos (OPAS, 2003). 
Chama a atenção que, apesar do pouco tempo de implantação, o PSF mostra uma adesão de no mínimo $50 \%$ dos municípios, indicando grande difusão do programa no Estado de São Paulo, é possível verificar também que os municípios de porte entre 50 a 100 mil habitantes são os que mais aderiram ao PSF, 2/3 dos mesmos (Tabela 6.1). Este fato demonstra que no Estado de São Paulo o PSF teve adesão dos municípios de todos os portes, contrariando o que se tem propagado, de que o PSF é preferencialmente um modelo de atenção para municípios de pequeno porte.

Já em relação aos municípios com PSF implantado, observa-se o predomínio desta implantação nos municípios de menor porte, cerca de $60 \%$ (Tabela 6.2). Entretanto, em relação ao número de equipes implantadas verifica-se uma maior freqüência (39\%) nos municípios de maior porte, seguidos pelos municípios de menor porte, que apresentam $30 \%$ das equipes implantadas (Tabela 6.2).

Pode contribuir para esta distribuição de equipes a forma de repasse dos incentivos federais de implantação do PSF (PAB Variável PACS/PSF), cujos valores aumentam com a cobertura populacional atingida pelo programa, uma vez que uma maior cobertura é mais facilmente atingida pelos municípios de menor porte. Já em relação aos municípios de maior porte é provável que o projeto Qualis/PSF, implantado no município de São Paulo com recursos federais e estaduais, tenha tido grande influência no total de equipes implantadas nestes municípios. Cabe lembrar que estas equipes representam cerca de $20 \%$ das equipes entrevistadas (208 ESF). 
Como esperado, a maior cobertura está na população residente nos municípios de porte menor que 20 mil habitantes, por volta de 6 vezes maior que a observada nos municípios de mais de 100 mil habitantes, verificandose aí uma relação inversa entre a cobertura populacional e o tamanho dos municípios.

Quando se compara o tempo de implantação das equipes de saúde da família do Estado de São Paulo com os demais Estados da região Sudeste e com a média nacional, observa-se que para todos a implantação do PSF é extremamente recente. O Estado de São Paulo apresenta a segunda maior freqüência de equipes implantadas há mais de 5 anos na região Sudeste (a maior é a do Estado de Minas Gerais, cerca de 10\%), e situa-se próximo da média nacional, que é de 6\%. (AVALIAÇÃO NORMATIVA - MS) Portanto, ao contrário do senso comum, a implantação do PSF no Estado de São Paulo condiz com o padrão brasileiro.

\subsubsection{Caracterização - Área de atuação das ESF}

Em relação à área de atuação apenas $9.6 \%$ das equipes atuam em áreas exclusivamente rurais, demonstrando que de maneira geral o PSF no Estado de São Paulo é um programa predominantemente urbano (Tabela $6.5)$.

Verifica-se uma expansão recente da atuação das equipes de saúde da família em área exclusivamente rural e urbano-rural, representando $11 \%$ nas equipes implantadas há 5 anos ou mais, e 33\% nas equipes implantadas 
há menos de 3 anos (Tabela 6.6). Evidencia-se que este fato é mais notável nas equipes implantadas entre 1 e 3 anos, em que esta proporção atinge $40 \%$.

Em relação ao porte dos municípios, é predominante a atuação em área urbana nas equipes dos municípios de porte maior que 20 mil habitantes, variando aproximadamente $64 \%$ nos municípios de porte entre 20 e 50 mil habitantes a $90 \%$ das equipes implantadas nos municípios acima de 100 mil habitantes. Observa-se ainda que nos municípios de menor porte, cerca de 2/3 das equipes atuam em área rural e urbano-rural (Tabela 6.7).

Uma das prováveis explicações para o aumento da atuação das equipes em área rural e urbano-rural pode ser a influência dos incentivos financeiros oriundos da Secretaria Estadual de Saúde, através do projeto Qualis/PSF/Interior, dirigido aos municípios de baixo Índice de Desenvolvimento Humano (IDH) e municípios com áreas de assentamento rural e/ou populações remanescentes de quilombos. Cabe ressaltar que o projeto Qualis/PSF/Interior foi iniciado em 2000. (SÃO PAULO, SECRETARIA ESTADUAL DA SAÚDE, 2002)

Em relação aos Estados da região Sudeste, os Estados de São Paulo e de Minas Gerais apresentam freqüências semelhantes de equipes implantadas em zona urbana, $65 \%$ e $64 \%$ respectivamente, e ambos situamse acima da média nacional (55\%). Também como esperado pode-se observar para o Estado de São Paulo a menor freqüência de equipes 
implantadas em zona rural, cerca de $10 \%$, situando-se abaixo da média brasileira (24\%). No ESP $25 \%$ das equipes atuam simultaneamente em ambas as áreas, acima da média nacional que é de $21 \%$, ocupando o segundo lugar dos Estados da região Sudeste. (AVALIAÇÃO NORMATIVA MS)

6.1.2.3 Caracterização - População adstrita às equipes de saúde a família

Aproximadamente $70 \%$ das equipes acompanham de 2.400 a 4.500 pessoas, estando de acordo com o parâmetro recomendado pelo Ministério da Saúde (Portaria n. 1886 de 18/12/1997) (BRASIL, MS, 1997). Por outro lado, chama a atenção que $14 \%$ das equipes têm população adstrita acima de 4.500 pessoas, e $2 \%$ não sabem quantas pessoas estão acompanhando (Tabela 6.8). Estes percentuais, apesar de baixos, merecem destaque, pois se constituem em inadequação na implantação do PSF, que tem como uma das diretrizes principais o conhecimento do território pelas equipes, para que as mesmas possam elaborar o diagnóstico de saúde do local onde atuam e o atendimento integral à população.

Em relação ao tempo de implantação, nota-se que $71 \%$ das equipes em todas as faixas pesquisadas acompanham de 2.400-4.500 pessoas, exceto as equipes implantadas entre 3 e 5 anos, que apresenta cerca de $33 \%$ das equipes com mais de 4.500 pessoas adstritas (Tabela 6.9). 
Em relação ao porte dos municípios, evidencia-se que quanto maior o porte, maior o percentual de equipes implantadas com mais de 4.500 pessoas adstritas (Tabela 6.10).

Verifica-se que mais da metade das equipes com população adstrita acima de 4.500 habitantes está nos municípios com mais de 100 mil habitantes (Tabela 6.9). Provavelmente devido à maior densidade demográfica, principalmente nas regiões periféricas destes municípios, onde o PSF está mais implantado. Todavia, este fato não deve minimizar a orientação do MS de no máximo 4.500 pessoas adstritas por equipe, para que um excessivo número de pessoas por equipe não comprometa a qualidade do trabalho das mesmas. Cabe ressaltar que esta era a orientação à época da pesquisa, sendo atualmente revisada para no máximo 4.000 pessoas adstritas por ESF, conforme Portaria da Atenção Básica nº 648 publicada em 28/03/2006. Portanto, a questão tem que ser considerada no planejamento inicial da implantação das equipes, e ser avaliada com freqüência pelas mudanças e crescimento constante, principalmente pelas áreas de invasão, que o território de abrangência apresenta principalmente nos grandes municípios.

$\mathrm{Na}$ região Sudeste aparecem as maiores freqüências de equipes com populações adstritas maior que 4.500 pessoas - nos Estados de São Paulo e Minas Gerais, $14 \%$ e $13 \%$ respectivamente. No entanto os dois Estados situam-se abaixo da média brasileira, cerca de $17 \%$. Em relação às equipes que acompanham no máximo 4.500 pessoas, novamente se 
observa que os Estados de São Paulo e Minas Gerais apresentam freqüência semelhante, entre $82 \%$ e $84 \%$, e situam-se acima da média nacional que é de 80\%. (AVALIAÇÃO NORMATIVA - MS)

\subsection{Infra-estrutura (áreas física, equipamentos e pessoal)}

6.2.1 Infra-estrutura da Unidade Básica de Saúde (UBS)

6.2.1.1 Número de equipes e dependências de área física por UBS

Tabela 6.11 - Existência de área física para o trabalho das ESF

\begin{tabular}{l|r|r}
\hline Área física para o trabalho das ESF & $\mathbf{N}^{\circ}$ & $\%$ \\
\hline Sim & 1038 & 99.52 \\
Não & 5 & 0.48 \\
\hline Total & 1043 & 100 \\
\hline
\end{tabular}

Apenas cinco equipes refeririam não ter alguma área física para desenvolvimento das suas atividades.

Tabela 6.12 - Equipes de saúde da família existentes por UBS

\begin{tabular}{l|r|r}
\hline \multicolumn{1}{c|}{$\mathbf{N}^{\circ}$ de ESF na UBS } & $\mathbf{N}^{\mathbf{2}}$ & \multicolumn{1}{c}{$\%$} \\
\hline Uma & 561 & 53.8 \\
Duas & 165 & 15.8 \\
Três & 104 & 10.0 \\
Quatro & 79 & 7.6 \\
Cinco & 67 & 6.4 \\
Seis & 35 & 3.4 \\
Sete & 14 & 1.3 \\
Sem Informação & 18 & 1.7 \\
\hline Total & 1043 & 100,0 \\
\hline
\end{tabular}

Aproximadamente, mais da metade das UBS possui apenas uma equipe, $16 \%$ possuem 2 equipes e 10\% das UBS possuem 3 equipes, totalizando cerca de $80 \%$ das UBS com no máximo 3 equipes. O número de equipes por UBS varia de 1 a 7 equipes. Destaca-se que em $11 \%$ das 
observações encontram-se 5 equipes ou mais por UBS, sugerindo mais de 20.000 pessoas adstritas por UBS.

Tabela 6.13 - Porte dos municípios e número de ESF por UBS

\begin{tabular}{|c|c|c|c|c|c|c|c|c|}
\hline \multicolumn{9}{|c|}{ Número de ESFI UBS } \\
\hline Porte municípios & 1.0 & 2.0 & 3.0 & 4.0 & 5.0 & 6.0 & 7.0 & Total \\
\hline \multirow[t]{2}{*}{$<20$ mil } & 248 & 58 & 3 & 1 & 0 & 0 & 0 & 310 \\
\hline & $80.0 \%$ & $18.7 \%$ & $1.0 \%$ & $0.3 \%$ & $0.0 \%$ & $0.0 \%$ & $0.0 \%$ & $100 \%$ \\
\hline \multirow[t]{2}{*}{20 a 50 mil } & 130 & 25 & 23 & 0 & 0 & 0 & 0 & 178 \\
\hline & $73.0 \%$ & $14.0 \%$ & $12.9 \%$ & $0.0 \%$ & $0.0 \%$ & $0.0 \%$ & $0.0 \%$ & $100 \%$ \\
\hline \multirow[t]{2}{*}{50 a $100 \mathrm{mil}$} & 90 & 21 & 14 & 9 & 0 & 0 & 0 & 134 \\
\hline & $67.2 \%$ & $15.7 \%$ & $10.4 \%$ & $6.7 \%$ & $0.0 \%$ & $0.0 \%$ & $0.0 \%$ & $100 \%$ \\
\hline \multirow[t]{2}{*}{$>100 \mathrm{mil}$} & 93 & 61 & 64 & 69 & 67 & 35 & 14 & 403 \\
\hline & $23.1 \%$ & $15.1 \%$ & $15.9 \%$ & $17.1 \%$ & $16.6 \%$ & $8.7 \%$ & $3.5 \%$ & $100 \%$ \\
\hline \multirow[t]{2}{*}{ Total } & 561 & 165 & 104 & 79 & 67 & 35 & 14 & 1025 \\
\hline & $54.7 \%$ & $16.1 \%$ & $10.1 \%$ & $7.7 \%$ & $6.5 \%$ & $3.4 \%$ & $1.4 \%$ & $100 \%$ \\
\hline
\end{tabular}

$\mathrm{n}=1043$

É importante ressaltar que $100 \%$ das UBS com 5, 6 e 7 ESF ocorrem nos municípios maiores que 100 mil habitantes. Estes municípios apresentam também $87 \%$ das UBS com 4 equipes de saúde da família.

Tabela 6.14 - Tempo de implantação das ESF e número de ESF por UBS

\begin{tabular}{|c|c|c|c|c|c|c|c|c|}
\hline \multicolumn{9}{|c|}{ Número de ESFI UBS } \\
\hline Tempo implantação & 1 & 2 & 3 & 4 & 5 & 6 & 7 & Total \\
\hline 5 anos ou + & $\begin{array}{r}15 \\
33.3 \%\end{array}$ & $\begin{array}{r}5 \\
11.1 \%\end{array}$ & $\begin{array}{r}17 \\
37.8 \%\end{array}$ & $\begin{array}{r}0 \\
0.0 \%\end{array}$ & $\begin{array}{r}8 \\
17.8 \%\end{array}$ & $\begin{array}{r}0 \\
0.0 \%\end{array}$ & $\begin{array}{r}0 \\
0.0 \%\end{array}$ & $\begin{array}{r}45 \\
100 \%\end{array}$ \\
\hline 3 a 5 anos & 62 & 15 & 10 & 23 & 25 & 0 & 0 & 135 \\
\hline & $45.9 \%$ & $11.1 \%$ & $7.4 \%$ & $17.0 \%$ & $18.5 \%$ & $0.0 \%$ & $0.0 \%$ & $100 \%$ \\
\hline 1 a 3 anos & 300 & 92 & 44 & 36 & 19 & 10 & 7 & 508 \\
\hline & $59.1 \%$ & $18.1 \%$ & $8.7 \%$ & $7.1 \%$ & $3.7 \%$ & $2.0 \%$ & $1.4 \%$ & $100 \%$ \\
\hline$<1$ ano & 179 & 52 & 33 & 19 & 14 & 25 & 7 & 329 \\
\hline & $54.4 \%$ & $15.8 \%$ & $10.0 \%$ & $5.8 \%$ & $4.3 \%$ & $7.6 \%$ & $2.1 \%$ & $100 \%$ \\
\hline Total & 556 & 164 & 104 & 78 & 66 & 35 & 14 & 1017 \\
\hline & $54.7 \%$ & $16.1 \%$ & $10.2 \%$ & $7.7 \%$ & $6.5 \%$ & $3.4 \%$ & $1.4 \%$ & $100 \%$ \\
\hline
\end{tabular}

Em $81 \%$ das UBS atuam no máximo 3 ESF, que é o parâmetro recomendado pelo MS. Entretanto, em 19\% delas o número de ESF é pelo menos 4. Verifica-se que UBS com 4 ESF é mais freqüente, cerca de $46 \%$, nas equipes implantadas entre 1 e 3 anos, e que UBS com 5 ESF são as mais verificadas, cerca de $40 \%$ nas implantadas entre 3 e 5 anos. Chama a 
atenção que mais de $2 / 3$ das UBS com 6 ou 7 ESF aparecem nas equipes implantadas há menos de 1 ano.

Tabela 6.15 - Número de ESF por UBS e número médio de consultórios médicos por ESF

\begin{tabular}{l|r|r|r}
\hline \multicolumn{3}{c}{ Relação do $\mathbf{n}^{\circ}$ de ESFI UBS com $\mathbf{n}^{\mathbf{0}}$ de consultório médico (CM) } \\
\hline $\begin{array}{c}\text { Número de ESF por } \\
\text { unidade de saúde }\end{array}$ & $\mathbf{N}^{\circ}$ & $\%$ & \multicolumn{1}{c}{ Média CM } \\
\hline 1 & 560 & 55,1 & 1,1 \\
2 & 164 & 16,1 & 1,8 \\
3 & 100 & 9,8 & 2,9 \\
4 & 77 & 7,6 & 3,4 \\
5 & 67 & 6,6 & 5,2 \\
6 & 35 & 3,4 & 5,4 \\
7 & 14 & 1,4 & 6,8 \\
\hline Total & 1017 & 100,0 & 2,1 \\
\hline $\mathrm{n}=1043$ & & &
\end{tabular}

Verifica-se o número médio de 1 consultório médico por UBS com uma equipe de saúde da família. O número de consultórios médicos é inferior ao de equipes existentes nas unidades de saúde, a exceção das unidades com 1 e 5 equipes.

Tabela 6.16 - Número de ESF por UBS e número médio de consultórios de enfermagem por ESF

\begin{tabular}{l|r|r|r}
\hline \multicolumn{3}{c}{ Relação do $\mathbf{n}^{\circ}$ de ESFI UBS com o $\mathbf{n}^{\circ}$ de consultórios de enfermagem (CE) } \\
\hline $\begin{array}{c}\text { Número de ESF } \\
\text { por unidade de saúde }\end{array}$ & $\mathbf{N}^{\circ}$ & $\%$ & Média de CE \\
\hline 1 & 436 & 52,2 & 0,7 \\
2 & 133 & 15,9 & 0,9 \\
3 & 89 & 10,7 & 1,3 \\
4 & 61 & 7,3 & 2 \\
5 & 67 & 8,0 & 2,1 \\
6 & 35 & 4,2 & 1,4 \\
7 & 14 & 1,7 & 2 \\
\hline Total & 835 & 100,0 & 1 \\
\hline $\mathrm{n}=1043$ & & &
\end{tabular}

Tendo-se por referência a disponibilidade de um consultório de enfermagem, todas as UBS estão abaixo desse número, com destaque as UBS com 6 e 7 equipes, com apenas 23\% e 25\% respectivamente, do recomendado. 
Tabela 6.17 - Distribuição das dependências de área física das UBS destinadas ao atendimento da população

\begin{tabular}{l|r|r|r|r}
\hline \multicolumn{1}{c|}{ Área física para atendimento } & \% Sim & \% Não & \% Sem informação & \multicolumn{1}{c}{ Total } \\
\hline Consultório médico & 97 & 1 & 2 & 100 \\
Sanitário p/ público & 97 & 1 & 2 & 100 \\
Recepção & 95 & 2 & 3 & 100 \\
Sanitário p/ funcionário & 93 & 3 & 4 & 100 \\
Sala p/ procedimentos básicos & 90 & 6 & 4 & 100 \\
Sala vacinação & 68 & 18 & 14 & 100 \\
Local p/ reunião & 64 & 20 & 16 & 100 \\
Consultório enfermagem & 55 & 25 & 20 & 100 \\
\hline
\end{tabular}

$\mathrm{n}=1043$

Nota-se que a maior freqüência de dependência de área física presente é o consultório médico (97\%), e a menor freqüência é o consultório de enfermagem (55\%), que juntamente com local para reunião $(64 \%)$ e sala de vacina $(68 \%)$ compõem os itens menos verificados.

Uma observação importante é que mais de $30 \%$ das ESF atuam em UBS sem sala de vacina, o que dificulta a realização de uma das ações de prevenção básica e fundamental de saúde pública, a imunização.

Considerando-se as três dependências menos freqüentes: consultório de enfermagem, local para reunião e sala de vacina, sugere que as UBS não apresentam a estrutura física mínima adequada para a realização das atividades previstas para o PSF.

Tabela 6.18 - Distribuição do conjunto de dependências de área física pesquisada segundo a classificação adotada

\begin{tabular}{|c|c|c|}
\hline Dependências de área física & $\mathbf{N}^{\circ}$ & $\%$ \\
\hline Adequada & 319 & 30.58 \\
\hline Suficiente & 532 & 51.01 \\
\hline Mínimo & 157 & 15.05 \\
\hline Insuficiente & 35 & 3.36 \\
\hline Total & 1043 & 100.0 \\
\hline
\end{tabular}


Cerca de $81 \%$ das equipes estão classificadas aqui como pelo menos suficientes em relação ao referencial adotado - $80 \%$ ou mais dos itens pesquisados neste caso das dependências de áreas físicas existentes nas UBS. Destas, apenas 30\% estão classificadas como adequadas, isto é, possuem $100 \%$ dos itens pesquisados. Chama a atenção que 3\% aparecem como insuficientes por possuírem menos de $50 \%$ destes itens.

Tabela 6.19 - Porte dos municípios e situação da área física das UBS segundo classificação adotada

\begin{tabular}{l|r|r|r|r|r}
\hline \multicolumn{7}{c}{ Situação da área física das UBS segundo referencial adotado } \\
\hline \multicolumn{1}{c|}{ Porte dos municípios } & \multicolumn{1}{c}{ Adequada } & Suficiente & \multicolumn{1}{c}{ Mínimo } & Insuficiente & \multicolumn{1}{c}{ Total } \\
\hline$<20$ mil & 64 & 119 & 121 & 14 & 318 \\
& $20.1 \%$ & $37.4 \%$ & $38.1 \%$ & $4.4 \%$ & $100 \%$ \\
20 a 50 mil & 42 & 50 & 82 & 5 & 179 \\
& $23.5 \%$ & $27.9 \%$ & $45.8 \%$ & $2.8 \%$ & $100 \%$ \\
50 a 100 mil & 32 & 35 & 63 & 7 & 137 \\
& $23.4 \%$ & $25.5 \%$ & $46.0 \%$ & $5.1 \%$ & $100 \%$ \\
& 181 & 112 & 106 & 10 & 409 \\
& $44.3 \%$ & $27.4 \%$ & $25.9 \%$ & $2.4 \%$ & $100 \%$ \\
\hline Total & 319 & 316 & 372 & 36 & 1043 \\
& $30.6 \%$ & $30.3 \%$ & $35.7 \%$ & $3.5 \%$ & $100 \%$ \\
\hline$n=1043$ & & & & &
\end{tabular}

A classificação pelo menos suficiente pode ser mais observada $(57 \%$ aproximadamente) nas equipes dos municípios com mais de 100 mil habitantes. O percentual de adequação varia inversamente ao porte dos municípios, de $20 \%$ nos menores de 20 mil a $44 \%$ nos maiores que 100 mil habitantes. Dentre os considerados insuficientes, $39 \%$ ocorrem nos municípios menores de 20 mil habitantes. 
Tabela 6.20 - Tempo de implantação e situação de área física segundo classificação adotada

\begin{tabular}{l|r|r|r|r|r}
\hline \multicolumn{7}{c}{ Situação da área física das UBS segundo referencial adotado } \\
\hline \multicolumn{1}{c}{ Tempo implantação } & \multicolumn{1}{c}{ Adequada } & \multicolumn{1}{c}{ Suficiente } & \multicolumn{1}{c}{ Mínimo } & Insuficiente & \multicolumn{1}{c}{ Total } \\
\hline 5 anos ou + & 24 & 9 & 11 & 1 & 45 \\
& $53.3 \%$ & $20.0 \%$ & $24.4 \%$ & $2.2 \%$ & $100 \%$ \\
3 a 5 anos & 62 & 35 & 38 & 2 & 137 \\
& $45.3 \%$ & $25.5 \%$ & $27.7 \%$ & $1.5 \%$ & $100 \%$ \\
1 a 3 anos & 163 & 152 & 176 & 24 & 515 \\
& $31.7 \%$ & $29.5 \%$ & $34.2 \%$ & $4.7 \%$ & $100 \%$ \\
$<1$ ano & 68 & 118 & 144 & 8 & 338 \\
& $20.1 \%$ & $34.9 \%$ & $42.6 \%$ & $2.4 \%$ & $100 \%$ \\
\hline Total & 317 & 314 & 369 & 35 & 1035 \\
& $30.6 \%$ & $30.3 \%$ & $35.7 \%$ & $3.4 \%$ & $100 \%$ \\
\hline
\end{tabular}

$\mathrm{n}=1043$

Em relação ao tempo de implantação, verifica-se nas equipes mais antigas um maior percentual de classificação adequada, aproximadamente $53 \%$. Este percentual cai para $20 \%$ nas equipes implantadas há menos de 1 ano, sugerindo uma relação inversa entre percentual de adequação de área física e tempo de implantação. O outro pólo mostra que $91 \%$ das situações de insuficientes ocorrem nas equipes implantadas há menos de 3 anos, sendo o menor percentual (9\%) naquelas entre 1 e 3 anos.

\subsubsection{Infra-estrutura da Unidade Básica de Saúde (UBS)}

6.2.2.1 Número de equipes por UBS e dependências de área física das UBS

Aproximadamente metade das UBS possui apenas uma equipe, sendo que em $81 \%$ delas atuam no máximo 3 ESF, que é o parâmetro recomendado pelo MS. Entretanto, em 19\% das UBS o número de ESF é pelo menos 4 (Tabela 6.12). No outro extremo apresentam-se 5 ESF que referem não ter UBS para a realização do atendimento da população (Tabela 6.11). 
Chama atenção que $100 \%$ das UBS com 5,6 e 7 ESF e $87 \%$ das UBS com 4 ESF ocorrem nos municípios maiores que 100 mil habitantes. Verifica-se que a UBS com 4 ESF é mais freqüente, cerca de 46\%, nas equipes implantadas entre 1 e 3 anos, e que a UBS com 5 ESF é cerca de $40 \%$ nas implantadas entre 3 e 5 anos. Mais de $2 / 3$ das UBS com 6 ou 7 ESF aparecem nas equipes implantadas há menos de 1 ano.

Uma questão que se coloca é a possibilidade que esta maior freqüência observada pode representar uma perda ou um "descuido" em relação ao parâmetro para a implantação do PSF nas equipes mais novas. Além disso, unidades com pelo menos 4 ESF indicam uma população adstrita acima de 20.000 pessoas, estando também em desacordo com o parâmetro recomendado pelo MS de uma unidade de saúde da família para atendimento de até 12.000 pessoas (Portaria n. 648 de 28/03/06). (BRASIL, MS, 2006)

Mesmo considerando-se a necessidade de um estudo mais detalhado para populações de maior densidade demográfica, sobre qual seria o número ideal e possível de equipes por UBS, vale ressaltar que, se a população adstrita for muito grande, as pessoas poderão morar muito distantes da unidade de saúde, contrariando um dos propósitos da atenção básica que é ser de fácil acesso e estar localizada o mais próximo da comunidade que atende. (STARFIELD, 2004) 
Apenas 5 equipes referem não ter alguma área física para desenvolvimento das suas atividades (Tabela 6.11). O número médio de 1 consultório médico por UBS com uma equipe de saúde da família é também apresentado. Cabe ressaltar que o número de consultório médico é ligeiramente inferior ao número de equipes existentes nas unidades de saúde (Tabela 6.16). Contudo, esta diferença se acentua em relação ao consultório de enfermagem, que apresenta valores sistematicamente menores que o número de equipes implantadas, com destaque para as UBS com 6 e 7 ESF, com cerca de 1/4 do recomendado (Tabela 6.18).

Observa-se ainda que a maior freqüência de dependência de área física é o consultório médico ( $97 \%$ ), e a menor o consultório de enfermagem (55\%) (Tabela 6.17). Portanto, evidencia-se uma estrutura física na qual se destaca o consultório médico, sugerindo um padrão clássico de UBS e favorecendo o predomínio de atividades ligadas à assistência médica. Entretanto, está nas diretrizes do PSF que os enfermeiros, entre outras atribuições, deverão realizar consultas de enfermagem (segundo os protocolos ou normas técnicas existentes e aprovadas pelo MS ou gestor municipal), o que pressupõe espaços adequados para a realização destas atividades. (BRASIL, MS, 2001; BRASIL, MS, 2006. Portaria n. 648 de 28/03/06)

Outro fato a ser considerado em relação à questão anterior é que mesmo com a possibilidade de compartilhamento das dependências das UBS, quando nela atuarem mais de uma equipe de saúde da família e 
segundo a recomendação do MS - que deve existir pelo menos 2 consultórios por ESF, a relação consultório de enfermagem / equipe, continua inadequada. (BRASIL, MS, 2001)

Quanto aos itens pesquisados verifica-se que além do consultório de enfermagem, o local para reunião $(64 \%)$ e a sala de vacina $(68 \%)$ compõem os itens menos verificados (Tabela 6.17).

Como ressaltado, cerca de $30 \%$ das equipes atuam em UBS sem sala de vacina dificultando a realização de uma importante ação de prevenção básica e fundamental de saúde pública que é a imunização (Tabela 6.15). Além disso, provavelmente a população é encaminhada para receber imunização em UBS próximas, onde atuam outros profissionais da atenção básica, o que pode dificultar o estabelecimento de vínculos entre ESF e população adstrita.

Nesta análise, considerando as três dependências menos freqüentes: consultório de enfermagem, local para reunião e sala de vacina, pode-se verificar que as UBS não apresentam a estrutura física mínima adequada para a realização das atividades previstas para o PSF.

Em relação à região Sudeste, observa-se que todos os Estados apresentam freqüência semelhante (por volta de 95\%) quanto à existência pelo menos um consultório médico por equipe. Já o Estado de São Paulo apresenta o maior percentual da região Sudeste da existência de pelo menos um consultório de enfermagem por equipe, situando-se abaixo da 
média nacional observada de cerca de 62\%. (AVALIAÇÃO NORMATIVA MS)

Quando se analisa o conjunto de dependências de área física e a classificação proposta neste estudo, verifica-se em geral que a maioria das equipes trabalha em unidades de saúde como pelo menos suficientes destas dependências, no entanto apenas $30 \%$ classificam-se como adequadas, e chama a atenção que $3 \%$ apontam-se como insuficientes (Tabela 6.18).

A classificação suficiente é mais observada em cerca de $57 \%$ das equipes dos municípios de mais de 100 mil habitantes. Observa-se que o percentual de adequação varia inversamente ao porte dos municípios, de $20 \%$ nos menores de 20 mil a $44 \%$ nos maiores que 100 mil habitantes. Dentre os considerados insuficientes, 39\% ocorrem nos municípios menores de 20 mil habitantes (Tabela 6.19).

Em relação ao tempo de implantação, nota-se nas equipes mais antigas o maior percentual (53\%) de classificação adequada. Este percentual diminui nas equipes implantadas há menos de 1 ano (Tabela 6.20). Evidencia-se que as equipes implantadas há mais tempo e os municípios de maior porte apresentam melhores condições de estrutura física, segundo os itens pesquisados neste estudo, sugerindo uma relação entre adequação de área física, tempo de implantação e porte dos municípios. 
6.2.3 Existência de equipamentos disponíveis para o trabalho das ESF

Os equipamentos encontrados com maior freqüência, acima de 90\%, são: régua antropométrica, balança infantil, fita métrica, balança adulto, esfignomanômetro, estetoscópio, e termômetro. Os menos disponíveis, abaixo de $50 \%$, são: oftalmoscópio (19\%), lanterna (38\%) e material para pequenas cirurgias (49\%). Estetoscópio de Pinard e Sonar para 70\% e 75\% das equipes. Já a presença de aparelho de aerosol, material para retirada de pontos, foco, otoscópio, mesa ginecológica e espéculos ginecológicos, varia de $81 \%$, glicosímetro, até $87 \%$, mesa e espéculos ginecológicos. Cerca de $31 \%$ das ESF não dispõem de geladeira de vacina.

Tabela 6.21 - Materiais e equipamentos para o atendimento das ESF

\begin{tabular}{|c|c|c|c|c|c|}
\hline \multirow{2}{*}{ Materiais / Equipamentos } & \multicolumn{2}{|c|}{ Sim } & \multicolumn{2}{|c|}{ Não } & \multirow{2}{*}{ Total } \\
\hline & $\mathbf{N}^{\circ}$ & $\%$ & $\mathbf{N}^{\circ}$ & $\%$ & \\
\hline Oftalmoscópio & 205 & 19,7 & 821 & 78,7 & 1043 \\
\hline Lanterna & 400 & 38,4 & 627 & 60,1 & 1043 \\
\hline Pequena Cirurgia & 517 & 49,6 & 510 & 48,9 & 1043 \\
\hline Impressora & 555 & 53,2 & 472 & 44,8 & 1043 \\
\hline Microcomputador & 582 & 55,8 & 444 & 42,6 & 1043 \\
\hline Geladeira Vacina & 702 & 67,3 & 327 & 31,1 & 1043 \\
\hline Esteto Pinard & 739 & 70,9 & 288 & 27,4 & 1043 \\
\hline Sonar & 792 & 75,9 & 236 & 22,6 & 1043 \\
\hline Glicosímetro & 846 & 83,3 & 181 & 17,2 & 1043 \\
\hline Aparelho Aerosol & 869 & 83,3 & 159 & 15,2 & 1043 \\
\hline Retirada de Pontos & 878 & 84,2 & 150 & 14,4 & 1043 \\
\hline Foco & 901 & 86,4 & 129 & 12,3 & 1043 \\
\hline Otoscópio & 902 & 86,5 & 126 & 12,1 & 1043 \\
\hline Mesa Ginecológica & 910 & 87,2 & 119 & 11,4 & 1043 \\
\hline Espéculos Ginecológico & 913 & 87,5 & 115 & 10,9 & 1043 \\
\hline Régua Antropométrica & 944 & 90,5 & 89 & 8,5 & 1043 \\
\hline Balança Infantil & 961 & 92,1 & 67 & 6,4 & 1043 \\
\hline Fita Métrica & 961 & 92,1 & 72 & 6,9 & 1043 \\
\hline Balança Adulto & 986 & 94,5 & 44 & 4,2 & 1043 \\
\hline Esfignomanômetro & 993 & 95,2 & 34 & 3,3 & 1043 \\
\hline Estetoscópio & 1006 & 96,5 & 26 & 2,5 & 1043 \\
\hline Termômetro & 1008 & 96,6 & 20 & 1,9 & 1043 \\
\hline
\end{tabular}

$\mathrm{n}=1043$ 
6.2.3.1 Existência do conjunto básico de equipamentos para o trabalho das ESF

Tabela 6.22 - Equipamentos disponíveis para o atendimento das ESF segundo classificação adotada

\begin{tabular}{l|r|r}
\hline $\begin{array}{c}\text { Equipamentos disponíveis } \\
\text { para o atendimento das ESF }\end{array}$ & $\mathbf{N}^{\circ}$ & \multicolumn{2}{c}{} \\
\hline Adequada & 39 & 3,7 \\
Suficiente & 526 & 50,4 \\
Mínimo & 401 & 38,4 \\
Insuficiente & 77 & 7,4 \\
\hline Total & 1043 & 100,0 \\
\hline
\end{tabular}

Os equipamentos encontrados com maior freqüência, acima de $90 \%$, são: régua antropométrica, balança infantil, fita métrica, balança adulto, esfignomanômetro, estetoscópio, e termômetro. Os menos disponíveis, abaixo de $50 \%$, são: oftalmoscópio (19\%), lanterna (38\%) e material para pequenas cirurgias (49\%). Estetoscópio de Pinard e Sonar para 70\% e $75 \%$ das equipes. Já a presença de aparelho de aerosol, material para retirada de pontos, foco, otoscópio, mesa ginecológica e espéculos ginecológicos, varia de $81 \%$, glicosímetro, até $87 \%$, mesa e espéculos ginecológicos. Cerca de 31\% das ESF não dispõem de geladeira de vacina.

Cerca de $54 \%$ das equipes estão classificadas como pelo menos suficiente em relação ao referencial adotado para alocação de equipamentos, sendo que destas, apenas $4 \%$ mostram-se adequadas. Chama a atenção que $38 \%$ das equipes apresentam padrão mínimo, denotando uma insuficiência de materiais e equipamentos para a realização do seu trabalho com maior resolubilidade. Outrossim, $7.4 \%$ das ESF 
encontram-se em situação ainda pior com insuficiência de equipamentos para proceder a atenção principalmente médica.

Tabela 6.23 - Porte dos municípios e situação de equipamentos nas UBS segundo classificação adotada

\begin{tabular}{l|r|r|r|r|r}
\hline \multicolumn{1}{c|}{ Porte dos municípios } & \multicolumn{6}{|c}{ Situação de equipamentos } \\
\cline { 2 - 6 } & \multicolumn{1}{c|}{ Adequada } & Suficiente & \multicolumn{1}{c}{ Mínimo } & Insuficiente & \multicolumn{1}{c}{ Total } \\
\hline$<20$ mil & 7 & 133 & 139 & 39 & 318 \\
20 a 50 mil & $2.2 \%$ & $41.8 \%$ & $43.7 \%$ & $12.3 \%$ & $100 \%$ \\
& 0 & 79 & 93 & 7 & 179 \\
50 a 100 mil & $0.0 \%$ & $44.1 \%$ & $52.0 \%$ & $3.9 \%$ & $100 \%$ \\
& 1 & 58 & 68 & 10 & 137 \\
$>100$ mil & $0.7 \%$ & $42.3 \%$ & $49.6 \%$ & $7.3 \%$ & $100 \%$ \\
& 31 & 256 & 101 & 21 & 409 \\
\hline Total & $7.6 \%$ & $62.6 \%$ & $24.7 \%$ & $5.1 \%$ & $100 \%$ \\
\hline
\end{tabular}

Verifica-se que nos municípios acima de 100 mil habitantes $70 \%$ das equipes classificam-se como pelo menos suficiente e que este percentual diminui nos demais portes variando entre $43 \%$ a $44 \%$. No outro extremo, $12 \%$ das ESF dos municípios menores que 20 mil habitantes apresentam a condição insuficiente.

Tabela 6.24 - Tempo de implantação das equipes e situação de equipamentos nas UBS segundo classificação adotada.

\begin{tabular}{|c|c|c|c|c|c|}
\hline \multirow{2}{*}{ Tempo implantação } & \multicolumn{5}{|c|}{ Situação de equipamentos } \\
\hline & Adequada & Suficiente & Mínimo & Insuficiente & Total \\
\hline \multirow[t]{2}{*}{5 anos ou +} & 6 & 32 & 7 & 0 & 45 \\
\hline & $13.3 \%$ & $71.1 \%$ & $15.6 \%$ & $0.0 \%$ & $100 \%$ \\
\hline \multirow[t]{2}{*}{3 a 5 anos } & 15 & 76 & 42 & 4 & 137 \\
\hline & $10.9 \%$ & $55.5 \%$ & $30.7 \%$ & $2.9 \%$ & $100 \%$ \\
\hline \multirow[t]{2}{*}{1 a 3 anos } & 8 & 250 & 227 & 30 & 515 \\
\hline & $1.6 \%$ & $48.5 \%$ & $44.1 \%$ & $5.8 \%$ & $100 \%$ \\
\hline \multirow[t]{2}{*}{$<1$ ano } & 10 & 165 & 121 & 42 & 338 \\
\hline & $3.0 \%$ & $48.8 \%$ & $35.8 \%$ & $12.4 \%$ & $100 \%$ \\
\hline Total & $\begin{array}{r}39 \\
3.8 \%\end{array}$ & $\begin{array}{r}523 \\
50.5 \%\end{array}$ & $\begin{array}{r}397 \\
38.4 \%\end{array}$ & $\begin{array}{r}76 \\
7.3 \%\end{array}$ & $\begin{array}{r}1035 \\
100 \%\end{array}$ \\
\hline
\end{tabular}

Dentre as equipes classificadas como pelo menos suficiente, $77 \%$ delas estão implantadas há menos de 3 anos. Na outra ponta, 55\% das ESF 
classificadas como insuficientes estão há menos de 1 ano. Observa-se que $84 \%$ das equipes implantadas há 5 anos ou mais se classificam como pelo menos suficiente e que este percentual diminui com o tempo de implantação, sendo $66 \%$ nas equipes implantadas entre 3 e 5 anos e $53 \%$ nas equipes implantadas há menos de 1 ano.

6.2.3.2 Existência de "kit" básico de equipamentos para o atendimento de adultos e crianças

Tabela 6.25 - "Kit" básico de equipamentos para atendimento de adultos e crianças por ESF segundo classificação adotada

\begin{tabular}{l|r|r}
\hline \multicolumn{1}{c|}{ Kit básico para atendimento de adultos e crianças } & $\mathbf{N}^{\mathbf{0}}$ & \multicolumn{1}{c}{$\%$} \\
\hline Adequada & 311 & 29,8 \\
Suficiente & 492 & 47,2 \\
Mínimo & 205 & 19,7 \\
Insuficiente & 35 & 3,4 \\
\hline Total & 1043 & 100,0 \\
\hline
\end{tabular}

Cerca de $77 \%$ das equipes apresentam classificação pelo menos suficiente em relação ao "kit" básico de atendimento de adultos e crianças, e apenas $30 \%$ destas como adequadas. No entanto, $3.4 \%$ das equipes apresentam padrão insuficiente.

6.2.3.3 Existência de "kit" básico de equipamentos para o atendimento de mulheres pelas ESF

Tabela 6.26 - "Kit" básico de equipamentos para atendimento de mulheres por ESF segundo classificação adotada

\begin{tabular}{l|r|r}
\multicolumn{1}{c|}{ Kit básico para atendimento de mulheres } & $\mathbf{N}^{\circ}$ & \multicolumn{1}{c}{$\%$} \\
\hline Adequada & 502 & 48,1 \\
Suficiente & 395 & 37,9 \\
Mínimo & 102 & 9,8 \\
Insuficiente & 44 & 4,2 \\
\hline Total & 1043 & 100,0 \\
\hline
\end{tabular}


Cerca de $86 \%$ das equipes classificam-se como pelo menos suficiente quanto à existência de kit básico para o atendimento das mulheres. No entanto, 4,2\% aparecem como insuficientes.

6.2.3.4 Existência de equipamentos para aumentar a resolubilidade das ESF

Tabela 6.27 - Equipamentos para aumentar a resolubilidade por ESF

\begin{tabular}{l|r|r|r|r}
\hline Equipamentos para aumentar a resolubilidade das ESF & \multicolumn{1}{|c|}{ Sim } & \% Sim & \multicolumn{1}{c|}{ Não } & \% Não \\
\hline Oftalmoscópio & 205 & 19,7 & 819 & 78,5 \\
Pequena cirurgia & 517 & 49,6 & 510 & 48,9 \\
Glicosímetro & 846 & 81,1 & 181 & 17,4 \\
Aparelho aerosol & 869 & 83,3 & 157 & 15,1 \\
Retirada de Pontos & 878 & 84,2 & 150 & 14,4 \\
Otoscópio & 902 & 86,5 & 126 & 12,1 \\
\hline
\end{tabular}

Em nenhuma equipe o conjunto dos equipamentos propostos para aumentar a resolubilidade da atenção prestada pelas mesmas estava disponível, sendo os itens menos encontrados: oftalmoscópio, (presente em apenas $19 \%$ das equipes) e material para pequena cirurgia (encontrado em aproximadamente $50 \%$ das equipes); demais equipamentos verificados: $81 \%$ (otoscópio) e $87 \%$ (glicosímetro) das equipes.

6.2.4 Existência de equipamentos para o trabalho das ESF

6.2.4.1 Equipamentos disponíveis para o trabalho das equipes

Os equipamentos mais observados, acima de $90 \%$ foram: régua antropométrica, balança infantil, fita métrica, balança adulto, esfignomanômetro, estetoscópio, e termômetro. Os menos disponíveis, abaixo de 50\%: oftalmoscópio (19\%), lanterna (38\%) e material para 
pequena cirurgia (49\%). Deve-se destacar a inexistência de sala de vacina para quase $1 / 3$ das ESF. Cabe ressaltar ainda que apenas aproximadamente metade das equipes possui micro e impressora o que dificulta o monitoramento do trabalho das equipes através do Sistema de Informação da atenção Básica (SIAB) (Tabela 6.21).

De maneira geral, a disponibilidade dos materiais necessários para se realizar um atendimento adequado da população mostra-se irregular, e em alguns casos precária, podendo comprometer uma atenção à saúde mais qualificada e resolutiva como preconiza as diretrizes do programa. (PSF, MS, 2006)

Em relação aos estados do Sudeste, São Paulo apresenta o maior percentual de equipes com oftalmoscópio, otoscópio, glicosímetro, aparelho de aerosol, material para retirada de ponto, material para pequena cirurgia e sonar, situando-se também em relação a estes equipamentos, acima da média nacional. Já em relação à existência de geladeira de vacina, apresenta índice menor que o Estado do Rio de Janeiro (cerca de $71 \%$ ) e situa-se também abaixo da média nacional, cerca de $73 \%$. (AVALIAÇÃO NORMATIVA - MS)

6.2.4.2 Existência do conjunto básico de equipamentos disponível para o trabalho das equipes

Considerando-se como conjunto básico de equipamentos, a existência de lanterna, otoscópio, régua antropométrica, balança infantil, fita 
métrica, balança adulto, esfignomanômetro, estetoscópio e termômetro, apenas metade das equipes pode ser classificada como pelo menos suficiente em relação à presença destes equipamentos para a realização do trabalho. No entanto, mais de $45 \%$ das equipes apresentam padrão mínimo, e 7,4\% apresentam um padrão insuficiente de alocação destes equipamentos, denotando uma condição insatisfatória do mesmo, reforçando - comprometimento da resolubilidade da atenção ambulatorial que as equipes devem prestar à população adstrita (Tabela 6.21).

Em relação ao porte dos municípios, evidencia-se que $70 \%$ das equipes dos municípios de porte acima de 100 mil habitantes classificam-se como pelo menos suficiente enquanto nos demais municípios esta condição pode ser observada em menos da metade das equipes (Tabela 6.23).

Quanto ao tempo de implantação, observa-se nas equipes implantadas há 5 anos ou mais que $85 \%$ apresentam disponibilidade pelo menos suficiente dos equipamentos básicos. Entretanto, esta condição apresenta-se em cerca de $66 \%$ das equipes implantadas entre 1 a 3 anos (Tabela 6.24).

Tanto as equipes mais antigas como as dos municípios de maior porte apresentam maior percentual de classificação pelo menos suficiente, de equipamentos para a realização de seu trabalho. 
6.2.4.3 Existência de "kit" básico de equipamentos para o atendimento de adultos e crianças

Quando se considera a existência de "kit" básico de equipamentos para o atendimento de crianças e adulto (lanterna, balança infantil e adulto, estetoscópio, esfignomanômetro, régua antropométrica, fita métrica, termômetro e otoscópio), observa-se que a classificação de pelo menos suficiente em $77 \%$ das equipes, e adequado para apenas $30 \%$ das mesmas. Contudo, mostra-se insuficiente em 3,4\% das equipes (Tabela 6.25).

Em relação aos Estados do Sudeste, São Paulo apresenta freqüência semelhante ao Estado do Rio de Janeiro quanto à existência de equipamento básico considerado no relatório do MS como a existência de balança infantil e adulto, estetoscópio, esfignomanômetro e termômetro; e também se situa acima da média nacional, de $81 \%$. (AVALIAÇÃO NORMATIVA - MS)

6.2.4.4 Existência de "kit" básico de equipamentos para o atendimento de mulheres

Nota-se que $86 \%$ das equipes possuem o kit básico para o atendimento das mulheres (balança adulto, estetoscópio, esfignomanômetro, estetoscópio de Pinard, sonar, mesa ginecológica, fita métrica, termômetro, foco, espéculos ginecológicos), classificando-se como pelo menos suficiente, e 4,2\% apresentam-se com insuficiente alocação destes equipamentos. (Tabela 6.26). 
Quanto à existência de equipamento ginecológico/obstétrico básico para o MS (mesa e espéculos ginecológicos, foco e estetoscópio de Pinard), nota-se que o Estado de São Paulo apresenta melhor classificação em relação aos estados do Sudeste - a média nacional que é de 62\%. (AVALIAÇÃO NORMATIVA - MS)

6.2.4.5 Existência de equipamentos para aumentar a resolubilidade das equipes

Em relação ao conjunto de equipamentos para aumentar a resolubilidade das equipes (oftalmoscópio, material para pequena cirurgia, glicosímetro, aparelho de aerossol, material para retirada de pontos, otoscópio), é lícito supor que se uma UBS possuir este conjunto ela apresenta maior possibilidade de contensão da demanda mais usual aos centros de saúde.

O estudo demonstra que em nenhuma equipe este conjunto estava disponível, sendo os itens menos encontrados: oftalmoscópio, apenas $20 \%$, lanterna, 38\% e material para pequena cirurgia, cerca de 50\% (Tabela 6.27).

Em relação à região Sudeste, o Estado de São Paulo apresenta para estes equipamentos maior freqüência que os estados da região Sudeste, e que a média nacional, para a qual as maiores diferenças observadas são relacionadas à existência de otoscópio - média nacional $=6 \%$, e glicosímetro - média nacional $=59 \% . \quad($ AVALIAÇÃO NORMATIVA - MS $)$ 
De maneira geral, a disponibilidade dos equipamentos necessários para a realização de um atendimento adequado mostra alocação diversificada, não obedecendo a um padrão mínimo, o que pode comprometer uma atenção à saúde mais qualificada e resolutiva, como preconiza as diretrizes do programa. (BRASIL, MS, 1997)

Neste sentido, ainda deve ser destacada a ausência de geladeira exclusiva para vacinas em cerca de $30 \%$ das UBS, o que reforça a questão da precariedade com que algumas equipes foram implantadas, comprometendo ainda mais a resolubilidade que se quer dar a atenção básica. O Estado de São Paulo apresenta percentual menor de existência de geladeira exclusiva para vacinas que a média nacional (73\%) e situa-se em segundo lugar da região Sudeste. (AVALIAÇÃO NORMATIVA - MS)

\subsubsection{Caracterização dos recursos humanos das ESF}

\subsubsection{Caracterização dos médicos das ESF}

\subsection{Número de médicos por ESF}

Tabela 6.28 - Médicos por ESF

\begin{tabular}{l|r|r}
\hline \multicolumn{1}{c}{ Quantidade de médicos } & $\mathbf{N}^{\circ}$ & $\%$ \\
\hline Um & 974 & 93,4 \\
Dois & 3 & 0,3 \\
$\geq$ três & 1 & 0,1 \\
Nenhum há menos de 60dias & 40 & 3.8 \\
Nenhum há mais de 60dias & 23 & 2,2 \\
Sem informação & 2 & 0,2 \\
\hline Total & 1043 & 100 \\
\hline
\end{tabular}


Cerca de $93 \%$ das equipes possuem um médico, e 2,2\% delas mostram que o médico estava ausente há mais de 60 dias. Chama a atenção a existência de 2 e 3 médicos por equipe.

\subsection{Tempo de atuação dos médicos nas ESF}

Tabela 6.29 - Tempo de atuação dos médicos nas ESF

\begin{tabular}{l|r|r}
\hline \multicolumn{1}{c}{ Tempo médico nas equipes } & $\mathbf{N}^{\circ}$ & $\%$ \\
\hline <1ano & 605 & 58,0 \\
1 a 2 anos & 248 & 23,8 \\
2 a 3 anos & 67 & 6,4 \\
> 3 anos & 29 & 2,8 \\
Sem informação & 94 & 9,0 \\
\hline Total & 1043 & 100,0 \\
\hline
\end{tabular}

Aproximadamente $82 \%$ dos médicos atuam nas equipes há menos de 3 anos, e $58 \%$ deles estão há menos de 1 ano na mesma equipe.

Tabela 6.30 - Tempo de implantação das ESF e tempo de atuação dos médicos

\begin{tabular}{l|r|r|r|r|r}
\hline \multicolumn{7}{c}{ Tempo de atuação do medico } \\
\hline Tempo implantação & \multicolumn{1}{c}{ < 1ano } & 1 a 2 anos & 2 a 3 anos & +de 3 anos & \multicolumn{1}{c}{ total } \\
\hline 5 anos ou + & 17 & 3 & 9 & 16 & 45 \\
3 a 5 anos & $37.8 \%$ & $6.7 \%$ & $20.0 \%$ & $35.6 \%$ & $100 \%$ \\
& 54 & 30 & 29 & 24 & 137 \\
1 a 3 anos & $39.4 \%$ & $21.9 \%$ & $21.2 \%$ & $17.5 \%$ & $100 \%$ \\
& 233 & 207 & 28 & 47 & 515 \\
< 1 ano & $45.2 \%$ & $40.2 \%$ & $5.4 \%$ & $9.1 \%$ & $100 \%$ \\
& 297 & 7 & 1 & 33 & 338 \\
\hline Total & $87.9 \%$ & $2.1 \%$ & $0.3 \%$ & $9.8 \%$ & $100 \%$ \\
\hline
\end{tabular}

$\mathrm{n}=1043$

Nas equipes implantadas há 5 anos ou mais, $64 \%$ dos médicos atuam nas mesmas há menos de 3 anos, e destes, 38\% há menos de 1 ano. Evidencia-se ainda que nas equipes implantadas entre 3 a 5 anos, apenas 18\% dos médicos atuam nas mesmas há mais de 3 anos. Estes dados sugerem uma alta rotatividade destes profissionais. 
Tabela 6.31 - Porte dos municípios e tempo de atuação dos médicos nas ESF

\begin{tabular}{l|r|r|r|r|r}
\hline \multicolumn{7}{c}{ Tempo de atuação dos médicos nas equipes } \\
\hline \multicolumn{1}{c|}{ Porte dos municípios } & \multicolumn{1}{c}{ 1ano } & $\mathbf{1}$ a 2 anos & $\mathbf{2}$ a 3 anos & + de 3 anos & \multicolumn{1}{c}{ Total } \\
\hline$<20$ mil & 210 & 68 & 13 & 27 & 318 \\
& $66.0 \%$ & $21.4 \%$ & $4.1 \%$ & $8.5 \%$ & $100 \%$ \\
& 97 & 55 & 9 & 18 & 179 \\
50 a 50 mil 100 mil & $54.2 \%$ & $30.7 \%$ & $5.0 \%$ & $10.1 \%$ & $100 \%$ \\
& 77 & 32 & 10 & 18 & 137 \\
> 100 mil & $56.2 \%$ & $23.4 \%$ & $7.3 \%$ & $13.1 \%$ & $100 \%$ \\
& 221 & 93 & 35 & 60 & 409 \\
Total & $54.0 \%$ & $22.7 \%$ & $8.6 \%$ & $14.7 \%$ & $100 \%$ \\
\hline
\end{tabular}

Aproximadamente $87 \%$ dos médicos das equipes dos municípios de porte menor que 20 mil habitantes atuam nas equipes há menos de 2 anos. Este percentual apresenta discreta diminuição com o porte do município, sendo $77 \%$ para os municípios com mais de 100 mil habitantes. Também se observa que o maior percentual de médicos atuando há mais de 2 anos na mesma equipe está nos municípios de porte maior que 100 mil habitantes, verifica-se que este percentual diminui com o porte dos municípios variando de $23 \%$ a $13 \%$.

6.2.5.1.3 Carga horária trabalhada, cumprida e vinculação trabalhista dos médicos das ESF

Tabela 6.32 - Carga horária contratada e carga horária trabalhada pelos médicos

\begin{tabular}{|c|c|c|c|c|}
\hline \multirow{2}{*}{ Carga horária } & \multicolumn{2}{|c|}{ Contratada } & \multicolumn{2}{|c|}{ Cumprida } \\
\hline & $\mathbf{N}^{\circ}$ & $\%$ & $\mathbf{N}^{\circ}$ & $\%$ \\
\hline $20 \mathrm{~h}$ & 26 & 2,5 & 69 & 6,6 \\
\hline $30 \mathrm{~h}$ & 10 & 1,0 & 105 & 10,1 \\
\hline $40 \mathrm{~h}$ & 931 & 89,3 & 753 & 72,3 \\
\hline Outra & 1 & 0,1 & 29 & 2,8 \\
\hline Sem informação & 75 & 7,2 & 85 & 8,2 \\
\hline Total & 1043 & 100,0 & 1041 & 100,0 \\
\hline
\end{tabular}


Cerca de $89 \%$ dos médicos referem contrato de trabalho de 40 horas semanais. Entretanto, quanto à carga horária efetivamente cumprida, este valor diminui para cerca de $72 \%$, sendo que $16 \%$ cumprem 30 horas ou menos. Em 3,5\% das ESF, o contrato do médico é inferior ao recomendado pelas normas do MS, percentual que aumenta para $17 \%$ em relação à efetivamente cumprida.

Tabela 6.33 - Vínculo contratual dos médicos das ESF

\begin{tabular}{l|r|r}
\hline \multicolumn{1}{c|}{ Vínculo médico } & $\mathbf{N}^{\mathbf{r}}$ & \% \\
\hline Estatutário & 98 & 10,5 \\
CLT & 566 & 60,5 \\
Contrato temporário & 168 & 17,9 \\
Comissionado & 19 & 2,0 \\
Bolsa & 0 & 0,0 \\
Prestação serviço & 35 & 3,7 \\
Cooperado & 2 & 0,2 \\
Contrato informal & 14 & 1,5 \\
Outros & 34 & 3,6 \\
\hline Total & 936 & 100,0 \\
\hline $\mathrm{n}=1043$ & &
\end{tabular}

Nota-se que $71 \%$ dos médicos apresentam vinculação trabalhista estável - cerca de $60 \%$ deles no regime da CLT e $10 \%$ no estatutário. Chama a atenção que $26 \%$ apresentam vinculação trabalhista inadequada frente à proposta do PSF - $18 \%$ via contrato temporário e $7,4 \%$ dos médicos são contratados de forma precária. 
Tabela 6.34 - Tempo de implantação das equipes e vínculo contratual dos médicos

\begin{tabular}{|c|c|c|c|c|c|c|c|c|c|}
\hline \multicolumn{10}{|c|}{ Vínculo contratual dos médicos } \\
\hline 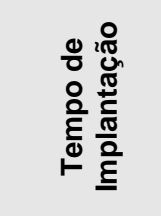 & 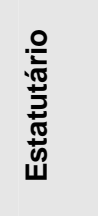 & ปَ & 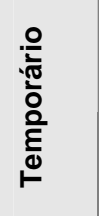 & $\begin{array}{l}\frac{0}{0} \\
\frac{\pi}{0} \\
\frac{0}{0} \\
\frac{0}{\varepsilon} \\
0 \\
0\end{array}$ & 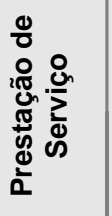 & $\begin{array}{l}\frac{0}{0} \\
\frac{\sigma}{\pi} \\
\frac{0}{0} \\
0 \\
ن\end{array}$ & 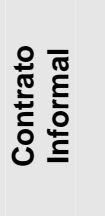 & 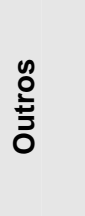 & 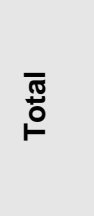 \\
\hline 5 anos out & & 29 & 2 & 4 & 1 & 0 & 0 & 0 & 43 \\
\hline 3 a 5 anos & $\begin{array}{r}16.3 \% \\
11\end{array}$ & $67.4 \%$ & $4.7 \%$ & $9.3 \%$ & $2.3 \%$ & $0.0 \%$ & $0.0 \%$ & $0.0 \%$ & $\begin{array}{r}100 \% \\
125\end{array}$ \\
\hline a d a dius & $\begin{array}{r}14 \\
11.2 \%\end{array}$ & $\begin{array}{r}81 \\
64.8 \%\end{array}$ & $12.8 \%$ & $\begin{array}{r}2 \\
1.6 \%\end{array}$ & $\begin{array}{r}4 \\
3.2 \%\end{array}$ & $0.0 \%$ & $2.4 \%$ & $4.0 \%$ & $\begin{array}{r}125 \\
100 \%\end{array}$ \\
\hline 1 a 3 anos & & 265 & 89 & & 23 & & 4 & 16 & 468 \\
\hline & $13.0 \%$ & $56.6 \%$ & $19.0 \%$ & $1.9 \%$ & $4.9 \%$ & $0.2 \%$ & $0.9 \%$ & $3.4 \%$ & $100 \%$ \\
\hline$<1$ ano & & 191 & & 4 & & & 7 & 13 & 300 \\
\hline & $5.3 \%$ & $63.7 \%$ & $20.3 \%$ & $1.3 \%$ & $2.3 \%$ & $0.3 \%$ & $2.3 \%$ & $4.3 \%$ & $100 \%$ \\
\hline Total & 98 & 566 & $\begin{array}{r}168 \\
170 \%\end{array}$ & $\begin{array}{r}19 \\
20 \%\end{array}$ & $\begin{array}{r}35 \\
370\end{array}$ & 2 & 14 & 34 & 936 \\
\hline & $10.5 \%$ & $60.5 \%$ & $17.9 \%$ & $2.0 \%$ & $3.7 \%$ & $0.2 \%$ & $1.5 \%$ & $3.6 \%$ & $100 \%$ \\
\hline
\end{tabular}

$\mathrm{n}=1043$

Observa-se que nas equipes implantadas há mais tempo o percentual de médicos contratados de forma estável é maior, variando entre $84 \%$ para as equipes implantadas há 5 anos ou mais, e $69 \%$ nas equipes implantadas há menos de 3 anos. Já o percentual de contratação temporária é maior nas equipes mais novas, variando de cerca de $5 \%$ nas equipes implantadas há 5 anos ou mais a cerca de $20 \%$ nas equipes implantadas mais recentemente. Observa-se que esta forma de contratação aumenta com a diminuição do tempo de implantação. O contrato informal está para mais de $2 \%$ dos médicos das equipes implantadas entre 3 e 5 anos, e naquelas implantadas há menos de 1 ano. 
Tabela 6.35 - Porte dos municípios e vínculo contratual dos médicos

\begin{tabular}{|c|c|c|c|c|c|c|c|c|c|}
\hline \multicolumn{10}{|c|}{ Vínculo contratual dos médicos } \\
\hline 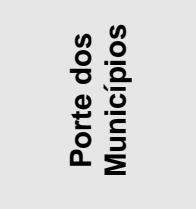 & 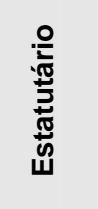 & ป & 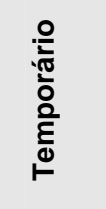 & 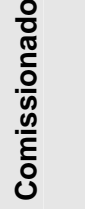 & 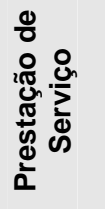 & $\begin{array}{l}\frac{0}{0} \\
\frac{\pi}{0} \\
\frac{0}{0} \\
0 \\
0\end{array}$ & 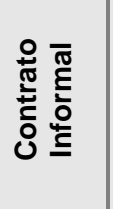 & 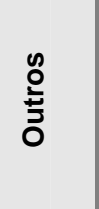 & 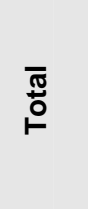 \\
\hline$<<20 \mathrm{mil}$ & 17 & 152 & 73 & 9 & 16 & 2 & 7 & 18 & 294 \\
\hline & $5.8 \%$ & $51.7 \%$ & $24.8 \%$ & $3.1 \%$ & $5.4 \%$ & $0.7 \%$ & $2.4 \%$ & $6.1 \%$ & $100 \%$ \\
\hline 220 a $50 \mathrm{mil}$ & 11 & 108 & 21 & 0 & 14 & 0 & 4 & 7 & 165 \\
\hline & $6.7 \%$ & $65.5 \%$ & $12.7 \%$ & $0.0 \%$ & $8.5 \%$ & $0.0 \%$ & $2.4 \%$ & $4.2 \%$ & $100 \%$ \\
\hline 550 a $100 \mathrm{mil}$ & 26 & 65 & 12 & 9 & 3 & 0 & 1 & 3 & 119 \\
\hline & 21,8 & 54,6 & 10,1 & 7,6 & 2,5 & 0 & 0,8 & 2,5 & $100 \%$ \\
\hline$>>100 \mathrm{mil}$ & & 241 & 62 & & 2 & 0 & 2 & 6 & 358 \\
\hline & $12.3 \%$ & $67.3 \%$ & $17.3 \%$ & $0.3 \%$ & $0.6 \%$ & $0.0 \%$ & $0.6 \%$ & $1.7 \%$ & $100 \%$ \\
\hline Total & $\begin{array}{r}98 \\
10.5 \%\end{array}$ & $\begin{array}{r}566 \\
60.5 \%\end{array}$ & $\begin{array}{r}168 \\
17.9 \%\end{array}$ & $\begin{array}{r}19 \\
2.0 \%\end{array}$ & $\begin{array}{r}35 \\
3.7 \%\end{array}$ & $\begin{array}{r}2 \\
0.2 \%\end{array}$ & $\begin{array}{r}14 \\
1.5 \%\end{array}$ & $\begin{array}{r}34 \\
3.6 \%\end{array}$ & $\begin{array}{r}936 \\
100 \%\end{array}$ \\
\hline
\end{tabular}

Nas equipes dos municípios de todos os portes, pelo menos $72 \%$ dos médicos são contratados de forma estável, exceto nos municípios menores que 20 mil habitantes, que apresentam $58 \%$ dos médicos contratados desta forma. Também se evidencia que $25 \%$ dos médicos destes municípios são contratados temporariamente. Nota-se que nos municípios de porte entre 20 e 50 mil habitantes e menor que 20 mil habitantes, $8,5 \%$ e $5,4 \%$ dos médicos, respectivamente, são contratados para prestação de serviço e $2,4 \%$ deles, em ambos os portes, via contrato informal. Estes percentuais são verificados em menos de $4 \%$ nos demais portes populacionais. 
6.2.5.1.4 Faixa salarial dos médicos das ESF

Tabela 6.36 - Salário dos médicos das ESF (bruto em reais)

\begin{tabular}{l|r|rr}
\hline \multicolumn{4}{c}{ Salário dos médicos das ESF (bruto em reais) } \\
\hline$<2.500$ & $N^{\circ}$ & 56 & $\%$ \\
$2.501-3.500$ & 93 & 5,9 \\
$3.501-4.000$ & 134 & 9,8 \\
$4.001-6.000$ & 647 & 14,2 \\
$>6.000$ & 16 & 68,4 \\
\hline Total & 946 & 1,7 \\
\hline $\mathrm{n}=1043$ & & 100 \\
\hline
\end{tabular}

A maioria dos médicos das ESF percebe pelo menos de 4.001 reais, e apenas $16 \%$ deles menos de 3.500 reais.

Tabela 6.37 - Porte dos municípios e salário dos médicos das ESF (bruto em reais)

\begin{tabular}{l|l|r|r|r|r|r|r}
\hline \multirow{2}{*}{ Porte dos municípios } & & \multicolumn{7}{|c}{ Salário dos médicos das ESF (em reais) } \\
\cline { 2 - 8 } & & $<\mathbf{2 . 5 0 0}$ & $\mathbf{2 . 5 0 1 - 3 . 5 0 0}$ & $\mathbf{3 . 5 0 1 - 4 . 0 0 0}$ & $\mathbf{4 . 0 0 1 - 6 . 0 0 0}$ & $>\mathbf{6 . 0 0 0}$ & total \\
\hline \multirow{3}{*}{20 mil } & $\mathrm{n}$ & 26 & 46 & 60 & 150 & 7 & 289 \\
& $\%$ & 9,0 & 15,9 & 20,8 & 51,9 & 2,4 & 100,0 \\
& $\mathrm{n}-50$ mil & 5 & 22 & 20 & 111 & 7 & 165 \\
& $\%$ & 3,0 & 13,3 & 12,1 & 67,3 & 4,2 & 100,0 \\
$50-100 \mathrm{mil}$ & $\mathrm{n}$ & 5 & 17 & 26 & 74 & 2 & 124 \\
& $\%$ & 4,0 & 13,7 & 21,0 & 59,7 & 1,6 & 100,0 \\
$>100 \mathrm{mil}$ & $\mathrm{n}$ & 20 & 8 & 28 & 312 & 0,0 & 368 \\
\hline \multirow{2}{*}{ Total } & $\%$ & 5,4 & 2,2 & 7,6 & 84,8 & 0,0 & 100,0 \\
\hline & $\mathrm{n}$ & 56 & 93 & 134 & 647 & 16 & 946 \\
& $\%$ & 5,9 & 9,8 & 14,2 & 68,4 & 1,7 & 100,0 \\
\hline
\end{tabular}

$\mathrm{n}=1043$

Nos municípios com população acima de 100 mil e entre 20 e 50 mil habitantes observa-se a maior freqüência de médicos que percebem pelo menos 4.001 reais, $85 \%$ e $72 \%$ respectivamente, enquanto nos municípios de porte menor que 20 mil habitantes $46 \%$ dos médicos das ESF percebem menos de 4.000 reais. 
Tabela 6.38 - Tempo de implantação das ESF e salário dos médicos (bruto em reais)

\begin{tabular}{|c|c|c|c|c|c|c|c|}
\hline \multirow[b]{2}{*}{ Tempo de implantação } & & \multicolumn{6}{|c|}{ Salário dos médicos das ESF (em reais) } \\
\hline & & $<2.500$ & $2.501-3.500$ & $3.501-4.000$ & 4.001-6.000 & $>6.000$ & Total \\
\hline \multirow[t]{2}{*}{5 anos ou +} & $\mathrm{n}$ & 0 & 2 & 2 & 38 & 0 & 42 \\
\hline & $\%$ & 0 & 4,8 & 4,8 & 90,5 & 0,0 & 100 \\
\hline \multirow[t]{2}{*}{3 a 5 anos } & $\mathrm{n}$ & 11 & 18 & 14 & 81 & 1 & 125 \\
\hline & $\%$ & 8,8 & 14,4 & 11,2 & 64,8 & 0,8 & 100 \\
\hline \multirow[t]{2}{*}{1 a 3 anos } & $\mathrm{n}$ & 37 & 44 & 62 & 318 & 8,0 & 469 \\
\hline & $\%$ & 7,9 & 9,4 & 13,2 & 67,8 & 1,7 & 100 \\
\hline \multirow[t]{2}{*}{ - de 1 ano } & $n$ & 8 & 29 & 55 & 205 & 7 & 304 \\
\hline & $\%$ & 2,6 & 9,5 & 18,1 & 67,4 & 2,3 & 100 \\
\hline \multirow[t]{2}{*}{ Total } & $n$ & 56 & 93 & 133 & 642 & 16 & 940 \\
\hline & $\%$ & 6,0 & 9,9 & 14,1 & 68,3 & 1,7 & 100 \\
\hline
\end{tabular}

$\mathrm{n}=1043$

Mais de $90 \%$ dos médicos das equipes implantadas há 5 anos ou mais percebem pelo menos 4.001 reais, nas demais equipes este percentual varia entre $65 \%$ a $68 \%$. Já nas equipes implantadas entre 3 a 5 anos observa-se o maior percentual de médicos com salário inferior a 3.500 reais.

\subsubsection{Caracterização dos Médicos das ESF}

6.2.5.2.1 Número de médicos por equipe de saúde da família

De forma semelhante aos demais Estados da região Sudeste e a média nacional, a maior parte das equipes, cerca de 93\%, possui apenas um médico. (AVALIAÇÃO NORMATIVA - MS)

Em geral verifica-se que em apenas 2\% delas a questão de o médico estar ausente há mais de 60 dias, indicando que no momento da pesquisa não estava havendo uma acentuada dificuldade em relação à presença deste profissional nas equipes (Tabela 6.28). 


\subsection{Tempo de atuação dos médicos nas ESF}

Mais da metade dos médicos atua nas equipes há menos de 1 ano e mais de 2/3 há menos de 3 anos (Tabela 6.29). Aqui cabe ressaltar que, se no momento da pesquisa não havia dificuldade da presença do médico nas equipes, como referido anteriormente, o trabalho recente da maioria destes profissionais nas equipes sugere a sua rotatividade, que sem dúvida acarreta problemas no estabelecimento de rotinas e do processo de trabalho que se espera deste profissional no PSF.

Evidencia-se que apenas $36 \%$ dos médicos das equipes implantadas há 5 anos ou mais atuam há mais de 3 anos nas mesmas, sendo que $1 / 3$ deles há menos de 1 ano. Também nas equipes implantadas entre 3 a 5 anos, apenas 19\% dos médicos atuam nas mesmas há mais de 3 anos. Estes dados refletem bem a alta rotatividade dos médicos nas equipes.

O pouco tempo de atuação dos médicos nas equipes também se apresenta como problema em todos os portes dos municípios. Observa-se que a maioria dos profissionais dos municípios menores que 20 mil habitantes $(87 \%)$ está atuando nas equipes há menos de 2 anos. Esta freqüência decresce discretamente com o aumento do porte do município, sendo aproximadamente $76 \%$ para os municípios com mais de 100 mil habitantes. Estes achados novamente sugerem dificuldades na fixação dos médicos nas ESF. 
Em relação aos Estados do Sudeste, São Paulo apresenta freqüência de médicos com permanência superior a 2 anos nas equipes, semelhante ao Estado de Minas Gerais, e superior à média nacional que é de 8\%. (AVALIAÇÃO NORMATIVA - MS)

6.2.5.2.3 Carga horária trabalhada, cumprida e vinculação trabalhista dos médicos das ESF

A maioria dos médicos refere contrato de trabalho de 40 horas semanais. Entretanto quando estes profissionais referem a carga horária efetivamente cumprida este valor diminui para cerca de $72 \%$, sendo que $16 \%$ cumprem 30 horas ou menos (Tabela 6.32 ).

Em relação aos Estados da região Sudeste as freqüências são semelhantes para carga horária contratada. Já em relação à carga horária cumprida, o Estado de São Paulo apresenta percentual menor que o Estado do Rio de Janeiro (83\%). Todos os estados do Sudeste apresentaram valores superiores à média nacional que é 59\%. (AVALIAÇÃO NORMATIVA $-\mathrm{MS})$

Quanto à vinculação trabalhista observa-se que de maneira geral, cerca de $2 / 3$ dos médicos apresentam vinculação estável, sendo $60 \%$ deles no regime da CLT e apenas $10 \%$ no estatutário. Cerca de $26 \%$ destes profissionais apresentam vinculação trabalhista não recomendada para o trabalho no PSF, $18 \%$ via contratado temporário e mais de $5 \%$ contratos ainda mais precários como prestação de serviço $(3,5 \%)$ e contrato informal 
de trabalho (1,5\%) (Tabela 6.33). Estas formas de contratação, além de ocasionarem insegurança e insatisfação nos profissionais acarretam constantes mudanças nos quadros de $\mathrm{RH}$ das equipes, dificultando a capacitação, o desenvolvimento do trabalho e a vinculação dos profissionais com a comunidade. (BRASIL, MS, 2003; DAL POZ, 2000)

Nas equipes mais antigas, o percentual de médicos contratados de forma estável é maior, variando de $84 \%$ a $69 \%$ nas equipes implantadas há menos de 3 anos. Já o percentual de contratação temporária é maior nas equipes mais novas, sendo $20 \%$ nas equipes implantadas há menos de 1 ano e cerca de $5 \%$ nas equipes implantadas há 5 anos ou mais. Nota-se que esta forma de contratação aumenta com a diminuição do tempo de implantação, sugerindo que o contrato temporário pode ter se tornado uma opção com a expansão do PSF. Cabe destacar que cerca de $9 \%$ dos médicos das equipes implantadas há mais de 5 anos aparecem como comissionados, menos de $2 \%$ nas outras faixas, enquanto que $5 \%$ dos mesmos das equipes implantadas entre 1 a 3 anos como contratados por prestação de serviço, variando de $2 \%$ a $3 \%$ nas outras faixas (Tabela 6.34).

A forma de contratação estável apresenta-se como a mais freqüente, acima de $70 \%$ em todos os portes de municípios, exceto nos menores de 20 mil habitantes, com menos de $60 \%$ dos médicos contratados desta maneira. Também se evidencia nestes municípios o maior percentual de contratação não estável, cerca de 43\%. 25\% dos médicos destes municípios são contratados em regime temporário (Tabela 6.35). 
Comparando-se as modalidades de vinculação trabalhista dos médicos dos Estados da região Sudeste, o ESP apresenta maior freqüência de vinculação trabalhista estável, cujo percentual para os demais estados não ultrapassa $31 \%$, valor observado para o Estado do Rio de Janeiro. Também se situa muito acima da média nacional, que é de $25 \%$. (AVALIAÇÃO NORMATIVA - MS)

\subsection{Faixa salarial dos médicos das ESF}

Aproximadamente $70 \%$ dos médicos do PSF do Estado de São Paulo recebem salário mensal bruto na faixa de 4 a 6 mil reais (Tabela 6.36). Este percentual é 1.6 vezes o percentual do Estado do Espírito Santo, duas vezes o do Estado de Minas gerais e 14 vezes Estado do Rio de Janeiro. Também apresenta percentual para esta faixa salarial 2 vezes maior que a média nacional observada, que é de 34\%. (AVALIAÇÃO NORMATIVA-MS)

Em relação ao tempo de implantação observa-se que em todas as faixas, entre $65 \%$ e $68 \%$ dos médicos percebem pelo menos 4.001 reais, exceto nas equipes mais antigas, cujo percentual é de $91 \%$. Já nas equipes implantadas entre 3 a 5 anos observa-se o maior percentual de médicos com salário inferior a 3.500 reais (Tabela 6.38). Quanto ao porte dos municípios verifica-se esta condição principalmente nos municípios com população acima de 100 mil, e entre 20 e 50 mil habitantes $85 \%$ e $72 \%$ respectivamente, enquanto nos municípios de porte menor que 20 mil 
habitantes $46 \%$ dos médicos das ESF relatam perceber menos de 4.000 reais (Tabela 6.37). (MACHADO, 2002)

\subsubsection{Caracterização dos enfermeiros das ESF}

\subsection{Número de enfermeiros por ESF}

Tabela 6.39 - Enfermeiros nas ESF

\begin{tabular}{l|r|r}
\multicolumn{1}{c|}{ Quantidade de enfermeiros } & $\mathbf{N}^{\circ}$ & \% \\
\hline Nenhum há menos de 60 dias & 25 & 2,4 \\
Nenhum há mais de 60 dias & 12 & 1,2 \\
Um & 985 & 95,8 \\
Dois & 6 & 0,6 \\
\hline Total & 1028 & 100,0 \\
\hline $\mathrm{n}=1043$ & &
\end{tabular}

Aproximadamente $96 \%$ das equipes possuem um enfermeiro, e em apenas $1 \%$ delas o enfermeiro aparece como ausente há mais de 60 dias.

\subsection{3.2 Tempo de atuação dos enfermeiros das ESF}

Tabela 6.40 - Tempo de atuação dos enfermeiros nas ESF

\begin{tabular}{l|r|r}
\hline Tempo do enfermeiro na ESF & $\mathbf{N}^{\circ}$ & $\%$ \\
\hline < 1 ano & 569 & 54,6 \\
1 a 2 anos & 277 & 26,6 \\
2 a 3 anos & 58 & 5,6 \\
> 3 anos & 43 & 4,1 \\
Sem informação & 96 & 9,2 \\
\hline Total & 1043 & 100,0 \\
\hline
\end{tabular}

Aproximadamente $54 \%$ dos enfermeiros atuam há menos de 1 ano nas equipes, e cerca de $86 \%$ há menos de 3 anos, e apenas $4 \%$ há mais de 3 anos. 
6.2.5.3.3 Carga horária contratada, cumprida e vinculação trabalhista dos enfermeiros das ESF

Tabela 6.41 - Carga horária contratada e cumprida pelos enfermeiros das ESF

\begin{tabular}{l|r|r|r|r}
\hline \multirow{2}{*}{ Enfermeiro } & \multicolumn{3}{|c|}{ Contratada } & \multicolumn{2}{c}{ Cumprida } \\
\cline { 2 - 5 } & $\mathbf{N}^{\mathbf{2}}$ & \multicolumn{1}{c}{$\%$} & $\mathbf{N}^{\mathbf{2}}$ & \multicolumn{1}{c}{$\%$} \\
\hline 20h & 6 & 0,6 & 16 & 1,6 \\
30h & 18 & 1,8 & 42 & 4,3 \\
40h & 955 & 97,3 & 90,6 & 93,3 \\
Outra & 2 & 0,2 & 7 & 0,7 \\
\hline Total & 981 & 100,0 & 971 & 100,0 \\
\hline $\mathrm{n}=1043$
\end{tabular}

Cerca de $97 \%$ dos enfermeiros pesquisados possuem contratos de trabalho de 40 horas semanais, e cerca de 93\% deles cumprem este horário.

Tabela 6.42 - Vínculo contratual dos enfermeiros nas ESF

\begin{tabular}{l|r|r}
\hline \multicolumn{1}{c|}{ Vínculo dos enfermeiros } & $\mathbf{N}^{\mathbf{2}}$ & $\mathbf{\%}$ \\
\hline Estatutário & 110 & 11,5 \\
CLT & 595 & 62,0 \\
Contrato temporário & 167 & 17,4 \\
Comissionado & 27 & 2,8 \\
Bolsa & 0 & 0,0 \\
Prestação serviço & 21 & 2,2 \\
Cooperado & 3 & 0,3 \\
Contrato informal & 9 & 0,9 \\
Outros & 27 & 2,8 \\
\hline Total & 959 & 100,0 \\
\hline n=1043 & &
\end{tabular}

$\mathrm{n}=1043$

A maior parte dos enfermeiros possui vinculação trabalhista estável, sendo $62 \%$ no regime CLT e $11 \%$ no estatutário. Cerca de $23 \%$ destes profissionais estão contratados em formas consideradas não adequadas; $17 \%$ via contrato temporário; e $6 \%$ de maneira mais precária. 
Tabela 6.43 - Tempo de implantação das ESF e tempo de atuação dos enfermeiros nas ESF

\begin{tabular}{|c|c|c|c|c|c|}
\hline \multicolumn{6}{|c|}{ Tempo de atuação do enfermeiro } \\
\hline Tempo implantação & $<1$ 1ano & 1 a 2 anos & 2 a 3 anos & + de 3 anos & Total \\
\hline 5 anos ou + & & 7 & 7 & 9 & 40 \\
\hline 3 a 5 anos & $\begin{array}{r}42.010 \\
45\end{array}$ & $\begin{array}{r}17.5 \% \\
19\end{array}$ & 24 & $\begin{array}{r}22.5 \% \\
33\end{array}$ & $\begin{array}{r}100 \% \\
121\end{array}$ \\
\hline & $37.2 \%$ & $15.7 \%$ & $19.8 \%$ & $27.3 \%$ & $100 \%$ \\
\hline 1 a 3 anos & 204 & 240 & 26 & & 466 \\
\hline & $43.8 \%$ & $51.5 \%$ & $5.6 \%$ & $0.2 \%$ & $100 \%$ \\
\hline$<1$ ano & 303 & 11 & & 0 & 315 \\
\hline & $96.2 \%$ & $3.5 \%$ & $0.3 \%$ & $0.0 \%$ & $100 \%$ \\
\hline Total & $\begin{array}{r}569 \\
60.1 \%\end{array}$ & $\begin{array}{r}277 \\
29.3 \\
\end{array}$ & $\begin{array}{r}58 \\
6.1 \% \\
\end{array}$ & $\begin{array}{r}43 \\
4.5 \% \\
\end{array}$ & $\begin{array}{r}947 \\
100 \% \\
\end{array}$ \\
\hline
\end{tabular}

$n=1043$

Observa-se que $78 \%$ dos enfermeiros das equipes implantadas há 5 anos ou mais e $72 \%$ dos enfermeiros das equipes implantadas entre 3 e 5 anos trabalham há menos de 3 anos nas equipes. Estes percentuais sugerem um acentuado grau de rotatividade dos mesmos.

Tabela 6.44 - Porte dos municípios e tempo de atuação dos enfermeiros nas ESF

\begin{tabular}{|c|c|c|c|c|c|}
\hline \multicolumn{6}{|c|}{ Tempo de atuação do enfermeiro } \\
\hline Porte dos municípios & $<1$ ano & 1 a 2 anos & 2 a 3 anos & + de 3 anos & Total \\
\hline$<20$ mil & $\begin{array}{r}203 \\
68.4 \%\end{array}$ & $\begin{array}{r}80 \\
26.9 \%\end{array}$ & $\begin{array}{r}11 \\
3.7 \%\end{array}$ & $\begin{array}{r}3 \\
1.0 \%\end{array}$ & $\begin{array}{r}297 \\
100 \%\end{array}$ \\
\hline 20 a 50 mil & $\begin{array}{r}96 \\
60.8 \%\end{array}$ & $\begin{array}{r}52 \\
32.9 \%\end{array}$ & $\begin{array}{r}7 \\
4.4 \%\end{array}$ & $\begin{array}{r}3 \\
1.9 \%\end{array}$ & $\begin{array}{r}158 \\
100 \%\end{array}$ \\
\hline 50 a 100 mil & $\begin{array}{r}82 \\
63.6 \%\end{array}$ & $\begin{array}{r}33 \\
25.6 \%\end{array}$ & $\begin{array}{r}6 \\
4.7 \%\end{array}$ & $\begin{array}{r}8 \\
6.2 \%\end{array}$ & $\begin{array}{r}129 \\
100 \%\end{array}$ \\
\hline$>100 \mathrm{mil}$ & $\begin{array}{r}188 \\
51.8 \%\end{array}$ & $\begin{array}{r}112 \\
30.0 \%\end{array}$ & $\begin{array}{r}34 \\
9.4 \%\end{array}$ & $\begin{array}{r}29 \\
8.0 \%\end{array}$ & $\begin{array}{r}363 \\
100 \%\end{array}$ \\
\hline Total & $\begin{array}{r}569 \\
60.1 \%\end{array}$ & $\begin{array}{r}277 \\
29.3\end{array}$ & $\begin{array}{r}58 \\
6.1 \%\end{array}$ & $\begin{array}{r}43 \\
4.5 \% \\
\end{array}$ & $\begin{array}{r}947 \\
100 \%\end{array}$ \\
\hline
\end{tabular}

$\mathrm{n}=1043$

Mais da metade dos enfermeiros das equipes de todos os portes atua nas mesmas há menos de 1 ano, variando de $52 \%$ nas equipes dos municípios de porte maior que 100 mil habitantes a $68 \%$ nas equipes daqueles menores que 20 mil habitantes. Menos de $20 \%$ dos enfermeiros das ESF dos municípios de todos os portes atuam nas mesmas há pelo 
menos 2 anos. Este percentual diminui do maior para o menor porte variando de $18 \%$ a $5 \%$.

Tabela 6.45 - Tempo de implantação das ESF e vínculo trabalhista dos enfermeiros

\begin{tabular}{|c|c|c|c|c|c|c|c|c|c|}
\hline \multicolumn{10}{|c|}{ Vinculo trabalhista dos enfermeiros das ESF } \\
\hline 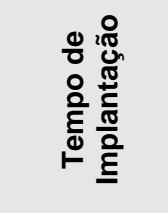 & 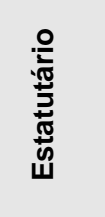 & ป & 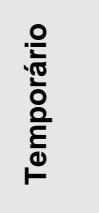 & 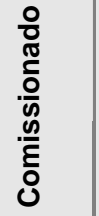 & 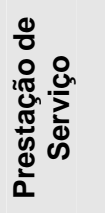 & $\begin{array}{l}\frac{0}{0} \\
\frac{\pi}{0} \\
\frac{0}{0} \\
0\end{array}$ & 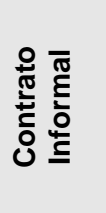 & $\begin{array}{l}\text { on } \\
\text { Dે̃ } \\
0\end{array}$ & 흉 \\
\hline 5 anos ou + & $\begin{array}{r}4 \\
91 \%\end{array}$ & $\begin{array}{r}27 \\
614 \%\end{array}$ & $\begin{array}{r}8 \\
182 \%\end{array}$ & 2 & $\begin{array}{r}1 \\
23 \%\end{array}$ & 0 & 0 & $\begin{array}{r}2 \\
15 \% \%\end{array}$ & $\begin{array}{r}44 \\
100 \%\end{array}$ \\
\hline 3 a 5 anos & & & & & 0 & & & & 126 \\
\hline & $11.1 \%$ & $65.1 \%$ & $18.3 \%$ & $1.6 \%$ & $0.0 \%$ & $0.8 \%$ & $0.8 \%$ & $2.4 \%$ & $100 \%$ \\
\hline 1 a 3 anos & & & & 13 & 10 & & 4 & 10 & \\
\hline & $11.3 \%$ & $63.3 \%$ & $17.4 \%$ & $2.8 \%$ & $2.1 \%$ & $0.2 \%$ & $0.8 \%$ & $2.1 \%$ & $100 \%$ \\
\hline$<1$ ano & & 184 & & 10 & 9 & & & 12 & 311 \\
\hline & $12.2 \%$ & $59.2^{\circ}$ & $17.0 \%$ & $3.2 \%$ & $2.9 \%$ & $0.3 \%$ & $1.3 \%$ & $3.9 \%$ & $100 \%$ \\
\hline Total & $\begin{array}{r}109 \\
11.4 \%\end{array}$ & $\begin{array}{r}591 \\
62.1 \%\end{array}$ & $\begin{array}{r}166 \\
17.4 \%\end{array}$ & $\begin{array}{r}27 \\
2.8 \%\end{array}$ & $\begin{array}{r}20 \\
2.1 \%\end{array}$ & $\begin{array}{r}3 \\
0.3 \%\end{array}$ & $\begin{array}{r}9 \\
0.9 \%\end{array}$ & $\begin{array}{r}27 \\
2.8 \%\end{array}$ & $\begin{array}{r}952 \\
100 \%\end{array}$ \\
\hline
\end{tabular}

$n=1043$

Evidencia-se, em todas as faixas de tempo de implantação das equipes, que cerca de $70 \%$ dos enfermeiros apresentam vínculo estável de trabalho, tendo a CLT como forma preferencial de contratação, variando de $59 \%$ para as equipes implantadas há menos de 1 ano a $65 \%$ para as equipes implantadas entre 3 e 5 anos.

Já o contrato temporário figura como segunda opção, variando entre $17 \%$ e $18 \%$. Cabe destacar que $8 \%$ dos enfermeiros das ESF implantadas há menos de 1 ano apresentam vínculos de trabalho mais precários, mesmo quadro verificado em $3 \%$ das equipes implantadas entre 3 e 5 anos. 
Tabela 6.46 - Porte dos municípios e vínculo contratual dos enfermeiros das ESF

\begin{tabular}{|c|c|c|c|c|c|c|c|c|c|}
\hline \multicolumn{10}{|c|}{ Vínculo trabalhista dos enfermeiros das ESF } \\
\hline 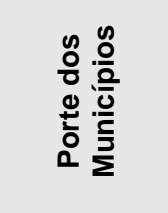 & 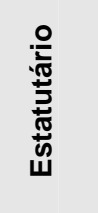 & $\stackrel{5}{0}$ & 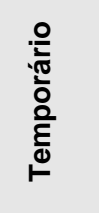 & $\begin{array}{l}\frac{0}{0} \\
\frac{\pi}{0} \\
\frac{0}{n} \\
\frac{0}{E} \\
\bar{\delta} \\
0\end{array}$ & 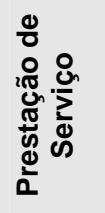 & $\begin{array}{l}\frac{0}{0} \\
\frac{\pi}{0} \\
\frac{0}{0} \\
0 \\
ن\end{array}$ & 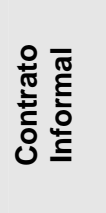 & 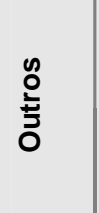 & 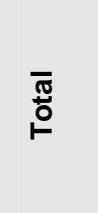 \\
\hline \multirow[t]{2}{*}{$<20$ mil } & 29 & 208 & 37 & 5 & 4 & 1 & 2 & 10 & 296 \\
\hline & $9.8 \%$ & $70.3 \%$ & $12.5 \%$ & $1.7 \%$ & $1.4 \%$ & $0.3 \%$ & $0.7 \%$ & $3.4 \%$ & $30.9 \%$ \\
\hline \multirow[t]{2}{*}{20 a 50 mil } & 18 & 106 & 29 & & 4 & & 2 & 5 & 169 \\
\hline & $10.7 \%$ & $62.7 \%$ & $17.2 \%$ & $2.4 \%$ & $2.4 \%$ & $0.6 \%$ & $1.2 \%$ & $3.0 \%$ & $17.6 \%$ \\
\hline \multirow[t]{2}{*}{50 a $100 \mathrm{mil}$} & & & 26 & 2 & 4 & & 0 & 5 & 132 \\
\hline & $11.4 \%$ & $59.8 \%$ & $19.7 \%$ & $1.5 \%$ & $3.0 \%$ & $0.8 \%$ & $0.0 \%$ & $3.8 \%$ & $13.8 \%$ \\
\hline \multirow[t]{2}{*}{$>100 \mathrm{mil}$} & & 202 & 75 & 16 & 9 & & 5 & 7 & 362 \\
\hline & $13.3 \%$ & $55.8 \%$ & $20.7 \%$ & $4.4 \%$ & $2.5 \%$ & $0.0 \%$ & $1.4 \%$ & $1.9 \%$ & $37.7 \%$ \\
\hline \multirow[t]{2}{*}{ Total } & 110 & 59.5 & 167 & 27 & 21 & 3 & 9 & 27 & 959 \\
\hline & $11.5 \%$ & $62.0 \%$ & $17.4 \%$ & $2.8 \%$ & $2.2 \%$ & $0.3 \%$ & $0.9 \%$ & $2.8 \%$ & \\
\hline
\end{tabular}

$\mathrm{n}=1043$

Os enfermeiros das equipes dos municípios de menor porte apresentam maior percentual de contratação estável e que o mesmo diminui nos municípios de maior porte, variando de $80 \%$ nos municípios com menos de 20 mil habitantes a $69 \%$ nos com mais de 100 mil habitantes. A vinculação estatutária aumenta discretamente com o porte dos municípios e a forma CLT com a diminuição do mesmo. Em todos os portes estudados, a forma preferencial de contratação é a CLT, variando de cerca de $56 \%$ para as equipes dos municípios de maior porte a $70 \%$ para os municípios de menor porte. Já a forma de contratação temporária figura como segunda opção de vinculação dos enfermeiros, variando de $13 \%$ para os municípios de menor porte a $21 \%$ para os de maior porte. Destaca-se que $8 \%$ dos enfermeiros das ESF apresentam vínculos precários de trabalho e que este percentual diminui com o porte dos municípios, sendo $4 \%$ nas ESF dos municípios com menos de 20 mil habitantes. 
6.2.5.3.4 Faixa salarial dos enfermeiros das ESF

Tabela 6.47 - Salário dos enfermeiros das ESF (bruto em reais)

\begin{tabular}{|c|c|c|}
\hline \multicolumn{3}{|c|}{ Salário enfermeiros das ESF (em reais) } \\
\hline $\mathbf{R} \$$ & $\mathbf{N}^{\circ}$ & $\%$ \\
\hline$<1.000$ & 99 & $10,3 \%$ \\
\hline $1.001-1.500$ & 196 & $20,4 \%$ \\
\hline $1.501-2.000$ & 217 & $22,6 \%$ \\
\hline $2.000-3.000$ & 335 & $34,8 \%$ \\
\hline$>3.000$ & 115 & $12,0 \%$ \\
\hline Total & 962 & $100 \%$ \\
\hline
\end{tabular}

Mais da metade dos enfermeiros percebe menos de 2 mil reais, cerca de $35 \%$ entre 2 e 3 mil reais de salário mensal e apenas $12 \%$ mais de 3 mil reais.

Tabela 6.48 - Porte dos municípios e salário dos enfermeiros das ESF (bruto em reais)

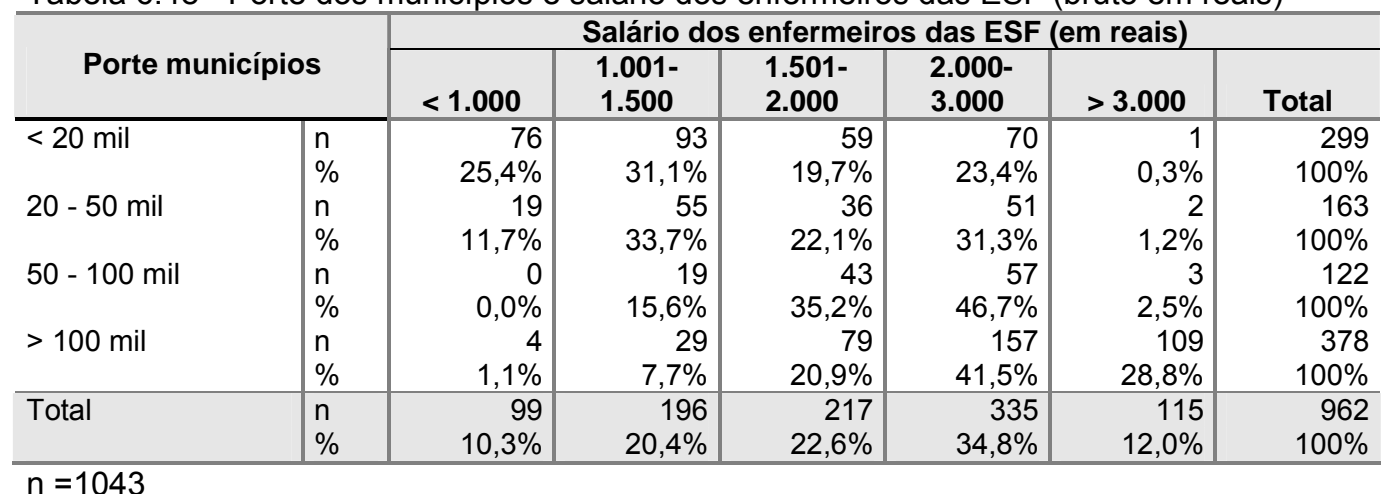

Nos municípios de menor porte, cerca de $76 \%$ dos enfermeiros percebem menos de 2 mil reais. Este percentual diminui com o porte dos municípios, sendo $30 \%$ nos municípios com mais de 100 mil habitantes. Observa-se ainda que $64 \%$ dos enfermeiros das ESF implantadas nos municípios de porte maior que 50 mil habitantes percebem pelo menos 2 mil reais. Chama a atenção que $29 \%$ dos enfermeiros das ESF dos municípios 
de porte maior que 100 mil habitantes percebem mais de 3 mil reais, o que se verifica em menos de $3 \%$ das ESF dos outros municípios.

Tabela 6.49 - Tempo de implantação e salário dos enfermeiros das ESF (bruto em reais)

\begin{tabular}{|c|c|c|c|c|c|c|c|}
\hline \multirow[b]{2}{*}{ Tempo implantação } & & \multicolumn{6}{|c|}{ Salário dos enfermeiros das ESF (em reais) } \\
\hline & & $<1.000$ & $\begin{array}{l}1.001- \\
1.500\end{array}$ & $\begin{array}{l}1.501- \\
2.000\end{array}$ & $\begin{array}{l}2.000- \\
3.000\end{array}$ & $>3.000$ & Total \\
\hline \multirow[t]{2}{*}{5 anos ou mais } & $\mathrm{n}$ & 0 & 5 & 11 & 0 & 24 & 40 \\
\hline & $\%$ & 0 & 12.5 & 27.5 & 0 & 60.0 & 100 \\
\hline \multirow[t]{2}{*}{3 a 5 anos } & $\mathrm{n}$ & 9 & 27 & 25 & 26 & 34 & 121 \\
\hline & $\%$ & 7.4 & 22.3 & 20.7 & 21.5 & 28.1 & 100 \\
\hline \multirow[t]{2}{*}{1 a 3 anos } & $\mathrm{n}$ & 50 & 94 & 95 & 204 & 40 & 483 \\
\hline & $\%$ & 10.4 & 19.5 & 19.7 & 42.1 & 8.3 & 100 \\
\hline \multirow[t]{2}{*}{$<1$ ano } & $\mathrm{n}$ & 40 & 70 & 83 & 104 & 17 & 314 \\
\hline & $\%$ & 12.7 & 22.3 & 26.4 & 33.2 & 5.4 & 100 \\
\hline \multirow[t]{2}{*}{ Total } & $n$ & 99 & 196 & 214 & 334 & 115 & 958 \\
\hline & $\%$ & 10,3 & 20,5 & 22,3 & 34,9 & 12 & 100 \\
\hline
\end{tabular}

$\mathrm{n}=1043$

$60 \%$ dos enfermeiros das equipes implantadas há 5 anos ou mais percebem pelo menos 3 mil reais, e as equipes implantadas entre 1 a 5 anos, cerca de $50 \%$ dos enfermeiros, percebem pelo menos 2.000 reais, e este percentual diminui para $39 \%$ nas equipes implantadas há menos de 1 ano. Nas equipes implantadas há menos de 3 anos, entre 30 e $35 \%$ dos enfermeiros percebem menos de 1.500 reais.

\subsubsection{Caracterização dos enfermeiros das ESF}

\subsection{Número de enfermeiros por ESF}

Aproximadamente $96 \%$ das equipes possuem um enfermeiro, não havendo diferença com os Estados do Sudeste e a média nacional. O resultado mostra que em apenas $1 \%$ das equipes o enfermeiro estava ausente há mais de 60 dias (Tabela 6.39). 


\subsection{Tempo de atuação dos enfermeiros nas ESF}

Em geral panorama mostra que os enfermeiros, semelhantemente aos médicos, também estavam atuando há pouco tempo nas equipes, sendo que aproximadamente metade há menos de 1 ano, e cerca de $86 \%$ há menos de 3 anos. Apenas 4\% atuavam há mais de 3 anos (Tabela 6.40).

Mostra também que menos de $1 / 3$ dos enfermeiros das equipes implantadas há 5 anos ou mais e das equipes implantadas entre 3 e 5 anos estavam trabalhando nas mesmas há mais de 3 anos (Tabela 6.43). Estes percentuais sugerem, como para os médicos, um alto grau de rotatividade, contrariando a impressão corrente de que havia menor rotatividade entre os enfermeiros.

Em relação ao porte dos municípios, evidencia-se que, variando entre $52 \%$ nas equipes dos municípios de maior porte a $68 \%$ nas equipes dos municípios de menor porte, os enfermeiros estão trabalhando nas mesmas há menos de 1 ano. Já o tempo de permanência acima de 2 anos aumenta com o porte dos municípios, variando de 4\% a 17\% (Tabela 6.44).

Em relação à região Sudeste, o Estado de São Paulo apresenta percentual de permanência dos enfermeiros nas equipes acima de 2 anos, discretamente menor que o Estado de Minas Gerais e que a média nacional (11\%). (AVALIAÇÃO NORMATIVA - MS) 
6.2.5.4.3 Carga horária trabalhada, cumprida e vinculação trabalhista dos enfermeiros das ESF

Cerca de $97 \%$ dos enfermeiros pesquisados possuem contratos de trabalho de 40 horas semanais e $91 \%$ deles cumprem este horário (Tabela 6.42). Comparando-se estes dados com os Estados da região Sudeste, verifica-se carga horária contratada semelhante, sendo todos acima de $96 \%$. No entanto, em relação à carga horária cumprida este percentual diminui, variando de $85 \%$ para o Estado do Espírito Santo a 93\% para o Estado de São Paulo. Todos acima da média nacional, que é de 78\%. (AVALIAÇÃO NORMATIVA - MS)

Em relação ao vínculo de trabalho, observa-se que $73 \%$ dos enfermeiros apresentam vínculos estáveis de trabalho, sendo $2 / 3$ deles no regime da CLT e $11 \%$ no estatutário. Cerca de $23 \%$ destes possuem contratos de trabalho inadequados e $17 \%$ na forma de contrato temporário (Tabela 6.42). (BRASIL, MS, 2003; DAL POZ, 2000)

Sobre a vinculação trabalhista nos Estados do Sudeste, verifica-se que os enfermeiros do Estado de São Paulo apresentam contratos de trabalho estáveis, aproximadamente 2,5 vezes maior que o Estado de Minas Gerais, bem como em relação à média nacional (AVALIAÇÃO NORMATIVA $-\mathrm{MS})$

Levando-se em consideração o tempo de implantação das equipes, verifica-se que a CLT é a forma preferida de contratação dos enfermeiros, 
variando de $59 \%$ para as equipes implantadas há menos de 1 ano a $65 \%$ para as implantadas entre 3 e 5 anos. Já a contratação temporária é a segunda opção, sendo que praticamente o tempo de implantação não influencia o percentual que varia de $17 \%$ a $18 \%$ (Tabela 6.45 ).

Quanto ao porte dos municípios, observa-se que a vinculação estável é mais freqüente, cerca de $80 \%$ nas equipes dos municípios de menor porte diminuindo para $69 \%$ nos municípios de maior porte. Já a forma de contratação temporária é a segunda opção de vinculação dos enfermeiros, variando de $13 \%$ para os municípios de menor porte a $21 \%$ para os de maior porte. $8 \%$ dos enfermeiros das ESF mais antigas apresentam vinculação de trabalho precária (Tabela 6.44).

\subsection{Faixa salarial dos enfermeiros das ESF}

Mais da metade dos enfermeiros percebe menos de 2 mil reais, cerca de $35 \%$ entre 2 e 3 mil reais de salário mensal e apenas $12 \%$ mais de 3 mil reais (Tabela 6.47). O Estado de São Paulo apresenta maior percentual de enfermeiros com salário mensal menor que mil reais, em relação aos estados da região Sudeste e à média nacional (2.8\%). Apresenta ainda freqüência menor que o Estado de Minas Gerais de enfermeiros com salário mensal de pelo menos 2 mil reais, e superior à média nacional que é $36 \%$ (AVALIAÇÃO NORMATIVA - MS)

De maneira geral observa-se que a maioria dos enfermeiros das equipes implantadas nos municípios de menor porte, cerca de $76 \%$, percebe 
menos de 2 mil reais e que 2/3 dos enfermeiros das ESF implantadas nos municípios com mais de 50 mil habitantes percebem pelo menos 2 mil reais. $29 \%$ dos enfermeiros das ESF dos municípios de porte maior que 100 mil habitantes percebem mais de 3 mil reais, verificado em menos de $3 \%$ das ESF dos outros municípios (Tabela 6.48).

$60 \%$ dos enfermeiros das equipes implantadas há 5 anos ou mais percebem pelo menos 3 mil reais e que nas equipes implantadas entre 1 a 5 anos, metade deles, pelo menos 2.000 reais. Observa-se também que nas equipes implantadas há menos de 3 anos aproximadamente $1 / 3$ destes profissionais percebem menos de 1.500 reais (Tabela 6.49).

6.2.5.5 Caracterização dos auxiliares de enfermagem das ESF

6.2.5.5.1 Número de auxiliares de enfermagem nas ESF

Tabela 6.50 - Número de auxiliares de enfermagem nas ESF

\begin{tabular}{l|r|r}
\hline \multicolumn{1}{c|}{$\begin{array}{c}\text { Quantidade de auxiliar de } \\
\text { enfermagem }\end{array}$} & $\mathbf{N}^{\circ}$ & $\%$ \\
\hline Nenhum $<60$ dias & 3 & 0,3 \\
Nenhum $>60$ dias & 14 & 1,4 \\
Um & 325 & 31,4 \\
Dois & 652 & 63,0 \\
Três ou + & 41 & 4,0 \\
\hline Total & 1035 & 100,0 \\
\hline
\end{tabular}

$\mathrm{n}=1043$

Cerca de $60 \%$ das equipes apresentam dois auxiliares de enfermagem e $30 \%$ delas contam com apenas um. Estes profissionais estão presentes em cerca $98 \%$ das equipes. O panorama mostra que estes profissionais estavam ausentes há mais de 60 dias em apenas cerca de $2 \%$ delas. 
6.2.5.5.2 Tempo de atuação dos auxiliares de enfermagem nas ESF

Tabela 6.51 - Tempo de atuação dos auxiliares de enfermagem nas ESF

\begin{tabular}{l|r|r}
\hline $\begin{array}{c}\text { Tempo de atuação do auxiliar } \\
\text { de enfermagem }\end{array}$ & $\mathbf{n}^{\circ}$ & \% \\
\hline < 1 ano & 455 & 43,6 \\
1 a 2 anos & 357 & 34,2 \\
2 a 3 anos & 101 & 9,7 \\
> 3 anos & 56 & 5,4 \\
Sem informação & 74 & 7,1 \\
\hline Total & 1043 & 100,0 \\
\hline
\end{tabular}

Cerca de $90 \%$ dos auxiliares de enfermagem atuam nas equipes há menos de 3 anos, e 43\% deles há menos de 1 ano, evidenciando a atuação dos auxiliares de enfermagem há pouco tempo na mesma equipe.

6.2 5.5.3 Carga horária contratada, cumprida e vinculação trabalhista dos auxiliares de enfermagem das ESF

Tabela 6.52 - Carga horária contratada e cumprida pelos auxiliares de enfermagem das ESF

\begin{tabular}{l|r|r|r|r}
\hline \multicolumn{1}{c|}{ Auxiliar de enfermagem } & \multicolumn{2}{c|}{ Contratada } & \multicolumn{2}{c}{ Cumprida } \\
\hline \multicolumn{1}{c|}{ Carga horária } & $\mathbf{N}^{\circ}$ & \multicolumn{1}{c}{$\%$} & \multicolumn{1}{c}{$\mathbf{N}^{\mathbf{2}}$} \\
\hline 20h & 2 & 0,2 & 8 & 0,8 \\
30h & 11 & 1,1 & 26 & 2,5 \\
40h & 998 & 95,7 & 971 & 93,1 \\
Outra & 2 & 0,2 & 5 & 0,5 \\
Sem informação & 30 & 2,9 & 33 & 3,2 \\
\hline Total & 1043 & 100,0 & 1043 & 100,0 \\
\hline
\end{tabular}

Mais de $95 \%$ dos auxiliares de enfermagem contratados para 40 horas de trabalho semanais e cerca de $93 \%$ referem cumprir estas 40 horas. 
Tabela 6.53 - Vínculo contratual dos auxiliares de enfermagem

\begin{tabular}{|c|c|c|}
\hline $\begin{array}{l}\text { Vínculo do auxiliar de } \\
\text { enfermagem }\end{array}$ & $\mathbf{N}^{\circ}$ & $\%$ \\
\hline Estatutário & 188 & 18,8 \\
\hline CLT & 594 & 59,5 \\
\hline Contrato Temporário & 146 & 14,6 \\
\hline Comissionado & 21 & 2,1 \\
\hline Bolsa & 0 & 0,0 \\
\hline Prestação Serviço & 12 & 1,2 \\
\hline Cooperado & 4 & 0,4 \\
\hline Contrato Informal & 4 & 0,4 \\
\hline Outros & 30 & 3,0 \\
\hline Total & 999 & 100,0 \\
\hline
\end{tabular}

Aproximadamente $79 \%$ dos auxiliares de enfermagem apresentam vinculações trabalhistas estáveis, sendo $60 \%$ deles no regime CLT e $19 \%$ no estatutário. $20 \%$ deles apresentam vinculação não estável, sendo quase $15 \%$ por meio de contratos temporários e $4 \%$ de contratações precárias.

Tabela 6.54 - Porte dos municípios e quantidade de auxiliares de enfermagem nas ESF

\begin{tabular}{|c|c|c|c|c|c|c|}
\hline \multirow[b]{2}{*}{ Porte dos municípios } & \multicolumn{6}{|c|}{ Quantidade de auxiliares de enfermagem } \\
\hline & $\begin{array}{l}\text { Nenhum } \\
\text { há menos } \\
\text { de } 60 \text { dias }\end{array}$ & $\begin{array}{l}\text { Nenhum } \\
\text { há mais } \\
\text { de } 60 \text { dias }\end{array}$ & 1 & 2 & 3 ou + & Total \\
\hline \multirow[t]{2}{*}{$<20$ mil } & 0 & 5 & 94 & 204 & 13 & 316 \\
\hline & $0.0 \%$ & $1.6 \%$ & $29.7 \%$ & $64.6 \%$ & $4.1 \%$ & $100 \%$ \\
\hline \multirow[t]{2}{*}{20 a $50 \mathrm{mil}$} & 1 & 0 & 46 & 122 & 7 & 176 \\
\hline & $0.6 \%$ & $0.0 \%$ & $26.1 \%$ & $69.3 \%$ & $4.0 \%$ & $100 \%$ \\
\hline \multirow[t]{2}{*}{50 a $100 \mathrm{mil}$} & 1 & 1 & 63 & 63 & 9 & 137 \\
\hline & $0.7 \%$ & $0.7 \%$ & $46.0 \%$ & $46.0 \%$ & $6.6 \%$ & $100 \%$ \\
\hline \multirow[t]{2}{*}{$>100 \mathrm{mil}$} & 1 & 8 & 122 & 263 & 12 & 496 \\
\hline & $0.2 \%$ & $2.0 \%$ & $30.0 \%$ & $64.8 \%$ & $3.0 \%$ & $100 \%$ \\
\hline \multirow[t]{2}{*}{ Total } & 3 & 14 & 325 & 652 & 41 & 1035 \\
\hline & $0.3 \%$ & $1.4 \%$ & $31.4 \%$ & $63.0 \%$ & $4.0 \%$ & $100 \%$ \\
\hline
\end{tabular}

$\mathrm{n}=1043$

Entre $65 \%$ e $69 \%$ das equipes de todos os portes de município estudado pode-se encontrar 2 auxiliares de enfermagem, exceto para os municípios entre 50 e 100 mil habitantes, onde este percentual diminui para 46\%. Nestes municípios $46 \%$ das equipes possuem 1 auxiliar de enfermagem e $7 \%$ mais de 3 . 
Tabela 6.55 - Tempo de implantação e quantidade de auxiliares de enfermagem nas ESF

\begin{tabular}{|c|c|c|c|c|c|c|}
\hline \multirow[b]{2}{*}{ Tempo de implantação } & \multicolumn{6}{|c|}{ Quantidade de auxiliar de enfermagem } \\
\hline & $\begin{array}{l}\text { Nenhum há } \\
\text { menos de } \\
60 \text { dias }\end{array}$ & $\begin{array}{l}\text { Nenhum } \\
\text { há mais } \\
\text { de } 60 \text { dias }\end{array}$ & 1 & 2 & 3 ou mais & Total \\
\hline 5 anos ou + & $\begin{array}{r}1 \\
2.2 \%\end{array}$ & $\begin{array}{r}0 \\
0.0 \%\end{array}$ & $\begin{array}{r}8 \\
17.8 \%\end{array}$ & $\begin{array}{r}32 \\
71.1 \%\end{array}$ & $\begin{array}{r}4 \\
8.9 \%\end{array}$ & $\begin{array}{r}45 \\
100 \%\end{array}$ \\
\hline 3 a 5 anos & $\begin{array}{r}1 \\
0.0 \%\end{array}$ & $\begin{array}{r}0 \\
0.0 \%\end{array}$ & $\begin{array}{r}53 \\
39.0 \%\end{array}$ & $\begin{array}{r}75 \\
55.1 \%\end{array}$ & $\begin{array}{r}8 \\
5.9 \%\end{array}$ & $\begin{array}{r}136 \\
100 \%\end{array}$ \\
\hline 1 a 3 anos & 1 & 10 & $150 \mid$ & 334 & 15 & 510 \\
\hline & $0.2 \%$ & $2.0 \%$ & $29.4 \%$ & $65.5 \%$ & $2.9 \%$ & $100 \%$ \\
\hline$<1$ ano & $\begin{array}{r}1 \\
0.3 \%\end{array}$ & $\begin{array}{r}4 \\
1.2 \%\end{array}$ & $\begin{array}{r}113 \\
33.5 \%\end{array}$ & $\begin{array}{r}205 \\
60.8 \%\end{array}$ & $\begin{array}{r}14 \\
4.2 \%\end{array}$ & $\begin{array}{r}337 \\
100 \%\end{array}$ \\
\hline Total & $\begin{array}{r}3 \\
0.3 \%\end{array}$ & $\begin{array}{r}14 \\
1.4 \%\end{array}$ & $\begin{array}{r}324 \\
31.5 \%\end{array}$ & $\begin{array}{r}646 \\
62.8 \%\end{array}$ & $\begin{array}{r}41 \\
4.0 \%\end{array}$ & $\begin{array}{l}1028 \\
100 \%\end{array}$ \\
\hline
\end{tabular}

$\mathrm{n}=1043$

Aproximadamente $71 \%$ das equipes implantadas há mais de 5 anos possuem dois auxiliares de enfermagem, enquanto apenas metade das equipes implantadas entre 3 e 5 anos conta com este número de profissionais.

Tabela 6.56 - Tempo de implantação e tempo de atuação dos auxiliares de enfermagem nas ESF

\begin{tabular}{|c|c|c|c|c|c|}
\hline \multirow[b]{2}{*}{ Tempo de implantação } & \multicolumn{5}{|c|}{ Tempo auxiliar de enfermagem } \\
\hline & $<1$ ano & $\begin{array}{l}1 \text { a } 2 \\
\text { anos }\end{array}$ & $\begin{array}{l}2 \text { a } 3 \\
\text { anos }\end{array}$ & $\begin{array}{c}+ \text { de } 3 \\
\text { anos }\end{array}$ & Total \\
\hline 5 anos ou + & 7 & 4 & 12 & 20 & 43 \\
\hline & $16.3 \%$ & $9.3 \%$ & $27.9 \%$ & $46.5 \%$ & $100 \%$ \\
\hline 3 a 5 anos & 28 & 27 & 41 & 31 & 127 \\
\hline & $22.0 \%$ & $21.3 \%$ & $32.3 \%$ & $24.4 \%$ & $100 \%$ \\
\hline 1 a 3 anos & 115 & 308 & 44 & 2 & 469 \\
\hline & $24.5 \%$ & $65.7 \%$ & $9.4 \%$ & $0.4 \%$ & $100 \%$ \\
\hline$<1$ ano & 305 & 16 & 3 & 0 & 324 \\
\hline & $94.1 \%$ & $4.9 \%$ & $0.9 \%$ & $0.0 \%$ & $100 \%$ \\
\hline Total & $\begin{array}{r}455 \\
47.2 \%\end{array}$ & $\begin{array}{r}355 \\
36.9 \%\end{array}$ & $\begin{array}{r}100 \\
10.4 \%\end{array}$ & $\begin{array}{r}53 \\
5.5 \%\end{array}$ & $\begin{array}{r}963 \\
100 \%\end{array}$ \\
\hline
\end{tabular}

$\mathrm{n}=1043$

$85 \%$ dos auxiliares de enfermagem das equipes implantadas há 5 anos ou mais atuam nas equipes há menos de 3 anos, e $76 \%$ nas equipes implantadas entre 3 e 5 anos. 
Tabela 6.57 - Porte dos municípios e tempo de atuação dos auxiliares de enfermagem nas ESF

\begin{tabular}{l|r|r|r|r|r}
\hline \multicolumn{1}{c}{ Tempo de atuação auxiliar de enfermagem } \\
\hline $\begin{array}{c}\text { Porte dos } \\
\text { municípios }\end{array}$ & \multicolumn{1}{c}{$<$ 1ano } & $\mathbf{1}$ a 2 anos & 2 a 3 anos & + de 3 anos & \multicolumn{1}{c}{ total } \\
\hline$<20$ mil & 163 & 109 & 23 & 5 & 300 \\
20 a 50 mil & $54.3 \%$ & $36.3 \%$ & $7.7 \%$ & $1.7 \%$ & $100 \%$ \\
& 72 & 75 & 12 & 7 & 166 \\
50 a 100 mil & $43.4 \%$ & $45.2 \%$ & $7.2 \%$ & $4.2 \%$ & $100 \%$ \\
& 60 & 43 & 7 & 13 & 123 \\
$>100$ mil & $48.8 \%$ & $35.0 \%$ & $5.7 \%$ & $10.6 \%$ & $100 \%$ \\
& 160 & 130 & 59 & 31 & 380 \\
\hline Total & $42.1 \%$ & $34.2 \%$ & $15.5 \%$ & $8.2 \%$ & $100 \%$ \\
\hline
\end{tabular}

$\mathrm{n}=1043$

Os municípios de porte acima de 100 mil habitantes são os que apresentam maior percentual, cerca de $23 \%$, de auxiliares de enfermagem com mais de 2 anos nas equipes.

Tabela 6.58 - Porte dos municípios e vínculo trabalhista dos auxiliares de enfermagem das ESF

\begin{tabular}{|c|c|c|c|c|c|c|c|c|c|}
\hline \multicolumn{10}{|c|}{ Vínculo trabalhista dos auxiliares de enfermagem } \\
\hline 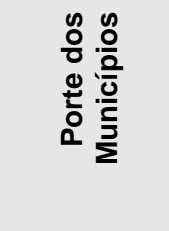 & 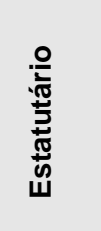 & $\stackrel{\vdash}{\cup}$ & 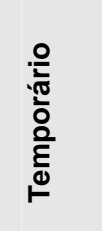 & $\begin{array}{l}\frac{0}{0} \\
\frac{\pi}{2} \\
\frac{0}{n} \\
\frac{n}{E} \\
\frac{0}{0}\end{array}$ & 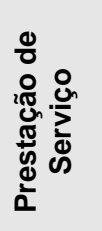 & $\begin{array}{l}\frac{0}{0} \\
\frac{\pi}{0} \\
\frac{0}{0} \\
0 \\
0\end{array}$ & 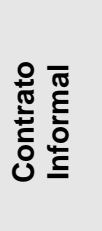 & 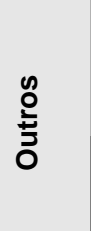 & $\begin{array}{l}\text { त } \\
\text { రீ }\end{array}$ \\
\hline \multirow[t]{2}{*}{$<20$ mil } & 50 & 206 & 31 & 4 & 1 & 1 & 1 & 9 & 303 \\
\hline & $16.5 \%$ & $68.0 \%$ & $10.2 \%$ & $1.3 \%$ & $0.3 \%$ & $0.3 \%$ & $0.3 \%$ & $3.0 \%$ & $100 \%$ \\
\hline \multirow[t]{2}{*}{20 a 50 mil } & & 112 & 20 & 5 & 4 & 2 & 0 & 6 & 173 \\
\hline & $13.9 \%$ & $64.7 \%$ & $11.6 \%$ & $2.9 \%$ & $2.3 \%$ & $1.2 \%$ & $0.0 \%$ & $3.5 \%$ & $100 \%$ \\
\hline \multirow[t]{2}{*}{50 a $100 \mathrm{mil}$} & & 71 & & 3 & 1 & 1 & 0 & 7 & 131 \\
\hline & $17.6 \%$ & $54.2 \%$ & $19.1 \%$ & $2.3 \%$ & $0.8 \%$ & $0.8 \%$ & $0.0 \%$ & $5.3 \%$ & $100 \%$ \\
\hline \multirow[t]{2}{*}{$>100 \mathrm{mil}$} & & 205 & 70 & 9 & 6 & 0 & 3 & 8 & 392 \\
\hline & $23.2 \%$ & $52.3 \%$ & $17.9 \%$ & $2.3 \%$ & $1.5 \%$ & $0.0 \%$ & $0.8 \%$ & $2.0 \%$ & $100 \%$ \\
\hline \multirow[t]{2}{*}{ Total } & 188 & 594 & 146 & 21 & 12 & 4 & 4 & 30 & 999 \\
\hline & $18.8 \%$ & $59.5 \%$ & $14.6 \%$ & $2.1 \%$ & $1.2 \%$ & $0.4 \%$ & $0.4 \%$ & $3.0 \%$ & $100 \%$ \\
\hline
\end{tabular}

Nos municípios de menor porte observa-se o maior percentual, cerca de $68 \%$ de auxiliares de enfermagem contratados via CLT, enquanto o maior percentual $(23 \%)$ com contrato estatutário está nas equipes dos municípios de maior porte. A contratação instável foi mais freqüente nos municípios de 
porte acima de 50 mil habitantes, sendo que em média $18 \%$ dos auxiliares de enfermagem destes municípios estão contratados de forma temporária. Os enfermeiros dos municípios entre 20 a 50 mil habitantes apresentam o maior percentual de vinculação precária (6.4\%).

Tabela 6.59 - Tempo de implantação e vínculo trabalhista dos auxiliares de enfermagem das ESF

\begin{tabular}{|c|c|c|c|c|c|c|c|c|c|}
\hline \multicolumn{10}{|c|}{ Vínculo trabalhista dos auxiliares de enfermagem das ESF } \\
\hline 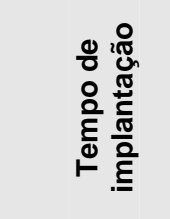 & 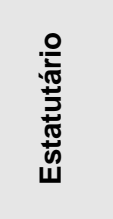 & $\frac{5}{u}$ & $\begin{array}{l}\frac{0}{2} \\
\frac{\pi}{2} \\
\frac{0}{2} \\
\frac{0}{0}\end{array}$ & 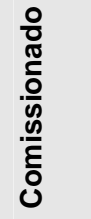 & 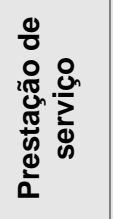 & $\begin{array}{l}\frac{0}{0} \\
\frac{\pi}{2} \\
\frac{0}{0} \\
0\end{array}$ & 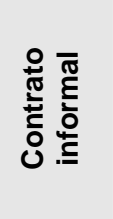 & $\begin{array}{l}\text { on } \\
\stackrel{0}{*} \\
0 \\
0\end{array}$ & $\begin{array}{l}\bar{\pi} \\
\text { 으 }\end{array}$ \\
\hline \multirow[t]{2}{*}{5 anos ou +} & & 25 & 7 & 2 & 1 & 0 & 0 & 3 & 45 \\
\hline & $15.6 \%$ & $55.6 \%$ & $15.6 \%$ & $4.4 \%$ & $2.2 \%$ & $0.0 \%$ & $0.0 \%$ & $6.7 \%$ & $100 \%$ \\
\hline \multirow[t]{2}{*}{3 a 5 anos } & 22 & & 26 & & 0 & & 0 & 3 & 133 \\
\hline & $16.5 \%$ & $58.6 \%$ & $19.5 \%$ & $2.3 \%$ & $0.0 \%$ & $0.8 \%$ & $0.0 \%$ & $2.3 \%$ & $100 \%$ \\
\hline \multirow[t]{2}{*}{1 a 3 anos } & 93 & 295 & 71 & 11 & 7 & & 2 & 13 & 493 \\
\hline & $18.9 \%$ & $59.8 \%$ & $14.4 \%$ & $2.2 \%$ & $1.4 \%$ & $0.2 \%$ & $0.4 \%$ & $2.6 \%$ & $100 \%$ \\
\hline \multirow[t]{2}{*}{$<1$ ano } & 64 & 192 & 41 & & & & 2 & 11 & 321 \\
\hline & $19.9 \%$ & $59.8 \%$ & $12.8 \%$ & $1.6 \%$ & $1.2 \%$ & $0.6 \%$ & $0.6 \%$ & $3.4 \%$ & $100 \%$ \\
\hline Total & $\begin{array}{r}186 \\
18.8 \%\end{array}$ & $\begin{array}{r}590 \\
59.5 \%\end{array}$ & $\begin{array}{r}145 \\
14.6 \%\end{array}$ & $\begin{array}{r}21 \\
2.1 \%\end{array}$ & $\begin{array}{r}12 \\
1.2 \%\end{array}$ & $\begin{array}{r}4 \\
0.4 \%\end{array}$ & $\begin{array}{r}4 \\
0.4 \%\end{array}$ & $\begin{array}{r}30 \\
3.0 \%\end{array}$ & $\begin{array}{r}992 \\
100 \%\end{array}$ \\
\hline
\end{tabular}

Evidencia-se que a contratação estável é um pouco mais freqüente, aproximadamente $80 \%$ nos auxiliares de enfermagem das equipes implantadas há menos de 1 ano, principalmente devido à forma estatutária. Já a forma de contrato temporário é discretamente mais freqüente, cerca de $20 \%$ nas equipes implantadas entre 3 e 5 anos. Cerca de $24 \%$ dos auxiliares de enfermagem das ESF implantadas há mais de 3 anos possuem contrato CLT e esta condição aparece em menos de $14 \%$ das equipes implantadas há menos de 3 anos. 
Tabela 6.60 - Salário dos auxiliares de enfermagem das ESF

\begin{tabular}{ll|r|rr}
\hline \multicolumn{5}{c}{ Salário dos auxiliares de enfermagem (bruto em reais) } \\
\hline & R\$ & & $\%$ & \\
\hline$<700$ & & 577 & & 58,5 \\
$700-901$ & 153 & 15,5 \\
$900-1.101$ & 97 & 9,8 \\
$1.100-1.301$ & & 142 & 14,4 \\
$>1.300$ & & 18 & 1,8 \\
\hline Total & & 987 & 100,0 \\
\hline $\mathrm{n}=1043$ & & &
\end{tabular}

Cerca de $59 \%$ dos auxiliares de enfermagem percebem menos de 700 reais, $74 \%$ menos que 900 reais e apenas $16 \%$ pelo menos 1.100 reais.

Tabela 6.61 - Porte dos municípios e salário dos auxiliares de enfermagem das ESF (bruto em reais)

\begin{tabular}{|c|c|c|c|c|c|c|c|}
\hline \multirow{2}{*}{$\begin{array}{l}\text { Porte dos } \\
\text { municípios }\end{array}$} & & \multicolumn{6}{|c|}{ Salário dos auxiliares de enfermagem (em reais) } \\
\hline & & $\%<700$ & $\% 700-901$ & $\begin{array}{c}\% 900- \\
1.101\end{array}$ & $\begin{array}{c}\% 1.100- \\
1.301\end{array}$ & $\%>1.300$ & Total \\
\hline \multirow{2}{*}{$<20$ mil } & $\mathrm{n}$ & 273 & 31 & 0 & 0 & 0 & 304 \\
\hline & $\%$ & 89,8 & 10,2 & 0,0 & 0,0 & 0,0 & 100,0 \\
\hline \multirow[t]{2}{*}{$20-50$ mil } & $\mathrm{n}$ & 152 & 16 & 0 & 0 & 1 & 169 \\
\hline & $\%$ & 89,9 & 9,5 & 0,0 & 0,0 & 0,6 & 100,0 \\
\hline \multirow[t]{2}{*}{$50-100$ mil } & $\mathrm{n}$ & 87 & 34 & 4 & 0 & 0 & 125 \\
\hline & $\%$ & 69,6 & 27,2 & 3,2 & 0,0 & 0,0 & 100,0 \\
\hline \multirow[t]{2}{*}{$>100$ mil } & $\mathrm{n}$ & 65 & 72 & 93 & 142 & 17 & 389 \\
\hline & $\%$ & 16,7 & 18,5 & 23,9 & 36,5 & 4,4 & 100,0 \\
\hline \multirow[t]{2}{*}{ Total } & $\mathrm{n}$ & 577 & 153 & 97 & 142 & 18 & 987 \\
\hline & $\%$ & 58,5 & 15,5 & 9,8 & 14,4 & 1,8 & 100,0 \\
\hline
\end{tabular}

$\mathrm{n}=1043$

Aproximadamente $90 \%$ dos auxiliares de enfermagem das ESF dos municípios de porte menor que 50 mil habitantes percebem menos que 700 reais e cerca de $40 \%$ dos auxiliares de enfermagem dos municípios com mais de 100 mil habitantes percebem pelo menos 1.100 reais. Este valor só é percebido por menos de $1 \%$ dos auxiliares de enfermagem das equipes dos municípios com porte entre 20 e 50 mil habitantes. 
Tabela 6.62 - Tempo de implantação das ESF e salário dos auxiliares de enfermagem das ESF (bruto em reais)

\begin{tabular}{|c|c|c|c|c|c|c|c|}
\hline \multirow[b]{2}{*}{ Tempo implantação } & & \multicolumn{6}{|c|}{ Salário dos auxiliares de enfermagem (em reais) } \\
\hline & & $<700$ & $700-900$ & $900-1.100$ & $\begin{array}{l}1.100- \\
1.300\end{array}$ & $>1.300$ & Total \\
\hline \multirow[t]{2}{*}{5 anos ou mais } & $\mathrm{n}$ & 13 & 5 & 1 & 25 & 0 & 44 \\
\hline & $\%$ & 29,5 & 11,4 & 2,3 & 56,8 & 0,0 & 100,0 \\
\hline \multirow[t]{2}{*}{3 a 5 anos } & $\mathrm{n}$ & 57 & 16 & 12 & 38 & 7 & 130 \\
\hline & $\%$ & 43,8 & 12,3 & 9,2 & 29,2 & 5,4 & 100 \\
\hline \multirow[t]{2}{*}{1 a 3 anos } & $n$ & 315 & 74 & 36 & 53 & 8 & 486 \\
\hline & $\%$ & 64,8 & 15,2 & 7,4 & 10,9 & 1,6 & 100 \\
\hline \multirow[t]{2}{*}{$<1$ ano } & $n$ & 188 & 57 & 48 & 25 & 3 & 321 \\
\hline & $\%$ & 58,6 & 17,8 & 15 & 7,8 & 0,9 & 100 \\
\hline \multirow[t]{2}{*}{ Total } & $n$ & 573 & 152 & 97 & 141 & 18 & 981 \\
\hline & $\%$ & 58,4 & 15,5 & 9,9 & 14,4 & 1,8 & 100 \\
\hline
\end{tabular}

$n=1043$

Aproximadamente $62 \%$ dos auxiliares de enfermagem das ESF implantadas há menos de 1 ano percebem menos de 700 reais e $67 \%$ dos auxiliares das ESF das equipes implantadas há mais de 5 anos pelo menos 1.100 reais. Este percentual diminui nas demais faixas, variando de $35 \%$ nas equipes implantadas entre 3 e 5 anos a $9 \%$ nas implantadas há menos de 1 ano.

6.2.5.6 Caracterização dos auxiliares de enfermagem das ESF

6.2.5.6.1 Número de auxiliares de enfermagem por ESF

Aproximadamente $2 / 3$ das equipes possuem dois auxiliares de enfermagem e 1/3 delas contam com apenas um (Tabela 6.50). O Estado de São Paulo apresenta 3 vezes mais equipes com 2 auxiliares de enfermagem que os demais Estados da região Sudeste, e 2.5 vezes mais que a média nacional observada, que é de 25\%. (AVALIAÇÃO NORMATIVA - MS) 
A prática tem demonstrado que o trabalho do auxiliar de enfermagem nas equipes de saúde da família tende a não ser modificado em relação ao trabalho que já vinha desempenhando nas unidades de saúde sem PSF, principalmente devido ao número de tarefas que estes profissionais têm rotineiramente nas UBS. Portanto, é provável que nas equipes com menos de 2 auxiliares de enfermagem, entre outras questões, existe maior dificuldade de que eles possam participar efetivamente das atividades previstas no PSF.

A "inadequação" do número de auxiliares de enfermagem menor que 2 por equipe é encontrada nos municípios entre 50 e 100 mil habitantes e nas equipes implantadas entre 3 e 5 anos (Tabela 6.54).

\subsection{Tempo de atuação dos auxiliares de enfermagem nas ESF}

De maneira geral, evidencia-se que a maioria dos auxiliares de enfermagem, assim como os demais profissionais da equipe atuam nas equipes há menos de 3 anos e, quase metade destes há menos de 1 ano (Tabela 6.51). Em relação aos Estados do Sudeste, o Estado de São Paulo apresenta menor percentual que o Estado de Minas Gerais, de auxiliares de enfermagem em atuação nas equipes há mais de 2 anos e também que a média nacional, de 19\%. (AVALIAÇÃO NORMATIVA - MS)

Dos auxiliares de enfermagem das equipes implantadas há 5 anos ou mais, $85 \%$ estão nas equipes há menos de 3 anos, e $76 \%$ nas equipes implantadas entre 3 e 5 anos. Este dado permite inferir que existe um certo 
grau de dificuldade na fixação dos auxiliares de enfermagem semelhantemente aos médicos e enfermeiros (Tabela 6.56).

Os municípios de porte acima de 100 mil habitantes apresentam maior percentual, cerca de $23 \%$ de auxiliares de enfermagem com mais de 2 anos nas equipes (Tabela 6.57).

6.2.5.6.3 Carga horária trabalhada, cumprida e vinculação trabalhista dos auxiliares de enfermagem das ESF

Em quase todas as equipes, pelo menos $93 \%$ dos auxiliares de enfermagem estão contratados em regime de 40 horas de trabalho semanais e cumprem esta carga horária (Tabela 6.52). Não se observa diferença acentuada entre os Estados do Sudeste, sendo que os mesmos se situam acima da média nacional observada de 87\%. (AVALIAÇÃO NORMATIVA MS)

Nota-se ainda que $80 \%$ dos auxiliares de enfermagem apresentam vinculação trabalhista estável e $20 \%$ não estáveis, sendo que destes, quase 15\% são contratados em regime temporário (Tabela 6.58). (BRASIL, MS, 2003; DAL POZ, 2000)

Em relação aos Estados do Sudeste evidencia-se que o Estado de São Paulo apresenta pelo menos 2 vezes mais auxiliares de enfermagem com contratos de trabalho estável que os demais Estados e, também, apresenta maior percentual que a média nacional observada de 54\%. 
O maior percentual de auxiliares de enfermagem contratados via CLT está nas equipes dos municípios de menor porte, enquanto o maior percentual com contrato estatutário, nas equipes dos municípios de maior porte. A forma de contratação não estável apresenta-se mais freqüente nos municípios de porte acima de 50 mil habitantes, sendo que em média $18 \%$ dos auxiliares de enfermagem destes municípios estão contratados desta maneira (Tabela 6.58). Evidencia-se que a contratação estável é um pouco mais freqüente, aproximadamente $80 \%$ nos auxiliares de enfermagem das equipes implantadas há menos de 1 ano. Já a forma de contrato temporário é discretamente mais freqüente, cerca de $20 \%$ nas equipes implantadas entre 1 e 3 anos (Tabela 6.59).

\subsection{Faixa salarial dos auxiliares de enfermagem das ESF}

Aproximadamente $59 \%$ dos auxiliares de enfermagem percebem menos de 700 reais, $74 \%$ menos que 900 reais, e apenas $16 \%$ pelo menos 1.100 reais (Tabela 6.60). O Estado de São Paulo apresenta percentual de enfermeiros das ESF que percebem pelo menos 900 reais, cinco vezes maior que os estados do Sudeste, e 10 vezes a média nacional que é $2.7 \%$. Apresenta, também, percentual menor que os estados da região Sudeste e que a média nacional $(90 \%)$ de auxiliares de enfermagem que recebem salário menor que 700 reais. (AVALIAÇÃO NORMATIVA - MS)

A maioria dos auxiliares de enfermagem das ESF dos municípios de porte menor que 50 mil habitantes percebe menos que 700 reais, enquanto 
que $40 \%$ dos auxiliares de enfermagem dos municípios com mais de 100 mil habitantes percebem pelo menos 1.100 reais. Este valor só é recebido por menos de $1 \%$ dos auxiliares de enfermagem das equipes dos municípios com porte entre 20 e 50 mil habitantes (Tabela 6.61). Em relação ao tempo de implantação observa-se que aproximadamente $2 / 3$ dos auxiliares de enfermagem das ESF implantadas há menos de 1 ano percebem menos de 700 reais, e 2/3 dos auxiliares das ESF das equipes implantadas há mais de 5 anos percebem pelo menos 1.100 reais. Este percentual diminui nas demais faixas, variando entre $35 \%$ nas equipes implantadas entre 3 e 5 anos a 9\% nas implantadas há menos de 1 ano (Tabela 6.62).

6.2.5.7 Caracterização dos agentes comunitários de saúde (ACS) das ESF

\subsection{Número de ACS por ESF}

Tabela 6.63 - Número de ACS por ESF

\begin{tabular}{l|r|rr}
\hline \multicolumn{1}{|c|}{$\mathbf{N}^{\circ}$} & & $\%$ & \\
\hline Quantidade de ACS nas ESF & 1 & & 0,1 \\
Menhum & 53 & 5,1 \\
De 4 a 6 4 & 822 & & 78,8 \\
Mais de 6 & 162 & 5 & 15,5 \\
Sem informação & 1043 & 0,5 \\
\hline Total & & & 100,0 \\
\hline
\end{tabular}

Apenas $5 \%$ das equipes possuem menos de 4 ACS. Aproximadamente $79 \%$ das equipes possuem de 4 a 6 ACS, estando de acordo com o parâmetro recomendado pelo MS e cerca de $15 \%$ delas possuem mais de 6 ACS. 
Tabela 6.64 - Porte dos municípios e quantidade de ACS nas ESF

\begin{tabular}{|c|c|c|c|c|c|}
\hline \multirow{2}{*}{ Porte dos municípios } & \multicolumn{5}{|c|}{ Quantidade de ACS nas ESF } \\
\hline & Nenhum & - de 4 & de 4 a 6 & + de 6 & Total \\
\hline$<20$ mil & 0 & 14 & 218 & 83 & 315 \\
\hline & $0.0 \%$ & $4.4 \%$ & $69.2 \%$ & $26.3 \%$ & $100 \%$ \\
\hline 20 a 50 mil & & 13 & 145 & 21 & 179 \\
\hline & $0.0 \%$ & $7.3 \%$ & $81.0 \%$ & $11.7 \%$ & $100 \%$ \\
\hline 50 a $100 \mathrm{mil}$ & 1 & 14 & 90 & 31 & 136 \\
\hline & $0.7 \%$ & $10.3 \%$ & $66.2 \%$ & $22.8 \%$ & $100 \%$ \\
\hline$>100 \mathrm{mil}$ & 0 & 12 & 369 & 27 & 408 \\
\hline & $0.0 \%$ & $2.9 \%$ & $90.4 \%$ & $6.6 \%$ & $100 \%$ \\
\hline Total & $\begin{array}{r}1 \\
0.1 \%\end{array}$ & $\begin{array}{r}53 \\
5.1 \%\end{array}$ & $\begin{array}{r}822 \\
79.2 \%\end{array}$ & $\begin{array}{r}162 \\
15.6 \%\end{array}$ & $\begin{array}{c}1038 \\
100 \%\end{array}$ \\
\hline
\end{tabular}

$\mathrm{n}=1043$

Os municípios de porte entre 50 a 100 mil habitantes apresentam maior percentual $(11 \%)$ de equipes com menos de $4 \mathrm{ACS}$, enquanto o maior percentual de equipes com mais de 4 ACS por equipe está nos municípios com mais de 100 mil habitantes.

Tabela 6.65 - Tempo de implantação e quantidade de ACS nas ESF

\begin{tabular}{|c|c|c|c|c|c|}
\hline \multicolumn{6}{|c|}{ Quantidade de ACS nas ESF } \\
\hline Tempo implantação & Nenhum & - de 4 & 4 a 6 & + de 6 & Total \\
\hline 5 anos ou mais & $\begin{array}{r}0 \\
0.0 \%\end{array}$ & $\begin{array}{r}6 \\
136 \%\end{array}$ & $\begin{array}{r}36 \\
818 \%\end{array}$ & $\begin{array}{r}2 \\
45 \%\end{array}$ & $\begin{array}{r}44 \\
100 \%\end{array}$ \\
\hline 3 a 5 anos & 0 & 9 & 118 & 10 & 137 \\
\hline & $0.0 \%$ & $6.6 \%$ & $86.1 \%$ & $7.3 \%$ & $100 \%$ \\
\hline 1 a 3 anos & 1 & 23 & 400 & 90 & 514 \\
\hline & $0.2 \%$ & $4.5 \%$ & $77.8 \%$ & $17.5 \%$ & $100 \%$ \\
\hline$<1$ ano & 0 & 11 & 264 & 60 & 335 \\
\hline & $0.0 \%$ & $3.3 \%$ & $78.8 \%$ & $17.9 \%$ & $100 \%$ \\
\hline Total & $\begin{array}{r}1 \\
0.1 \%\end{array}$ & $\begin{array}{r}49 \\
4.8 \%\end{array}$ & $\begin{array}{r}818 \\
79.4 \%\end{array}$ & $\begin{array}{r}162 \\
15.7 \%\end{array}$ & $\begin{array}{r}1030 \\
100 \%\end{array}$ \\
\hline
\end{tabular}

$\mathrm{n}=1043$

Verifica-se que nas equipes implantadas há mais tempo o percentual de equipes com menos de 4 ACS é maior, variando entre $3 \%$ nas ESF implantadas há menos de 1 ano a $14 \%$ nas ESF implantadas há 5 anos ou mais. Observa-se que há um aumento percentual de equipes com 6 ACS nas equipes implantadas há menos de 3 anos. 
6.2 5.7.2 Carga horária contratada, cumprida e vinculação trabalhista dos ACS das ESF

Tabela 6.66 - Carga horária contratada e cumprida pelos ACS das ESF

\begin{tabular}{|c|c|c|c|c|}
\hline \multirow[b]{2}{*}{ Carga horária } & \multicolumn{2}{|c|}{ Contratada } & \multicolumn{2}{|c|}{ Cumprida } \\
\hline & $\mathrm{N}^{0}$ & $\%$ & $\mathbf{N}^{0}$ & $\%$ \\
\hline $20 \mathrm{~h}$ & 11 & 1,1 & 7 & 0,7 \\
\hline $30 \mathrm{~h}$ & 4 & 0,4 & 9 & 0,9 \\
\hline $40 \mathrm{~h}$ & 1022 & 98 & 1017 & 97,5 \\
\hline Outra & 1 & 0,1 & 2 & 0,2 \\
\hline Sem informação & 5 & 0,5 & 8 & 0,8 \\
\hline Total & 1043 & 100 & 1043 & 100 \\
\hline
\end{tabular}

Cerca de $98 \%$ dos ACS são contratados por 40 horas de trabalho semanais, e cerca de 97\% cumprem esta carga horária.

Tabela 6.67 - Vínculo contratual dos ACS nas ESF

\begin{tabular}{l|r|r}
\hline \multicolumn{1}{c}{ Vínculo contratual ACS } & $\mathbf{N}^{\mathbf{2}}$ & $\%$ \\
\hline Estatutário & 61 & 5,8 \\
CLT & 644 & 61,7 \\
Contrato Temporário & 194 & 18,6 \\
Comissionado & 23 & 2,2 \\
Bolsa & 4 & 0,4 \\
Prestação Serviço & 41 & 3,9 \\
Cooperado & 2 & 0,2 \\
Contrato Informal & 7 & 0,7 \\
Outros & 43 & 4,1 \\
Sem Informação & 24 & 2,3 \\
\hline Total & 1043 & 100,0 \\
\hline
\end{tabular}

Cerca de $67 \%$ dos ACS são contratados com vínculo estável de trabalho; $30 \%$ são contratados através de modalidade não estável; e 19\% destes na forma de contrato temporário. Nota-se um aumento de precarização de trabalho (12\%) nos ACS em relação aos demais profissionais das equipes. 
Tabela 6.68 - Tempo de implantação e vínculo dos ACS nas ESF

Vínculo trabalhista dos ACS nas ESF

\begin{tabular}{|c|c|c|c|c|c|c|c|c|c|c|}
\hline 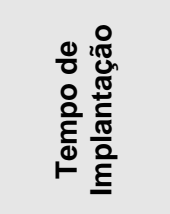 & 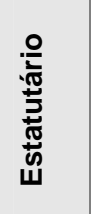 & $\frac{5}{u}$ & $\begin{array}{l}\frac{0}{\frac{1}{2}} \\
\frac{0}{0} \\
\frac{0}{E} \\
\frac{\varrho}{\varrho}\end{array}$ & $\begin{array}{l}\frac{0}{0} \\
\frac{\pi}{0} \\
\frac{0}{n} \\
\frac{.0}{E} \\
\bar{\delta}\end{array}$ & 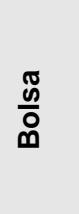 & 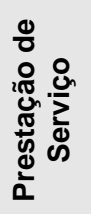 & $\begin{array}{l}\frac{0}{0} \\
\frac{\pi}{0} \\
\frac{0}{0} \\
0\end{array}$ & $\begin{array}{l}\text { స్ } \\
\text { है } \\
\text { 을 }\end{array}$ & 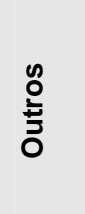 & 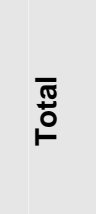 \\
\hline \multirow[t]{2}{*}{5 anos ou +} & & 30 & 5 & 1 & 0 & 1 & 0 & 0 & 3 & 44 \\
\hline & $9.1 \%$ & $68.2 \%$ & $11.4 \%$ & $2.3 \%$ & $0.0 \%$ & $2.3 \%$ & $0.0 \%$ & $0.0 \%$ & $6.8 \%$ & $100 \%$ \\
\hline \multirow[t]{2}{*}{3 a 5 anos } & & & & & & 7 & 1 & & 10 & 133 \\
\hline & $3.0 \%$ & $63.9 \%$ & $15.8 \%$ & $3.0 \%$ & $0.8 \%$ & $5.3 \%$ & $0.8 \%$ & $0.0 \%$ & $7.5 \%$ & $100 \%$ \\
\hline \multirow[t]{2}{*}{1 a 3 anos } & 20 & 325 & 103 & 14 & 1 & 22 & 1 & & 14 & 504 \\
\hline & $4.0 \%$ & $64.5 \%$ & $20.4 \%$ & $2.8 \%$ & $0.2 \%$ & $4.4 \%$ & $0.2 \%$ & $0.8 \%$ & $2.8 \%$ & $100 \%$ \\
\hline \multirow[t]{2}{*}{$<1$ ano } & 32 & 199 & & & & 11 & 0 & & 16 & 331 \\
\hline & $9.7 \%$ & $60.1 \%$ & $19.3 \%$ & $1.2 \%$ & $0.6 \%$ & $3.3 \%$ & $0.0 \%$ & $0.9 \%$ & $4.8 \%$ & $100 \%$ \\
\hline \multirow[t]{2}{*}{ Total } & 60 & 639 & 193 & 23 & & 41 & 2 & 7 & 43 & 1012 \\
\hline & $5.9 \%$ & $63.1 \%$ & $19.1 \%$ & $2.3 \%$ & $0.4 \%$ & $4.1 \%$ & $0.2 \%$ & $0.7 \%$ & $4.2 \%$ & $100 \%$ \\
\hline
\end{tabular}

Evidencia-se que $77 \%$ dos ACS das equipes implantadas há mais de 5 anos apresentam vinculação trabalhista estável e que nas equipes implantadas há menos de 5 anos este percentual é de $69 \%$. A CLT é a forma preferencial de contratação em todas faixas de tempo estudadas, variando de cerca de $60 \%$ para os ACS das equipes implantadas há menos de 1 ano a $69 \%$ nas equipes com 5 anos ou mais de implantação. Observa-se também que a forma de contrato temporário é a segunda opção de vinculação dos ACS, sendo aproximadamente $20 \%$ das equipes implantadas há menos de 1 ano. Os ACS das equipes implantadas entre 1 a 3 e 3 a 5 anos apresentam maior percentual de vinculação precária, $8 \%$ e 10\%, respectivamente. 
Tabela 6.69 - Porte dos municípios e vínculo trabalhista dos ACS nas ESF

\begin{tabular}{|c|c|c|c|c|c|c|c|c|c|c|}
\hline \multicolumn{11}{|c|}{ Vínculo trabalhista dos ACS nas ESF } \\
\hline 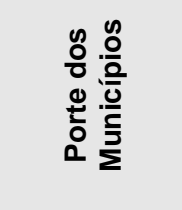 & 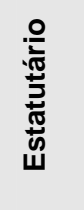 & $\stackrel{5}{0}$ & 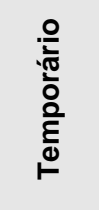 & 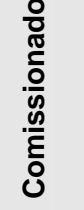 & $\begin{array}{l}\frac{\pi}{0} \\
\frac{\mathscr{0}}{0}\end{array}$ & 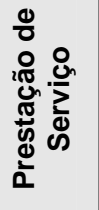 & $\begin{array}{l}\frac{0}{\pi} \\
\frac{\pi}{0} \\
\frac{0}{0} \\
0 \\
ن\end{array}$ & 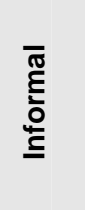 & 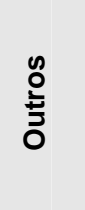 & 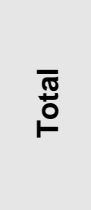 \\
\hline \multirow[t]{2}{*}{$<20$ mil } & 15 & 220 & 41 & 8 & 1 & 6 & 1 & 3 & 16 & 311 \\
\hline & $4.8 \%$ & $70.7 \%$ & $13.2 \%$ & $2.6 \%$ & $0.3 \%$ & $1.9 \%$ & $0.3 \%$ & $1.0 \%$ & $5.1 \%$ & $100 \%$ \\
\hline \multirow[t]{2}{*}{20 a 50 mil } & & 125 & 29 & 4 & & 4 & 0 & 1 & 5 & 178 \\
\hline & $4.5 \%$ & $70.2 \%$ & $16.3 \%$ & $2.2 \%$ & $1.1 \%$ & $2.2 \%$ & $0.0 \%$ & $0.6 \%$ & $2.8 \%$ & $100 \%$ \\
\hline \multirow[t]{2}{*}{50 a $100 \mathrm{mil}$} & & & & & & 1 & & 0 & 6 & 134 \\
\hline & $6.0 \%$ & $59.7 \%$ & $27.6 \%$ & $0.7 \%$ & $0.0 \%$ & $0.7 \%$ & $0.7 \%$ & $0.0 \%$ & $4.5 \%$ & $100 \%$ \\
\hline \multirow[t]{2}{*}{$>100 \mathrm{mil}$} & 30 & 219 & 87 & 10 & & 30 & & 3 & 16 & 396 \\
\hline & $7.6 \%$ & $55.3 \%$ & $22.0 \%$ & $2.5 \%$ & $0.3 \%$ & $7.6 \%$ & $0.0 \%$ & $0.8 \%$ & $4.0 \%$ & $100 \%$ \\
\hline \multirow[t]{2}{*}{ Total } & 61 & 644 & 194 & & & 41 & & 7 & 43 & 1019 \\
\hline & $6.0 \%$ & $63.2 \%$ & $19.0 \%$ & $2.3 \%$ & $0.4 \%$ & $4.0 \%$ & $0.2 \%$ & $0.7 \%$ & $4.2 \%$ & $100 \%$ \\
\hline
\end{tabular}

$\mathrm{n}=1043$

O percentual de contratação estável apresenta-se maior nas equipes dos municípios de menor porte, diminuindo de $75 \%$ para $63 \%$ nas equipes dos municípios de maior porte. Já a forma de contratação temporária é aproximadamente $28 \%$ das equipes dos municípios de porte entre 50 a 100 mil, e $22 \%$ das equipes dos municípios maiores que 100 mil habitantes. $8 \%$ dos ACS das ESF dos municípios de porte maior que 100 mil habitantes têm contratos em regime de Prestação de Serviço.

\subsection{Faixa salarial dos ACS das ESF}

Tabela 6.70 - Salário dos ACS das ESF

\begin{tabular}{|c|c|c|}
\hline \multicolumn{3}{|c|}{ Salário dos ACS em reais } \\
\hline $\mathbf{R} \$$ & $\mathbf{N}^{\circ}$ & $\%$ \\
\hline$<251$ & 241 & 23.8 \\
\hline $250-300$ & 108 & 10.7 \\
\hline $300-350$ & 263 & 26.0 \\
\hline $350-450$ & 291 & 28.8 \\
\hline$>450$ & 109 & 10.8 \\
\hline Total & 1012 & 100,0 \\
\hline
\end{tabular}


Aproximadamente $64 \%$ dos ACS percebem pelo menos 300 reais e $35 \%$ deles menos de 300 reais.

Tabela 6.71 - Porte dos municípios e salário dos ACS das ESF (salário bruto em reais)

\begin{tabular}{|c|c|c|c|c|c|c|c|}
\hline \multirow[b]{2}{*}{ Porte dos municípios } & & \multicolumn{6}{|c|}{ Salário dos ACS (em reais) } \\
\hline & & $\%<251$ & $\begin{array}{c}\% 250- \\
300\end{array}$ & $\begin{array}{c}\% 300- \\
350\end{array}$ & $\begin{array}{c}\% 350- \\
450\end{array}$ & $\%>450$ & Total \\
\hline \multirow[t]{2}{*}{$<20$ mil } & $\mathrm{n}$ & 133 & 43 & 98 & 33 & 2 & 309 \\
\hline & $\%$ & 43.0 & 13.9 & 31.7 & 10.7 & 0.6 & 100,0 \\
\hline \multirow[t]{2}{*}{$20-50$ mil } & $\mathrm{n}$ & 45 & 19 & 79 & 32 & 1 & 176 \\
\hline & $\%$ & 25.6 & 10.8 & 44.9 & 18.2 & 0.6 & 100,0 \\
\hline \multirow[t]{2}{*}{$50-100 \mathrm{mil}$} & $\mathrm{n}$ & 27 & 14 & 52 & 33 & 4 & 130 \\
\hline & $\%$ & 20.8 & 10.8 & 40.0 & 25.4 & 3.1 & 100,0 \\
\hline \multirow[t]{2}{*}{$>100 \mathrm{mil}$} & $\mathrm{n}$ & 36 & 32 & 34 & 193 & 102 & 397 \\
\hline & $\%$ & 9.1 & 8.1 & 8.6 & 48.6 & 25.7 & 100,0 \\
\hline \multirow[t]{2}{*}{ Total } & $\mathrm{n}$ & 241 & 108 & 263 & 291 & 109 & 1012 \\
\hline & $\%$ & 23.8 & 10.7 & 26.0 & 28.8 & 10.8 & 100,0 \\
\hline
\end{tabular}

$\mathrm{n}=1043$

A maioria dos ACS das equipes dos municípios de maior porte percebe pelo menos de 350 reais, este percentual diminui do maior para o menor porte variando entre $74 \%$ a $11 \%$. Já $88 \%$ dos ACS dos municípios de menor porte percebem menos de 350 reais, sendo $43 \%$ deles menos de 250 reais. Este percentual diminui nos demais municípios, variando entre $26 \%$ nos municípios com população entre 20 a 50 mil habitantes a $9 \%$ nos com mais de 100 mil.

Tabela 6.72 - Tempo de implantação e salário dos ACS das ES (salário bruto em reais)

\begin{tabular}{|c|c|c|c|c|c|c|c|}
\hline \multirow{2}{*}{$\begin{array}{l}\text { Tempo de } \\
\text { implantação }\end{array}$} & & \multicolumn{6}{|c|}{ Salário dos ACS (em reais) } \\
\hline & & $\%<251$ & $\%$ 250-300 & $\% 300-350$ & $\% 350-450$ & $\%>450$ & total \\
\hline 5 anos ou + & $\mathrm{n}$ & 4 & 2 & 8 & 25 & 3 & 42 \\
\hline & $\%$ & 9.5 & 4.8 & 19.0 & 59.5 & 7.1 & 100 \\
\hline 3 a 5 anos & $\mathrm{n}$ & 22 & 20 & 14 & 63 & 11 & 130 \\
\hline & $\%$ & 16.9 & 15.4 & 10.8 & 48.5 & 8.5 & 100 \\
\hline 1 a 3 anos & $\mathrm{n}$ & 122 & 52 & 171 & 120 & 39 & 504 \\
\hline & $\%$ & 24.2 & 10.3 & 33.9 & 23.8 & 7.7 & 100 \\
\hline$<1$ ano & $\mathrm{n}$ & 93 & 32 & 67 & 81 & 56 & 329 \\
\hline & $\%$ & 28.3 & 9.7 & 20.4 & 24.6 & 17.0 & 100 \\
\hline Total & $\begin{array}{l}n \\
\%\end{array}$ & $\begin{array}{r}241 \\
24.0\end{array}$ & $\begin{array}{r}106 \\
105\end{array}$ & $\begin{array}{r}260 \\
25.9\end{array}$ & $\begin{array}{r}289 \\
28.8\end{array}$ & $\begin{array}{r}109 \\
108\end{array}$ & $\begin{array}{r}1005 \\
100\end{array}$ \\
\hline
\end{tabular}


Nota-se que nas equipes implantadas há mais tempo um maior percentual de ACS percebe mais de 350 reais. Este percentual decresce das equipes mais antigas para as mais recentes, variando entre $67 \%$ a $42 \%$, exceto nas equipes implantadas entre 1 e 3 anos, que apresentam $32 \%$. Observa-se também nas equipes implantadas há mais tempo que $33 \%$ dos ACS percebem menos de 350 reais e este percentual aumenta nas equipes de implantação mais recente, variando de $33 \%$ a $58 \%$, exceto nas implantadas entre 1 e 3 anos com percentual de $68 \%$.

\subsubsection{Caracterização dos ACS das ESF}

\subsection{Número de ACS por ESF}

Apenas $5 \%$ das equipes possuem menos de 4 ACS, sendo que a maioria das equipes possui mais de 4 ACS, estando de acordo com o parâmetro recomendado pelo MS (Tabela 6.63).

Evidencia-se que o maior percentual de equipes com menos de 4 ACS pode ser observado nas equipes dos municípios de porte entre 50 a 100 mil habitantes, enquanto que o maior percentual de equipes com mais de 4 ACS pode ser verificado nos municípios de maior porte (Tabela 6.64).

Chama a atenção que nas equipes mais antigas o percentual de equipes com menos de 4 ACS é maior, da mesma forma há um aumento das equipes com 6 ACS nas equipes implantadas há menos de um ano (Tabela 6.65). Em relação aos Estados da região Sudeste, observa-se que o 
Estado de São Paulo apresenta o maior número de equipes com 4 a 6 ACS, sendo que todos os Estados do Sudeste apresentam maior percentual que a média nacional (56\%). Entretanto, em relação às equipes com de mais 6 ACS, o Estado de São Paulo apresenta o menor percentual da região Sudeste, e também menor freqüência que a média nacional (cerca de 38\%). (AVALIAÇÃO NORMATIVA - MS)

6.2.5.8.2 Carga horária trabalhada, cumprida e vinculação trabalhista dos ACS das ESF

Evidencia-se que quase $100 \%$ dos ACS são contratados e cumprem 40 horas de trabalho semanal (Tabela 6.66). Entre os profissionais das equipes, os ACS são os que mais cumprem a jornada de trabalho. Não se observa diferença acentuada deste percentual entre o estado de São Paulo, os demais Estados do sudeste e a média nacional observada (AVALIAÇÃO NORMATIVA - MS)

Cerca de $67 \%$ dos ACS possuem contrato de trabalho estável, sendo $62 \%$ nos moldes da CLT. Chama a atenção que quase $1 / 3$ deles apresenta vinculação trabalhista não estável, $18 \%$ na forma de contrato temporário, e $16 \%$ nas formas mais precárias (comissionado, bolsa, prestação de serviço, cooperado, contrato informal incluindo outros) (Tabela 6.67). Cabe ressaltar que há uma maior precarização no contrato de trabalho dos ACS que nos demais profissionais das equipes, sendo os únicos que apresentam "bolsa" como modalidade de contratação. 
Em relação aos Estados do Sudeste, evidencia-se que o Estado de São Paulo apresenta cerca de 2 vezes menos contratos irregulares que a média dos demais Estados e que a média nacional, ambos aproximadamente $72 \%$. (AVALIAÇÃO NORMATIVA - MS)

Em relação ao tempo de implantação das equipes, verifica-se que os ACS das equipes implantadas há mais de 5 anos apresentam maior percentual de vinculação trabalhista estável, sendo que este percentual diminui com o tempo de implantação das equipes, variando de $77 \%$ a $70 \%$ (Tabela 6.68). A vinculação CLT é a forma preferencial de contratação, variando de $60 \%$ para os ACS das equipes implantadas há menos de 1 ano a cerca de $69 \%$ nas equipes com 5 anos ou mais de implantação. Os ACS das equipes mais recentes e das mais antigas, $10 \%$ e $9 \%$ respectivamente, são estatutários. Evidencia-se ainda que o contrato temporário é a segunda opção de vinculação dos ACS, sendo maior, aproximadamente $20 \%$ nas equipes implantadas há menos de 3 anos (Tabela 6.68).Outro fato é que os ACS com contratos mais precários, $17 \%$ das equipes implantadas entre 3 e 5 anos, sendo em torno de $11 \%$ nas demais faixas (Tabela 6.68).

Chama a atenção que os ACS das equipes dos municípios de menor porte apresentam maior percentual de vinculação estável, que diminui de $75 \%$ para $63 \%$ nas equipes dos municípios de maior porte (Tabela 6.69).

As modalidades não estáveis podem ser mais notadas nos municípios de maior porte, sendo que o maior percentual de contrato 
temporário, aproximadamente $23 \%$, é verificado nas equipes dos municípios de porte maior que 50 mil habitantes. Evidencia-se que $8 \%$ dos ACS das equipes dos municípios com mais de 100 mil habitantes possuem contratos para prestação de serviço (Tabela 6.69).

\subsection{Faixa salarial dos ACS das ESF}

Aproximadamente $2 / 3$ dos ACS percebem pelo menos 300 reais e $1 / 3$ deles menos de 300 reais (Tabela 6.70 ). Verifica-se que o número de ACS com salário de pelo menos 300 reais no Estado de São Paulo é mais de 4 vezes maior que os Estados do Sudeste, e quase 7 vezes maior que a média nacional (10\%). Já o percentual de ACS que percebem até 250 reais é 4 vezes menor que os estados do Sudeste e 3 vezes a média nacional que é de 78\%. (AVALIAÇÃO NORMATIVA - MS)

A maioria dos ACS das equipes dos municípios de maior porte percebe pelo menos de 350 reais, variando entre $74 \%$ a $11 \%$ do maior para o menor. Já $88 \%$ dos ACS dos municípios de menor porte percebem menos de 350 reais, sendo $43 \%$ deles menos de 250 reais (Tabela 6.71).

Nota-se que nas equipes implantadas há mais tempo, um maior percentual de ACS percebe mais de 350 reais, variando entre $67 \%$ nas equipes mais antigas a $42 \%$ para as mais recentes, exceto nas equipes implantadas entre 1 e 3 anos, que apresentam 32\%. Observa-se também nas equipes implantadas há mais tempo que $1 / 3$ dos ACS percebe menos de 350 reais e este percentual aumenta nas equipes de implantação mais 
recente, variando de $33 \%$ a $58 \%$, exceto nas implantadas entre 1 e 3 anos com percentual de 68\% (Tabela 6.72).

\subsection{Ações desenvolvidas pelos profissionais das ESF}

6.3.1 Atividades realizadas pelos médicos dentre as previstas para as ESF

6.3.1.1 Atividades realizadas pelos médicos das ESF

Tabela 6.73 - Atividades realizadas pelos médicos dentre as previstas para as ESF

\begin{tabular}{l|c|r|r|r}
\hline \multirow{2}{*}{ Atividades realizadas pelos médicos } & Sim & \multicolumn{1}{c|}{ Não } & \multicolumn{1}{c}{$\begin{array}{c}\text { Sem } \\
\text { informação }\end{array}$} & \multirow{2}{*}{ Total } \\
\cline { 2 - 4 } & \multicolumn{1}{c|}{$\%$} & \multicolumn{1}{c}{$\%$} & \multicolumn{1}{c}{$\%$} & \\
\hline Reunião Comunidade & $41.4 \%$ & $50.0 \%$ & $8.5 \%$ & 1043 \\
Grupos Educativos & $63.8 \%$ & $27.1 \%$ & $9.1 \%$ & 1043 \\
Reunião Equipe & $82.5 \%$ & $9.1 \%$ & $8.4 \%$ & 1043 \\
Visita Domiciliar & $86.9 \%$ & $5.0 \%$ & $8.1 \%$ & 1043 \\
Ginecologia / Obstetrícia & $71.0 \%$ & $20.1 \%$ & $8.8 \%$ & 1043 \\
Atividades Clínicas Básicas & $76.0 \%$ & $15.2 \%$ & $8.7 \%$ & 1043 \\
Pediatria & $86.3 \%$ & $4.9 \%$ & $8.8 \%$ & 1043 \\
Clínica Médica & $90.6 \%$ & $0.8 \%$ & $8.6 \%$ & 1043 \\
\hline
\end{tabular}

Do conjunto de atividades comuns que devem ser realizadas por todos os profissionais das equipes, mais de $82 \%$ dos médicos realizam visitas domiciliares e participam da reunião de equipe, $64 \%$ desenvolvem grupos educativos e apenas $41 \%$ participam de reuniões na comunidade. Em relação ao atendimento nas clínicas básicas, 90\% realizam consultas em clínica médica.

Ressalta-se que cerca de $20 \%$ dos médicos referem não realizar consultas em ginecologia-obstetrícia e 5\% em pediatria. 
Tabela 6.74 - Realização das atividades previstas para os médicos nas ESF segundo classificação adotada

\begin{tabular}{|c|c|c|}
\hline $\begin{array}{l}\text { Atividades realizadas pelos } \\
\text { médicos }\end{array}$ & $\mathbf{N}^{\circ}$ & $\%$ \\
\hline Adequada & 317 & 30,4 \\
\hline Suficiente & 248 & 23,8 \\
\hline Mínimo & 354 & 33,9 \\
\hline Insuficiente & 124 & 11,9 \\
\hline Total & 1043 & 100,0 \\
\hline
\end{tabular}

Aproximadamente $54 \%$ dos médicos das equipes realizam atividades classificadas como pelo menos suficiente em relação ao proposto pelas diretrizes do programa. Chama a atenção que $12 \%$ realizam atividades classificadas como insuficiente para o PSF.

Tabela 6.75 - Tempo de implantação das equipes e realização das atividades previstas para os médicos nas ESF segundo classificação adotada

\begin{tabular}{|c|c|c|c|c|c|}
\hline \multicolumn{6}{|c|}{ Atividades realizadas pelos médicos das ESF } \\
\hline Tempo implantação & Adequada & Suficiente & Mínimo & Insuficiente & Total \\
\hline 5 anos ou + & 23 & 11 & 8 & 3 & 45 \\
\hline & $51.1 \%$ & $24.4 \%$ & $17.8 \%$ & $6.7 \%$ & $4.3 \%$ \\
\hline 3 a 5 anos & 62 & 26 & 33 & 16 & 137 \\
\hline & $45.3 \%$ & $19.0 \%$ & $24.1 \%$ & $11.7 \%$ & $13.2 \%$ \\
\hline 1 a 3 anos & 151 & 127 & 182 & 55 & 515 \\
\hline & $29.3 \%$ & $24.7 \%$ & $35.3 \%$ & $10.7 \%$ & $49.8 \%$ \\
\hline$<1$ ano & 79 & 82 & 130 & 47 & 338 \\
\hline & $23.4 \%$ & $24.3 \%$ & $38.5 \%$ & $13.9 \%$ & $32.7 \%$ \\
\hline Total & $\begin{array}{r}315 \\
30.4 \%\end{array}$ & $\begin{array}{r}246 \\
23.8 \%\end{array}$ & $\begin{array}{r}353 \\
34.1 \%\end{array}$ & $\begin{array}{r}121 \\
11.7 \%\end{array}$ & 1035 \\
\hline
\end{tabular}

$\mathrm{n}=1043$

Evidencia-se que os médicos das equipes implantadas há mais tempo apresentam maior percentual de classificação pelo menos suficiente de realização das atividades proposta para eles no PSF, variando de $75 \%$ para as equipes implantadas há 5 anos ou mais, a $48 \%$ para as equipes implantadas há menos de 1 ano. 
Tabela 6.76 - Porte dos municípios e realização das atividades previstas para os médicos nas ESF segundo classificação adotada

\begin{tabular}{l|r|r|r|r|r}
\hline \multicolumn{7}{c}{ Atividades realizadas pelos } & médicos das ESF \\
\hline \multicolumn{1}{c}{$\begin{array}{c}\text { Porte dos } \\
\text { municípios }\end{array}$} & Adequada & Suficiente & Mínimo & Insuficiente & \multicolumn{1}{c}{ Total } \\
\hline$<20$ mil & 58 & 80 & 140 & 40 & 318 \\
& $18.2 \%$ & $25.2 \%$ & $44.0 \%$ & $12.6 \%$ & $30.5 \%$ \\
& 51 & 39 & 72 & 17 & 179 \\
50 a 50 mil 100 mil & $28.5 \%$ & $21.8 \%$ & $40.2 \%$ & $9.5 \%$ & $17.2 \%$ \\
& 33 & 48 & 42 & 14 & 137 \\
$>100$ mil & $24.1 \%$ & $35.0 \%$ & $30.7 \%$ & $10.2 \%$ & $13.1 \%$ \\
& 175 & 81 & 100 & 53 & 409 \\
\hline Total & $42.8 \%$ & $19.8 \%$ & $24.4 \%$ & $13.0 \%$ & $39.2 \%$ \\
\hline
\end{tabular}

Nos municípios de maior porte o número de médicos das ESF que realizam atividades classificadas como pelo menos suficiente apresenta-se em maior quantidade, diminuindo nas equipes dos municípios de menor porte. Este percentual varia de $43 \%$ nas equipes dos municípios de porte menor que 20 mil habitantes a $62 \%$ nas equipes dos municípios com mais de 100 mil habitantes.

\subsubsection{Atendimentos clínicos realizados pelos médicos das ESF}

Tabela 6.77 - Tempo de implantação das ESF, porte dos municípios e realização de consultas em clínica médica pelos médicos das ESF

\begin{tabular}{|c|c|c|c|c|c|c|c|}
\hline \multirow{2}{*}{$\begin{array}{c}\text { Médico } \\
\text { Tempo implantação }\end{array}$} & \multicolumn{3}{|c|}{ Consulta clínica médica } & \multirow{2}{*}{$\begin{array}{c}\text { Médico } \\
\text { Porte municípios }\end{array}$} & \multicolumn{3}{|c|}{ Consulta clínica médica } \\
\hline & Não & Sim & Total & & Não & Sim & Total \\
\hline 5 anos ou + & $\begin{array}{r}1 \\
2.3 \%\end{array}$ & $\begin{array}{r}42 \\
97.7 \%\end{array}$ & $\begin{array}{r}43 \\
100 \%\end{array}$ & $<20$ mil & $\begin{array}{r}2 \\
0.7 \%\end{array}$ & $\begin{array}{r}291 \\
99.3 \%\end{array}$ & $\begin{array}{r}293 \\
100 \%\end{array}$ \\
\hline 3 a 5 anos & $\begin{array}{r}1 \\
0.8 \%\end{array}$ & $\begin{array}{r}125 \\
99.2 \%\end{array}$ & $\begin{array}{r}126 \\
100 \%\end{array}$ & 20 a 50 mil & $\begin{array}{r}1 \\
0 . \%\end{array}$ & 166 & $\begin{array}{r}167 \\
100 \%\end{array}$ \\
\hline 1 a 3 anos & & 475 & 478 & 50 a $100 \mathrm{mil}$ & 1 & 127 & 128 \\
\hline$<1$ ano & $\begin{array}{r}0.6 \% \\
3 \\
1.0 \%\end{array}$ & $\begin{array}{r}99.4 \% \\
303 \\
99.0 \%\end{array}$ & $\begin{array}{r}100 \% \\
306 \\
100 \%\end{array}$ & $>100 \mathrm{mil}$ & $\begin{array}{r}0.8 \% \\
4 \\
1.1 \%\end{array}$ & $\begin{array}{r}99.2 \% \\
361 \\
98.9 \%\end{array}$ & $\begin{array}{r}100 \% \\
365 \\
100 \%\end{array}$ \\
\hline Total & $\begin{array}{r}8 \\
0.8 \%\end{array}$ & $\begin{array}{r}945 \\
99.2 \%\end{array}$ & $\begin{array}{r}953 \\
100 \%\end{array}$ & Total & $\begin{array}{r}8 \\
0.8 \% \\
\end{array}$ & $\begin{array}{r}945 \\
99.2 \% \\
\end{array}$ & $\begin{array}{r}953 \\
100 \% \\
\end{array}$ \\
\hline
\end{tabular}

$\mathrm{n}=1043$ 
Não houve variação significativa na realização de consultas de clínica médica em relação ao tempo de implantação ou ao porte dos municípios.

Tabela 6.78 - Tempo de implantação das ESF, porte dos municípios e realização de consultas de pediatria pelos médicos das ESF

\begin{tabular}{|c|c|c|c|c|c|c|c|}
\hline \multicolumn{8}{|c|}{ Consulta clínica em pediatria-médico das ESF } \\
\hline Tempo implantação & Não & Sim & Total & Porte dos municípios & Não & Sim & Total \\
\hline \multirow[t]{2}{*}{5 anos ou +} & 3 & 39 & 42 & $<20$ mil & 25 & 268 & 293 \\
\hline & $7.1 \%$ & $92.9 \%$ & $100 \%$ & & $8.5 \%$ & $91.5 \%$ & $100 \%$ \\
\hline \multirow[t]{2}{*}{3 a 5 anos } & & 122 & 126 & 20 a $50 \mathrm{mil}$ & 10 & 157 & 167 \\
\hline & $3.2 \%$ & $96.8 \%$ & $100 \%$ & & $6.0 \%$ & $94.0 \%$ & $100 \%$ \\
\hline \multirow[t]{2}{*}{1 a 3 anos } & 21 & 457 & 478 & 50 a $100 \mathrm{mil}$ & 2 & 125 & 127 \\
\hline & $4.4 \%$ & $95.6 \%$ & $100 \%$ & & $1.6 \%$ & $98.4 \%$ & $100 \%$ \\
\hline \multirow[t]{2}{*}{$<1$ ano } & 23 & 282 & 305 & $>100 \mathrm{mil}$ & 14 & 350 & 364 \\
\hline & $7.5 \%$ & $92.5 \%$ & $100 \%$ & & $3.8 \%$ & $96.2 \%$ & $100 \%$ \\
\hline \multirow[t]{2}{*}{ Total } & 51 & 900 & 951 & Total & 51 & 900 & 951 \\
\hline & $5.4 \%$ & $94.6 \%$ & $100 \%$ & & $5.4 \%$ & $94.6 \%$ & $100 \%$ \\
\hline
\end{tabular}

$n=1043$

Não houve variação significativa da realização de consultas de pediatria pelos médicos das equipes em relação ao tempo de implantação ou ao porte dos municípios.

Tabela 6.79 - Tempo de implantação, porte dos municípios e realização de consultas de ginecologia e obstetrícia pelos médicos das ESF

$$
\text { Atendimento clínico em ginecologia e obstetrícia - médico das ESF }
$$

\begin{tabular}{|c|c|c|c|c|c|c|c|}
\hline Tempo implantação & Não & Sim & Total & Porte dos municípios & Não & Sim & Total \\
\hline \multirow[t]{2}{*}{5 anos ou +} & 6 & 36 & 42 & $<20$ mil & 104 & 189 & 293 \\
\hline & $14.3 \%$ & $85.7 \%$ & $100 \%$ & & $35.5 \%$ & $64.5 \%$ & $100 \%$ \\
\hline \multirow[t]{2}{*}{3 a 5 anos } & 20 & 106 & 126 & 20 a 50 mil & 25 & 142 & 167 \\
\hline & $15.9 \%$ & $84.1 \%$ & $100 \%$ & & $15.0 \%$ & $85.0 \%$ & $100 \%$ \\
\hline \multirow[t]{2}{*}{1 a 3 anos } & 94 & 384 & 478 & 50 a $100 \mathrm{mil}$ & 24 & 103 & 127 \\
\hline & $19.7 \%$ & $80.3 \%$ & $100 \%$ & & $18.9 \%$ & $81.1 \%$ & $100 \%$ \\
\hline \multirow[t]{2}{*}{$<1$ ano } & & 215 & 305 & $>100 \mathrm{mil}$ & 57 & 307 & 364 \\
\hline & $29.5 \%$ & $70.5 \%$ & $100 \%$ & & $15.7 \%$ & $84.3 \%$ & $100 \%$ \\
\hline Total & $\begin{array}{r}210 \\
22.1 \%\end{array}$ & $\begin{array}{r}741 \\
77.9 \%\end{array}$ & $\begin{array}{r}951 \\
100 \%\end{array}$ & Total & $\begin{array}{r}210 \\
22.1 \%\end{array}$ & $\begin{array}{r}741 \\
77.9 \%\end{array}$ & $\begin{array}{r}951 \\
100 \%\end{array}$ \\
\hline
\end{tabular}

$\mathrm{n}=1043$

Cerca de 1/3 dos médicos das equipes implantadas há menos de 1 ano não realiza atendimento clínico em ginecologia e obstetrícia. Este percentual diminui com o maior tempo de implantação, variando entre $30 \%$ 
nas equipes implantadas mais recentemente a $14 \%$ nas equipes implantadas há mais e 5 anos. Nota-se ainda que, os médicos dos municípios de menor porte realizam menos atendimentos em ginecologia/ obstetrícia que os médicos dos municípios de porte acima de 50 mil habitantes.

6.3.2 Atividades realizadas pelos médicos dentre as previstas para as ESF considerações

\subsubsection{Atividades realizadas pelos médicos das ESF}

Sobre as atividades que os médicos mais realizam, pelo menos $82 \%$ são consultas em clínica médica, consultas em pediatria, visitas domiciliares e reuniões de equipe. Já a atividade menos realizada (42\%) é a reunião com a comunidade (Tabela 6.73). (Brasil. MS, 2002)

Em geral verifica-se que aproximadamente $54 \%$ dos médicos das ESF realizam atividades pelo menos suficiente em relação ao esperado para os mesmos, segundo as diretrizes do PSF, e cerca de $1 / 3$ destes profissionais realiza atividades classificadas como insuficientes, segundo a mesma proposição (Tabela 6.74). Quando se considera o tempo de implantação das equipes e o porte dos municípios, evidencia-se que os médicos das equipes implantadas há mais tempo e das equipes dos municípios de maior porte apresentam maior percentual de realização de atividades classificadas como pelo menos suficiente (Tabelas 6.76 e 6.77). 
Parece haver uma relação, tanto entre tempo de implantação das equipes quanto o porte dos municípios, na realização das atividades esperadas para os médicos, sugerindo que o maior tempo de implantação pode ser um fator positivo no estabelecimento destas atividades e, que os municípios maiores apresentam mais condições de realização das mesmas, incluindo disponibilidade e seleção destes profissionais além de supervisão e capacitação. Estas são questões que devem ser mais bem estudadas, pois podem indicar formas de superação das dificuldades apresentadas.

\subsubsection{Atendimentos clínicos realizados pelos médicos das ESF}

Em relação aos atendimentos clínicos verifica-se que $90 \%$ dos médicos realizam consultas em clínica médica, cabendo destacar que $20 \%$ mencionam não realizar consultas em ginecologia / obstetrícia e cerca de $5 \%$ em pediatria (Tabela 6.73). Estes dados sugerem inadequação na participação dos médicos no PSF, principalmente relacionadas à atenção integral que deve ser prestada a todos os membros da família e comunidade, enquanto primeira fonte de atenção à saúde da população adstrita. Esta inadequação pode ser conseqüência, entre outros fatos, a aspectos ligados à própria graduação, que deveria propiciar uma formação mais integral e não tão especializada, ao maior tempo de atuação dos profissionais nas suas especialidades de origem, insuficiência de ações e modelos de capacitação, que dessem conta de vencer estas dificuldades além de uma maior priorização para a mesma. (BRASIL, MS, 2005) 
Não houve variação significativa na realização de consultas de clínica médica e pediatria em relação ao tempo de implantação ou ao porte dos municípios (Tabelas 6.78 e 6.79). Entretanto, em relação à realização de consultas em ginecologia e obstetrícia verifica-se um aumento das mesmas nas equipes implantadas há mais tempo, variando de $70 \%$ para as equipes com menos de 1 ano de implantação a $86 \%$ para as equipes com mais de 5 anos. Nota-se ainda que os médicos dos municípios de menor porte realizam menos atendimentos em ginecologia e obstetrícia que os médicos dos municípios de porte acima de 50 mil habitantes (Tabela 6.79).

Em relação aos demais Estados do Sudeste e à média nacional, verifica-se que o Estado de São Paulo apresenta percentuais inferiores na realização de atendimentos em clínica médica, pediatria e em ginecologia e obstetrícia. (AVALIAÇÃO NORMATIVA - MS)

Em geral, observa-se que em algumas situações o tempo de implantação atuou positivamente na adequação da realização das atividades esperadas para os médicos das equipes de saúde da família. Entretanto, fica evidente que é necessário implementar a participação deste profissional no programa saúde da família e qualificar esta participação. Esta deve ser a preocupação dos gestores e dos responsáveis pela capacitação das equipes. 
6.3.3 Atividades realizadas pelos enfermeiros dentre as previstas para as ESF

6.3.3.1 Atividades realizadas pelos enfermeiros das ESF

Tabela 6.80 - Atividades realizadas pelos enfermeiros dentre as previstas para as ESF

\begin{tabular}{l|r|r|r|r}
\multicolumn{1}{c}{ Atividades enfermeiros } & \multicolumn{1}{c|}{ Sim } & \multicolumn{1}{c|}{ Não } & \multicolumn{1}{c}{$\begin{array}{c}\text { Sem } \\
\text { informação }\end{array}$} & \multirow{2}{*}{ Total } \\
\cline { 2 - 4 } & \multicolumn{1}{c|}{$\%$} & \multicolumn{1}{c}{$\%$} & \multicolumn{1}{c}{$\%$} & \\
\hline Visita Domiciliar & 90,6 & 2,4 & 7 & 1043 \\
Reunião Equipe & 88,6 & 4 & 7,4 & 1043 \\
Grupos Educativos & 77 & 15,2 & 7,8 & 1043 \\
Treinamento ACS & 64,4 & 26,9 & 8,6 & 1043 \\
Treinamento Auxiliar Enfermagem & 55,7 & 36,2 & 8,1 & 1043 \\
Reunião Comunidade & 51,1 & 41,6 & 7,3 & 1043 \\
Pediatria & 68,7 & 23,7 & 7,6 & 1043 \\
Clinica Médica & 68,6 & 23,9 & 7,6 & 1043 \\
Ginecologia e Obstetrícia & 58,9 & 33,4 & 7,8 & 1043 \\
Atividades Clínicas Básicas & 57,9 & 34,4 & 7,7 & 1043 \\
\hline
\end{tabular}

As atividades mais realizadas pelos enfermeiros, acima de $89 \%$, são visitas domiciliares e reuniões de equipe. Observa-se que $77 \%$ dos enfermeiros realizam grupos educativos. A atividade menos realizada, cerca de $51 \%$, é a reunião com a comunidade. Entretanto, evidencia-se que apenas $56 \%$ dos enfermeiros realizam treinamento para os ACS e $64 \%$ para os auxiliares de enfermagem. Apenas $57 \%$ dos enfermeiros realizam o conjunto de atividades nas três clínicas básicas, sendo que, cerca de $68 \%$ deles realizam atividades clínicas em clínica médica e pediatria, e 58\% em ginecologia e obstetrícia.

Tabela 6.81 - Atividades realizadas pelos enfermeiros dentre as previstas para as ESF segundo classificação adotada

\begin{tabular}{l|r|r}
\hline \multicolumn{1}{c|}{ Atividades enfermeiros } & $\mathbf{N}^{\mathbf{2}}$ & \% \\
\hline Adequada & 244 & 23,4 \\
Suficiente & 194 & 18,6 \\
Mínimo & 336 & 32,2 \\
Insuficiente & 269 & 25,8 \\
\hline Total & 1043 & 100 \\
\hline
\end{tabular}


De maneira geral, apenas $42 \%$ dos enfermeiros realizam atividades pelo menos suficiente e $26 \%$ insuficiente em relação às atividades previstas para o PSF.

Tabela 6.82 - Porte dos municípios e realização das atividades previstas para os enfermeiros nas ESF segundo classificação adotada

\begin{tabular}{l|r|r|r|r|r}
\hline \multicolumn{1}{c}{ Porte dos municípios } & \multicolumn{6}{|c}{ Atividades dos enfermeiros } \\
\cline { 2 - 6 } & Adequada & Suficiente & \multicolumn{1}{c}{ Mínimo } & Insuficiente & \multicolumn{1}{c}{ Total } \\
\hline < 20 mil & 51 & 47 & 110 & 110 & 318 \\
20 a 50 mil & $16.0 \%$ & $14.8 \%$ & $34.6 \%$ & $34.6 \%$ & $100 \%$ \\
& 43 & 27 & 61 & 48 & 179 \\
50 a 100 mil & $24.0 \%$ & $15.1 \%$ & $34.1 \%$ & $26.8 \%$ & $100 \%$ \\
& 21 & 24 & 47 & 45 & 137 \\
> 100 mil & $15.3 \%$ & $17.5 \%$ & $34.3 \%$ & $32.8 \%$ & $100 \%$ \\
& 129 & 96 & 118 & 66 & 409 \\
\hline Total & $31.5 \%$ & $23.5 \%$ & $28.9 \%$ & $16.1 \%$ & $100 \%$ \\
\hline $\mathrm{n}=1043$ & 244 & 194 & 336 & 269 & 1043 \\
& $23.4 \%$ & $18.6 \%$ & $32.2 \%$ & $25.8 \%$ & $100 \%$ \\
\hline
\end{tabular}

Nota-se nos municípios de maior porte um maior percentual de equipes com enfermeiros que realizam atividades pelo menos suficiente das previstas pelo programa, sendo que este percentual diminui nos demais portes, variando entre $55 \%$ a $31 \%$. Já nos municípios com menos de 20 mil habitantes e nos municípios de porte entre 50 a 100 mil habitantes verificase o maior percentual de enfermeiros com atividades classificadas como insuficiente $35 \%$ e $33 \%$, respectivamente.

Tabela 6.83 - Tempo de implantação das equipes e realização das atividades previstas para os enfermeiros nas ESF segundo classificação adotada

\begin{tabular}{|c|c|c|c|c|c|}
\hline \multirow{2}{*}{ Tempo implantação } & \multicolumn{5}{|c|}{ Atividades dos enfermeiros } \\
\hline & Adequada & Suficiente & Mínimo & Insuficiente & Total \\
\hline 5 anos ou + & 18 & 12 & 9 & $\begin{array}{r}6 \\
123 \%\end{array}$ & 45 \\
\hline 3 a 5 anos & $\begin{array}{r}40.0 \% \\
46\end{array}$ & $\begin{array}{r}26.1 \% \\
27\end{array}$ & $\begin{array}{r}20.0 \% \\
36\end{array}$ & $\begin{array}{r}13.3 \% \\
28\end{array}$ & $\begin{array}{r}100 \% \\
137\end{array}$ \\
\hline & $33.6 \%$ & $19.7 \%$ & $26.3 \%$ & $20.4 \%$ & $100 \%$ \\
\hline 1 a 3 anos & 123 & 88 & 161 & 143 & 515 \\
\hline & $23.9 \%$ & $17.1 \%$ & $31.3 \%$ & $27.8 \%$ & $100 \%$ \\
\hline$<1$ ano & 57 & 66 & 127 & & 338 \\
\hline & $16.9 \%$ & $19.5 \%$ & $37.6 \%$ & $26.0 \%$ & $100 \%$ \\
\hline Total & $\begin{array}{r}244 \\
23.4 \%\end{array}$ & $\begin{array}{r}194 \\
18.6 \%\end{array}$ & $\begin{array}{r}336 \\
32.2 \%\end{array}$ & $\begin{array}{r}269 \\
25.8 \%\end{array}$ & $\begin{array}{r}1043 \\
100 \%\end{array}$ \\
\hline
\end{tabular}


Verifica-se nas equipes implantadas há 5 anos ou mais que cerca de $67 \%$ de enfermeiros realizam atividades pelo menos suficiente para o PSF. Este percentual diminui com o tempo de implantação, sendo aproximadamente $36 \%$ nas equipes implantadas há menos de 1 ano.

\subsubsection{Atendimentos clínicos realizados pelos enfermeiros das ESF}

Tabela 6.84 - Tempo de implantação das ESF, porte dos municípios e realização de atendimento clínico em clínica médica pelos enfermeiros das ESF

\begin{tabular}{l|r|r|r|l|r|r|r|r}
\hline \multicolumn{7}{c}{ Atendimento clínico em clínica médica realizado pelos enfermeiros das ESF } \\
\hline Tempo implantação & \multicolumn{1}{c|}{ não } & \multicolumn{1}{c|}{ sim } & Total & Porte dos municípios & \multicolumn{1}{c}{ não } & \multicolumn{1}{c}{ sim } & Total \\
\hline 5 anos ou + & 4 & 38 & 42 & $<20$ mil & 90 & 210 & 300 \\
& $9.5 \%$ & $90.5 \%$ & $100 \%$ & & $30.0 \%$ & $70.0 \%$ & $100 \%$ \\
3 a 5 anos & 27 & 97 & 124 & 20 a 50 mil & 52 & 114 & 166 \\
& $21.8 \%$ & $78.2 \%$ & $100 \%$ & & $31.3 \%$ & $68.7 \%$ & $100 \%$ \\
1 a 3 anos & 142 & 341 & 483 & 50 a $100 \mathrm{mil}$ & 43 & 83 & 126 \\
& $29.4 \%$ & $70.6 \%$ & $100 \%$ & & $34.1 \%$ & $65.9 \%$ & $100 \%$ \\
< 1 ano & 76 & 239 & 315 & $>100 \mathrm{mil}$ & 64 & 308 & 372 \\
& $24.1 \%$ & $75.9 \%$ & $100 \%$ & & $17.2 \%$ & $82.8 \%$ & $100 \%$ \\
\hline Total & 249 & 715 & 964 & Total & 249 & 715 & 964 \\
& $25.8 \%$ & $74.2 \%$ & $100 \%$ & & $25.8 \%$ & $74.2 \%$ & $100 \%$ \\
\hline
\end{tabular}

$\mathrm{n}=1043$

$70 \%$ a $78 \%$ dos enfermeiros das equipes implantadas há pelo menos 5 anos realizam atendimento clínico em clínica médica. Este percentual aumenta para $90 \%$ nas equipes implantadas há mais de 5 anos. Em relação ao porte dos municípios, observa-se que entre $30 \%$ a $34 \%$ dos enfermeiros das equipes dos municípios de porte menor que 100 mil habitantes não realizam atendimento clínico em clínica médica. Este percentual diminui para $17 \%$ nos municípios com mais de 100 mil habitantes. 
Tabela 6.85 - Tempo de implantação, porte dos municípios e realização de atendimento clínico em pediatria pelos enfermeiros das ESF

\begin{tabular}{|c|c|c|c|c|c|c|c|}
\hline \multicolumn{8}{|c|}{ Atendimento clínico em pediatria realizado pelos enfermeiros das ESF } \\
\hline Tempo implantação & Não & Sim & Total & Porte dos municípios & Não & Sim & Total \\
\hline \multirow[t]{2}{*}{5 anos ou +} & 2 & & 42 & $<20$ mil & 119 & 180 & 299 \\
\hline & $4.8 \%$ & $95.2 \%$ & $100 \%$ & & $39.8 \%$ & $60.2 \%$ & $100 \%$ \\
\hline \multirow[t]{2}{*}{3 a 5 anos } & 19 & 105 & 124 & 20 a 50 mil & 51 & 115 & 166 \\
\hline & $15.3 \%$ & $84.7 \%$ & $100 \%$ & & $30.7 \%$ & $69.3 \%$ & $100 \%$ \\
\hline \multirow[t]{2}{*}{1 a 3 anos } & 140 & 342 & 482 & 50 a $100 \mathrm{mil}$ & & & 126 \\
\hline & $29.0 \%$ & $71.0 \%$ & $100 \%$ & & $30.2 \%$ & $69.8 \%$ & $100 \%$ \\
\hline \multirow[t]{2}{*}{$<1$ ano } & 86 & 230 & 316 & $>100 \mathrm{mil}$ & & 334 & 373 \\
\hline & $27.2 \%$ & $72.8 \%$ & $100 \%$ & & $10.5 \%$ & $89.5 \%$ & $100 \%$ \\
\hline \multirow[t]{2}{*}{ Total } & 247 & 717 & 964 & Total & 247 & 717 & 964 \\
\hline & $25.6 \%$ & $74.4 \%$ & $100 \%$ & & $25.6 \%$ & $74.4 \%$ & $100 \%$ \\
\hline
\end{tabular}

$\mathrm{n}=1043$

A realização de atendimento clínico em clínica pediátrica pelos enfermeiros apresenta-se mais nas equipes com maior tempo de implantação, variando entre $71 \%$ a $73 \%$ nas equipes implantadas há menos de 3 anos, e 95\% nas implantadas há mais de 5 anos.

Em relação ao porte populacional observa-se que estas atividades estão presentes em cerca de $90 \%$ das equipes dos municípios com mais de 100 mil habitantes, e em cerca de $60 \%$ das equipes dos municípios de porte menor que 20 mil habitantes.

Tabela 6.86 - Porte dos municípios, tempo de implantação e realização de atendimento clínico em ginecologia e obstetrícia pelos enfermeiros das ESF

\begin{tabular}{|c|c|c|c|c|c|c|c|}
\hline \multicolumn{8}{|c|}{ Atendimento clínico em ginecologia e obstetrícia realizado pelos enfermeiros das ESF } \\
\hline Porte dos municípios & Não & Sim & Total & Tempo implantação & Não & Sim & Total \\
\hline$<20$ mil & 152 & 147 & 299 & 5 anos ou + & 6 & 36 & 42 \\
\hline & $50.8 \%$ & $49.2 \%$ & $100 \%$ & & 14.3 & $85.7 \%$ & $100 \%$ \\
\hline 20 a 50 mil & & 107 & 165 & 3 a 5 anos & 35 & 89 & 124 \\
\hline $500100 \mathrm{mil}$ & $35.2 \%$ & $64.8 \%$ & $100 \%$ & 1020 ? 2 & $28.2 \%$ & $71.8 \%$ & $\begin{array}{r}100 \% \\
480\end{array}$ \\
\hline 50 a $100 \mathrm{mil}$ & $\begin{array}{r}57 \\
45.2 \%\end{array}$ & $\begin{array}{r}69 \\
54.8 \%\end{array}$ & $\begin{array}{r}126 \\
100 \%\end{array}$ & 1 a 3 anos & $\begin{array}{r}166 \\
34.6 \%\end{array}$ & $\begin{array}{r}314 \\
65.4 \%\end{array}$ & $\begin{array}{r}480 \\
100 \%\end{array}$ \\
\hline$>100 \mathrm{mil}$ & & 291 & 372 & $<1$ ano & 141 & 175 & 316 \\
\hline & $21.8 \%$ & $78.2 \%$ & $100 \%$ & & $44 . .6 \%$ & $55.4 \%$ & $100 \%$ \\
\hline Total & $\begin{array}{r}348 \\
36.2 \%\end{array}$ & $\begin{array}{r}614 \\
63.8 \%\end{array}$ & $\begin{array}{r}962 \\
100 \%\end{array}$ & Total & $\begin{array}{r}348 \\
36.2 \%\end{array}$ & $\begin{array}{r}614 \\
63.8 \%\end{array}$ & $\begin{array}{r}962 \\
100 \%\end{array}$ \\
\hline
\end{tabular}


A realização de atendimentos em GO pelos enfermeiros aumenta com o porte dos municípios, sendo verificado um percentual de $49 \%$ para as equipes dos municípios com menos de 20 mil habitantes e $78 \%$ para as equipes dos municípios de porte acima de 100 mil habitantes.

Em relação ao tempo de implantação das equipes observa-se que $85 \%$ dos enfermeiros das equipes implantadas há mais de 5 anos realizam consultas em GO, havendo uma diminuição deste percentual para $55 \%$ nas equipes com menos de 1 ano de implantação.

6.3.4 Atividades realizadas pelos enfermeiros dentre as previstas para as ESF - considerações

\subsubsection{Atividades realizadas pelos enfermeiros das ESF}

Das atividades previstas para os enfermeiros das ESF (atendimento clínico em clínica médica, pediatria e ginecologia / obstetrícia, reunião com a comunidade, reunião de equipe, atividades em grupos, treinamento de auxiliares de enfermagem e de ACS e visita domiciliar), das atividades mais realizadas, pelo menos $80 \%$ são visitas domiciliares e reuniões de equipe. (Tabela 6.80). (BRASIL, MS, 2002; BRASIL, MS, 2006). Da mesma maneira que o observado para os médicos, apenas metade dos enfermeiros das ESF participa de reunião com a comunidade. Outro ponto a ser destacado é que somente $55 \%$ dos enfermeiros realizam treinamento para os ACS, enquanto que $64 \%$ realizam para os auxiliares de enfermagem (Tabela 6.80). 
Cabe ressaltar que uma das atribuições específicas dos enfermeiros é o treinamento dos ACS e dos auxiliares de enfermagem, portanto, são preocupantes os baixos percentuais apresentados para esta atividade (BRASIL, MS, 2002)

Menos de 2/3 dos enfermeiros das ESF realizam atendimento clínico nas clínicas básicas. Estes achados podem ser, entre outros aspectos, além do despreparo de alguns enfermeiros para o papel esperado deles no PSF, também pelo fato do processo de trabalho tanto dos enfermeiros como dos demais profissionais da equipe ainda estarem em construção.

Chama a atenção que menos da metade dos enfermeiros das ESF realiza atividades pelo menos suficiente em relação às atividades previstas para eles no PSF (Tabela 6.81). Em relação ao tempo de implantação, verifica-se que esta condição pode ser mais observada (55\%) nos municípios de maior porte, sendo menor nos demais municípios (31\%-37\%), enquanto a classificação insuficiente ocorre mais nas equipes dos municípios com menos de 20 mil e com população entre 50 a 100 mil habitantes, sendo $35 \%$ e $36 \%$, respectivamente (Tabela 6.82).

Quanto ao tempo de implantação, observa-se que $2 / 3$ dos enfermeiros que realizam atividades pelo menos suficiente para o PSF, estão nas equipes implantadas há 5 anos ou mais. Este percentual diminui com o tempo de implantação, sendo aproximadamente $36 \%$ nas equipes implantadas há menos de 1 ano. Os achados sugerem, como verificado na 
realização destas atividades pelos médicos das ESF, a existência de uma relação positiva entre as mesmas e o maior tempo de implantação e o maior porte dos municípios, cabendo aqui as mesmas considerações (Tabela $6.83)$.

Em relação aos estados do Sudeste e a média nacional, observa-se que o Estado de São Paulo apresenta percentual maior de realização de participação em reunião de equipe (média nacional $=91 \%$ ) e um pouco maior em relação à realização de reunião com a comunidade (média nacional $=51 \%$ ) e em relação à visita domiciliar, apresenta freqüência semelhante (média nacional $=96 \%) .($ AVALIAÇÃO NORMATIVA - MS)

6.3.4.2 Atendimentos clínicos realizados pelos enfermeiros das ESF

Em relação às atividades clínicas verifica-se que menos de $2 / 3$ dos enfermeiros realizam atendimento nas três áreas básicas, sendo que $1 / 3$ não realiza atendimento em ginecologia obstetrícia e cerca de $24 \%$ em clínica médica (Tabela 6.80).(BRASIL, MS, 2005). Em relação à região Sudeste, o Estado de São Paulo apresenta freqüência semelhante de realização de atendimentos clínicos nas clínicas básicas e se situa acima da média nacional $(57 \%)$. Já em relação à realização de atendimento em clínica médica, o Estado de São Paulo apresenta freqüência semelhante à média nacional $(70 \%)$ e menor que o estado do Rio de Janeiro. (AVALIAÇÃO NORMATIVA - MS) 
Em relação ao atendimento em pediatria, o Estado de São Paulo apresenta valor semelhante à média das freqüências apresentadas pelos outros estados e inferior à média nacional de $77 \%$. Em relação aos atendimentos em ginecologia e obstetrícia o Estado de São Paulo apresenta freqüência menor que os Estados da região Sudeste e que a média nacional (75\%). (AVALIAÇÃO NORMATIVA - MS)

A maioria dos enfermeiros das equipes implantadas há mais de 5 anos realiza atendimento clínico em clínica médica, enquanto nas equipes implantadas há menos de 5 anos este percentual varia de $71 \%$ a $78 \%$. (Tabela 6.84). Em relação ao porte dos municípios, observa-se que entre $31 \%$ a $34 \%$ dos enfermeiros das equipes dos municípios com menos de 100 mil habitantes não realizam este atendimento, enquanto nas equipes dos municípios de porte acima de 100 mil habitantes a percentagem é menor que $20 \%$ (Tabela 6.84).

Os resultados mostram que a realização de atendimento clínico em pediatria pelos enfermeiros aumentou com o tempo de implantação das equipes, variando de $71 \%$ nas equipes mais recentes a $95 \%$ nas equipes implantadas pelo menos 5 anos (Tabela 6.85). Em relação ao porte populacional, observa-se que estas atividades estão presentes em cerca de 90\% das equipes dos municípios de porte acima de 100 mil habitantes, e entre $70 \%$ a $60 \%$ nas equipes dos municípios de porte menor que $100 \mathrm{mil}$ habitantes (Tabela 6.85). 
Quanto ao atendimento em ginecologia e obstetrícia pelos enfermeiros das ESF, verifica-se um aumento do mesmo conforme aumento do porte dos municípios, variando entre $49 \%$ para as equipes dos municípios de menor porte, a $78 \%$ para as equipes dos municípios de porte acima de 100 mil habitantes (Tabela 6.86). Em pouco mais da metade das equipes implantadas há menos de 1 ano os enfermeiros realizam atendimento clínico em ginecologia e obstetrícia e, o desempenho na realização desta atividade melhora nas equipes implantadas há mais tempo, variando entre $66 \%$ a $86 \%$ nas equipes implantadas entre 1 e 3 anos e nas implantadas pelo menos 5 anos respectivamente (Tabela 6.86).

6.3.5 Atividades realizadas pelos auxiliares de enfermagem dentre as previstas para as ESF

Tabela 6.87 - Atividades realizadas pelos auxiliares de enfermagem dentre as previstas para as ESF

\begin{tabular}{l|r|r|r|r}
\multicolumn{1}{c|}{$\begin{array}{c}\text { Atividades dos auxiliares } \\
\text { de enfermagem }\end{array}$} & \% Sim & \% Não & $\begin{array}{c}\text { \% } \\
\text { Sem informação }\end{array}$ & \multicolumn{1}{c}{ Total } \\
\hline Visita Domiciliar & 93,0 & 4,5 & 2,5 & 1043 \\
Reunião Comunidade & 42,7 & 54,8 & 2,5 & 1043 \\
Reunião Equipe & 90,9 & 6,6 & 2,5 & 1043 \\
Atividades Grupos & 64,4 & 33,0 & 2,6 & 1043 \\
\hline
\end{tabular}

A atividade mais realizada pelos auxiliares de enfermagem é a visita domiciliar (cerca de 93\%) e reunião de equipe (cerca de 91\%). Já as atividades de grupos e reunião com a comunidade são as menos realizadas, sendo que esta última é realizada por apenas $43 \%$ destes profissionais. 
Tabela 6.88 - Realização das atividades previstas para os auxiliares de enfermagem nas ESF segundo classificação adotada

\begin{tabular}{l|r|rr}
\hline $\begin{array}{c}\text { Atividades dos auxiliares de } \\
\text { enfermagem }\end{array}$ & $\mathbf{N}^{\circ}$ & \multicolumn{2}{c}{} \\
\hline Adequada & & 95 & 9,1 \\
Suficiente & 0 & & 0,0 \\
Mínimo & 578 & 55,4 \\
Insuficiente & 370 & 35,5 \\
Sem Informação & 0 & 0,0 \\
\hline Total & 1043 & 100 \\
\hline
\end{tabular}

Observa-se que apenas $9 \%$ dos auxiliares de enfermagem apresentam classificação adequada de realização das atividades previstas para eles no PSF, e que $36 \%$ apresentam classificação insuficiente. Além disto, chama a atenção a ausência da classificação suficiente.

Tabela 6.89 - Tempo de implantação, porte dos municípios e situação das atividades realizadas pelos auxiliares de enfermagem das ESF segundo classificação adotada

\begin{tabular}{|c|c|c|c|c|c|c|c|c|c|}
\hline \multicolumn{10}{|c|}{ Atividades dos auxiliares de enfermagem das ESF } \\
\hline 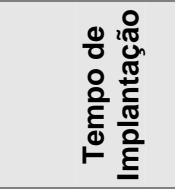 & $\begin{array}{l}\frac{\pi}{\frac{\pi}{\pi}} \\
\frac{\pi}{\frac{\pi}{\sigma}} \\
\frac{d}{\alpha}\end{array}$ & $\frac{\stackrel{0}{\xi}}{\stackrel{\underline{E}}{\Sigma}}$ & 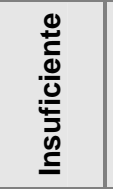 & 丞 & 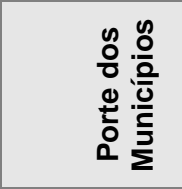 & $\begin{array}{l}\frac{\pi}{0} \\
\frac{\pi}{0} \\
\frac{0}{0} \\
\frac{0}{2}\end{array}$ & & 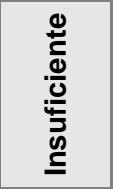 & हٓ \\
\hline 5 anos ou + & $\begin{array}{r}0 \\
0.0 \%\end{array}$ & $\begin{array}{r}27 \\
60.0 \%\end{array}$ & $\begin{array}{r}18 \\
40.0 \%\end{array}$ & $\begin{array}{r}45 \\
100 \%\end{array}$ & $<20$ mil & $\begin{array}{r}33 \\
10.4 \%\end{array}$ & $\begin{array}{r}198 \\
62.3 \%\end{array}$ & $\begin{array}{r}87 \\
27.4 \%\end{array}$ & $\begin{array}{r}318 \\
100 \%\end{array}$ \\
\hline 3 a 5 anos & & $\begin{array}{r}62 \\
45.3 \%\end{array}$ & $\begin{array}{r}70 \\
51 . \%\end{array}$ & $\begin{array}{r}137 \\
100 \%\end{array}$ & 20 a 50 mil & $\begin{array}{r}14 \\
7.8 \%\end{array}$ & $\begin{array}{r}114 \\
63.7 \%\end{array}$ & $\begin{array}{r}51 \\
28.5 \%\end{array}$ & $\begin{array}{r}179 \\
100 \%\end{array}$ \\
\hline 1 a 3 anos & $\begin{array}{r}59 \\
59 \\
11.5 \%\end{array}$ & $\begin{array}{r}288 \\
55.9 \%\end{array}$ & $\begin{array}{r}168 \\
326 \%\end{array}$ & $\begin{array}{r}515 \\
100 \%\end{array}$ & 50 a 100 mil & $\begin{array}{r}19 \\
139 \%\end{array}$ & $\begin{array}{r}74 \\
540 \%\end{array}$ & $\begin{array}{r}44 \\
321 \%\end{array}$ & $\begin{array}{r}137 \\
100 \%\end{array}$ \\
\hline$<1$ ano & $\begin{array}{r}30 \\
8.9 \%\end{array}$ & $\begin{array}{r}198 \\
58.6 \%\end{array}$ & $\begin{array}{r}110 \\
32.5 \%\end{array}$ & $\begin{array}{r}338 \\
100 \%\end{array}$ & $>100$ mil & $\begin{array}{r}29 \\
7.1 \%\end{array}$ & $\begin{array}{r}192 \\
46.9 \%\end{array}$ & $\begin{array}{r}188 \\
46.0 \% \\
\end{array}$ & $\begin{array}{r}409 \\
100 \%\end{array}$ \\
\hline Total & $\begin{array}{r}94 \\
9.1 \%\end{array}$ & $\begin{array}{r}575 \\
55.6 \% \\
\end{array}$ & $\begin{array}{r}366 \\
35.4 \% \\
\end{array}$ & $\begin{array}{r}1035 \\
100 \% \\
\end{array}$ & Total & $\begin{array}{r}95 \\
9.1 \% \\
\end{array}$ & $\begin{array}{r}578 \\
55.4 \% \\
\end{array}$ & $\begin{array}{r}370 \\
35.5 \% \\
\end{array}$ & $\begin{array}{r}1043 \\
100 \%\end{array}$ \\
\hline
\end{tabular}

Nota-se que, em nenhuma das equipes implantadas há 5 anos ou mais, os auxiliares de enfermagem realizam o conjunto de atividades esperadas e, o percentual de classificação pelo menos mínimo aumenta com a diminuição do tempo de implantação, variando de $60 \%$ a $68 \%$, exceto nos municípios com equipes implantadas entre 3 e 5 anos. Estas equipes 
também apresentam $51 \%$ dos auxiliares de enfermagem com realização insuficiente das atividades esperadas.

Em relação ao porte dos municípios, observa-se que o percentual de equipes com atividades classificadas como pelo menos mínimo aumenta do maior para o menor porte, variando entre $54 \%$ a $73 \%$. E também que o padrão insuficiente aumenta com o tamanho da população, sendo cerca de $28 \%$ para as equipes dos municípios de porte menor que 20 mil habitantes e, cerca de $46 \%$ nas equipes dos municípios de porte maior que 100 mil habitantes.

6.3.6 Atividades realizadas pelos auxiliares de enfermagem dentre as previstas para as ESF - considerações

Entre as atividades previstas para os auxiliares de enfermagem no PSF (visita domiciliar, reunião com comunidade, reunião de equipe, atividade em grupos), as atividades mais realizadas por eles, acima de $90 \%$, são as visitas domiciliares e as reuniões de equipe. Já as atividades de grupos e reuniões com a comunidade são as menos realizadas (esta última é realizada por apenas $43 \%$ destes profissionais) (Tabela 6.87). Juntamente com os médicos os auxiliares de enfermagem, são os profissionais das ESF que menos realizam reunião com comunidade e atividades em grupos. (BRASIL, MS, 2002)

Em relação à classificação adotada, ressalta-se a ausência da classificação suficiente na realização das atividades previstas no PSF. Cerca 
de $1 / 3$ dos auxiliares de enfermagem apresentam classificação insuficiente de realização destas atividades e apenas $9 \%$ apresentam classificação adequada, caracterizando um padrão bipolar adequado-mínimo de participação no PSF (Tabela 6.88).

Evidencia-se ainda que em nenhuma das equipes implantadas há 5 anos ou mais, os auxiliares de enfermagem realizam as atividades esperadas. Nas equipes implantadas há mais de 3 anos pode-se verificar o menor percentual, cerca de $49 \%$ de desempenho pelo menos mínimo na realização destas atividades. Nas demais equipes estes percentuais aumentaram das mais antigas para as mais recentemente implantadas, com uma variação entre $60 \%$ e 66 \% (Tabela 6.89).Em relação ao porte dos municípios observa-se que $54 \%$ dos auxiliares de enfermagem das equipes daqueles de maior porte, mais que 100 mil habitantes, apresentam desempenho pelo menos suficiente na realização das atividades previstas no PSF, sendo que este desempenho é maior nas equipes dos municípios de menor porte (Tabela 6.89). Todas estas questões observadas em relação à participação dos auxiliares nas ESF, novamente apontam a necessidade de revê-la, pois parece haver maior dificuldade para que os auxiliares de enfermagem atuem conforme o esperado no PSF. (SHIMIZU, DYTZ, LIMA, et al, 2004)

Um dos fatores positivos na adequação destas atividades parece ser o tempo de implantação, indicando, possivelmente, que os auxiliares de enfermagem podem se tornar mais capacitados no decorrer do tempo. Em 
relação ao porte dos municípios, um dos possíveis fatores da realização de atividades insuficiente pode estar relacionado ao tamanho do território de abrangência e, principalmente, de influência, que estão sob a responsabilização das equipes, uma vez que, se estas áreas forem muito extensas podem trazer atendimentos adicionais nas atividades tradicionais dos auxiliares de enfermagem. Outra questão pode ser o fato de que algumas equipes contam com menos de 2 auxiliares de enfermagem, fato que na prática tem se percebido não ser a melhor situação de alocação deste profissional nas ESF.

6.3.7 Atividades realizadas pelos ACS dentre as previstas para as ESF

Tabela 6.90 - Atividades realizadas pelos ACS dentre as previstas para as ESF

\begin{tabular}{l|r|r|r|r}
\multicolumn{1}{c|}{ Atividades dos ACS } & \% Sim & \multicolumn{1}{c}{ \% Não } & $\begin{array}{c}\text { \% Sem } \\
\text { informação }\end{array}$ & \multicolumn{1}{c}{ Total } \\
\hline Visita domiciliar & 99 & 0 & 1 & 1043 \\
Reunião comunidade & 54,6 & 44,1 & 1,3 & 1043 \\
Reunião equipe & 95,2 & 3,9 & 0,9 & 1043 \\
Atividade em grupo & 72,1 & 26,9 & 1 & 1043 \\
\hline
\end{tabular}

Pelo menos $95 \%$ dos ACS realizam visitas domiciliares e participam das reuniões de equipe, e $72 \%$ das atividades em grupo. A atividade menos realizada pelos ACS é a reunião com a comunidade, cerca de 55\%.

Tabela 6.91 - Realização das atividades previstas para os ACS nas ESF segundo classificação adotada

\begin{tabular}{l|r|r}
\multicolumn{1}{c|}{ Atividades ACS } & $\mathbf{N}^{\mathbf{2}}$ & \% \\
\hline Adequada & 473 & 45,3 \\
Mínimo & 539 & 51,7 \\
Insuficiente & 31 & 3,0 \\
\hline Total & 1043 & 100,0 \\
\hline
\end{tabular}


Pode-se verificar a classificação adequada para $46 \%$ dos ACS e o padrão mínimo para mais de $50 \%$. Nenhuma equipe apresenta classificação suficiente, e apenas $3 \%$ estão classificadas como insuficiente.

Tabela 6.92 - Tempo de implantação, porte dos municípios e situação das atividades realizadas pelos ACS nas ESF segundo classificação adotada

\begin{tabular}{|c|c|c|c|c|c|c|c|c|c|}
\hline \multicolumn{10}{|c|}{ Atividades dos ACS das ESF } \\
\hline 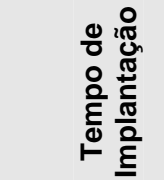 & $\begin{array}{l}\frac{\pi}{0} \\
\frac{\pi}{2} \\
\frac{0}{0} \\
\frac{d}{0}\end{array}$ & 冚 & 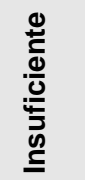 & $\begin{array}{l}\bar{\nwarrow} \\
\text { 음 }\end{array}$ & 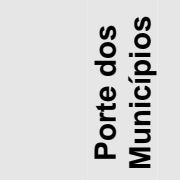 & $\begin{array}{l}\frac{\pi}{0} \\
\frac{\pi}{2} \\
\frac{0}{0} \\
\frac{\pi}{2}\end{array}$ & 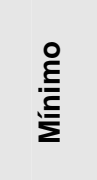 & 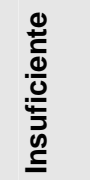 & $\begin{array}{l}\text { đూ } \\
\text { రீ }\end{array}$ \\
\hline \multirow[t]{2}{*}{5 anos ou +} & & & 0 & 45 & $<20 \mathrm{mil}$ & 112 & 194 & 12 & 318 \\
\hline & $22.2 \%$ & $77.8 \%$ & $0.0 \%$ & $100 \%$ & & $35.2 \%$ & $61.0 \%$ & $3.8 \%$ & $100 \%$ \\
\hline \multirow[t]{2}{*}{3 a 5 anos } & & 44 & & 137 & 20 a $50 \mathrm{mil}$ & 75 & & & 179 \\
\hline & $66.4 \%$ & $32.1 \%$ & $1.5 \%$ & $100 \%$ & & $41.9 \%$ & $54.7 \%$ & $3.4 \%$ & $100 \%$ \\
\hline \multirow[t]{2}{*}{1 a 3 anos } & 238 & 262 & 15 & 515 & 50 a $100 \mathrm{mil}$ & 59 & & & 137 \\
\hline & $46.2 \%$ & $50.9 \%$ & $2.9 \%$ & $100 \%$ & & $43.1 \%$ & $52.6 \%$ & $4.4 \%$ & $100 \%$ \\
\hline \multirow[t]{2}{*}{$<1$ ano } & 130 & 195 & 13 & 338 & $>100$ mil & 227 & 175 & 7 & 409 \\
\hline & $38.5 \%$ & $57.7 \%$ & $3.8 \%$ & $100 \%$ & & $55.5 \%$ & $42.8 \%$ & $1.7 \%$ & $100 \%$ \\
\hline Total & $\begin{array}{r}469 \\
45.3 \%\end{array}$ & $\begin{array}{r}536 \\
51.8 \%\end{array}$ & $\begin{array}{r}30 \\
2.9 \%\end{array}$ & $\begin{array}{r}1035 \\
100 \%\end{array}$ & Total & $\begin{array}{r}473 \\
45.3 \%\end{array}$ & $\begin{array}{r}539 \\
51.7 \%\end{array}$ & $\begin{array}{r}31 \\
3.0 \%\end{array}$ & $\begin{array}{r}1043 \\
100 \%\end{array}$ \\
\hline
\end{tabular}

Verifica-se nas equipes implantadas há menos de 1 ano o menor percentual de equipes com ACS com classificação adequada na realização das atividades esperadas no PSF. Este percentual apresenta aumento com o tempo de implantação, exceto nas equipes implantadas há pelo menos 5 anos, que apresentam o menor valor, cerca de $22 \%$. Nenhuma das ESF implantadas há 5 anos apresenta classificação insuficiente, enquanto que nas equipes implantadas há menos de 1 ano verifica-se o maior percentual $(4 \%)$.

Em relação ao porte dos municípios as ESF dos municípios menores que 20 mil habitantes apresentam menor percentual de ACS com 
classificação adequada, e que este percentual aumenta com o porte dos municípios, variando entre $35 \%$ a $56 \%$.

6.3.8 Atividades realizadas pelos ACS dentre as previstas para as ESF considerações

A maioria, pelo menos $95 \%$, dos ACS realiza visitas domiciliares e participa das reuniões de equipe, e $72 \%$ das atividades em grupo, enquanto apenas metade refere realizar reunião com a comunidade (Tabela 6.90). (BRASIL, MS, 2002; BRASIL, MS, 2002). Evidencia-se que praticamente metade dos ACS apresenta classificação adequada na realização das atividades que deveriam realizar no PSF e, metade o padrão mínimo (Tabela 6.91). Nenhuma equipe apresenta a classificação suficiente. Aqui, semelhantemente aos auxiliares de enfermagem, evidencia-se um padrão bipolar adequado-mínimo na realização de atividades esperadas no PSF. Cabe destacar que dentre os profissionais da equipe, os ACS são os que apresentam maior percentual de classificação adequada na realização de suas atividades no programa, seguidos dos auxiliares de enfermagem, e, também, o menor percentual de insuficiente, novamente seguidos pelos auxiliares de enfermagem.

Quanto ao tempo de implantação das ESF, observa-se que os ACS das equipes implantadas há mais de 5 anos apresentam o menor percentual (22\%) de classificação adequada na realização das atividades propostas pelas diretrizes do PSF (Tabela 6.92). Vê-se que este percentual diminuiu 
com o tempo de implantação das equipes e o porte dos municípios, em $38 \%$ das equipes implantadas há menos de 1 ano e, em $66 \%$ das equipes implantadas entre 3 e 5 anos (Tabela 6.92). Em relação ao porte dos municípios, nota-se nas equipes dos municípios com mais de 100 mil habitantes o maior percentual de classificação adequada na realização destas atividades, e que o mesmo diminui com o porte dos municípios, variando de $61 \%$ a $49 \%$ (Tabela 6.92 ).

Em geral parece que o maior tempo de implantação favorece o estabelecimento das atividades esperadas para os ACS nas equipes de PSF, e que também há uma maior facilidade para que este processo de trabalho seja mais adequado nos municípios de maior porte.

\subsubsection{Ações das ESF por área de atenção à saúde}

\subsubsection{Ações das ESF na saúde da mulher}

Tabela 6.93 - Ações das ESF na atenção à saúde da mulher

\begin{tabular}{|c|c|c|c|}
\hline Ações saúde da mulher & \% Sim & \% Não & $\%$ Total \\
\hline $\begin{array}{l}\text { Pré-natal (consulta médica) } \\
\text { Pré-natal (consulta de enfermagem) } \\
\text { Prevenção do câncer de colo de útero (coleta de material) } \\
\text { Planejamento familiar (ação educativa) } \\
\text { Planejamento familiar (oferta de métodos) } \\
\text { Tratamento de corrimento vaginal }\end{array}$ & $\begin{array}{r}73,1 \\
54 \\
80,9 \\
56,9 \\
74,6 \\
84,2\end{array}$ & $\begin{array}{r}26,9 \\
46 \\
19,1 \\
43,1 \\
25,4 \\
15,8\end{array}$ & $\begin{array}{l}100 \\
100 \\
100 \\
100 \\
100 \\
100\end{array}$ \\
\hline
\end{tabular}
$\mathrm{n}=1043$

$27 \%$ dos médicos e $46 \%$ dos enfermeiros das ESF não realizam consultas de pré-natal. As ações mais realizadas, pelo menos $80 \%$ são: 
tratamento de corrimento vaginal e coleta de material para prevenção de câncer ginecológico.

Tabela 6.94 - Tempo de implantação, porte dos municípios e realização de ações na saúde da mulher pelas ESF conforme classificação adotada

\begin{tabular}{|c|c|c|c|c|c|c|c|c|c|c|c|}
\hline \multicolumn{12}{|c|}{ Ações das ESF na saúde da mulher } \\
\hline 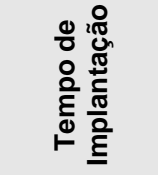 & $\begin{array}{l}\frac{\pi}{0} \\
\frac{\pi}{0} \\
\frac{0}{0} \\
\frac{d}{\alpha}\end{array}$ & 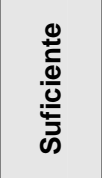 & 站 & 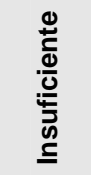 & $\begin{array}{l}\bar{\pi} \\
\text { రే }\end{array}$ & 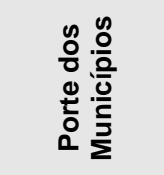 & $\begin{array}{l}\frac{\pi}{0} \\
\frac{\pi}{2} \\
\frac{0}{0} \\
\frac{d}{2}\end{array}$ & 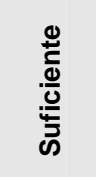 & : & 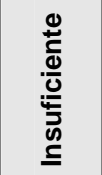 & $\begin{array}{l}\overline{\text { }} \\
\text { 아 }\end{array}$ \\
\hline \multirow[t]{2}{*}{5 anos ou +} & 13 & 13 & 17 & 2 & 45 & $<20 \mathrm{mil}$ & 42 & 72 & 125 & 79 & 318 \\
\hline & $28.9 \%$ & $28.9 \%$ & $37.8 \%$ & $4.4 \%$ & $100 \%$ & & $13.2 \%$ & $22.6 \%$ & $39.3 \%$ & $24.8 \%$ & $100 \%$ \\
\hline \multirow[t]{2}{*}{3 a 5 anos } & 46 & 41 & 37 & 13 & 137 & 20 a $50 \mathrm{mil}$ & 47 & 46 & 59 & 27 & 179 \\
\hline & $33.6 \%$ & $29.9 \%$ & $27.0 \%$ & $9.5 \%$ & $100 \%$ & & $26.3 \%$ & $25.7 \%$ & $33.0 \%$ & $15.1 \%$ & $100 \%$ \\
\hline \multirow[t]{2}{*}{1 a 3 anos } & 134 & 137 & 164 & 80 & 515 & 50 a $100 \mathrm{mil}$ & & 46 & 43 & & 137 \\
\hline & $26.0 \%$ & $26.6 \%$ & $31.8 \%$ & $15.5 \%$ & $100 \%$ & & $21.2 \%$ & $33.6 \%$ & $31.4 \%$ & $13.9 \%$ & $100 \%$ \\
\hline \multirow[t]{2}{*}{$<1$ ano } & & & 129 & & 338 & $>100 \mathrm{mil}$ & 125 & 105 & 124 & & 409 \\
\hline & $14.8 \%$ & $22.8 \%$ & $38.2 \%$ & $24.3 \%$ & $100 \%$ & & $30.6 \%$ & $25.7 \%$ & $30.3 \%$ & $13.4 \%$ & $100 \%$ \\
\hline \multirow[t]{2}{*}{ Total } & 243 & 268 & 347 & 177 & 1035 & Total & 243 & 269 & 351 & 180 & 1043 \\
\hline & $23.5 \%$ & $25.9 \%$ & $33.5 \%$ & 17.1 & $100 \%$ & & $23.3 \%$ & $25.8 \%$ & $33.7 \%$ & $17.3 \%$ & $100 \%$ \\
\hline
\end{tabular}

Nota-se que as equipes implantadas há menos de 1 ano apresentam maior percentual da classificação insuficiente na realização das ações de atenção à saúde da mulher, sendo que este percentual diminui nas equipes implantadas há mais tempo, variando entre $25 \%$ a $5 \%$. Observa-se que cerca de $36 \%$ das ESF dos municípios com porte menor que 20 mil habitantes realizam ações na saúde da mulher, classificadas como pelo menos suficientes, e que nos demais porte populacional, este percentual varia entre $52 \%$ a $56 \%$. 


\subsubsection{Ações das ESF na saúde da criança}

Tabela 6.95 - Ações das ESF na atenção à saúde da criança

\begin{tabular}{|c|c|c|c|}
\hline Ações saúde da criança & $\begin{array}{c}\% \\
\text { Sim }\end{array}$ & $\begin{array}{c}\% \\
\text { Não }\end{array}$ & $\begin{array}{c}\% \\
\text { Total }\end{array}$ \\
\hline Acompanhamento do crescimento e desenvolvimento $<2$ anos (consulta médica) & 71,1 & 28,9 & 100 \\
\hline Acor & 66,3 & 33,7 & 100 \\
\hline Assi & 85 & 15 & 100 \\
\hline Assi & 48,6 & 51,4 & 100 \\
\hline & & 23,4 & 100 \\
\hline Vigilâ & 72,2 & 27,8 & 100 \\
\hline Vigilância nı & 62 & 37,2 & 100 \\
\hline Vigilância nutricional - PCCN (suplementação alimentar) & 50,8 & 49,2 & 100 \\
\hline
\end{tabular}

$\mathrm{n}=1043$

As ações menos realizadas pelas ESF na atenção a saúde da criança, aproximadamente $50 \%$, são consultas de enfermagem na assistência às doenças prevalentes na infância e suplementação alimentar para vigilância nutricional. A atividade mais realizada, cerca de $85 \%$ são consultas médicas às doenças prevalentes da infância. As atividades realizadas por pelo menos $70 \%$ das equipes são: terapia de reidratação oral, consulta médica de acompanhamento e desenvolvimento de crianças menores de 2 anos e vigilância nutricional (identificação de casos).

Tabela 6.96 - Tempo de implantação, porte dos municípios e realização de ações na saúde da criança pelas ESF conforme classificação adotada

\begin{tabular}{|c|c|c|c|c|c|c|c|c|c|c|c|}
\hline \multicolumn{12}{|c|}{ Ações das ESF na saúde da criança } \\
\hline 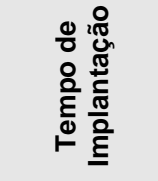 & $\begin{array}{l}\frac{\pi}{0} \\
\frac{\pi}{2} \\
\frac{0}{0} \\
\frac{0}{0}\end{array}$ & 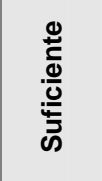 & 总 & 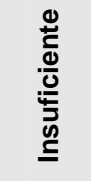 & 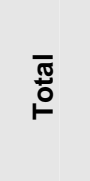 & 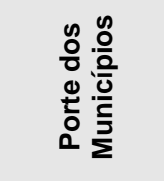 & $\begin{array}{l}\frac{\pi}{0} \\
\frac{\pi}{2} \\
\frac{0}{0} \\
\frac{d}{0} \\
\frac{0}{4}\end{array}$ & 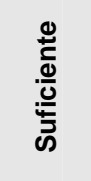 & 趇 & 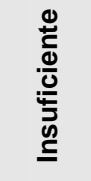 & $\begin{array}{l}\bar{\pi} \\
\text { ő }\end{array}$ \\
\hline \multirow[t]{2}{*}{5 anos ou +} & & & & 3 & 45 & $<20 \mathrm{mil}$ & 53 & 37 & 138 & 90 & 318 \\
\hline & $20.0 \%$ & $20.0 \%$ & $53.3 \%$ & $6.7 \%$ & $100 \%$ & & $16.7 \%$ & $11.6 \%$ & $43.4 \%$ & $28.3 \%$ & $100 \%$ \\
\hline \multirow[t]{2}{*}{3 a 5 anos } & & & & 18 & 137 & 20 a $50 \mathrm{mil}$ & 42 & & & 26 & 179 \\
\hline & $17.5 \%$ & $10.2 \%$ & $59.1 \%$ & $13.1 \%$ & $100 \%$ & & $23.5 \%$ & $16.8 \%$ & $45.3 \%$ & $14.5 \%$ & $100 \%$ \\
\hline \multirow[t]{2}{*}{1 a 3 anos } & 109 & 69 & 231 & 106 & 515 & 50 a $100 \mathrm{mil}$ & 28 & 26 & 63 & 20 & 137 \\
\hline & $21.2 \%$ & $13.4 \%$ & $44.9 \%$ & $20.6 \%$ & $100 \%$ & & $20.4 \%$ & $19.0 \%$ & $46.0 \%$ & $14.6 \%$ & $100 \%$ \\
\hline \multirow[t]{2}{*}{$<1$ ano } & & & 159 & & 338 & $>100 \mathrm{mil}$ & 67 & 50 & 215 & 77 & 409 \\
\hline & $13.6 \%$ & $14.5 \%$ & $47.0 \%$ & $24.9 \%$ & $100 \%$ & & $16.4 \%$ & $12.2 \%$ & $52.6 \%$ & $18.8 \%$ & $100 \%$ \\
\hline \multirow[t]{2}{*}{ Total } & 188 & 141 & 495 & 211 & 1035 & Total & 190 & 143 & 497 & 213 & 1043 \\
\hline & $18.2 \%$ & $13.6 \%$ & $47.8 \%$ & $20.4 \%$ & $100 \%$ & & $18.2 \%$ & $13.7 \%$ & $47.7 \%$ & $20.4 \%$ & $100 \%$ \\
\hline
\end{tabular}

$n=1043$ 
As equipes implantadas há mais de 5 anos e entre 1 e 3 anos apresentam percentuais maiores de realização de ações na saúde da criança, classificadas como pelo menos suficiente, enquanto a realização de atividades classificadas como insuficiente aumenta com a diminuição do porte populacional, variando entre $7 \%$ a $25 \%$.

As equipes dos municípios de porte entre 20 a 100 mil habitantes apresentam maior percentual de realização das ações previstas para atenção à criança no PSF. Já as equipes dos municípios de maior e menor portes apresentam maior percentual de classificação insuficiente na realização destas ações.

Tabela 6.97 - Realização de imunização segundo calendário básico do Programa Nacional de Imunização (PNI)

\begin{tabular}{l|r|rr}
\hline Imunização PNI & $\mathbf{N}^{\circ}$ & & \\
\hline Sim & & 576 & \\
Não & 447 & 42.23 \\
Sem informação & 20 & 1.92 \\
\hline Total & 1043 & 100.0 \\
\hline
\end{tabular}

Apenas 55\% das ESF referem a realização da imunização sua UBS.

6.3.9.3 Ações das ESF na saúde do adulto (controle da hipertensão arterial e diabetes)

Tabela 6.98 - Ações de controle da hipertensão arterial e do diabetes pelas ESF

\begin{tabular}{l|r|r|r}
\multicolumn{1}{c|}{ Ações saúde do adulto } & \% Sim & \% Não & \multicolumn{1}{c}{ \% Total } \\
\hline Controle do diabetes (diagnóstico) & 94,7 & 5,3 & 100 \\
Controle do diabetes (glicemia capilar) & 86,6 & 13,4 & 100 \\
Controle do diabetes (tratamento) & 96,3 & 3,7 & 100 \\
Controle da hipertensão (diagnóstico) & 95,9 & 4,1 & 100 \\
Controle da hipertensão (tratamento) & 96,1 & 3,9 & 100 \\
\hline
\end{tabular}


Pode-se verificar que as ações de controle dos diabetes e hipertensão arterial são realizadas por mais de $90 \%$ das equipes, exceto glicemia capilar, realizada por $86 \%$ das equipes.

Tabela 6.99 - Tempo de implantação, porte dos municípios e realização de ações de controle da hipertensão arterial e do diabetes pelas ESF segundo classificação adequada

\begin{tabular}{|c|c|c|c|c|c|c|c|c|c|c|c|}
\hline \multicolumn{12}{|c|}{ Ações das ESF no controle do diabetes e da hipertensão arterial } \\
\hline 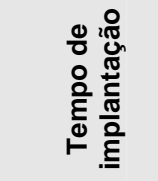 & $\begin{array}{l}\frac{\pi}{0} \\
\frac{\pi}{0} \\
\frac{0}{0} \\
\frac{d}{0}\end{array}$ & 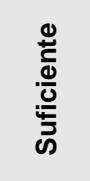 & & 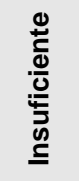 & $\begin{array}{l}\text { त्ञ } \\
\text { 음 }\end{array}$ & 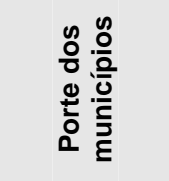 & $\begin{array}{l}\frac{\pi}{\frac{\pi}{0}} \\
\frac{\pi}{0} \\
\frac{0}{0} \\
\frac{0}{2}\end{array}$ & 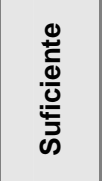 & & 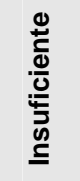 & त्ञ \\
\hline 5 anos ou + & $\begin{array}{r}41 \\
01\end{array}$ & 2 & 2 & 0 & $\begin{array}{r}45 \\
100 \%\end{array}$ & $<20$ mil & 232 & 61 & 9 & 16 & 318 \\
\hline 3 a 5 anos & $\begin{array}{r}91.1 \% \\
112\end{array}$ & $\begin{array}{r}4.4 \% \\
16\end{array}$ & $\begin{array}{r}4.4 \% \\
2\end{array}$ & $\begin{array}{r}0.0 \% \\
7\end{array}$ & $\begin{array}{r}100 \% \\
137\end{array}$ & 20 a $50 \mathrm{mil}$ & $\begin{array}{r}3.0 \% \\
142\end{array}$ & $\begin{array}{r}19.2 \% \\
27\end{array}$ & $\begin{array}{r}2.8 \% \\
4\end{array}$ & $\begin{array}{r}.0 \% \\
6\end{array}$ & $\begin{array}{r}100 \% \\
179\end{array}$ \\
\hline & $81.8 \%$ & $11.7 \%$ & $1.5 \%$ & $5.1 \%$ & $100 \%$ & & $79.3 \%$ & $15.1 \%$ & $2.2 \%$ & $3.4 \%$ & $100 \%$ \\
\hline 1 a 3 anos & 420 & & 10 & 30 & 515 & 50 a $100 \mathrm{mil}$ & 112 & & 0 & 7 & 137 \\
\hline & $81.6 \%$ & $10.7 \%$ & $1.9 \%$ & 5.8 & $100 \%$ & & $81.8 \%$ & $13.1 \%$ & $0.0 \%$ & $5.1 \%$ & $100 \%$ \\
\hline$<1$ ano & 248 & 53 & & 30 & 338 & $>100 \mathrm{mil}$ & 339 & 22 & 8 & 40 & 409 \\
\hline & $73.4 \%$ & $15.7 \%$ & $2.1 \%$ & $8.9 \%$ & $100 \%$ & & $82.9 \%$ & $5.4 \%$ & $2.0 \%$ & $9.8 \%$ & $100 \%$ \\
\hline Total & $\begin{array}{r}821 \\
79.3 \%\end{array}$ & $\begin{array}{r}126 \\
12.2 \%\end{array}$ & $\begin{array}{r}21 \\
2.0 \%\end{array}$ & $\begin{array}{r}67 \\
6.5 \%\end{array}$ & $\begin{array}{r}1035 \\
100 \%\end{array}$ & Total & $\begin{array}{r}825 \\
79.1 \%\end{array}$ & $\begin{array}{r}128 \\
12.3 \%\end{array}$ & $\begin{array}{r}21 \\
2.0 \%\end{array}$ & $\begin{array}{r}69 \\
6.6 \%\end{array}$ & $\begin{array}{r}1043 \\
100 \%\end{array}$ \\
\hline
\end{tabular}

$\mathrm{n}=1043$

Não apresenta variações significativas na realização das ações da saúde do adulto pelas ESF, nem devido ao tempo de implantação ou, ao porte dos municípios. 


\subsubsection{Ações das ESF na eliminação da hanseníase e no controle da}

tuberculose

Tabela 6.100 - Ações das ESF no controle da hanseníase e da tuberculose

\begin{tabular}{|c|c|c|c|c|c|c|}
\hline \multirow[b]{2}{*}{ Realização de Ações (TB e HANSEN) } & \multicolumn{2}{|c|}{ Sim } & \multicolumn{2}{|c|}{ Não } & \multicolumn{2}{|c|}{ Total } \\
\hline & $\begin{array}{l}\text { Freqüên } \\
\text {-cia }\end{array}$ & $\%$ & $\begin{array}{l}\text { Freqüên } \\
\text {-cia }\end{array}$ & $\%$ & $\begin{array}{l}\text { Freqüên- } \\
\text { cia }\end{array}$ & $\%$ \\
\hline $\begin{array}{l}\text { Eliminação da hanseníase } \\
\text { (diagnóstico) }\end{array}$ & 418 & 41,2 & 596 & 58,8 & 1014 & 100 \\
\hline $\begin{array}{l}\text { Eliminação da hanseníase } \\
\text { (tratamento) }\end{array}$ & 151 & 22,9 & 507 & 77,1 & 658 & 100 \\
\hline $\begin{array}{l}\text { Eliminação da hanseníase } \\
\text { (dispensação de medicamentos) }\end{array}$ & 142 & 21,6 & 516 & 78,4 & 658 & 100 \\
\hline $\begin{array}{l}\text { Controle da tuberculose } \\
\text { (diagnóstico) }\end{array}$ & 649 & 64,0 & 365 & 36,0 & 1014 & 100 \\
\hline $\begin{array}{l}\text { Controle da tuberculose } \\
\text { (tratamento) }\end{array}$ & 316 & 43,2 & 415 & 56,8 & 731 & 100 \\
\hline $\begin{array}{l}\text { Controle da tuberculose } \\
\text { (tratamento supervisionado) }\end{array}$ & 278 & 38,7 & 440 & 61,3 & 718 & 100 \\
\hline $\begin{array}{l}\text { Controle da tuberculose } \\
\text { (dispensação de medicamentos) }\end{array}$ & 298 & 40,9 & 430 & 59,1 & 728 & 100 \\
\hline
\end{tabular}

$\mathrm{n}=1043$

A realização das atividades relacionadas ao controle da tuberculose

e de eliminação da hanseníase não se apresenta superior a $43 \%$, exceto diagnóstico de tuberculose, realizado por 2/3 das equipes.

Tabela 6.101 - Tempo de implantação, porte dos municípios e realização de ações de controle de tuberculose e eliminação da hanseníase pelas ESF segundo classificação adotada

\begin{tabular}{|c|c|c|c|c|c|c|c|c|c|c|c|}
\hline \multicolumn{12}{|c|}{ Ações das ESF no controle da tuberculose e na eliminação da hanseníase } \\
\hline 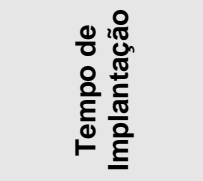 & $\begin{array}{l}\frac{\pi}{2} \\
\frac{\pi}{2} \\
\frac{d}{0} \\
\frac{d}{2}\end{array}$ & 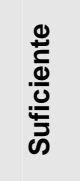 & & 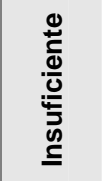 & సँّ & 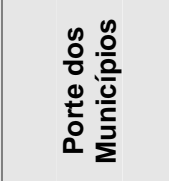 & $\begin{array}{l}\frac{\pi}{0} \\
\frac{\pi}{\sigma} \\
\frac{0}{0} \\
\frac{d}{2}\end{array}$ & 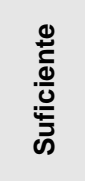 & 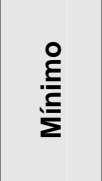 & 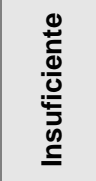 & $\begin{array}{l}\text { त्ञ } \\
\text { 으 }\end{array}$ \\
\hline \multirow[t]{2}{*}{5 anos ou mais } & & & 15 & 30 & 45 & $<20$ mil & 31 & 15 & 64 & 208 & 318 \\
\hline & $0.0 \%$ & $0.0 \%$ & $33.3 \%$ & $66.7 \%$ & $4.3 \%$ & & $9.7 \%$ & $4.7 \%$ & $20.1 \%$ & $65.4 \%$ & $30.5 \%$ \\
\hline \multirow[t]{2}{*}{3 a 5 anos } & & & & & 137 & 20 a 50 mil & & 7 & 23 & 142 & 179 \\
\hline & $6.6 \%$ & $1.5 \%$ & $39.4 \%$ & $52.6 \%$ & $13.2 \%$ & & $3.9 \%$ & $3.9 \%$ & $12.8 \%$ & $79.3 \%$ & $17.2 \%$ \\
\hline \multirow{2}{*}{1 a 3 anos } & & & & 382 & 515 & 50 a $100 \mathrm{mil}$ & & & & 128 & 137 \\
\hline & $4.1 \%$ & $4.1 \%$ & $17.7 \%$ & $74.2 \%$ & $49.8 \%$ & & $1.5 \%$ & $0.7 \%$ & $4.4 \%$ & $93.4 \%$ & $13.1 \%$ \\
\hline \multirow[t]{2}{*}{$<1$ ano } & 13 & & 47 & 274 & 338 & $>100 \mathrm{mil}$ & & 4 & $\begin{array}{r}714 \\
114\end{array}$ & 288 & 409 \\
\hline & $3.8 \%$ & $1.2 \%$ & $13.9 \%$ & $81.1 \%$ & $32.7 \%$ & & $0.7 \%$ & $1.0 \%$ & $27.9 \%$ & $70.4 \%$ & $39.2 \%$ \\
\hline Total & $\begin{array}{r}43 \\
4.2 \%\end{array}$ & $\begin{array}{r}27 \\
2.6 \%\end{array}$ & $\begin{array}{r}207 \\
20.0 \%\end{array}$ & $\begin{array}{r}758 \\
73.2 \%\end{array}$ & $\begin{array}{r}1035 \\
100 \%\end{array}$ & Total & $\begin{array}{r}43 \\
4.1 \%\end{array}$ & $\begin{array}{r}27 \\
2.6 \%\end{array}$ & $\begin{array}{r}207 \\
19.8 \%\end{array}$ & $\begin{array}{r}766 \\
73.4 \%\end{array}$ & $\begin{array}{r}1043 \\
100 \%\end{array}$ \\
\hline
\end{tabular}


Em relação ao tempo de implantação o percentual de ações de controle de tuberculose e hanseníase, pelo menos suficiente pelas equipes, apresenta-se muito baixo, não ultrapassando 10\%. Já em relação ao porte dos municípios este percentual, apesar de baixo, é maior nos municípios de porte menor que 20 mil habitantes, diminuindo nos demais portes.

\subsubsection{Ações das ESF na realização das ações de vigilância epidemiológica}

Tabela 6.102 - Ações das ESF na realização das ações de vigilância epidemiológica

\begin{tabular}{l|r|r|r}
\hline \multicolumn{1}{c|}{ Ações de vigilância epidemiológica } & \% Sim & \% Não & \% Total \\
\hline Vigilância epidemiológica (notificação de dnc) & 85 & 15 & 100 \\
Vigilância epidemiológica (investigação dos casos de dnc) & 56,8 & 43,2 & 100 \\
Vigilância epidemiológica (ações de controle de casos e surtos) & 52,4 & 47,6 & 100 \\
\hline $\mathrm{n}=1043$
\end{tabular}
$\mathrm{n}=1043$

Observa-se que $85 \%$ das equipes realizam apontamento das doenças, de notificação compulsória, e apenas metade realiza investigação de casos e controle de casos e surtos.

Tabela 6.103 - Tempo de implantação, porte dos municípios e realização das ações de vigilância epidemiológica pelas ESF conforme classificação adotada

\begin{tabular}{|c|c|c|c|c|c|c|c|c|c|}
\hline \multicolumn{10}{|c|}{ Ações das ESF em vigilância epidemiológica } \\
\hline 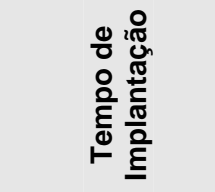 & $\begin{array}{l}\frac{\pi}{0} \\
\frac{\pi}{2} \\
\frac{0}{0} \\
\frac{d}{0} \\
\frac{0}{\alpha}\end{array}$ & 站 & 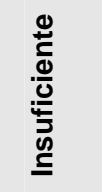 & $\begin{array}{l}\text { శٓ } \\
\text { రే }\end{array}$ & 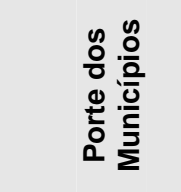 & $\frac{\frac{\pi}{2}}{\frac{\pi}{2}}$ & 站 & 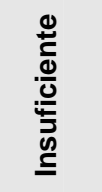 & $\begin{array}{l}\text { శ్ } \\
\text { రొ }\end{array}$ \\
\hline \multirow[t]{2}{*}{5 anos ou mais } & 35 & 3 & 7 & 45 & $<20 \mathrm{mil}$ & 152 & 27 & 139 & 318 \\
\hline & $77.8 \%$ & $6.7 \%$ & $15.6 \%$ & $4.3 \%$ & & $47.8 \%$ & $8.5 \%$ & $43.7 \%$ & $30.5 \%$ \\
\hline \multirow[t]{2}{*}{3 a 5 anos } & & 11 & 37 & 137 & 20 a 50 mil & 43 & 26 & 110 & 179 \\
\hline & $65.0 \%$ & $8.0 \%$ & $27.0 \%$ & $13.2 \%$ & & $24.0 \%$ & $14.5 \%$ & $61.5 \%$ & $17.2 \%$ \\
\hline \multirow[t]{2}{*}{1 a 3 anos } & 239 & 45 & 231 & 515 & 50 a $100 \mathrm{mil}$ & 36 & 11 & 90 & 137 \\
\hline & $46.4 \%$ & $8.7 \%$ & $44.9 \%$ & $49.8 \%$ & & $26.3 \%$ & $8.0 \%$ & $65.7 \%$ & $13.1 \%$ \\
\hline \multirow[t]{2}{*}{$<1$ ano } & 128 & 48 & 162 & 338 & $>100 \mathrm{mil}$ & 261 & 43 & 105 & 409 \\
\hline & $37.9 \%$ & $14.2 \%$ & $47.9 \%$ & $32.7 \%$ & & $63.8 \%$ & $10.5 \%$ & $25.7 \%$ & $39.2 \%$ \\
\hline Total & $\begin{array}{r}491 \\
47.4 \%\end{array}$ & $\begin{array}{r}107 \\
10.3 \%\end{array}$ & $\begin{array}{r}437 \\
42.2 \%\end{array}$ & $\begin{array}{r}1035 \\
100 \%\end{array}$ & Total & $\begin{array}{r}492 \\
47.2 \%\end{array}$ & $\begin{array}{r}107 \\
10.3 \%\end{array}$ & $\begin{array}{r}444 \\
426 \%\end{array}$ & $\begin{array}{r}1043 \\
100 \%\end{array}$ \\
\hline
\end{tabular}

$\mathrm{n}=1043$ 
As equipes implantadas há mais tempo apresentam maior percentual de classificação adequada na realização das ações de vigilância epidemiológica, que diminui com o tempo de implantação das mesmas, variando de $38 \%$ nas equipes implantadas há menos de 1 ano, a $78 \%$ nas equipes implantadas há mais de 5 anos. Já em relação ao porte dos municípios, observa-se que menos de $30 \%$ das equipes dos municípios entre 20 e 100 mil habitantes apresentam esta classificação na realização das ações de vigilância epidemiológica, observada em cerca de $64 \%$ das equipes dos municípios de maior porte e, em $48 \%$ das equipes dos de menor porte.

6.3.9.6 Ações das ESF na realização das ações de investigação de óbitos

Tabela 6.104 - Tempo de implantação, porte dos municípios e realização das ações de investigação de óbitos pelas ESF

\begin{tabular}{l|r|r|r|l|r|r|r}
\hline \multicolumn{7}{c}{ Ações de investigação de óbitos } \\
\hline Tempo de Implantação & \multicolumn{1}{c|}{ Sim } & Não & Total & Porte dos Municípios & \multicolumn{1}{c}{ Sim } & \multicolumn{1}{c}{ Não } & Total \\
\hline 5 anos ou + & 21 & 24 & 45 & $<20$ mil & 101 & 211 & 312 \\
& $46.7 \%$ & $53.3 \%$ & $100 \%$ & & $32.4 \%$ & $67.6 \%$ & $100 \%$ \\
3 a 5 anos & 72 & 63 & 135 & 20 a 50 mil & 56 & 121 & 177 \\
& $53.3 \%$ & $46.7 \%$ & $100 \%$ & & $31.6 \%$ & $68.4 \%$ & $100 \%$ \\
1 a 3 anos & 195 & 303 & 498 & 50 a 100 mil & 38 & 94 & 132 \\
& $39.2 \%$ & $60.8 \%$ & $100 \%$ & & $28.8 \%$ & $71.2 \%$ & $100 \%$ \\
$<1$ ano & 136 & 194 & 330 & $>100$ mil & 230 & 163 & 393 \\
& $41.2 \%$ & $58.8 \%$ & $100 \%$ & & $58.5 \%$ & $41.5 \%$ & $100 \%$ \\
\hline Total & 424 & 584 & 1008 & Total & 425 & 589 & 1014 \\
& $42.1 \%$ & $57.9 \%$ & $100 \%$ & & $41.9 \%$ & $58.1 \%$ & $100 \%$ \\
\hline $\mathrm{n}=1043$ & & & & &
\end{tabular}

Mais da metade das equipes implantadas entre 3 e 5 anos realiza ações de investigação de óbitos. Para as demais equipes este percentual varia de $39 \%$ a $47 \%$. Em relação ao porte dos municípios verifica-se que $59 \%$ das equipes dos municípios de maior porte realizam estas ações. Nos demais, este percentual varia entre $30 \%$ e $32 \%$. 
6.3.9.7 Ações das ESF na realização das ações de investigação de internações hospitalares

Tabela 6.105 - Tempo de implantação, porte dos municípios e realização de ações de investigação de internações hospitalares pelas ESF segundo classificação adotada

\begin{tabular}{|c|c|c|c|c|c|c|c|}
\hline \multicolumn{8}{|c|}{ Ações de investigação de internações } \\
\hline $\begin{array}{c}\text { Tempo de } \\
\text { implantação }\end{array}$ & Sim & Não & Total & $\begin{array}{l}\text { Porte dos } \\
\text { municípios }\end{array}$ & Sim & Não & Total \\
\hline 5 anos ou + & $\begin{array}{r}25 \\
55.6 \%\end{array}$ & $\begin{array}{r}20 \\
44.4 \%\end{array}$ & $\begin{array}{r}45 \\
100 \%\end{array}$ & $<20$ mil & $\begin{array}{r}131 \\
41.7 \%\end{array}$ & $\begin{array}{r}183 \\
58.3 \%\end{array}$ & $\begin{array}{r}314 \\
100 \%\end{array}$ \\
\hline 3 a 5 anos & $\begin{array}{r}97 \\
72.4 \%\end{array}$ & $\begin{array}{r}37 \\
27.6 \%\end{array}$ & $\begin{array}{r}134 \\
100 \%\end{array}$ & 20 a 50 mil & $\begin{array}{r}87 \\
49.2 \%\end{array}$ & $\begin{array}{r}90 \\
50.8 \%\end{array}$ & $\begin{array}{r}177 \\
100 \%\end{array}$ \\
\hline 1 a 3 anos & $\begin{array}{r}245 \\
49.2 \%\end{array}$ & $\begin{array}{r}253 \\
50.8 \%\end{array}$ & $\begin{array}{r}498 \\
100 \%\end{array}$ & 50 a $100 \mathrm{mil}$ & $\begin{array}{r}52 \\
39.7 \%\end{array}$ & $\begin{array}{r}79 \\
60.3 \%\end{array}$ & $\begin{array}{r}131 \\
100 \%\end{array}$ \\
\hline$<1$ ano & $\begin{array}{r}164 \\
49.5 \% \\
\end{array}$ & $\begin{array}{r}167 \\
50.5 \%\end{array}$ & $\begin{array}{r}331 \\
100 \%\end{array}$ & $>100 \mathrm{mil}$ & $\begin{array}{r}262 \\
66.8 \%\end{array}$ & $\begin{array}{r}130 \\
33.2 \%\end{array}$ & $\begin{array}{r}392 \\
100 \%\end{array}$ \\
\hline Total & $\begin{array}{r}531 \\
52.7 \%\end{array}$ & $\begin{array}{r}477 \\
47.3 \%\end{array}$ & $\begin{array}{l}1008 \\
100 \%\end{array}$ & Total & $\begin{array}{r}532 \\
52.5 \%\end{array}$ & $\begin{array}{r}482 \\
47.5 \%\end{array}$ & $\begin{array}{l}1014 \\
100 \%\end{array}$ \\
\hline
\end{tabular}

$\mathrm{n}=1043$

Apenas metade das equipes realiza ações de investigação de internações. Evidencia-se que $72 \%$ das equipes implantadas entre 3 a 5 anos realizam estas ações, e que este percentual é maior nas equipes implantadas há mais de 3 anos. Nas demais faixas este percentual fica ao redor de 50\%. Em relação ao porte dos municípios observa-se que esta ação é realizada por $67 \%$ das equipes dos municípios de maior porte e, por menos da metade das equipes de porte menor que 100 mil habitantes. 
6.3.9.8 Ações das ESF na realização das ações de acompanhamento em saúde mental

Tabela 6.106 - Tempo de implantação, porte dos municípios e realização de ações de acompanhamento em saúde mental segundo classificação adotada

\begin{tabular}{l|r|r|r|l|r|r|r}
\hline \multicolumn{1}{c|}{$\begin{array}{c}\text { Tempo de } \\
\text { implantação }\end{array}$} & \multicolumn{1}{c|}{ Sim } & \multicolumn{1}{c}{ Não } & \multicolumn{1}{c}{ Total } & $\begin{array}{c}\text { Porte dos } \\
\text { municípios }\end{array}$ & \multicolumn{1}{c|}{ Sim } & Não & \multicolumn{1}{c}{ Total } \\
\hline 5 anos ou + & 31 & 14 & 45 & $<20$ mil & 180 & 134 & 314 \\
& $68.9 \%$ & $31.1 \%$ & $4.5 \%$ & & $57.3 \%$ & $42.7 \%$ & $30.9 \%$ \\
3 a 5 anos & 73 & 62 & 135 & 20 a 50 mil & 106 & 71 & 177 \\
& $54.1 \%$ & $45.9 \%$ & $13.4 \%$ & & $59.9 \%$ & $40.1 \%$ & $17.4 \%$ \\
1 a 3 anos & 263 & 235 & 498 & 50 a 100 mil & 58 & 75 & 133 \\
& $52.8 \%$ & $47.2 \%$ & $49.4 \%$ & & $43.6 \%$ & $56.4 \%$ & $13.1 \%$ \\
$<1$ ano & 151 & 180 & 331 & $>100$ mil & 176 & 215 & 391 \\
& $45.6 \%$ & $54.4 \%$ & $32.8 \%$ & & $45.0 \%$ & $55.0 \%$ & $38.5 \%$ \\
\hline Total & 518 & 491 & 1009 & Total & 520 & 495 & 1015 \\
& $51.3 \%$ & $48.7 \%$ & $100 \%$ & & $51.2 \%$ & $48.8 \%$ & $100 \%$ \\
\hline $\mathrm{n}=1043$
\end{tabular}

A realização das ações de saúde mental apresenta aumento pelas equipes e é maior nas equipes implantadas há pelo menos 5 anos, diminuindo nas implantadas há menos tempo, variando entre $69 \%$ nas equipes mais antigas a $46 \%$ nas equipes com menos de 1 ano de implantação. Verifica-se também a realização desta ação por $58 \%$ das equipes dos municípios de porte maior que 50 mil habitantes, e $45 \%$ das equipes dos municípios de porte menor que 50 mil habitantes.

6.3.9.9 Ações das ESF na realização das ações de doenças de transmissão sexual

Tabela 6.107 - Ações das ESF na realização das ações de DST

\begin{tabular}{l|r|r|r|r}
\hline \multicolumn{1}{c|}{ Ações em tuberculose e hanseníase } & \% Sim & \% Não & $\begin{array}{r}\text { \% Não } \\
\text { se aplica }\end{array}$ & \% Total \\
\hline DST (diagnóstico) & 80,7 & 19,3 & 100 & \\
DST (tratamento) & 74,9 & 25,1 & 100 & \\
\hline $\mathrm{n}=1043$ & &
\end{tabular}


Aproximadamente $81 \%$ das equipes realizam o diagnóstico das DST, enquanto $75 \%$ realizam ações de tratamento das DST.

6.3.10. Realização de atividades educativas continuadas em grupos populacionais

Tabela 6.108 - Realização de atividades educativas continuadas em grupos populacionais

\begin{tabular}{l|r|r|r}
\hline \multicolumn{1}{c|}{$\begin{array}{c}\text { Realização de atividades educativas } \\
\text { continuadas em grupos populacionais }\end{array}$} & \% Sim & \% Não & \% Total \\
\hline Gestantes & 61,5 & 38,5 & 100 \\
Menores de 2 anos para monitoramento de crescimento & 29,1 & 70,9 & 100 \\
e desenvolvimento & 17,3 & 82,7 & 100 \\
Desnutridos & 11,3 & 88,7 & 100 \\
Escolares & 71,7 & 28,3 & 100 \\
Diabéticos & 74,1 & 25,9 & 100 \\
Hipertensos & 17,2 & 82,8 & 100 \\
Adolescentes & 17,7 & 82,3 & 100 \\
Idosos & & &
\end{tabular}

Mais de $80 \%$ das ESF não realizam as atividades de grupos para desnutridos, escolares, adolescentes, idosos, e quanto ao monitoramento das atividades de crescimento e desenvolvimento para menores de 2 anos não apresenta realização por mais de $70 \%$ delas. As ações mais realizadas são as atividades de grupos para diabéticos e hipertensos, $72 \%$ e $74 \%$, respectivamente, e grupos de gestantes, realizados por $62 \%$ das ESF.

6.3.11 Ações das ESF por área de atenção à saúde

6.3.11.1 Ações das ESF na saúde da mulher

As ações mais realizadas pelas equipes, acima de $80 \%$ são: prevenção de câncer de colo de útero (coleta de material) e tratamento de 
corrimento vaginal (Tabela 6.93). Chama a atenção que $27 \%$ dos médicos e $46 \%$ dos enfermeiros das ESF não realizam consultas de pré-natal, indicando uma certa fragilidade na atenção a esta área que é muito demandada para atenção nas UBS (Tabela 6.93). Quanto às ações de planejamento familiar, há mais ações de oferta de métodos do que ações educativas, $75 \%$ e $57 \%$, respectivamente, sugerindo haver necessidade de maior incorporação de ações educativas, como proposto nas diretrizes do PSF, incluindo as de orientação para a prevenção de gravidez indesejada.

Apenas metade das equipes realiza ações na saúde da mulher, classificadas como pelo menos suficientes, e, que $17 \%$ apresentam a classificação insuficiente (Tabela 6.94). Quando se considera o tempo de implantação das equipes e o porte dos municípios, verifica-se que as implantadas há mais de 1 ano e as dos municípios de porte maior que 20 mil habitantes apresentam percentual maior, cerca de $64 \%$, de realização de ações classificadas, pelo menos como suficiente na saúde da mulher. Entretanto, as equipes implantadas há menos de 1 ano e as dos municípios menores apresentam maior percentual de classificação insuficiente na realização destas ações; este percentual diminui tanto nas equipes mais antigas como nas dos municípios de menor porte (Tabela 6.94).

Em relação à média nacional o Estado de São Paulo apresenta freqüência semelhante de realização de consulta médica de pré-natal e de tratamento das afeç̧ões ginecológicas; maior freqüência de coleta de material para prevenção de câncer de colo de útero e na oferta de métodos 
contraceptivos e freqüência acentuadamente menor na realização de consultas de pré-natal e nas ações educativas de planejamento familiar. Em relação aos estados do Sudeste apresenta menor freqüência para realização de atendimentos clínicos em ginecologia e obstetrícia para médicos e enfermeiros. (AVALIAÇÃO NORMATIVA - MS)

\subsubsection{Ações das ESF na saúde da criança}

As ações mais realizadas pelas equipes na saúde da criança, acima de $70 \%$, são consultas médicas de atenção as doenças prevalentes da infância e de acompanhamento e desenvolvimento de crianças menores de 2 anos, e terapia de reidratação oral (Tabela 6.95). Já a consulta médica para vigilância nutricional diminui um pouco, sendo realizada por $2 / 3$ das equipes. Também, 2/3 das equipes realizavam consultas de enfermagem de acompanhamento e desenvolvimento de menores de 2 anos, e apenas metade na assistência às doenças prevalentes na infância. Considerando-se que $15 \%$ dos médicos não realizam consultas pediátricas e o baixo desempenho dos enfermeiros nas ações da saúde da criança, o panorama indica que a atuação das equipes necessita de revisão para que se alcance a resolubilidade e integralidade da atenção prevista no programa.

Em relação ao tempo de implantação das equipes, observa-se que 1/4 das equipes implantadas há menos de 1 ano apresenta maior percentual de classificação insuficiente na realização de ações na saúde da criança e, que este percentual diminui nas equipes implantadas há mais tempo (Tabela 
6.96). Quanto ao porte populacional, nota-se que a classificação insuficiente é mais presente nas equipes dos municípios de maior e menor porte, $28 \%$ e 19\%, respectivamente (Tabela 6.96). Cabe ressaltar que apenas metade das ESF refere a realização da imunização básica do Programa Nacional de Imunização (PNI) na UBS. Um dos fatores que pode explicar esta inadequação é a ausência de geladeira de vacina em algumas unidades, e o outro fato talvez seja a pré-definição de locais de vacinação nos municípios com dificuldade de descentralizar esta ação para mais UBS. De qualquer forma não justifica que principalmente crianças recebam assistência médica, de enfermagem e de prevenção em um local e tenham que se deslocar para outro para serem imunizadas. Esta atitude, além de dificultar a vida das pessoas, possibilita a quebra de vínculo entre família e as ESF.

Em relação à média nacional, o Estado de São Paulo apresenta freqüência notadamente maior de equipes que realizam consulta médica de acompanhamento do crescimento e desenvolvimento de menores de 2 anos, e para doenças prevalentes da infância, além de ações de terapia de reidratação oral, freqüência semelhante na realização de consulta de enfermagem de acompanhamento do crescimento e desenvolvimento de menores de 2 anos, e menor freqüência em todas as ações de vigilância nutricional. O Estado de São Paulo também apresenta menor percentual de realização de imunização que a média nacional, que é de $64 \%$. (AVALIAÇÃO NORMATIVA - MS) 
6.3.11.3 Ações das ESF na saúde do adulto (controle da hipertensão arterial e diabetes)

A maioria das equipes realiza ações de controle de diabetes e hipertensão arterial, com discreta diminuição para a realização de glicemia capilar $(86 \%)$, não havendo variações significativas na realização destas ações pelas ESF relacionadas ao tempo de implantação ou ao porte dos municípios (Tabela 6.98).

Em relação à média nacional, o Estado de São Paulo apresenta freqüência discretamente maior para todas as ações, exceto para a realização de glicemia capilar onde apresenta freqüência acentuadamente maior. (AVALIAÇÃO NORMATIVA - MS)

6.3.11.4 Ações das ESF na eliminação da hanseníase e no controle da tuberculose

O desempenho das equipes no controle da tuberculose e na eliminação da hanseníase encontra-se muito aquém do esperado, sendo que os valores encontrados de realização destas atividades, exceto diagnóstico de tuberculose e de hanseníase, não ultrapassa a marca de $30 \%$, sugerindo que, tratamento e dispensação de medicamentos para estas patologias devem ser centralizados (Tabela 6.100). Cabe ainda destacar que apenas $27 \%$ das equipes realizam tratamento supervisionado para tuberculose, uma ação que poderia mais facilmente ser incorporada no PSF, 
já que as equipes já têm, nas suas atividades diárias, a realização de visitas domiciliares às famílias cadastradas e aos casos priorizados.

Em relação ao tempo de implantação, o percentual, pelo menos suficiente na realização de ações de controle de tuberculose e eliminação da hanseníase pelas equipes é muito pequeno, não ultrapassando 10\% (Tabela 6.101). Já em relação ao porte dos municípios, este percentual, apesar de não ultrapassar $15 \%$, apresenta uma tendência de aumento nos municípios de menor porte (Tabela 6.101). O Estado de São Paulo apresenta menor desempenho que os estados da região Sudeste e que a média nacional para diagnóstico de tuberculose e diagnóstico e tratamento de hanseníase. Já em relação ao tratamento supervisionado, apresenta maior desempenho da região Sudeste, semelhante ao Estado do Rio de Janeiro e maior que a média nacional (23\%). (AVALIAÇÃO NORMATIVA - MS)

6.3.11.5 Ações das ESF na realização das ações de vigilância epidemiológica

Observa-se que $85 \%$ das equipes realizam notificação compulsória de doenças e, apenas metade das equipes realiza investigação de casos e controle de casos e surtos (Tabela 6.102).

Quanto ao tempo de implantação das equipes verifica-se que a realização das ações de vigilância epidemiológica pelas equipes está mais presente nas equipes implantadas há mais tempo, variando entre $38 \%$ naquelas implantadas há menos de 1 ano, a $78 \%$ nas implantadas há mais 
de 5 anos, sugerindo uma adequação destas atividades nas ESF com maior tempo de implantação (Tabela 6.103). Já em relação ao porte dos municípios observa-se que menos de $30 \%$ das equipes dos municípios entre 20 e 100 mil habitantes realizam estas ações (Tabela 6.103). O baixo desempenho das equipes na realização das ações de investigação epidemiológica, principalmente, na investigação de casos e controle de casos e surtos, é preocupante e pode demonstrar, além de uma possível centralização destas atividades nos serviços municipais de saúde, uma dificuldade na incorporação destas ações pelas próprias equipes.

Cabe destacar que a adstrição da população, o trabalho em equipe multiprofissional, além do próprio processo de trabalho das ESF, deveriam ser condições facilitadoras para a realização destas ações.

Em relação à média nacional o Estado de São Paulo apresenta freqüências semelhantes na realização das ações de vigilância epidemiológica. (AVALIAÇÃO NORMATIVA - MS)

6.3.11.6 Ações das ESF na realização das ações de investigação de óbitos

Quando se considera a importância do conhecimento das causas de óbitos da população para se planejar ações e serviços de saúde e, que poucos eventos desta natureza devem ocorrer mensalmente na população adstrita às ESF, chama atenção que apenas $41 \%$ das equipes realizam esta ação (Tabela 6.104). Observa-se que esta ação é realizada por metade das equipes implantadas entre 3 e 5 anos, e nas demais equipes o percentual 
varia entre $39 \%$ e $47 \%$. Em relação ao porte dos municípios verifica-se que quase $60 \%$ das equipes dos municípios de maior porte realizam estas ações. Nos demais municípios este percentual gira em torno de 30\% (Tabela 6.104). As equipes do Estado de São Paulo apresentam menor freqüência na realização de investigação de óbitos que a média nacional (49\%). (AVALIAÇÃO NORMATIVA - MS)

\subsubsection{Ações das ESF na realização das ações de investigação de} internações hospitalares

Como relacionado no item anterior, a investigação de óbitos e a investigação das internações hospitalares da população atendida pelas equipes possibilitariam, inclusive, o monitoramento da resolubilidade das ações desenvolvidas pelas equipes na prevenção de internações, evitáveis por adequada atenção da atenção básica (CAMINAL, SANCHES, MORALES, ET AL, 2002). Portanto, ressalta-se o fato de que pouco mais da metade das equipes realizam esta ação (Tabela 6.105). Quanto ao tempo de implantação, evidencia-se que $70 \%$ das equipes implantadas entre 3 a 5 anos realizam investigações de internações hospitalares. Nas demais faixas este percentual gira ao redor de $50 \%$. Em relação ao porte dos municípios observa-se a realização desta ação por $67 \%$ das equipes dos municípios de maior porte, sendo realizada por menos da metade das equipes de porte menor que 100 mil habitantes (Tabela 6.105). O Estado de são Paulo apresenta freqüência semelhante à média nacional na realização das ações de investigação de internações hospitalares. 
6.3.11.8 Ações das ESF na realização das ações de acompanhamento em saúde mental

Evidencia-se que a realização das ações de saúde mental aumentou nas equipes implantadas há mais tempo, variando entre $46 \%$ nas equipes implantadas há menos de 1 ano e a $69 \%$ nas equipes implantadas há mais de 5 anos (Tabela 6.106). Verifica-se que esta suficiência foi maior nos municípios de porte menor que 50 mil habitantes e diminui nos municípios de porte maior que 50 mil habitantes (Tabela 6.106). Os dados sugerem que a maturidade propicia a incorporação das ações de saúde mental pelas equipes. Já em relação ao fato da maior incorporação desta ação pelas equipes dos municípios de menor porte, pode ser devido à menor disponibilidade de equipamentos para tratamento no âmbito dos municípios.

6.3.11.9 Ações das ESF na realização das ações de doenças de transmissão sexual

Quanto às equipes que realizam mais diagnósticos (81\%) que tratamentos das DST (75\%) (Tabela 6.107), este fato contraria a resolubilidade que se espera das equipes de saúde da família, pois é função do serviço público diagnosticar e realizar tratamentos. Em relação à média nacional, o Estado de São Paulo apresenta freqüência semelhante em relação ao diagnóstico das DST e inferior em relação ao tratamento das mesmas. (AVALIAÇÃO NORMATIVA - MS) 
6.3.12 Realização de atividades educativas continuadas em grupos

populacionais

As atividades de grupo mais realizadas concentram-se nos casos de diabéticos e hipertensos, o que está em consonância com o perfil anterior. Entretanto, as atividades de grupos para desnutridos, escolares, adolescentes, idosos e de monitoramento das atividades de crescimento e desenvolvimento para menores de 2 anos apresentam-se como realizadas por menos de $30 \%$ das equipes (Tabela 6.108). O baixo percentual de atividades educativas de grupo, sem levar em consideração a qualidade dos mesmos, principalmente as ações dirigidas aos adolescentes, escolares e idosos, questiona a articulação com a comunidade e a abrangência intersetorial esperada nas ações do PSF.

\subsection{Instrumentos de planejamento e organização do trabalho das ESF}

6.4.1 Existência dos instrumentos de planejamento do trabalho das equipes de ESF

Tabela 6.109 - Instrumentos de planejamento do trabalho das ESF

\begin{tabular}{l|r|r|r|r}
\hline \multicolumn{1}{c|}{ Instrumentos de planejamento trabalho das ESF } & \% Sim & \% Não & \% Sem informação & Total \\
\hline Área abrangência. & 97,1 & 2,2 & 0,7 & 100 \\
Mapa área abrangência & 72,6 & 26 & 1,4 & 100 \\
SIAB & 57,7 & 39,8 & 2,5 & 100 \\
Existência prontuário & 95,3 & 3,4 & 1,3 & 100 \\
Existência de prontuário familiar & 66,2 & 32,5 & 1,3 & 100 \\
Prontuário familiar c/ prontuários individuais & 64,5 & 22,2 & 13,2 & 100 \\
Prontuário familiar com ficha A & 34,9 & 51,8 & 13,3 & 100 \\
Prontuário familiar com situação de risco & 26,4 & 60,7 & 12,9 & 100 \\
Cronograma atividades médico & 63,3 & 34,8 & 1,9 & 100 \\
Cronograma atividades enfermeiro & 62,4 & 35,1 & 2,5 & 100 \\
Cronograma atividades auxiliar enfermagem & 53,7 & 44,7 & 1,6 & 100 \\
Cronograma atividades ACS & 54,0 & 44,7 & 1,3 & 100 \\
\hline
\end{tabular}
$\mathrm{n}=1043$ 
Evidencia-se que $97 \%$ das equipes têm área de abrangência definida para atuarem, e $73 \%$ delas possuem mapa desta área. Quanto à anotação sistematizada dos dados relativos ao atendimento dos usuários, $95 \%$ das equipes têm prontuário e apenas $66 \%$ utilizam prontuários familiares.

Cerca de 2/3 das equipes utilizam prontuários familiares compostos por prontuários individuais, mas apenas $1 / 3$ possuem a Ficha $A$, e $26 \%$ possuem anotações sobre situação de risco das famílias. Observa-se ainda que a existência de cronograma semanal de atividades é observada para $53 \%$ dos auxiliares de enfermagem, $54 \%$ dos ACS, $62 \%$ dos médicos e $63 \%$ dos enfermeiros; $40 \%$ das equipes não usam o SIAB para o planejamento e monitoramento das ações.

Tabela 6.110 - Existência dos instrumentos de planejamento do trabalho das ESF segundo classificação adequada

\begin{tabular}{lr|r|r}
\hline \multicolumn{3}{c}{ Instrumentos de planejamento do trabalho das ESF } \\
\hline \multicolumn{2}{c|}{ Porte dos municípios } & Total & \% \\
\hline Adequada & 58 & $5.6 \%$ \\
Suficiente & 281 & $26.9 \%$ \\
Mínimo & 408 & $39.1 \%$ \\
Insuficiente & 296 & $28.4 \%$ \\
\hline Total & 1043 & $100 \%$ \\
\hline
\end{tabular}

No geral, a existência de instrumentos de planejamento do trabalho das equipes é muito baixa, sendo a classificação adequada observada em apenas $32 \%$ delas e insuficiente em $28 \%$.

Tabela 6.111 - Porte dos municípios e existência dos instrumentos de planejamento do trabalho para as ESF 


\begin{tabular}{l|r|r|r|r|r}
\hline \multicolumn{1}{c|}{ municípios } & & & & & 135 \\
\hline$<20$ mil & 9 & 37 & 137 & $42.5 \%$ & 318 \\
& $2.8 \%$ & $11.6 \%$ & $43.1 \%$ & 60 & $100 \%$ \\
20 a 50 mil & 8 & 34 & 77 & 179 \\
& $4.5 \%$ & $19.0 \%$ & $43.0 \%$ & $33.5 \%$ & $100 \%$ \\
50 a 100 mil & 6 & 30 & 57 & 44 & 137 \\
& $4.4 \%$ & $21.9 \%$ & $41.6 \%$ & $32.1 \%$ & $100 \%$ \\
& 35 & 180 & 137 & 57 & 409 \\
\hline Total & $8.6 \%$ & $44.0 \%$ & $33.5 \%$ & $13.9 \%$ & $100 \%$ \\
\hline $\mathrm{n}=1043$ & 58 & 281 & 408 & 296 & 1043 \\
\hline
\end{tabular}

As equipes dos municípios com menos de 20 mil habitantes apresentam menor percentual da classificação pelo menos suficiente que as equipes implantadas nos municípios de maior porte, variando de $14 \%$ a $52 \%$.

Tabela 6.112 - Tempo de implantação e existência dos instrumentos de planejamento do trabalho para as ESF

\begin{tabular}{l|r|r|r|r|r}
\hline $\begin{array}{c}\text { Tempo de } \\
\text { implantação }\end{array}$ & \multicolumn{1}{c|}{ Adequada } & \multicolumn{1}{c|}{ Suficiente } & \multicolumn{1}{c|}{ Mínimo } & \multicolumn{1}{l}{ Insuficiente } \\
\hline 5 anos ou & 7 & 21 & 14 & 3 & 45 \\
& $15.6 \%$ & $46.7 \%$ & $31.1 \%$ & $6.7 \%$ & $100 \%$ \\
3 a 5 anos & 12 & 48 & 57 & 20 & 137 \\
& $8.8 \%$ & $35.0 \%$ & $41.6 \%$ & $14.6 \%$ & $100 \%$ \\
1 a 3 anos & 27 & 123 & 233 & 132 & 515 \\
& $5.2 \%$ & $23.9 \%$ & $45.2 \%$ & $25.5 \%$ & $100 \%$ \\
< 1 ano & 12 & 88 & 99 & 139 & 338 \\
& $3.6 \%$ & $26.0 \%$ & $29.3 \%$ & $41.1 \%$ & $100 \%$ \\
\hline Total & 58 & 280 & 403 & 294 & 1035 \\
& $5.6 \%$ & $27.1 \%$ & $38.9 \%$ & $28.4 \%$ & $100 \%$ \\
\hline
\end{tabular}

$\mathrm{n}=1043$

Nas ESF implantadas há pelo menos 5 anos ressalta-se a condição pelo menos suficiente para a existência de instrumentos de planejamento do trabalho, sendo esta condição menos verificada nas equipes implantadas há menos tempo, variando entre $62 \%$ a $30 \%$. 
6.4.2 Existência de área de abrangência definida e de mapa da área de abrangência para as ESF

Tabela 6.113 - Tempo de implantação, porte dos municípios e existência de área de abrangência definida para as ESF

\begin{tabular}{|c|c|c|c|c|c|c|c|}
\hline \multicolumn{8}{|c|}{ Área de abrangência } \\
\hline $\begin{array}{c}\text { Tempo } \\
\text { implantacão }\end{array}$ & Sim & Não & Total & $\begin{array}{l}\text { Porte dos } \\
\text { municípios }\end{array}$ & Sim & Não & Total \\
\hline 5 anos ou + & $\begin{array}{r}44 \\
97.8 \%\end{array}$ & $\begin{array}{r}1 \\
2.2 \%\end{array}$ & $\begin{array}{r}45 \\
100 \%\end{array}$ & $<20$ mil & $\begin{array}{r}304 \\
96.5 \%\end{array}$ & $\begin{array}{r}11 \\
3.5 \%\end{array}$ & $\begin{array}{r}315 \\
30.4 \%\end{array}$ \\
\hline 3 a 5 anos & 137 & 0 & 137 & 20 a 50 mil & 174 & $\begin{array}{r}0.0 \\
5\end{array}$ & 179 \\
\hline & $100.0 \%$ & $0.0 \%$ & $13.3 \%$ & & $97.2 \%$ & $2.8 \%$ & $17.3 \%$ \\
\hline 1 a 3 anos & 495 & 18 & 513 & 50 a $100 \mathrm{mil}$ & 130 & 7 & 137 \\
\hline & $96.5 \%$ & $3.5 \%$ & $49.9 \%$ & & $94.9 \%$ & $5.1 \%$ & $13.2 \%$ \\
\hline$<1$ ano & 330 & 4 & 334 & $>100 \mathrm{mil}$ & 405 & 0 & \\
\hline & $98.8 \%$ & $1.2 \%$ & $32.5 \%$ & & $100.0 \%$ & $0.0 \%$ & $39.1 \%$ \\
\hline Total & $\begin{array}{r}1006 \\
97.8 \%\end{array}$ & $\begin{array}{r}23 \\
2.2 \%\end{array}$ & $\begin{array}{l}1029 \\
100 \%\end{array}$ & Total & $\begin{array}{r}1013 \\
97.8 \%\end{array}$ & $\begin{array}{r}23 \\
2.2 \%\end{array}$ & $\begin{array}{c}1036 \\
100 \%\end{array}$ \\
\hline
\end{tabular}

Nem o tempo de implantação, nem o tamanho dos municípios destacam-se como relevantes para a existência de área de abrangência definida para as equipes.

Tabela 6.114 - Tempo de implantação, porte dos municípios e existência de mapa da área de abrangência.

\begin{tabular}{l|r|r|r|l|r|r|r}
\hline \multicolumn{7}{c}{ Existência de área de abrangência e mapa da área de abrangência por ESF } \\
\hline \multicolumn{1}{c|}{ Tempo implantação } & \multicolumn{1}{c|}{ Sim } & \multicolumn{1}{c}{ Não } & Total & Porte dos municípios & Sim & Não & Total \\
\hline 5 anos ou + & 42 & 3 & 45 & $<20$ mil & 225 & 89 & 314 \\
& $93.3 \%$ & $6.7 \%$ & $100 \%$ & & $71.7 \%$ & $28.3 \%$ & $100 \%$ \\
3 a 5 anos & 104 & 31 & 135 & 20 a 50 mil & 124 & 55 & 179 \\
& $77.0 \%$ & $23.0 \%$ & $100 \%$ & & $69.3 \%$ & $30.7 \%$ & $100 \%$ \\
1 a 3 anos & 356 & 152 & 508 & 50 a $100 \mathrm{mil}$ & 86 & 50 & 136 \\
& $70.1 \%$ & $29.9 \%$ & $100 \%$ & & $63.2 \%$ & $36.8 \%$ & $100 \%$ \\
$<1$ ano & 250 & 83 & 333 & $>100 \mathrm{mil}$ & 322 & 77 & 399 \\
& $75.1 \%$ & $24.9 \%$ & $100 \%$ & & $80.7 \%$ & $19.3 \%$ & $100 \%$ \\
\hline Total & 752 & 269 & 1021 & Total & 757 & 271 & 1028 \\
& $73.7 \%$ & $26.3 \%$ & $100 \%$ & & $73.6 \%$ & $26.4 \%$ & $100 \%$ \\
\hline
\end{tabular}

$n=1043$

Considerando-se o tempo de implantação das equipes, verifica-se que mais de $90 \%$ das equipes dos municípios com pelo menos 5 anos possuem mapa da área de abrangência. Nas demais faixas variam entre $70 \%$ a $77 \%$. 
Em relação ao porte populacional verifica-se que o mapa de abrangência está presente nos municípios com mais de 100 mil habitantes, sendo menos observado nos municípios com população entre 50 a 100 mil habitantes, nos demais e populacional nota-se que a classificação insuficiente apresenta freqüência semelhante por volta dos $70 \%$.

6.4.3 Utilização das informações do SIAB para planejamento das atividades das ESF

Tabela 6.115 - Tempo de implantação, porte dos municípios e utilização do SIAB para programar as ações das equipes

\begin{tabular}{l|r|r|r|l|r|r|r|r}
\hline \multicolumn{7}{c}{ Utilização do SIAB para planejamento das ações } \\
\hline \multicolumn{1}{c|}{ Tempo implantação } & \multicolumn{1}{c|}{ Sim } & Não & total & Porte dos municípios & Sim & Não & Total \\
\hline 5 anos ou + & 14 & 29 & 43 & $<20$ mil & 158 & 154 & 312 \\
& $32.6 \%$ & $67.4 \%$ & $100 \%$ & & $50.6 \%$ & $49.4 \%$ & $100 \%$ \\
3 a 5 anos & 41 & 95 & 136 & 20 a 50 mil & 87 & 90 & 177 \\
& $30.1 \%$ & $69.9 \%$ & $100 \%$ & & $49.2 \%$ & $50.8 \%$ & $100 \%$ \\
1 a 3 anos & 232 & 271 & 503 & 50 a 100 mil & 63 & 69 & 132 \\
& $46.1 \%$ & $53.9 \%$ & $100 \%$ & & $47.7 \%$ & $52.3 \%$ & $100 \%$ \\
< 1 ano & 124 & 205 & 329 & $>100$ mil & 107 & 289 & 396 \\
& $37.7 \%$ & $62.3 \%$ & $100 \%$ & & $27.0 \%$ & $73.0 \%$ & $100 \%$ \\
\hline Total & 411 & 600 & 1011 & Total & 415 & 602 & 1017 \\
& $40.7 \%$ & $59.3 \%$ & $100 \%$ & & $40.8 \%$ & $59.2 \%$ & $100 \%$ \\
\hline $\mathrm{n}=1043$
\end{tabular}

$70 \%$ das equipes mais antigas reportam que não utilizam o SIAB para programar as ações, este valor diminui para $57 \%$ nas ESF implantadas há mais de 3 anos.

Em relação ao porte do município, a freqüência de equipes que utilizam o SIAB aumenta com a diminuição porte do município, com uma variação de $27 \%$ nos municípios de porte maior a $50 \%$ nos municípios de menor porte. 
6.4.4 Existência de cronograma semanal de atividades para os profissionais das ESF

Tabela 6.116 - Tempo de implantação e existência de cronograma semanal de atividades para os profissionais das ESF

\begin{tabular}{|c|c|c|c|c|}
\hline \multicolumn{5}{|c|}{ Existência de cronograma semanal de atividades para os profissionais das equipes } \\
\hline $\begin{array}{c}\text { Tempo } \\
\text { implantação }\end{array}$ & Médico & Enfermeiro & $\begin{array}{l}\text { Auxiliar de } \\
\text { enfermagem }\end{array}$ & ACS \\
\hline \multirow[t]{2}{*}{5 anos ou +} & 34 & 36 & 36 & 29 \\
\hline & $75.6 \%$ & $80.0 \%$ & $80.0 \%$ & $64.4 \%$ \\
\hline \multirow[t]{2}{*}{3 a 5 anos } & 107 & 104 & 90 & 94 \\
\hline & $78.7 \%$ & $78.2 \%$ & $66.2 \%$ & $69.1 \%$ \\
\hline \multirow[t]{2}{*}{1 a 3 anos } & 340 & 339 & 275 & 286 \\
\hline & $67.7 \%$ & $67.8 \%$ & $54.5 \%$ & $56.3 \%$ \\
\hline \multirow[t]{2}{*}{$<1$ ano } & 175 & 168 & 155 & 150 \\
\hline & $52.6 \%$ & $50.6 \%$ & $46.5 \%$ & $45.0 \%$ \\
\hline \multirow[t]{2}{*}{ Total } & 656 & 647 & 556 & 559 \\
\hline & $64.6 \%$ & $64.1 \%$ & $54.6 \%$ & $54.7 \%$ \\
\hline
\end{tabular}

De maneira geral verifica-se que para todos os profissionais das ESF a existência de cronograma semanal de atividades é mais observada nas equipes implantadas há mais tempo, exceto para médicos e ACS nos quais o maior valor concentra-se nas equipes implantadas entre 3 a 5 anos. Para os médicos e enfermeiros este percentual é semelhante, variando entre aproximadamente $50 \%$ para as equipes implantadas há menos de 1 ano e $80 \%$ para as equipes implantadas há mais de 3 anos. Já em relação aos auxiliares de enfermagem o percentual varia de $38 \%$ a $74 \%$, e para os ACS, de $38 \%$ a $64 \%$. 
Tabela 6.117 - Porte dos municípios e existência de cronograma semanal de atividades para os profissionais das equipes

\begin{tabular}{l|r|r|r|r}
\hline \multicolumn{4}{c}{ Cronograma semanal de atividades para os profissionais das equipes } \\
\hline $\begin{array}{c}\text { Porte dos } \\
\text { municípios }\end{array}$ & \multicolumn{1}{c}{ Médicos } & Enfermeiros & $\begin{array}{c}\text { Auxiliar de } \\
\text { enfermagem }\end{array}$ & ACS \\
\hline$<20$ mil & 142 & 142 & 119 & 120 \\
& $45.8 \%$ & $45.8 \%$ & $38.0 \%$ & $38.3 \%$ \\
& 111 & 111 & 85 & 97 \\
50 a 5100 mil & $63.1 \%$ & $63.1 \%$ & $48.0 \%$ & $54.5 \%$ \\
& 82 & 82 & 59 & 63 \\
$>100$ mil & $61.2 \%$ & $61.2 \%$ & $44.4 \%$ & $47.0 \%$ \\
& 325 & 325 & 297 & 283 \\
\hline Total & $80.6 \%$ & $80.6 \%$ & $73.7 \%$ & $70.0 \%$ \\
\hline $\mathrm{n}=1043$ & 660 & 660 & 560 & 563 \\
& $64.5 \%$ & $64.5 \%$ & $54.6 \%$ & $54.7 \%$ \\
\hline
\end{tabular}

A existência de cronograma semanal de atividades está para todos os profissionais das equipes e é mais presente nos municípios de maior porte. Para os médicos e enfermeiros as observações são idênticas, variando de $46 \%$ nos municípios de menor porte a $80 \%$ nos municípios de porte maior que 100 mil habitantes. Para os auxiliares de enfermagem e ACS este percentual é semelhante, variando entre $38 \%$ a $74 \%$ e $38 \%$ a $70 \%$ respectivamente.

\subsubsection{Utilização de prontuário pelas ESF e tipos existentes nas UBS}

Tabela 6.118 - Prontuário e tipo de prontuário utilizado pelas ESF

\begin{tabular}{l|c|c|c|c}
\hline \multicolumn{3}{c}{ Utilização de prontuário pelas ESF } \\
\hline & Sim & Não & $\begin{array}{c}\text { Tempo } \\
\text { inf. }\end{array}$ & Total \\
\hline Utiliza prontuário & 95,3 & 3,4 & 1,3 & $100 \%$ \\
Prontuário + ficha clínica individual & 87,7 & 10,7 & 1,5 & $100 \%$ \\
Prontuário + resultados de exames & 84,8 & 13,8 & 1,4 & $100 \%$ \\
Prontuário + ficha B do SIAB & 22,3 & 76 & 1,6 & $100 \%$ \\
Prontuário + ficha C do SIAB & 26,8 & 71,7 & 1,4 & $100 \%$ \\
Prontuário familiar & 66,2 & 32,5 & 1,3 & $100 \%$ \\
Prontuário familiar + prontuários individuais & 64,5 & 22,2 & 13,2 & $100 \%$ \\
Prontuário familiar + ficha A & 34,1 & 50,5 & 15,3 & $100 \%$ \\
Pront. familiar + situação de risco ou dinâmica familiar & 26,4 & 60,7 & 12,9 & $100 \%$ \\
\hline
\end{tabular}

$\mathrm{n}=1043$ 
Cerca de $95 \%$ das equipes utilizam prontuário para anotar as informações referentes aos atendimentos realizados, sendo que entre $85 \%$ a $88 \%$ são compostos por fichas clínicas individuais e resultados de exames. Apenas $66 \%$ das equipes utilizam prontuário familiar e $64 \%$ referem que o prontuário familiar é composto de prontuários individuais. Apenas, cerca de $34 \%$ possuem dados relativos ao cadastro das famílias (Ficha A do SIAB) e apenas $26 \%$ possuem dados sobre situação de risco ou da dinâmica familiar.

6.4.6 Atendimento a pacientes não agendados

Tabela 6.119 - Atendimento a pacientes não agendados pelas ESF

\begin{tabular}{l|r|r}
\hline \multicolumn{1}{c|}{ ESF atende pacientes não agendados } & $\mathbf{N}^{\circ}$ & $\%$ \\
\hline Sim & 978 & 93,8 \\
Não & 29 & 2,8 \\
Sem informação & 36 & 3,5 \\
\hline Total & 1043 & 100 \\
\hline
\end{tabular}

Quase $100 \%$ das equipes atendem a pacientes não agendados. Isto pode refletir uma incorporação das ações de Pronto Atendimento para a população adstrita.

Tabela 6.120 - Procedimentos para pacientes não agendados

\begin{tabular}{l|r|r}
\hline \multicolumn{1}{c|}{ Procedimentos para pacientes não agendados } & $\mathbf{N}^{\circ}$ & $\mathbf{\%}$ \\
\hline Encaminha para o PA & 10 & 1,0 \\
Avalia e atende se for urgência ou agenda não & 558 & 53,5 \\
urgência & 440 & 42,2 \\
Atende todos que procuram & 32 & 3,1 \\
Sem informação & 1040 & 99,7 \\
\hline Total & & \\
\hline
\end{tabular}

Apenas $10 \%$ das equipes encaminham os pacientes não agendados diretamente para o PA; $53 \%$ das equipes atendem os usuários em caso de 
urgência ou agendam as não urgências, e 42\% atendem todos que procuram atendimento. Estes dados reforçam que as equipes estão disponíveis para a população.

\subsection{Existência de vagas diárias para pacientes não agendados pelas}

\section{ESF}

Tabela 6.121 - Existência de vagas diárias para pacientes não agendados

\begin{tabular}{l|c|c}
\hline $\begin{array}{c}\text { Existência de } \mathbf{n}^{\circ} \text { de vagas diárias } \\
\text { para pacientes não agendados }\end{array}$ & Total & $\%$ \\
\hline Sim & 545 & $53.6 \%$ \\
Não & 471 & $46.4 \%$ \\
\hline Total & 1016 & $100 \%$ \\
\hline $\mathrm{n}=1043$
\end{tabular}

Praticamente metade das equipes reserva vagas diárias para atendimentos não agendados e metade não reserva.

Tabela 6.122 - Tempo de implantação, porte dos municípios e existência de vagas diárias para pacientes não agendados

\begin{tabular}{|c|c|c|c|c|c|c|c|}
\hline \multicolumn{8}{|c|}{ Existência de $n^{\circ}$ de vagas diárias para pacientes não aqendados } \\
\hline Tempo implantação & $\operatorname{sim}$ & não & Total & Porte dos municípios & $\operatorname{sim}$ & não & Total \\
\hline \multirow[t]{2}{*}{5 anos ou +} & 11 & 34 & 45 & $<20$ mil & 206 & 104 & 310 \\
\hline & $24.4 \%$ & $75.6 \%$ & $100 \%$ & & $66.5 \%$ & $33.5 \%$ & $30.5 \%$ \\
\hline \multirow[t]{2}{*}{3 a 5 anos } & 84 & & 136 & 20 a 50 mil & 86 & & 176 \\
\hline & $61.8 \%$ & $38.2 \%$ & $13.5 \%$ & & $48.9 \%$ & $51.1 \%$ & $17.3 \%$ \\
\hline \multirow[t]{2}{*}{1 a 3 anos } & 262 & 241 & 503 & 50 a $100 \mathrm{mil}$ & 65 & & 134 \\
\hline & $52.1 \%$ & $47.9 \%$ & $49.9 \%$ & & $48.5 \%$ & $51.5 \%$ & $13.2 \%$ \\
\hline \multirow[t]{2}{*}{$<1$ ano } & 186 & 139 & 325 & > $100 \mathrm{mil}$ & 188 & 208 & 396 \\
\hline & $57.2 \%$ & $42.8 \%$ & $32.2 \%$ & & $47.5 \%$ & $52.5 \%$ & $39.0 \%$ \\
\hline \multirow[t]{2}{*}{ Total } & 543 & 466 & 1009 & Total & 545 & 471 & 1016 \\
\hline & $53.8 \%$ & $46.2 \%$ & $100 \%$ & & $53.6 \%$ & $46.4 \%$ & $100 \%$ \\
\hline
\end{tabular}

$\mathrm{n}=1043$

Chama a atenção que apenas $24 \%$ das equipes implantadas há 5 anos ou mais reservam vagas diárias para atendimentos eventuais. Nas demais equipes este percentual está em $50 \%$. Em relação ao porte dos municípios, verifica-se que cerca de metade das equipes dos municípios de 
porte maior que 20 mil habitantes não reserva vagas diárias para atendimento a pacientes não agendados.

6.5.1 Participação dos profissionais nas reuniões de equipe

Tabela 6.123 - Participação dos profissionais das ESF nas reuniões de equipe

\begin{tabular}{l|r|r|r|r}
\multicolumn{1}{c|}{ Reunião de equipe } & \multicolumn{1}{c}{ Sim } & \multicolumn{1}{c}{ Não } & Sem informação & \multicolumn{1}{c}{ Total } \\
\hline Médicos & 82,5 & 9,1 & 8,4 & 100,0 \\
Enfermeiros & 90,9 & 6,6 & 2,5 & 100,0 \\
Auxiliares de enfermagem & 88,6 & 4,0 & 7,4 & 100,0 \\
ACS & 95,2 & 3,9 & 0,9 & 100,0 \\
\hline
\end{tabular}

$\mathrm{n}=1043$

De maneira geral esta atividade apresenta-se incorporada por pelo menos $90 \%$ enfermeiros e ACS, e pelo menos $80 \%$ dos médicos e auxiliares de enfermagem.

Tabela 6.124 - Tempo de implantação e participação de reunião de equipe pelos profissionais das ESF

\begin{tabular}{|c|c|c|c|c|}
\hline \multicolumn{5}{|c|}{ Participação de reunião de equipes pelos profissionais das ESF } \\
\hline $\begin{array}{c}\text { Tempo } \\
\text { implantação }\end{array}$ & Médico & Enfermeiro & $\begin{array}{l}\text { Auxiliar de } \\
\text { enfermagem }\end{array}$ & ACS \\
\hline \multirow[t]{2}{*}{5 anos ou +} & 38 & 39 & 39 & 43 \\
\hline & $92.7 \%$ & $100 \%$ & $95.1 \%$ & $100 \%$ \\
\hline \multirow[t]{2}{*}{3 a 5 anos } & 107 & 119 & 122 & 132 \\
\hline & $87.7 \%$ & $100 \%$ & $91.0 \%$ & $100 \%$ \\
\hline \multirow[t]{2}{*}{1 a 3 anos } & 415 & 451 & 460 & 482 \\
\hline & $88.5 \%$ & $100 \%$ & $91.8 \%$ & $100 \%$ \\
\hline \multirow[t]{2}{*}{$<1$ ano } & 292 & 307 & 319 & 328 \\
\hline & $92.7 \%$ & $100 \%$ & $95.8 \%$ & $100 \%$ \\
\hline \multirow[t]{2}{*}{ Total } & 852 & 916 & 940 & 985 \\
\hline & $90.0 \%$ & $100 \%$ & $93.2 \%$ & $100 \%$ \\
\hline
\end{tabular}

$\mathrm{n}=1043$

Não há variações significativas da participação dos profissionais nas reuniões de equipe em relação ao tempo de implantação ou ao porte dos municípios. 


\subsection{Instrumentos de planejamento e organização do trabalho das ESF}

6.6.1 Existência dos Instrumentos de planejamento do trabalho das equipes de ESF

No panorama geral, a existência dos instrumentos de planejamento do trabalho das equipes apresenta-se muito baixa, sendo que apenas $1 / 3$ classificam-se como adequada e quase este mesmo quantitativo apresenta a condição insuficiente (Tabela 6.110).

Em relação ao tempo de implantação, observa-se que nas equipes mais antigas e nas dos municípios de maior porte, a condição pelo menos suficiente para a existência do conjunto de instrumentos para o planejamento do trabalho, está mais presente (Tabela 6.111). Esta condição varia entre $30 \%$ a $62 \%$ das equipes mais novas para as mais antigas e de $14 \%$ a $52 \%$ dos municípios menores para os maiores, sugerindo que o tempo de implantação das equipes pode ser um fator de adequação na incorporação destes instrumentos e que os municípios de maior porte podem deter melhores condições para a incorporação dos mesmos (Tabela 6.111).

6.6.2 Existência de área de abrangência definida e de mapa da área de abrangência para as ESF

Evidencia-se que quase todas as equipes têm área de abrangência definida para o exercício de suas atividades. Cabe destacar, no entanto, que aproximadamente 1/3 das ESF não possui o mapa da área (Tabela 6.113). 
A definição da área de abrangência que se concretiza pela realização do cadastramento das famílias e o mapeamento desta área com a elaboração pelas equipes dos mapas ditos "falados", "animados" ou "vivos", possibilitam primeiro a identificação de todas as pessoas e famílias sob responsabilização das equipes e através dos mapas, a visualização do território por toda a equipe com localização dos principais aspectos selecionados pelas mesmas quanto a áreas e grupos de risco aos quais as equipes precisam dar mais atenção como também a rede de apoio para o desenvolvimento de suas atividades. Estes dados possibilitam que as equipes realizem o diagnóstico de saúde da comunidade e o planejamento das atividades das ESF. (BRASIL, MS, 2001)

Observa-se que nem o tempo de implantação nem o tamanho dos municípios apresentam-se como relevantes para a existência de área de abrangência definida para as equipes (Tabela 6.113). No entanto, em relação à existência de mapa da área de abrangência verifica-se variações tanto em relação ao tempo de implantação quanto ao porte dos municípios (Tabela 6.114). Considerando-se o tempo de implantação das equipes, verifica-se que $90 \%$ das equipes mais antigas possuem mapa da área de abrangência. As demais faixas apresentam variação entre $70 \%$ a $77 \%$ (Tabela 6.114).

Em relação ao porte dos municípios, o mesmo aparece menos verificado (2/3) nas equipes dos municípios de porte entre 50 a 100 mil 
habitantes e mais verificado (80\%) nos municípios com mais de 100 mil habitantes (Tabela 6.114).

Em relação aos Estados do sudeste, o Estado do Rio de Janeiro apresenta a maior freqüência, cerca de $78 \%$, de equipes que possuem mapa de área de abrangência. $O$ Estado de São Paulo apresenta freqüência superior à média nacional (55\%) para esta condição. (AVALIAÇÃO NORMATIVA - MS)

6.6.3 Utilização das informações do SIAB para planejamento das atividades das ESF

Chama a atenção que quase $40 \%$ das equipes não usam o SIAB para o planejamento e monitoramento das ações, fato coerente com o baixo percentual da existência de equipamento de informática à disposição das ESF e também com o insuficiente treinamento de preenchimento do mesmo pelas equipes (Tabela 6.115). Cabe lembrar que o Sistema de Informação da Atenção Básica (SIAB), foi elaborado para registrar informações de ações da atenção básica de maneira geral, mas que se concretizou como o sistema de informações do PACS/PSF, que apresenta informações do cadastramento dos profissionais que estão atuando nas equipes e várias informações sócio-demográficas, de morbidade e mortalidade que permitem o planejamento de ações e o acompanhamento de saúde referente às famílias cadastradas. Portanto, mesmo frente a algumas limitações que existem na sua utilização, é um instrumento fundamental para o 
desenvolvimento do trabalho das equipes devendo ser utilizado por $100 \%$ das mesmas. (MEDINA, 2002; SIAB, 2000)

Quanto ao tempo de implantação das ESF, verifica-se que apenas $1 / 3$ das equipes implantadas há pelo menos 3 anos utilizavam o SIAB para programar suas ações. Este percentual aumenta nas equipes implantadas há menos de 3 anos, mas não atinge metade das mesmas (Tabela 6.115).

Quanto ao porte do município chama a atenção que a freqüência de equipes que não utilizam o SIAB é maior nos municípios com mais de 100 mil habitantes, diminuindo nas dos municípios de menor porte variando entre $50 \%$ a $73 \%$ respectivamente (Tabela 6.115 ).

Parece haver uma tendência de que as equipes dos municípios de menor porte e as equipes com menor tempo de implantação utilizem o SIAB para o planejamento de suas atividades. De qualquer maneira, a utilização do SIAB pelas equipes está muito aquém do esperado, uma vez que este instrumento foi idealizado para o planejamento e monitoramento das atividades que costumam ser mais freqüentes na demanda de atenção básica aos serviços de saúde tendo seu maior significado de utilização em nível local.

Em relação aos estados do sudeste, tanto São Paulo quanto o Rio de Janeiro apresentam as maiores freqüências de utilização do SIAB para planejamento de suas ações e ambos situam-se acima da média nacional, que é de 49\%. (AVALIAÇÃO NORMATIVA - MS) 
6.6.4 Existência de cronograma semanal de atividades para os profissionais das ESF

A existência de cronograma semanal de atividades é observada para $53 \%$ dos auxiliares de enfermagem, $54 \%$ dos ACS, $62 \%$ dos médicos e $63 \%$ dos enfermeiros (Tabela 6.116). É preocupante o baixo percentual de existência de cronograma semanal de atividades para todos os profissionais das equipes, pois se espera que componha o planejamento e a organização do trabalho as equipes a forma como estes profissionais se incluem na definição das ações necessárias as populações, incluindo suas próprias necessidades de capacitação, além da determinação dos períodos que serão dedicados, no caso dos médicos e enfermeiros, aos atendimentos clínicos programados e eventuais, bem como da distribuição de reunião de equipe e com a comunidade e visita domiciliar ou outras atividades que as equipes julgarem necessárias.

No panorama geral, vê-se a existência de cronograma semanal de atividades para todos os profissionais das equipes pode mais observada naquelas com mais tempo de implantação e nas equipes dos municípios maiores, sugerindo a possibilidade de haver uma relação entre eles (Tabela 6.117). Portanto, mesmo considerando que o tempo de implantação das equipes possa ser um fator e adequação, é preocupante que menos da metade das equipes tenha relatado não possuir cronograma semanal de atividades. (SÃO PAULO, SECRETARIA MUNICIPAL DE SAÚDE, 2005) 
6.6.5 Utilização de prontuário pelas ESF e tipo de prontuário existentes nas UBS

Em relação à anotação sistematizada dos dados relativos ao atendimento dos usuários, $95 \%$ das equipes têm prontuário e destas apenas $66 \%$ referem utilizar prontuários familiares (Tabela 6.118). (SCHRAIBER, NEMES, MENDES-GONÇALVES, 2000). Quanto à composição dos prontuários familiares verifica-se que $64 \%$ possuem prontuários individuais, aproximadamente $1 / 3$ possuem a Ficha A do SIAB (cadastramento das famílias-situação da família quanto à morbidade, condições de moradia, trabalho, saneamento e aspectos sócio-econômico e cultural), e apenas $26 \%$ possuem anotações sobre situação de risco das famílias, como por exemplo, a Ficha B do SIAB (que permite o acompanhamento de algumas condições de saúde como, por exemplo, gestante, criança, hanseníase, tuberculose, diabetes e hipertensão arterial) (Tabela 6.118).

A existência de prontuário familiar com os dados cadastrais das famílias, e de dados sobre situações de risco como a existência de doenças, condições de violência, desemprego e escolaridade ou da dinâmica familiar, permitiria trabalhar com uma abordagem diferenciada e mais ampliada incorporando outros determinantes da saúde. Entretanto, observa-se que além de a maioria das equipes não utilizar prontuários familiares ainda não existe uma clareza sobre a composição dos mesmos. 
6.6.6 Atendimento a pacientes não agendados

Quase $100 \%$ das equipes atendem a pacientes não agendados, sendo que apenas $1 \%$ encaminha estes pacientes diretamente para o PA; $53 \%$ realizam triagem para atendimento de urgência e $42 \%$ atendem todos que procuram as UBS (Tabela 6.121). Estes dados sugerem a incorporação das ações de Pronto Atendimento juntamente com $\mathrm{o}$ atendimento as consultas programadas evidenciando que as equipes estão de algum modo disponíveis para a população e demonstram um padrão condizente com o esperado para as mesmas.

De maneira geral, pouco mais da metade das equipes reservam vagas diárias para atendimentos eventuais (Tabela 6.121). Chama a atenção que nas equipes mais antigas observa-se que menos de $2 / 3$ das equipes reservam estas vagas e que nas demais este percentual varia de $52 \%$ a $62 \%$ (Tabela 6.122). Em relação ao porte dos municípios verifica-se $2 / 3$ das equipes dos municípios de porte maior que 20 mil reservam vagas diárias (Tabela 6.122).

A não existência de vagas diárias destinadas a pacientes não agendados pode significar entre outras questões, dificuldades no planejamento das atividades das equipes, desequilíbrio entre ações programáticas e de PA, com tendência a realizar mais PA com menor possibilidade de incorporar outras ações esperadas no PSF ou no outro 
extremo um atendimento sem flexibilização para entender a realidade da população adstrita. (SCHRAIBER, NEMES, MENDES-GONÇALVES, 2000).

6.6.7 Participação dos profissionais nas reuniões de equipe

Esta atividade apresenta-se incorporada pela maioria dos profissionais das equipes, sendo os médicos os auxiliares de enfermagem os que menos participam (Tabela 6.123). Não há variações significativas da participação dos profissionais nas reuniões de equipe em relação ao tempo de implantação ou ao porte dos municípios (Tabela 6.124). Cabe ressaltar a importância das reuniões de equipe para o processo de trabalho do PSF, enquanto um espaço destinado ao planejamento e avaliação das atividades, discussão de casos e de capacitação das equipes.

Os estados de São Paulo e do Rio de Janeiro apresentam freqüências semelhantes de médicos, enfermeiros, auxiliares de enfermagem e ACS que participam das reuniões de equipe, e ambos discretamente maiores da região Sudeste.

O Estado de São Paulo apresenta participação semelhante à média nacional para médicos, enfermeiros e auxiliares de enfermagem (média nacional observada: $82 \%=$ médicos; $91 \%=$ enfermeiros; $87 \%=$ auxiliares de enfermagem) e superior a de ACS que é de 90\%. (AVALIAÇÃO NORMATIVA - MS) 


\subsection{Capacitação das ESF}

\subsubsection{Capacitação geral das ESF}

Tabela 6.125 - Capacitação dos profissionais das ESF

\begin{tabular}{l|r|r|r|r|r}
\hline \multicolumn{5}{c}{ Capacitação dos profissionais das equipes } \\
\hline & Médico & Enfermeiro & Auxiliar de enfermagem & ACS & ESF \\
\hline Aidpi & 15,1 & 14 & 3,9 & 8,1 & 10,3 \\
Diabetes & 43,6 & 46,1 & 50,7 & 61,6 & 50,5 \\
Hipertensão & 45,9 & 46,1 & 55,6 & 62,5 & 52,5 \\
Dst/ Aids & 35,7 & 37 & 33,7 & 50,7 & 39,3 \\
Hanseníase. & 34 & 37,9 & 32,6 & 51,7 & 39 \\
Imunização. & 22,2 & 54,4 & 50,4 & 52,8 & 45 \\
Saúde Mulher & 35,5 & 40,5 & 34,7 & 48 & 39,7 \\
Treinamento .Introdutório. & 57,1 & 65,6 & 66,6 & 83,3 & 68,2 \\
Treinamento .Preenchimento SIAB & 39,4 & 58,8 & 47,9 & 76,1 & 55,6 \\
Tuberculose & 37,1 & 42,6 & 35,7 & 51,8 & 41,8 \\
\hline
\end{tabular}

$\mathrm{n}=1043$

O percentual de capacitações realizadas pelos profissionais das equipes figura muito baixo, à exceção de treinamento introdutório e para preenchimento do SIAB para os ACS.

A capacitação mais realizada pelos médicos está no treinamento introdutório e as menos referidas são imunização e AIDPI. Os enfermeiros referem ter realizado mais capacitação em treinamento introdutório, preenchimento do SIAB e imunização e menos em AIDPI. Os auxiliares de enfermagem receberam mais capacitação em treinamento introdutório, hipertensão arterial, diabetes e menos em AIDPI. Já os ACS receberam capacitação em todas as áreas acima de $50 \%$, exceto em saúde da mulher $(48 \%)$. 
Tabela 6.126 - Situação do conjunto de capacitações dos profissionais das equipes segundo classificação adotada

\begin{tabular}{l|r|r|r|r|r}
\hline \multicolumn{1}{c|}{ Capacitações das ESF } & ACS & Auxiliar enfermagem & Médico & Enfermeiro & ESF \\
\hline Adequada & 5,5 & 2,3 & 3,5 & 5,0 & 3,9 \\
Suficiente & 32.0 & 15,8 & 13,1 & 17,7 & 19,7 \\
Mínima & 22,8 & 25,4 & 22,9 & 25,7 & 24,3 \\
Insuficiente & 39,7 & 41,0 & 34,7 & 34,6 & 35,8 \\
Sem informação & 8.0 & 15,4 & 25,8 & 17,0 & 16,5 \\
\hline Total & 100 & 100,0 & 100,0 & 100 & 100,0 \\
\hline
\end{tabular}

Em geral os ACS apresentaram maior percentual de condição pelo menos suficiente de capacitações, e este percentual não ultrapassa $40 \%$. Para os demais profissionais este percentual não ultrapassa $23 \%$.

Tabela 6.127 - Tempo de implantação e condição pelo menos suficiente de capacitação dos profissionais das ESF segundo classificação adotada

\begin{tabular}{l|r|r|r|r|r}
\hline \multicolumn{5}{c}{ Condição pelo menos suficiente de capacitação das ESF } \\
\hline \multicolumn{1}{c|}{ Tempo implantação } & \multicolumn{1}{c}{ ACS } & Auxiliar enfermagem & Enfermeiro & Médico \\
\hline 5 anos ou + & 25 & 16 & 11 & 12 \\
& $55.6 \%$ & $35.6 \%$ & $24.4 \%$ & $26.6 \%$ \\
3 a 5 anos & 53,0 & 22 & 48 & 34 \\
& $38.7 \%$ & $16.1 \%$ & $35 \%$ & $24.8 \%$ \\
1 a 3 anos & 230,0 & 91 & 125 & 88 \\
& $44.7 \%$ & $17.7 \%$ & $24.3 \%$ & $17.1 \%$ \\
$<1$ ano & 79,0 & 37 & 53 & 37 \\
& $23.4 \%$ & $11 \%$ & $16.7 \%$ & $11 \%$ \\
\hline Total & 387,0 & 166 & 237 & 171 \\
& $37.4 \%$ & $15.9 \%$ & $22.9 \%$ & $16.5 \%$ \\
\hline$n=1043$ & & & &
\end{tabular}

Os médicos e auxiliares de enfermagem das equipes implantadas há mais tempo apresentaram mais a condição pelo menos suficiente de capacitação que as implantadas mais recentemente.

Verifica-se que há um aumento do percentual de enfermeiros que apresentaram esta condição nas equipes implantadas há mais tempo, variando de $17 \%$ a $35 \%$, exceto nas equipes com 5 anos ou mais cujo valor é $24 \%$. De maneira semelhante, as equipes mais antigas apresentam maior percentual de ACS na condição de capacitação referida, exceto as equipes implantadas entre 3 e 5 anos, variando entre $23 \%$ a $57 \%$. 
Tabela 6.128 - Porte dos municípios e condição pelo menos suficiente de capacitação dos profissionais das ESF segundo classificação adotada

\begin{tabular}{|c|c|c|c|c|}
\hline \multicolumn{5}{|c|}{ Condição pelo menos suficiente de capacitação das ESF } \\
\hline Porte dos municípios & ACS & Auxiliar enfermagem & Enfermeiro & Médico \\
\hline \multirow[t]{2}{*}{$<20$ mil } & 78 & 39 & 44 & 48 \\
\hline & $24.5 \%$ & $12.2 \%$ & $13.9 \%$ & $15.1 \%$ \\
\hline \multirow{2}{*}{20 a 50 mil } & 69 & 25 & 27 & 35 \\
\hline & $44.1 \%$ & $14.0 \%$ & $15.1 \%$ & $19.6 \%$ \\
\hline \multirow[t]{2}{*}{50 a $100 \mathrm{mil}$} & 73 & 24 & 39 & 31 \\
\hline & $53.3 \%$ & $17.5 \%$ & $28.5 \%$ & $22.6 \%$ \\
\hline \multirow[t]{2}{*}{$>100 \mathrm{mil}$} & 161 & 78 & 127 & \\
\hline & $39.4 \%$ & $19.1 \%$ & $31.0 \%$ & $14.4 \%$ \\
\hline \multirow[t]{2}{*}{ Total } & 391 & 166 & 237 & 173 \\
\hline & $37.5 \%$ & $15.9 \%$ & $22.7 \%$ & $16.6 \%$ \\
\hline
\end{tabular}

$\mathrm{n}=1043$

O percentual da condição pelo menos suficiente de capacitação dos profissionais das equipes tende a aumentar com o porte dos municípios, exceto para ACS e médicos dos municípios de maior porte onde este valor diminui, se aproximando do percentual dos municípios menores.

6.7.2 Existência de programa sistemático de educação continuada para os profissionais das equipes

Tabela 6.129 - Existência de programa sistemático de educação continuada para os profissionais das ESF

\begin{tabular}{l|r|r|r|r}
\hline Programa de educação continuada & \% Sim & \% Não & \% Sem informação & \multicolumn{1}{|c}{ Total } \\
\hline Médico & 36,8 & 60,6 & 2,6 & 100 \\
Enfermeiro & 35,7 & 61,9 & 2,4 & 100 \\
Auxiliar de enfermagem & 31,9 & 66 & 2,1 & 100 \\
ACS & 35,7 & 62,5 & 1,8 & 100 \\
\hline$n=1043$
\end{tabular}

$\mathrm{n}=1043$

Menos de $40 \%$ dos profissionais estavam ligados a um programa sistemático de educação continuada. 


\subsection{Capacitação das ESF}

\subsubsection{Capacitação geral das ESF}

Em relação às capacitações recebidas pelas equipes a classificação adotada por este estudo para a condição adequada espera-se capacitação em $100 \%$ dos itens pesquisados, que correspondem às ações a serem desenvolvidas pela atenção básica prevista na NOAS/2002. (BRASIL, MS, 2002; BRASIL, MS, 2006)

Cabe ressaltar que não se considerou a necessidade individual dos profissionais nestas áreas e as informações referem-se às capacitações recebidas após o início do trabalho no PSF. Observa-se que em média, as três capacitações mais realizadas: treinamento introdutório, hipertensão e diabetes, por menos de 2/3 das equipes (Tabela 6.125).

As capacitações em AIDPI, imunização, hanseníase e saúde da mulher figuram como as menos realizadas e não ultrapassaram $40 \%$ das equipes. Apenas $40 \%$ das ESF realizaram treinamento introdutório e somente $39 \%$ delas para preenchimento do SIAB (Tabela 6.125).

Observando-se as capacitações realizadas por categoria profissional é possível verificar que os médicos receberam mais capacitação em treinamento introdutório e menos em imunização e AIDPI; os enfermeiros em treinamento introdutório, preenchimento do SIAB e imunização e menos em AIDPI; os auxiliares de enfermagem realizaram mais capacitações em 
treinamento introdutório, hipertensão arterial e diabetes e menos em AIDPI, já os ACS receberam capacitação em todas as áreas acima de $50 \%$, exceto em saúde da mulher e em AIDPI (Tabela 6.125).

Quando se considera o conjunto de capacitações que deveria ser realizado pelas equipes, chama a atenção o baixo percentual da condição pelo menos suficiente do mesmo que as equipes apresentaram, e que, exceto para os ACS, não alcançou $1 / 3$ das ESF (Tabela 6.126). Esta condição figura mais nas equipes implantadas há mais tempo e nos municípios de maior porte, e de maneira geral tende a aumentar com o tempo e o porte, exceto para ACS e médicos, onde se verifica uma diminuição nos municípios acima de 100 mil habitantes, cujos percentuais se aproximam ao dos municípios de menor porte (Tabela 6.127). Estas observações sugerem que o tempo de implantação das equipes possa ser um fator positivo na capacitação das equipes nas áreas previstas de atuação da atenção básica.

Considerando-se que estas áreas de atenção são fundamentais no atendimento da demanda que usualmente utilizam os serviços das UBS e que os profissionais notadamente os médicos que migram para trabalhar no PSF vêm de diversas especialidades, que é necessário a incorporação de perspectivas e ferramentas diferenciadas para avançar na integralidade e resolubilidade da atenção previstas no PSF, é preocupante o baixo percentual destas capacitações. (MACHADO, 2002) 
6.8.1.1 Capacitação das ESF em Treinamento Introdutório e preenchimento do Sistema de Informação da Atenção Básica (SIAB)

Treinamento introdutório (68\%) e treinamento para preenchimento do SIAB (55\%), são as duas capacitações mais realizadas pelas equipes. Quando observados individualmente, os médicos são os que menos participaram de capacitações para preenchimento do SIAB e do treinamento introdutório, $40 \%$ e $57 \%$ respectivamente. Os ACS são os que mais realizaram estas capacitações, sendo que $83 \%$ participaram do treinamento introdutório e $76 \%$ do preenchimento do SIAB (Tabela 6.125). Chamam a atenção, além do baixo percentual de realização destas capacitações, as diferenças entre as várias categorias na realização do dos mesmos. Estas capacitações são estratégicas na diferenciação de outras formas de atenção básica e deveriam ser realizadas para $100 \%$ das equipes, preferencialmente antes do início das atividades, uma vez que é nestas capacitações que são apresentados os princípios, as diretrizes do PSF e a organização do trabalho, além da operacionalização do sistema de informação que são a base para o planejamento, o monitoramento das atividades e do processo de trabalho das equipes. (BRASIL, MS, 2001; BRASIL, MS, 2000)

Em relação aos Estados do Sudeste, São Paulo apresenta freqüência de médicos e enfermeiros que participaram de treinamento introdutório, menor que as observadas para os estados do Espírito Santo e do Rio de Janeiro. Apresenta também freqüência menor que a média nacional, cerca de $62 \%$. Já em relação ao treinamento para preenchimento 
do SIAB o Estado de São Paulo apresenta freqüência menor que o Estado do Rio de Janeiro para médicos e enfermeiros e situa-se acima da média nacional que é de $38 \%$ médicos e $55 \%$ enfermeiros. (AVALIAÇÃO NORMATIVA - MS)

\subsubsection{Capacitação das ESF em saúde da criança}

A capacitação com menor freqüência de realização pelas equipes, cerca de 10\%, aparece como o treinamento na estratégia Atenção Integral a Doenças Prevalentes na Infância - AIDPI, sendo realizada por apenas $4 \%$ dos auxiliares de enfermagem, não ultrapassando $15 \%$ para os demais profissionais (Tabela 6.125). Apenas $22 \%$ dos médicos realizaram capacitação em imunização, e para os demais componentes da equipe este percentual situou-se ao redor de 50\% (Tabela 6.125). Em relação aos estados do Sudeste, São Paulo apresenta maior freqüência de médicos e enfermeiros com esta capacitação e inferior à média nacional, que é $17 \%$ para os médicos e $21 \%$ para os enfermeiros. Já quanto à capacitação em imunização realizada pelos médicos e enfermeiros, o Estado de São Paulo apresenta freqüência inferior à do Rio de Janeiro e situa-se acima da média nacional (17\%, médicos e 50\%, enfermeiros). (AVALIAÇÃO NORMATIVA MS) 


\subsubsection{Capacitação das ESF em saúde da mulher}

Evidencia-se que, de maneira geral, os percentuais de capacitação em saúde da mulher estão baixos, não ultrapassando na média $40 \%$ das equipes. Os profissionais que apresentam maior freqüência de capacitação em saúde da mulher são os ACS, cerca de $48 \%$, e os enfermeiros, cerca de $40 \%$. Apenas cerca de $35 \%$ dos médicos e dos auxiliares de enfermagem realizaram esta capacitação (Tabela 6.125). O Estado de São Paulo apresenta freqüência inferior que o Rio de Janeiro tanto para os médicos, cerca de $55 \%$ como para os enfermeiros, cerca de $44 \%$. Apresenta freqüência superior a media nacional, para os médicos (31\%) e inferior para os enfermeiros (44\%). (AVALIAÇÃO NORMATIVA - MS)

\subsubsection{Capacitação das ESF em diabetes e hipertensão arterial}

A busca ativa e o controle do diabetes e da hipertensão arterial são duas ações consideradas estratégicas na atenção a saúde do adulto e na redução da morbi-mortalidade conseqüentes destas patologias. Assim, chama a atenção que o percentual de médicos e enfermeiros com capacitação nestas áreas não tenha ultrapassado $50 \%$ dos mesmos (Tabela 6.125). O Estado de São Paulo apresenta percentuais de capacitação em hipertensão arterial e diabetes para médicos e enfermeiros inferiores que os apresentados pelo Rio de Janeiro; apresenta ainda nas duas áreas, percentuais um pouco maiores que a média nacional, tanto para os médicos (42\%) como para os enfermeiros (45\%). (AVALIAÇÃO NORMATIVA - MS) 


\subsubsection{Capacitação as ESF em hanseníase, tuberculose e DST/AIDS}

Verifica-se que os ACS são os profissionais que apresentaram maior percentual de capacitação nestas áreas, acima de $50 \%$. Para os demais profissionais este percentual apresenta uma variação entre $33 \%$, capacitação dos auxiliares de enfermagem em hanseníase, a $43 \%$, capacitação dos enfermeiros em tuberculose (Tabela 6.125). O Estado de São Paulo, apresenta para os médicos e enfermeiros percentuais de capacitação em hanseníase inferiores aos Estados do Espírito Santo e Rio de Janeiro, e apresenta média semelhante à nacional para os médicos (34\%) e inferior para os enfermeiros (42\%). (AVALIAÇÃO NORMATIVA MS)

Quanto à capacitação em tuberculose, o Estado de São Paulo apresenta em relação à região Sudeste, situação semelhante à observada anteriormente. Já o Estado de São Paulo apresenta percentual de capacitação de médicos e enfermeiros em tuberculose superior a média nacional (34\% médicos e 40\% enfermeiros). (AVALIAÇÃO NORMATIVA MS)

6.8.2 Existência e programa sistemático de educação continuada para os profissionais das equipes

Ressalta-se o pequeno número de profissionais que referiram estarem ligados a um programa sistemático de educação continuada (Tabela 6.129). Cabe destacar também que uma das formas pensadas para a 
superação da ausência de formação específica de recursos humanos para atuarem no PSF é exatamente a vinculação dos mesmos a programas deste tipo. Estes baixos percentuais podem estar ligados ao fato dos Pólos de Capacitação em Saúde da Família estarem atuando de maneira incipiente frente à demanda crescente por capacitação apresentada pelas equipes de saúde da família, sendo necessário ampliar não somente o número de capacitações como repensar o formato das mesmas. (BRASIL, MS, 2000)

\subsubsection{Participação e controle social por profissionais das ESF}

Tabela 6.130 - Participação regular em reuniões do CMS (Conselho Municipal de Saúde) ou CLS (Conselho Local de Saúde) por profissionais das ESF

\begin{tabular}{l|c|c}
\hline $\begin{array}{c}\text { Participação em reunião do } \\
\text { CMS ou CLS }\end{array}$ & $\mathbf{N}^{\circ}$ & $\%$ \\
\hline Sim & 344 & 33,0 \\
Não & 677 & 64,9 \\
Sem informação & 22 & 2,1 \\
\hline Total & 1043 & 100,0 \\
\hline
\end{tabular}

Apenas $33 \%$ dos profissionais das ESF participam regularmente de reuniões do CMS ou CLS. Valores muito baixos para uma ação prevista nas diretrizes do PSF. (BRASIL, MS, 1997)

Quanto aos estados do Sudeste todos apresentam freqüência inferior a 50\%, o Estado de São Paulo apresenta freqüência menor que o Estado do Rio de Janeiro que é de $42 \%$, e próxima da média nacional, que é de 37\%. (AVALIAÇÃO NORMATIVA - MS) 


\section{CONSIDERAÇÕES FINAIS}

\section{Caracterização dos municípios com PSF implantado no estado} de São Paulo

$\mathrm{Na}$ primeira parte deste estudo procurou-se verificar as características da implantação do programa saúde da família no Estado de São Paulo. Um dos aspectos que pode ser observado é que a implantação do PSF inicia-se principalmente pelos municípios de maior porte, entretanto, a grande expansão do mesmo ocorre nos municípios de menor porte e nas equipes implantadas mais recentemente. Portanto, a primeira questão a ser considerada refere-se a pouca maturidade do programa no Estado, principalmente considerando-se a magnitude das mudanças que estão propostas no PSF. Contudo, o tempo de implantação do PSF no Estado de São Paulo condizia com o padrão brasileiro apresentando percentual semelhante de equipes implantadas há mais de 5 anos.

Outro aspecto que chamou a atenção foi a boa penetração do programa no Estado, com adesão de mais da metade dos municípios. Com destaque, a maior adesão proporcional (cerca de 2/3) aconteceu nos municípios com população entre 50 a 100 mil habitantes. Este fato contraria o que se tem propagado de que o PSF é preferentemente um modelo para municípios de pequeno porte. 
Como esperado, pode-se observar uma cobertura populacional dos municípios de menor porte. Entretanto, vale notar que apenas $11 \%$ da população do Estado estavam cobertas pelas ESF.

Outra característica do PSF no Estado é ser um programa predominantemente urbano. Entretanto, verifica-se que houve um crescimento da atuação em área rural e urbano-rural nas equipes implantadas há menos 3 anos. Este crescimento coincide com a destinação de incentivos estaduais para implantação do PSF em áreas de assentamentos rurais e de baixo índice de desenvolvimento humano. Dessa maneira é bem provável que o Estado tenha tido um papel importante na expansão do PSF na cobertura destas áreas.

Em relação à população adstrita, mais de $70 \%$ das equipes estavam de acordo com o parâmetro recomendado pelo MS. As equipes implantadas entre 3 e 5 anos e as equipes dos municípios de maior porte apresentaram maior percentual desta inadequação. Em parte, este fato se deve, provavelmente, devido à maior densidade demográfica nestes municípios, principalmente nas suas regiões periféricas, local preferencial de implantação do PSF nas grandes cidades.

Quanto ao número de equipes atuando por UBS, pode-se observar que na sua grande maioria trabalhavam no máximo 3 equipes, de acordo com o parâmetro recomendado pelo MS. Entretanto, constata-se que em $20 \%$ das UBS atuavam equipes em número acima do parâmetro 
recomendável. Há que se destacar que $2 / 3$ das UBS onde atuam de 6 a 7 equipes foram observadas naquelas implantadas há menos de 1 ano.

Com relação às dependências de área física destaca-se a maior freqüência para o consultório médico, havendo em média um consultório médico por equipe. Entretanto, é preciso destacar que esta proposição só foi observada naquelas UBS que apresentavam 1 ESF ou 5 ESF. Nas demais, o número médio de consultório médico foi discretamente inferior ao número de equipes existentes na unidade. Já o número de consultório de enfermagem, em média, era de meio por ESF.

Chamou atenção ainda a ausência de sala de vacina em mais de $20 \%$ nas UBS. Além disso, constatou-se que $2 / 3$ das UBS não apresentavam sala de reunião. Esta estrutura física sugere um padrão clássico de UBS em que se destaca o consultório médico. A ausência de sala de vacina e de consultório de enfermagem em algumas UBS indica que as UBS não apresentavam estrutura mínima adequada para a realização das atividades previstas pelo PSF. As informações recolhidas sugerem que a situação de adequação da área física para o trabalho das equipes, encontrava-se nos municípios maiores e nas equipes implantadas há mais tempo.

Vale destacar que o Estado de São Paulo situa-se abaixo da média nacional, em relação ao número de consultório por enfermagem por equipe. 
Quanto à existência do conjunto de equipamentos básicos para a realização do trabalho no PSF, apenas $4 \%$ das equipes apresentaram-se na classe adequada, isto é, dispunham de $100 \%$ dos itens pesquisados, enquanto que, menos de $2 / 3$ apresentavam a condição suficiente, isto é, a existência de pelo menos $80 \%$ destes equipamentos. Somente $40 \%$ das equipes apresentaram a condição mínima de equipamentos.

Sobre o "kit" básico para o atendimento de adultos, crianças e mulheres, verificou-se que os mesmos estavam ausentes para aproximadamente $20 \%$ das equipes. Com relação à disponibilidade do "kit" de equipamento que poderia contribuir para a maior resolubilidade assistencial da população adstrita, apenas $20 \%$ das equipes relataram a sua presença. Dentro o rol de equipamentos pesquisados, os itens menos encontrados são: oftalmoscópio e material para pequena cirurgia. Outro aspecto importante a ser destacado é que mais de $30 \%$ das UBS não dispunham de geladeira de vacina. De maneira geral a disponibilidade dos equipamentos necessários para se realizar um atendimento adequado à população mostrou-se irregular e em alguns casos precária o que pode comprometer uma atenção mais qualificada e resolutiva como preconiza as diretrizes do programa.

Em relação aos recursos humanos, questão fundamental na implantação do PSF, constatou-se que a maioria dos municípios contava com a equipe de saúde da família preconizada pelo MS. Somente em $2 \%$ das equipes os profissionais não estavam presentes há mais de 60 dias. 
Cabe-se destacar que a maioria das equipes contava com 2 auxiliares de enfermagem. Relativamente ao tempo de trabalho dos profissionais nas equipes, nota-se que a maioria estava nas equipes há menos de 3 anos. Considerando-se ESF com pelo menos 3 anos de implantação, há uma grande rotatividade dos profissionais, ou seja, apenas $22 \%$ dos médicos, $26 \%$ dos enfermeiros e $30 \%$ dos auxiliares de enfermagem estavam trabalhando na mesma equipe neste período. Cabe informar que esta observação não foi apurada com relação aos ACS. Em relação ao porte dos municípios há discreta tendência de maior tempo de permanência dos profissionais nas ESF nos municípios de maior porte. Também é importante ressaltar que o pouco tempo de permanência dos profissionais nas equipes, notadamente dos médicos, dificulta entre outros aspectos, o estabelecimento de rotinas, a capacitação dos profissionais e o estabelecimento de vínculos com a população.

A maioria dos profissionais é contratada para jornada de trabalho de 40 horas semanais, conforme preconizado pelas normas do MS para a implantação do PSF. Entretanto, pode-se verificar diferenças no cumprimento desta jornada, sendo os ACS os que mais cumprem, e os médicos os que menos cumprem.

Em relação à forma de vínculos contratuais dos profissionais, a maioria das equipes possuía contratos estáveis de trabalho, principalmente por meio de CLT. No entanto, pelo menos $20 \%$ dos profissionais apresentavam formas de contratação inadequadas para o PSF, 
principalmente, via contrato temporário. Há que se destacar, ainda, que os ACS e os médicos figuram como os profissionais que mais apresentaram formas de vinculação inadequadas e precárias, principalmente sendo do tipo de contratação informal e prestação de serviço para os médicos e, comissionamento ou prestação de serviço para os ACS. As formas de contratação não estáveis são fatores de inadequação para o trabalho do PSF, que além de rotatividade nas equipes, e os prejuízos dela decorrentes, provocam insegurança aos trabalhadores, devendo por isso ser desestimuladas.

Em relação ao tempo de implantação das equipes, observa-se que o percentual de vinculação trabalhista estável não apresentou variações significativas para os auxiliares de enfermagem e enfermeiros. Quanto aos ACS e aos médicos, constatou-se uma discreta diminuição desta nas equipes mais novas. As equipes mais antigas apresentam um aumento de médicos estatutários, enquanto que nas equipes recentemente implantadas, o contrato temporário é o mais adotado, tanto para os ACS quanto para os médicos. Levando em consideração o porte do município, verifica-se que nos menores a proporção de médicos contratados via contrato temporário é maior que nos demais municípios. Quanto à proporção dos demais profissionais contratados na forma temporária, verifica-se que esta é, diferentemente, menor nos municípios menores.

Em relação ao salário, em geral observa-se que $70 \%$ dos médicos percebem pelo menos 4.000 reais; $47 \%$ dos enfermeiros, 2.000 reais; $41 \%$ 
dos auxiliares de enfermagem, 700 reais; e que $40 \%$ dos ACS percebem pelo menos 350 reais. O que chama a atenção é que a diferença entre a proporção dos que percebem mais e aqueles que percebem menos, é maior entre os profissionais médicos, invertendo-se nas demais categorias, isto é, o percentual dos que ganham menos é maior do que aqueles que ganham mais. Verifica-se ainda que proporcionalmente os profissionais das equipes implantadas há mais tempo e os municípios de maior porte percebem os maiores salários. Existe uma diferença acentuada da proporção de profissionais que recebem o maior valor considerado na pesquisa para os salários dos profissionais das ESF do Estado de São Paulo e os dos estados da região Sudeste, relação esta mais acentuada para auxiliares de enfermagem e ACS. A exceção é constituída pelos enfermeiros em relação a uma situação, pois esta proporção em São Paulo é menor que a verificada em Minas Gerais. Em relação à média nacional esta proporção é maior para todos os profissionais das equipes paulistas.

Das atividades previstas para os profissionais das ESF, a realização de visita domiciliar é uma importante "ferramenta" do trabalho, pois possibilita o monitoramento da condição de saúde da população adstrita. Visita domiciliar é uma das questões diferenciais com outras formas de atenção básica $(A B)$, não porque elas não possam ser realizadas nestes outros modos de $A B$, mas sim porque é atribuição das equipes de saúde da família realizá-las. Verifica-se que a mesma apresenta-se como a atividade mais realizada pelos profissionais das equipes, enquanto reunião com a comunidade, outra possibilidade importante de ação ainda pouco explorada 
foi a atividade menos realizada. Em geral, $76 \%$ dos médicos e apenas $57 \%$ dos enfermeiros relataram desenvolver atendimentos nas clínicas básicas, isto é, em: pediatria, clínica médica e ginecologia/obstetrícia. Quando se toma o conjunto das atividades clínicas, a mais realizada por médicos e enfermeiros é o atendimento clínico em clínica médica, e a menos realizada é atendimento clínico em ginecologia e obstetrícia. Apesar dos percentuais elevados observados referentes aos atendimentos clínicos pelos médicos, esta situação demonstra uma condição preocupante quando se pensa na integralidade da atenção que as ESF devem prestar a todos os componentes das famílias, indiscriminadamente.

Cabe destacar que cerca de $1 / 3$ dos enfermeiros não realizam treinamentos, contrariando uma de suas atribuições específicas, previstas para o PSF. De maneira geral, constata-se que os atendimentos clínicos dos médicos e de enfermagem nas três clínicas básicas são realizados mais pelos profissionais das equipes implantadas há mais tempo e nos municípios de maior porte populacional. Estes achados podem significar que os municípios de maior porte têm maior facilidade em selecionar e capacitar seus profissionais e que o tempo de implantação pode ser um fator de superação desta inadequação. É importante colocar que é necessário minimizar esta diversidade na realização das atividades clínicas individuais esperadas para os profissionais do PSF, no sentido de conseguir práticas de saúde orientadas para a integralidade da atenção a saúde. Portanto, é fundamental para a continuidade do PSF selecionar profissionais mais 
preparados e enfatizar as capacitações dos mesmos, inclusive, nas práticas clínicas.

Considerando-se a classificação adotada para a realização do conjunto de atividades esperadas dos profissionais das equipes, observa-se que os médicos, enfermeiros e ACS das equipes implantadas há mais tempo e dos municípios de maior porte apresentaram maior percentual da classificação pelo menos suficiente, na realização destas ações, sugerindo que tempo de implantação e o porte dos municípios podem ser fatores de adequação para as mesmas. Entretanto, observou-se que os auxiliares de enfermagem das ESF implantadas há menos tempo e os dos municípios menores apresentavam os maiores percentuais de adequação na realização destas ações.

A maioria das equipes realizou ações relacionadas à atenção da saúde da mulher, exceto ações educativas em planejamento familiar, realizada por apenas metade das ESF. Cabe ressaltar que $20 \%$ dos médicos e metade dos enfermeiros não realizavam consultas em pré-natal, o que torna esta atenção bastante comprometida. As equipes implantadas há mais de 1 ano e nos municípios de porte maior que 20 mil habitantes apresentaram proporcionalmente maior freqüência de pelo menos suficiente na realização destas ações.

A atenção à saúde da criança apresentou-se como uma das áreas de fragilidade do PSF, principalmente pela não realização, por algumas 
equipes, de ações consideradas estratégicas. Destaca-se que 1/3 dos médicos e dos enfermeiros não realizava consulta médica de acompanhamento e desenvolvimento de crianças menores de 2 anos, uma das ações estratégicas para a saúde da criança. Também merece destaque que em cerca de $40 \%$ das equipes a atividade de imunização não era realizada nas UBS. Em geral o desempenho das ESF nesta área foi muito baixo, sendo que pouco mais de $1 / 3$ alcançou a condição pelo menos suficiente. A condição insuficiente foi mais observada nas equipes implantadas há menos de 1 ano e nos municípios com população menor que 20 mil habitantes.

As equipes apresentaram um bom desempenho em relação às ações de controle do diabetes e da hipertensão arterial, sendo este desempenho, aparentemente, não foi influenciada pelo tempo de implantação ou porte dos municípios.

Quanto às atividades de controle da tuberculose e eliminação da hanseníase, chama a atenção o baixo desempenho das equipes, inclusive no tratamento supervisionado de tuberculose, uma ação que poderia ser mais facilmente assumida pelas ESF através dos ACS que têm como atribuição a realização diária de visita domiciliar.

Das ações tradicionais de vigilância epidemiológica, a notificação compulsória de doenças foi incorporada por boa parte das equipes. Entretanto, apenas metade das equipes realizava investigação e controle de 
casos e de surtos, sendo estas atividades as que as equipes poderiam ter maior participação, tanto pelo processo de trabalho preconizado pelo PSF, como pela adstrição das mesmas no território. A realização destas atividades foi mais presente nas equipes implantadas há mais tempo e nas de maior e menor porte. A variação na realização das ações de vigilância epidemiológica provavelmente se deve à estruturação das áreas de vigilância epidemiológica nos sistemas municipais de saúde.

A investigação de óbitos estava presente em menos da metade das equipes e, a investigação das internações em pouco mais da metade das equipes. Ambas ações eram mais realizadas pelas equipes implantadas entre 3 e 5 anos e pelas equipes dos municípios de maior porte. Novamente cabe destacar que estas são ações em que se esperava que as ESF tivessem melhor desempenho pelas questões já relacionadas anteriormente.

Apenas metade das equipes realiza algum tipo de ação em saúde mental. Estas ações foram mais observadas nas equipes implantadas há mais tempo e nos municípios de maior porte.

As equipes apresentaram bom desempenho no controle das DST, principalmente na realização de diagnóstico sem, contudo, haver correspondência no tratamento que revela percentual discretamente menor nas práticas das equipes.

Quanto às atividades educativas em grupos, considerada uma das estratégias de promoção, chama atenção o baixo desempenho das ESF na 
realização dessas para desnutridos, adolescentes, escolares, idosos e no monitoramento do crescimento e desenvolvimento dos menores de 2 anos. Este achado questiona a integralidade da atenção preconizada pelo PSF.

Analisando a utilização dos instrumentos de planejamento do trabalho das equipes, verifica-se que a mesma foi satisfatória, exceto para a utilização de prontuário familiar do SIAB e do cronograma semanal de atividades para os profissionais das equipes, que para todos eles se mostrou baixa.

A existência de mapa da área e cronograma semanal de atividades, mostrou-se mais presente nas equipes implantadas há mais tempo e nos municípios maiores, enquanto que, a utilização do SIAB foi mais presente nas equipes dos municípios de menor porte. A utilização adequada destes instrumentos de planejamento e de organização do trabalho possibilitaria às equipes melhor compreensão e manejo do território e da situação de saúde da população adstrita.

Quanto ao tipo de prontuário nota-se que tanto os prontuários tradicionais como os familiares apresentaram basicamente a mesma composição, atentando ao fato que ambos apresentam um baixo percentual de registros. A melhor adequação de informações dos pacientes nos prontuários poderia ajudar os profissionais das equipes a realizarem um atendimento mais integral. 
Em relação à organização do trabalho das equipes, a maioria delas apresentou como parte da rotina do trabalho o atendimento à demanda espontânea e a participação dos profissionais nas reuniões internas de equipe. No entanto, a reserva de vagas diárias para os atendimentos eventuais, não compunha a maioria das rotinas de trabalho.

Consideradas as áreas de atuação previstas na atenção básica, em geral as ESF receberam capacitação insuficiente e irregular, sendo que somente $4 \%$ das equipes receberam capacitação adequada. Os ACS são os profissionais que mais receberam treinamentos e os médicos os que menos receberam. Os médicos receberam mais capacitação em treinamento introdutório e menos em AIDPI e imunização; os enfermeiros receberam mais treinamento introdutório, preenchimento do SIAB e em imunização e menos em AIDPI; os auxiliares de enfermagem realizaram mais capacitação em treinamento introdutório, hipertensão arterial e diabetes e menos em AIDPI, já os ACS receberam capacitação em todas as áreas acima de $50 \%$, exceto em saúde da mulher e em AIDPI.

A condição pelo menos suficiente em relação à realização de capacitação foi mais verificada nas equipes implantadas há mais tempo e nos municípios de maior porte. Parece existir uma relação positiva entre tempo de implantação e realização de capacitação profissional nas equipes.

Com relação à participação regular dos profissionais em reuniões do Conselho Municipal Saúde e/ou Conselho Local de Saúde apresentou baixa 
freqüência, muito aquém do esperado ao confrontar o ideal do PSF, que supõem o envolvimento das equipes com os assuntos relacionados à comunidade e ao programa.

Uma das questões que pôde ser verificada neste estudo foi que a implantação e o trabalho realizado pelas equipes de saúde da família no período analisado apresentou graus variados de aproximação com os aspectos relevantes das diretrizes da estratégia saúde da família. Algumas vezes estas aproximações puderam ser relacionadas ao tempo de implantação, algumas vezes ao tamanho dos municípios e muitas vezes não foi possível evidenciar com clareza qual a lógica que estava envolvida para maior ou menor aproximação entre o proposto nas diretrizes do PSF e as variáveis contempladas neste estudo. Sem dúvida a correta observação das proposições da saúde da família podem contribuir para avanços importantes na forma de prestar assistência à saúde das pessoas, incluindo a oportunidade de se estabelecer projetos mais amplos no trabalho em saúde, através de "cuidados integrais", do trabalho multidisciplinar, além de possibilitar, incluir, aproximar e considerar as diferenças socioeconômicas e culturais nas ações de saúde, de maneira a diminuir as iniqüidades e resultar melhorias nas vidas das pessoas. Entretanto, na maioria das vezes, estas possibilidades, referem-se muito mais às potencialidades existentes nos enunciados, naquilo que é recomendado, do que propriamente em sua efetivação no cotidiano das ESF. 
Dessa maneira, para que a estratégia saúde da família possa produzir os resultados esperados é preciso "cuidar" da sua implantação e isto pressupõe uma série de medidas capazes de prover os meios adequados pára o seu desenvolvimento. É importante destacar que o porte dos municípios não deveria ser uma questão diferenciadora da alocação destes meios, e que o tempo de implantação deveria ser um aliado no sentido do estabelecimento de rotinas adequadas, na qualificação do trabalho das equipes e no estabelecimento de vínculos entre a equipe e esta com a comunidade.

A existência de condições adequadas, área física, equipamentos e insumos, além da seleção e contratação adequada de profissionais, bem como da capacitação para o trabalho no PSF, é sem dúvida uma definição e decisão dos gestores. Para isso é necessário conhecer a estratégia saúde da família não só do ponto de vista das suas possibilidades, mas também dos seus limites, inclusive do significado que esta forma de atenção à saúde deve acarretar na reorganização do sistema municipal de saúde. Não se trata somente de mudanças na forma de prestar assistência à saúde, o que pressupõe mudanças na organização dos serviços, na inserção dos profissionais e nas tecnologias que deverão ser alocadas na atenção básica, mas também promover mudanças na forma como a população está acostumada a receber atenção à sua saúde. Este último aspecto pode ser evidenciado com a proposição do médico generalista para atender a todas as faixas etárias e a ambos os sexos, em contraposição à forma tradicional, usualmente encontrados na maioria das unidades básicas de saúde, que 
contam com pediatra, clínico geral e o gineco-obstetra. Assim, o entendimento e a participação da população constituem elemento fundamental para o maior ou menor sucesso da implantação da estratégia saúde da família.

Além disso, é papel do gestor prover condições para o adequado processo de trabalho na atenção básica e em todos os níveis e serviços sob sua responsabilidade, tanto na adequação de área física, insumos e equipamentos, quanto na proposição de pactos e contratos com os profissionais de saúde baseados em vínculo com a clientela, responsabilidade com os resultados de suas intervenções e compromisso com a melhora dos indicadores de saúde do município.

Dessa maneira, a situação verificada neste estudo, possibilita sugerir que a estratégia da Saúde da Família deve receber atenção adequada para que toda a sua potencialidade não se perca por inadequações implantação. Portanto, é recomendável um esforço, dos gestores, no sentido de garantir a alocação adequada de estrutura física, equipamentos e insumos, bem como dos recursos humanos necessários às equipes de saúde da família. A estrutura física e equipamentos adequados ao trabalho, pelo menos segundo o padrão mínimo proposto pelo MS, poderia ser verificada através de um "check list", que deveria ser observado no momento da qualificação das equipes para o recebimento dos incentivos financeiros do MS. É importante ressaltar que o MS destina recursos por equipe de saúde da família implantada, para ajudarem os municípios a superarem inadequações 
desta natureza. Quanto aos recursos humanos, fundamentais para o PSF, primeiramente é necessário cuidar da seleção dos profissionais, depois estabelecer contratos de trabalho adequados e, finalmente vincular estes profissionais a programas de educação continuada, educação permanente ou qualquer outro desde que se garanta as habilidades e visões necessárias ao trabalho proposto.

Entretanto, apesar de algumas dificuldades e inadequações que precisam ser superadas não se pode negar os aspectos positivos que a implantação do PSF no Estado de São Paulo propiciou, como por exemplo, a incorporação de responsabilização territorial, a ampliação da assistência com a implantação de mais de mil equipes de saúde, a sua distribuição nas periferias dos municípios maiores e para as populações das zonas rurais, incluindo as áreas de assentamento e quilombolas.

Dessa maneira, a recomendação que os achados deste estudo possibilita fazer diz respeito, principalmente à necessidade de se observarem às diretrizes de implantação da estratégia saúde da família. Em outros termos, muito foi realizado, mas há ainda muito a ser feito para que se alcance os resultados propostos pelo PSF, e conseqüentemente à adequada e justa atenção à saúde das pessoas. 


\section{REFERÊNCIAS BIBLIOGRÁFICAS}

BRASIL, CF. Constituição (1988) Constituição da República Federativa do Brasil. Brasília/ DF,1998.

BRASIL, Fernandes A.S., Seclen-Polacin, J. A (org). Brasília: Organização Pan-americana de Saúde, 2004.

BRASIL, MS - Ministério da Saúde. A implantação da Unidade de Saúde da família. Brasil: Ministério da Saúde, 2000.

Avaliação de implantação do Programa de Saúde da Família PSF. Brasília: Ministério da saúde, 2002.

Avaliação Normativa do Programa Saúde da Família no Brasil.

Monitoramento da Implantação e Funcionamento das Equipes de Saúde da Família - 2001/2002. Brasília: Ministério da Saúde, 2004.

. Monitoramento na Atenção Básica de Saúde: Roteiros para

Reflexão e Ação. Brasília: Ministério da Saúde, 2004.

. Norma Operacional Básica - SUS 01/1996. Portaria MS n. 2203.

Diário Oficial da União, Brasília, 06 nov 1996.

.1998. Portaria n. 347 de 27.03.03. Aprova o Manual para a

Organização da Atenção Básica no Sistema único de Saúde, constante do Anexo I desta Portaria. DOU de 17.11.1998.

2003. Portaria n. 347 de 27.03.03. Aprova a Convocatória Pública para que Municípios e Distrito Federal apresentem Projetos de Expansão e Consolidação do Saúde da Família- PROESF e os Respectivos Critérios de Elegibilidade, Prazos e Condições de Financiamento, mediante Transferências Diretas do Fundo nacional de Saúde aos Fundos Municipais 
de Saúde de Municípios Participantes e dá Outras Providencias. DOU de 28.03.03, Seção I.

. Portaria n. 648 de 28 de março de 2003. Saúde. Coordenadoria da Atenção Básica. Manual do Trabalho do Agente Comunitário de Saúde. Guia para capacitação do ACS. Brasília: Ministério da Saúde, 2000.

. Portaria n. 1.434 de 14.07.2004. Define mudanças no financiamento da atenção básica em saúde e dá outras providências. Disponível em http;//dtr2004.saude.gov.br/dab/legislaçao/portaria 143414 $07 \quad 04$ pdf. Visitado em 20 mar 2006.

Portaria n. 2607 de 10.12.2004. Aprova o Plano Nacional de Saúde. DOU nº 328 de 13.12.2004. p.29 e 30. Brasil. Ministério da Saúde, Avaliação Normativa do Programa Saúde da Família no Brasil.

Monitoramento da Implantação e Funcionamento das Equipes de Saúde da Família - 2001/2002. Brasília: Ministério da Saúde, 2004.

. Portaria número 3925 de 13.11.1998. Aprova o Manual para a Organização da Atenção Básica no Sistema único de Saúde, constante do Anexo I desta Portaria. DOU de 17.11.1998.

. Revista Brasileira de Medicina de Família e Comunidade. v.1. n.1, Brasília: Ministério da Saúde, 2004.

. Revista Brasileira de Saúde da Família. Edição Especial. Brasília: Ministério da Saúde, 2002.

. Revista Brasileira de Saúde da Família. Edição especial. Brasília: Ministério da Saúde, 2003. . Revista Brasileira de Saúde da Família. Edição Especial. Brasília: Ministério da Saúde, 2004.

. Saúde da Família. Construindo um Novo Modelo. Os municípios já têm histórias para contar. Brasília: Ministério da Saúde, 1996. 
. Saúde da Família. Caminhos da conquista da qualidade. Brasília: Ministério da Saúde, 2000.

. Secretaria de Assistência à Saúde. Coordenação de Saúde. Saúde da Família: uma estratégia para a reorientação do modelo assistencial. Brasília: Ministério da Saúde, 1997.

. Secretaria de Políticas de Saúde. Departamento da Atenção Básica. Indicadores de Monitoramento da Implementação do PSF em Grandes Centros Urbanos. Viana A L (coord.). Brasília: Ministério da Saúde, 2005.

. Secretaria de Políticas de Saúde. Departamento da Atenção Básica. Reunião dos Coordenadores dos pólos de capacitação, formação e educação permanente em saúde da família: relatório final. Brasília: Ministério da Saúde, 2002.

. Secretaria de Políticas de Saúde. Departamento da Atenção Básica. Educação Permanente. Caderno 3. Brasília: Ministério da Saúde, 2000. Seminários de Experiências Internacionais em Saúde da

Família: Relatório Final. Brasília: Ministério da Saúde, 1999. - Tribunal de Contas da União. Relatório de Auditoria de natureza Operacional. Programa de Saúde da Família - PSF. Brasília: Ministério da Saúde, 2002.

BRASIL. Lei n. 8080 de setembro de 1990. Dispõe sobre as condições para a promoção, proteção e recuperação da saúde e o funcionamento dos serviços correspondentes. DOU, DF, 19 set.1990.

. Lei n. 8142 de 28 de dezembro de 1990. Dispõe sobre a participação da comunidade na gestão do SUS e sobre as transferências intergovernamentais de recursos financeiros na área da saúde. Diário Oficial da União. Brasília, DF, 28 dez 1990. 
. Lei $n^{\circ} \mathbf{1 0 . 5 0 7}$ de 10 de julho de 2002. Cria a profissão de Agentes

Comunitários de Saúde.

CAMINAL, J.; Sanches, E.; Morales et al. Avances en España en la investigación con el indicador "Hospitalización por enfermedades sensibles a cuidados de atención primaria", 2002. in: Revista Esp. Salud. Publica, mayo-jun. 2002, v.76.n.3.

CAMPOS, F.E.; Aguiar. Especialização em saúde da família: uma estratégia para apoio à expansão da Atenção Básica nas grandes cidades. In: Revista Brasileira de Saúde da Família. Brasília: Ministério da Saúde, 2005.

COHN, A., Elias, P. E. Saúde no Brasil: Políticas e Organização de Serviços. São Paulo: Cortez, 1996.

DAL POZ, M.R. Câmbios em la contratacion de recursos humanos: el caso Del Programa de Salud de la Família em Brasil. OPAS. Sistemas e serviços de saúde. Temas (on line): 2000. disponível em:

http://www.opas.org.br/servico/temas documentodetalhe.cfm?codSubTema= 1487\&Cod.Específico=5142 . Visitado em 20 mar 2006.

DECLARAÇÃO DE ALMA-ATA. Conferência Internacional sobre Cuidados Primários da Saúde. Alma - Ata, URSS, 6-12 de setembro de 1978. disponível em http://www.opas.org.br/coletiva/uploadArq/Alma-Ata.pdf. Visitado em 20 mar 2006.

DONNAGELO, M. C. F. Medicina e Sociedade: o médico e seu mercado de trabalho. São Paulo: Pioneira, 1975.

ELIAS, P. E. Reforma ou Contra-Reforma na Proteção Social à Saúde. São Paulo: Lua Nova,1997.

ESCOREL, S. Reviravolta na Saúde: origem e articulação do movimento sanitário. Rio de Janeiro: Fio Cruz, 1988. 
GADAMER H.G. O mistério da Saúde o cuidado da Saúde e a Arte da Medicina. Lisboa: edições 70 Lda, 1997.

MACHADO, M. H. Programa Saúde da Família no Brasil - Algumas considerações sobre o perfil dos médicos e enfermeiros. in: Os sinais vermelho do PSF. Souza F. (org). São Paulo: Hucitec, 2002.

MANUAL ACS. Manual do Trabalho do Agente Comunitário de Saúde. Guia para capacitação do ACS. Brasília: Ministério da Saúde, 2000.

MEDINA, M.G.; Aquino, R. Avaliando o Programa de Saúde da Família. in: Os sinais vermelho do PSF. Souza F. (org.). São Paulo: Hucitec, 2002.

MENDES-GONÇALVES, R.B. Tecnologia e Organização Social das Práticas de Saúde: características tecnológicas do processo de trabalho na rede estadual de centros de saúde de São Paulo. São Paulo: Hucitec, 1994.

OPAS. Organização Pan-americana de Saúde. Experiências e Desafios da atenção básica e saúde da família. Ministério da Saúde. Série Temática. dez/2003.

PAIM, J. S. Saúde, política e reforma sanitária. Salvador: ISC - Instituto de Saúde Coletiva, 2002.

SÃO PAULO. SECRETARIA ESTADUAL DA SAÚDE. Saúde no Estado de São Paulo: compromisso com o cidadão. São Paulo: Imprensa Oficial do ESP, 2002.

SCHRAIBER, L.B; NEMES, M.I.B., MENDES-GONÇALVES, R.B. Saúde do Adulto. Programas e Ações na Unidade Básica. São Paulo: Hucitec,2000. SHIMIZU, H; LIMA, M.G., et al. A prática do auxiliar de enfermagem do programa saúde da família. in Revista Latino Americana de Enfermagem, set/ out. 2004, v. 12, n 5, p.713-720. ISSN 0104- 169. 
SIAB. Manual do Sistema de Informação de Atenção Básica. 2. ed., Brasília: Ministério da Saúde, 2000.

SILVA, J.; DALMASO A.S.W. Agente Comunitário de Saúde - o ser, o saber, o fazer. Rio de Janeiro: Fiocruz, 2002.

STARFIELD, B. Atenção primária: equilibrio entre necessidades de saúde, serviços e tecnologia. Brasília: Unesco Brasil, Ministério da Saúde, 2004.

UNGLERT, C.V.S. Territorialização em Sistemas de Saúde. In: Mendes (org). Distrito Sanitário. O processo social de mudanças nas práticas sanitárias do sistema único de saúde. 3. ed. Rio de Janeiro: Hucitec, 1995.

VIANA, A. L. D’Avila; Dal Poz. M.. A reforma do Sistema de Saúde no Brasil e o Programa de Saúde da Família. Rio de Janeiro: PHYSIS, Revista Saúde Coletiva, 1998.

VILAÇA, Mendes E. (org). As políticas de saúde no Brasil nos anos 80: a conformação da reforma sanitária e a construção da hegemonia do projeto neoliberal. In: Distrito Sanitário: Hucitec,1995. 


\section{ANEXO I - QUESTIONÁRIO DA PESQUISA}


MINISTÉRIO DA SAÚDE

SECRETARIA DE POLÍTICAS DE SAÚDE

DEPARTAMENTO DE ATENÇÃO BÁSICA

COORDENAÇÃO DE ACOMPANHAMENTO E AVALIAÇÃO DA ATENÇÃO BÁSICA 
MONITORAMENTO DA IMPLANTAÇÃO E FUNCIONAMENTO DAS

EQUIPES DE SAÚDE DA FAMÍLIA NO BRASIL

- MANUAL DE PREENCHIMENTO DO ROTEIRO DE OBSERVAÇÕES - 


\section{Sumário}

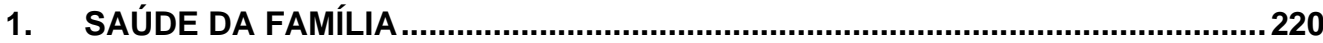

1.1. Instruções para o preenchimento do roteiro de observações a ser aplicado

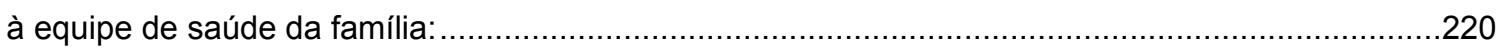

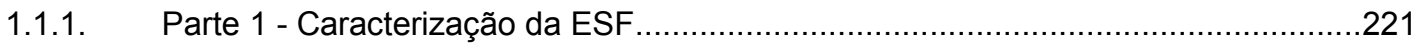

1.1.2. Parte 2 - Implantação da Equipe de Saúde da Família ............................................222

1.1.3. Parte 3 - Infra-estrutura da Unidade Básica de Saúde .............................................224

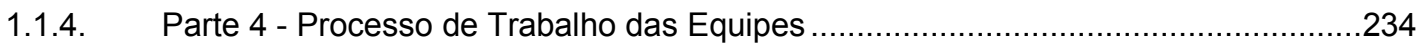

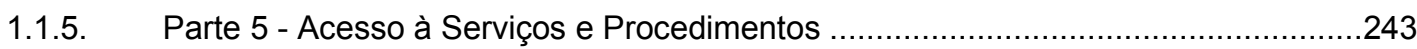

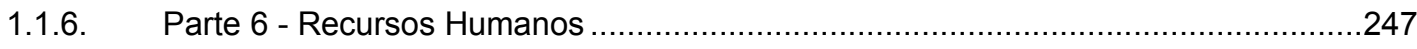

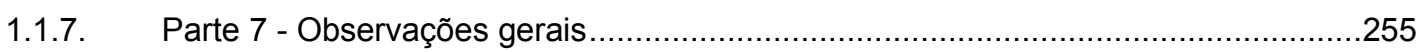

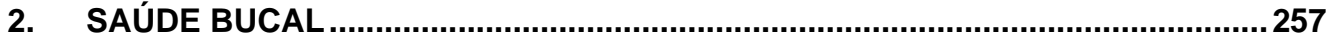

2.1. Instruções para preenchimento do roteiro de observações a ser aplicado à equipe

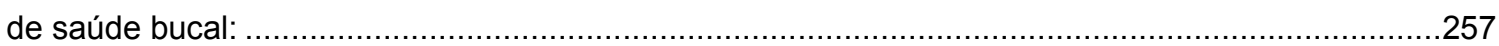

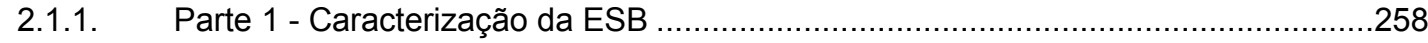

2.1.2. Parte 2 - Implantação da Equipe de Saúde Bucal ................................................259

2.1.3. Parte 3 - Infra-estrutura da Unidade Básica de Saúde ...........................................262

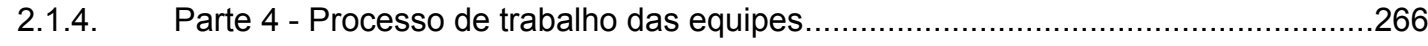

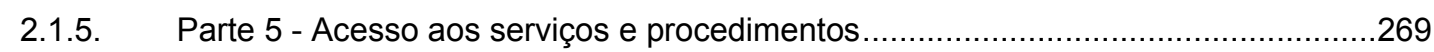

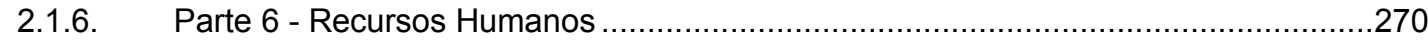

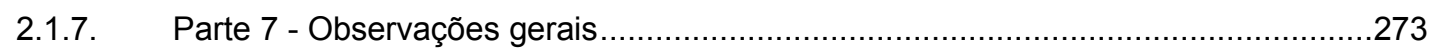




\section{Introdução}

O roteiro de observações descrito a seguir será utilizado no monitoramento da implantação e funcionamento do programa de saúde da família nos municípios onde as equipes estão implantadas e recebendo recursos do Ministério da Saúde.

Chegando ao município, o entrevistador deverá localizar o Gestor Municipal e colocá-lo a par dos objetivos do estudo. Em caso de sua ausência procurar o coordenador local do PSF. O entrevistador deverá fazer explicações quanto à natureza do trabalho, enfatizando que a ação não se trata de uma auditoria e sim de um monitoramento para verificar as necessidades de qualificação das ações do Saúde da Família nos municípios dos Estados.

Havendo a possibilidade do encontro com o gestor ser na secretaria municipal de saúde é importante que o entrevistador solicite o código das unidades de saúde (SIA/SUS) onde se localizam as equipes de saúde da família, pois esta informação deverá conter no roteiro de observações. Neste momento também deverá ser solicitada a relação dos profissionais cadastrados no SIAB.

O entrevistador deverá se deslocar para a(s) unidade(s) de saúde onde as ESF atendem e comunicá-las do objetivo do estudo. Se não for possível o deslocamento até a unidade de saúde por motivos operacionais, a entrevista ainda assim poderá ser realizada 
caso seja possível localizar os membros da equipe. Neste caso, os dados referentes à unidade de saúde que são de observação direta não deverão ser preenchidos.

O roteiro de observações deverá ser preenchido a partir de entrevistas com os componentes da ESF que estiverem presentes à unidade no momento, mas algumas questões deverão ser preenchidas após observação direta do entrevistador. Deverão estar presentes à entrevista pelo menos o médico ou o enfermeiro da equipe. Em sua ausência, o entrevistador deverá identificar algum informante que possa dar o maior número de informações possível. Na ausência do médico e/ou enfermeiro, deverá ser registrado nas considerações finais o motivo da ausência do mesmo (Anotar as situações referentes à licença gestante, caso de doença, ausência devido a treinamento, desligamento, falta, carga horária alternativa, entre outros que caracterizem a situação em questão). Se os profissionais médicos e/ou enfermeiro não estiverem presentes e for possível aos entrevistadores retornar ao município, deve ser feita nova tentativa. Se estes profissionais estiverem fora da unidade realizando atividades de campo, o entrevistador deverá aguardar ou voltar depois.

Não é necessário que o entrevistador faça as perguntas exatamente da forma como as mesmas estão colocadas no roteiro de observações. O entrevistador deverá, ao contrário, utilizar sua experiência para detectar problemas que a equipe pode não colocar explicitamente. Se porventura o entrevistador detectar respostas que não correspondem à realidade, o mesmo deverá lançar mão de outras estratégias como conversa com usuários, permanência em maior tempo na unidade de saúde, etc. É importante que o entrevistador consiga relatar no roteiro de observações o que de fato está acontecendo com aquela equipe e como a mesma vem funcionando. 
As questões deverão ser assinaladas com um X. O entrevistador não deve preencher a lacuna com números, a não ser nas questões onde este procedimento for o adequado.

ATENÇÃO: Conferir, ao final da entrevista, se todos os campos estão completos e se não há respostas duplicadas ou incoerentes com a realidade observada. No caso de estarem presentes mais de um entrevistador, enquanto um desenvolve a conversa, o outro deverá conferir se todos os itens estão sendo devidamente registrados no roteiro de observações e se há algum que precisa ser abordado ou retomado.

Não seria excesso de zelo lembrar que a postura do entrevistador deve ser de permanente respeito diante do gestor local e dos profissionais das equipes. Nenhum juízo de valor ou julgamento deverá ser emitido diante das observações, devendo ser o mais imparcial possível. É bom reforçar que o papel do entrevistador é observar para coletar os dados referidos no Roteiro de Observações. 


\section{Saúde da Família}

Instruções para o preenchimento do roteiro de observações a ser aplicado à equipe de saúde da família:

Roteiro de observações no.

O coordenador local será responsável pela numeração destes roteiros de observações. Se algum roteiro de observações for invalidado, repetir a numeração num roteiro de observações em branco e escrever na primeira folha ocupando toda a página que o mesmo foi cancelado.

No caso dos entrevistadores encontrarem equipes que não estavam na programação, utilizar os roteiros de observações sobressalentes e deixar este item em branco.

A primeira página do roteiro de observações deverá sempre ser toda preenchida. O primeiro quadro apresentado deverá ser preenchido pelo entrevistador ao final do dia, após a conferência do roteiro de observações. As instruções quanto a este campo estão no fim do manual.

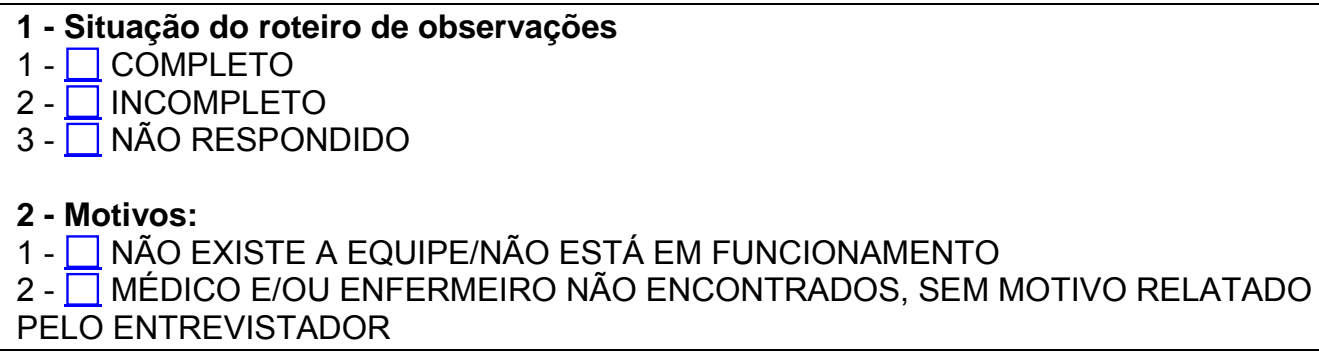




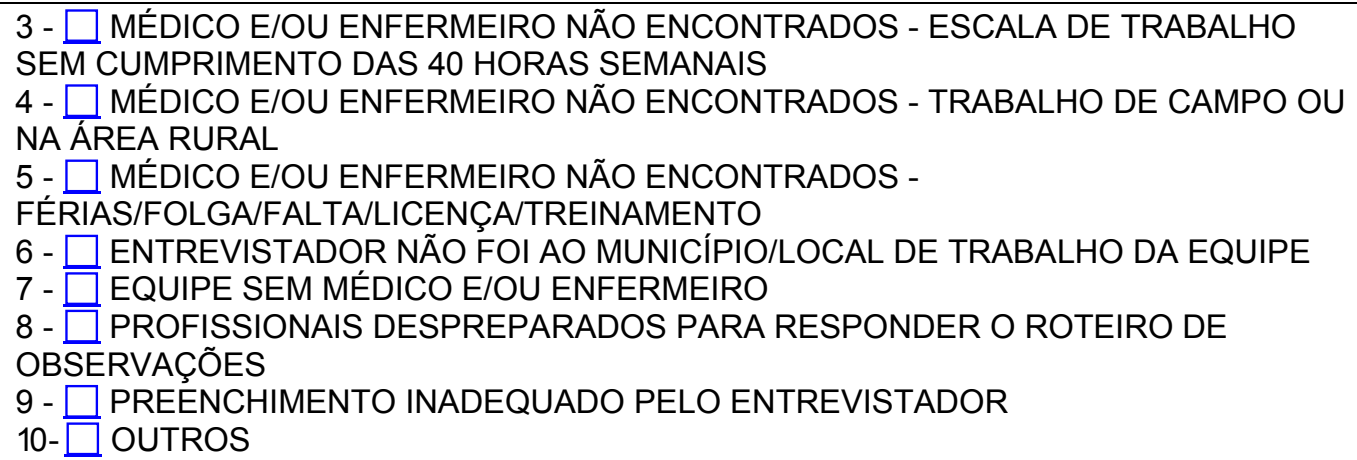

Preencher com o nome completo do entrevistador e data da entrevista

\section{Entrevistador(a):}

Data da Entrevista: ___ $\quad I \quad I 2001$

\section{Parte 1 - Caracterização da ESF}

Neste bloco, serão registrados os dados gerais de identificação do estado, município e equipe. Os itens que não estão numerados não comporão o banco de dados, mas são importantes instrumentos de verificação da composição da equipe.

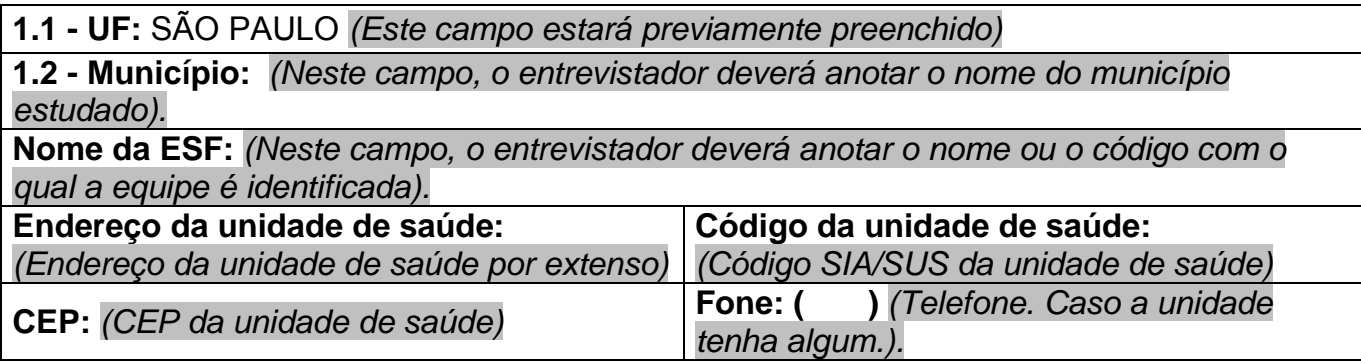


Se a equipe realiza suas atividades em mais de uma unidade de saúde, registrar aqui o endereço daquela que é a sede da equipe, ou a que a mesma atende com mais freqüência. Pode ser registrado telefone público (orelhão).

\section{Componentes da ESF}

Médico: (Nome do médico da equipe)

CRM/UF: (Registro Profissional)

Enfermeiro: (Nome do enfermeiro da equipe)

COREN/UF: (Registro Profissional)

\section{Parte 2 - Implantação da Equipe de Saúde da Família}

Este bloco do instrumento agrupa questões que pretendem avaliar características e o processo de implantação da ESF.

2.1 - Nesta questão, o entrevistador deverá perguntar à equipe há quanto tempo a mesma está em funcionamento. Lembrar que em muitas situações, os primeiros profissionais que compuseram a equipe podem não ser aqueles que estão respondendo o roteiro de observações. Caso nenhum dos componentes da equipe saiba informar, preencher com a informação prestada pelo gestor municipal. Lembrar que no item 2 o tempo de funcionamento é de 3 a 4 anos e 11 meses e no item 3 , o tempo de funcionamento é de 1 ano a 2 anos e 11 meses. 


\begin{tabular}{|c|c|}
\hline 2.1 - Esta ESF está em funcionamento há & lanto tempo? \\
\hline $\begin{array}{l}1-\square 5 \text { ANOS OU MAIS } \\
2-\square \text { DE } 3 \text { A } 4 \text { ANOS E } 11 \text { MESES } \\
3-\square \text { DE } 1 \text { A } 2 \text { ANOS E } 11 \text { MESES }\end{array}$ & $\begin{array}{l}4 \text { - } \square \text { ENTRE } 6 \text { MESES E } 1 \text { ANO } \\
5-\square \text { ENTRE } 3 \text { E } 6 \text { MESES } \\
6-\square \text { MENOS DE } 3 \text { MESES }\end{array}$ \\
\hline
\end{tabular}

2.2 - Nesta questão o entrevistador deverá marcar a opção adequada conforme a informação prestada pela equipe.

\section{2 - A ESF atua em zona: $\quad 1$ - $\square$ URBANA $\quad 2$ - $\square$ RURAL 3 - $\square$ EM AMBAS}

2.3 - Nesta questão o entrevistador deverá assinalar as opções abaixo, conforme a categoria populacional. O entrevistador deverá perguntar à ESF qual a população acompanhada por ela. Esta questão deverá ser de fato preenchida com a informação prestada pela ESF mesmo que seja estimada e que não coincida com o cadastro do SIAB. Se a equipe só souber o número de famílias, usar esta informação e multiplicá-la pela média de indivíduos por família daquele estado. A opção 4 - Não sabe, deverá ser usada em último caso, quando nem de forma estimada a equipe conseguir dar a informação da população acompanhada por ela.

\begin{tabular}{ll}
\hline & $1-\square$ MENOS DE 2.400 PESSOAS \\
2.3 - População acompanhada por esta & $2-\square$ DE 2.400 A 4.500 PESSOAS \\
ESF: & $3-\square$ MAIS DE 4.500 PESSOAS \\
& $4-\square$ NÃO SABE \\
\hline
\end{tabular}

2.4 - Nesta questão o entrevistador deverá assinalar as opções abaixo, conforme a existência ou não de área de abrangência definida. $\mathrm{O}$ entrevistador deverá perguntar à ESF se há área de abrangência definida para a equipe. Observar qual instrumento 
possibilita à equipe a identificação da área pela qual a mesma tem responsabilidade sanitária. Estes instrumentos poderão ser mapa da área, lista dos bairros ou das ruas que limitam as áreas, algum documento da secretaria de saúde que aponte as áreas por equipe, etc. Se a equipe não souber informar, marcar a opção 2 - Não.

\section{4 - Existe área de abrangência definida para a equipe?

$1-\square \operatorname{SIM} \quad 2-\square$ NÃO

2.5 - Nesta questão o entrevistador deverá assinalar as opções abaixo. O entrevistador deverá perguntar a ESF se há mapa da área de abrangência disponível para o seu uso na unidade de saúde e solicitá-lo para verificação. Se a equipe não souber informar, marcar a opção 2 - Não.

\section{5 - Existe mapa da área de abrangência da ESF na unidade de saúde?

$1-\square \operatorname{SIM} \quad 2-\square$ NÃO

\section{Parte 3 - Infra-estrutura da Unidade Básica de Saúde}

Este bloco se destina a avaliar em que condições estruturais têm se dado o trabalho da ESF e se a infra-estrutura local atende as recomendações do Ministério da Saúde para o funcionamento do PSF no município. 
3.1 - Nesta questão, o entrevistador deverá observar se a ESF conta com alguma área física, que funcione como unidade de saúde, onde a mesma desenvolve suas atividades. A tipologia da unidade não é a informação preponderante neste momento, nem se a unidade é própria, alugada, emprestada, etc. O importante é identificar se a equipe possui alguma estrutura física mínima que sirva de referência para a comunidade quanto ao desenvolvimento das atividades assistenciais ou se a equipe atua como equipe volante, desenvolvendo suas atividades apenas nos domicílios e na comunidade, que levaria o entrevistador a assinalar a opção 2 - Não. Se a resposta for 2 - Não, o entrevistador deverá responder apenas as questões 3.5, 3.6 e 3.8 deste bloco. Se porventura a SMS ou equipe informarem que a unidade de saúde está em reforma, verificar se está ou não. Se for uma informação não verídica, e de fato a equipe não contar com unidade de saúde para a execução dos trabalhos, marcar a opção 2 - Não.

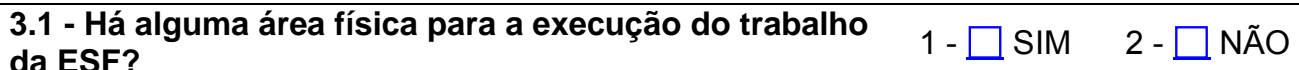

3.2 - Nesta questão o entrevistador deverá perguntar quantas ESF atendem na unidade de saúde citada abaixo, onde trabalha a ESF entrevistada. Registrar o número de equipes, incluindo a mesma. Se a resposta à pergunta anterior for 2 - Não, pular esta questão. Para cada equipe de saúde da família deverá ser aplicado um roteiro de observações, mesmo que existam várias na mesma unidade física e os dados referentes à unidade física se repitam.

\section{2 - Quantas ESF existem na Unidade de Saúde acima} citada? 
3.3 - Para o preenchimento desta questão, o entrevistador deverá observar in loco a presença do espaço físico em questão. Lembrar que o entrevistador deverá anotar a quantidade de ambientes existente na unidade de saúde como um todo e não apenas a quantidade disponível apenas para a equipe de saúde entrevistada. Se a resposta à pergunta 3.1 for 2 - Não, pular esta questão.

Se a(s) equipe(s) de saúde da família divide $(\mathrm{m})$ a unidade de saúde com outros profissionais e/ou setores, contar apenas os consultórios disponíveis para a(s) equipe(s) de saúde da família e não todos os existentes na unidade de saúde.

- No item a), deverá ser observada a presença ou não de sala de recepção ou espera na unidade de saúde onde a ESF atende. A sala de recepção ou espera é considerada o espaço onde os usuários aguardam para serem atendidos.

- No item b), deverá ser observada a quantidade de consultórios médicos em funcionamento na unidade de saúde onde a ESF atende.

- No item c), deverá ser observada a quantidade de consultórios de enfermagem em funcionamento naquela unidade de saúde.

- No item d), deverá ser observada a quantidade de salas equipadas para a realização de procedimentos básicos como curativos e injeções na unidade de saúde onde a ESF atende.

- No item e), verificar a quantidade de salas de vacina na unidade de saúde onde a ESF atende. A sala de vacinas deverá necessariamente conter geladeira usada para armazenamento das vacinas.

- No item f), verificar a quantidade de sanitários para o público existente na unidade. Se houver um masculino outro feminino considerar dois sanitários.

- No item g), verificar a quantidade de sanitários existentes para funcionários. Se houver sanitários para o uso de todos (funcionários e público) considerar sanitários para o público.

- No item h), verificar a quantidade de salas para reuniões na USF. Não considerar como sala de reuniões as salas referidas acima nos itens $a, b, c, d$, e.

Se a equipe realiza suas atividades em mais de uma unidade de saúde, registrar aqui a informação referente àquela que é a sede da equipe, ou onde a equipe atende com mais freqüência. 
Se algum consultório for utilizado por outros profissionais que não são da equipe de saúde da família (especialistas, por exemplo), investigar se é em um período de tempo que ela desenvolve suas atividades em outra unidade de saúde na sua área. Se ela tem que dispor do consultório para que o mesmo seja utilizado por outros profissionais que não são da equipe, em qualquer período de tempo, sendo obrigada a desenvolver outras atividades durante este horário, não podendo contar com este consultório se necessário, NÃO considerá-lo.

Se só houver um consultório para o médico e para o enfermeiro, contar como um consultório médico e nenhum consultório de enfermagem.

Se houver somente apenas um sanitário para público e funcionários preencher como sanitário para público.

Considerar como sala de reuniões apenas se esta for utilizada para este fim ou trabalhos em grupo etc. Não considerar como sala de reuniões consultórios médico, de enfermagem, sala de vacina etc.

3.3 - Quantificar a existência das seguintes dependências na unidade de saúde onde esta equipe atende com mais freqüência:

a) SALA DE RECEPÇÃO OU

ESPERA

b) CONSULTÓRIO

MÉDICO. 
C) CONSULTÓRIO DE

ENFERMAGEM.

d) SALA DE PROCEDIMENTOS

BÁSICOS.

e) SALA DE

VACINAS

F ) SANITARIOS PARA O PÚBLICO

g) SANITÁRIOS PARA FUNCIONARIOS

h) ESPAÇO PARA REUNIÕES

3.4 - Nesta questão o entrevistador deverá assinalar se a ESF dispõe ou não dos materiais e equipamentos listados. O entrevistador deverá verificar in loco a presença dos mesmos e marcar que estão disponíveis. Se os equipamentos estiverem disponíveis, mas sem condições de uso no momento, assinalar a opção 3. Se o equipamento não pertence ao sistema de saúde e é de propriedade do profissional, a alternativa assinalada deverá ser a 2 - Não. Se a resposta à pergunta 3.1 for 2 - Não, pular esta questão.

Em relação ao segundo item BALANÇA DE ADULTO, será aceita balança de banheiro. Em relação ao item GELADEIRA EXCLUSIVA PARA VACINA será considerada geladeira exclusiva para vacina mesmo aquelas que contiverem insulina, porém não outros itens.

3.4 - A ESF dispõe, em sua unidade de saúde, dos seguintes materiais e equipamentos para atendimento da população?
a) APARELHO DE AEROSSOL,
1 - $\square$ SIM 2 - $\square$ NÃO $3-\square$ SIM MAS NEBULIZADOR OU ESPAÇADOR SEM CONDIÇÕES DE USO
b) BALANÇA DE ADULTO
1 - $\square$ SIM 2 - $\square$ NÃO $3-\square$ SIM MAS SEM CONDIÇÕES DE USO
c) BALANÇA INFANTIL 1 - $\square$ SIM 2- $\square$ NÃO 3- $\square$ SIM MAS
d) ESPÉCULOS GINECOLÓGICOS SEM CONDIÇÕES DE USO
e) ESTETOSCÓPIO $1-\square$ SIM 2- $\square$ NÃO 3- $\square$ SIM MAS SEM CONDIÇÕES DE USO $1-\square$ SIM 2- $\square$ NÃO 3- $\square$ SIM MAS SEM CONDIÇÕES DE USO 


\begin{tabular}{|c|c|c|}
\hline f) & ESTETOSCÓPIO DE PINARD & $\begin{array}{l}1 \text { - } \square \text { SIM } 2 \text { - } \square \text { NÃO } 3-\square \text { SIM MAS } \\
\text { SEM CONDIÇÕES DE USO }\end{array}$ \\
\hline g) & FOCO & $\begin{array}{l}1-\square \text { SIM } 2-\square \text { NÃO } 3-\square \text { SIM MAS } \\
\text { SEM CONDIČÕES DE USO }\end{array}$ \\
\hline h) & GELADEIRA EXCLUSIVA PARA VACINA & $\begin{array}{l}1-\square \text { SIM } 2-\square \text { NÃO } 3-\square \text { SIM MAS } \\
\text { SEM CONDIÇÕES DE USO }\end{array}$ \\
\hline i) & GLICOSÍMETRO & $\begin{array}{l}1-\square \text { SIM } 2-\square \text { NÃO } 3-\square \text { SIM MAS } \\
\text { SEM CONDIÇÕES DE USO }\end{array}$ \\
\hline j) & IMPRESSORA & $\begin{array}{l}1-\square \text { SIM } 2-\square \text { NÃO } 3-\square \text { SIM MAS } \\
\text { SEM CONDIÇÕES DE USO }\end{array}$ \\
\hline k) & LANTERNA & $\begin{array}{l}1-\square \text { SIM } 2 \text { - } \square \text { NÃO } 3-\square \text { SIM MAS } \\
\text { SEM CONDIÇÕES DE USO }\end{array}$ \\
\hline l) & MATERIAL PARA PEQUENA CIRURGIA & $\begin{array}{l}1-\square \text { SIM } 2 \text { - } \square \text { NÃO } 3-\square \text { SIM MAS } \\
\text { SEM CONDIÇÕES DE USO }\end{array}$ \\
\hline m) & $\begin{array}{l}\text { MATERIAL PARA RETIRA } \\
\text { PONTOS }\end{array}$ & $\begin{array}{l}1-\square \text { SIM } 2-\square \text { NÄO } 3-\square \text { SIM MAS } \\
\text { SEM CONDIÇÕES DE USO }\end{array}$ \\
\hline n) & MESA GINECOLÓGICA & $\begin{array}{l}1-\square \text { SIM } 2-\square \text { NÃO } 3-\square \text { SIM MAS } \\
\text { SEM CONDIÇÕES DE USO }\end{array}$ \\
\hline o) & MICROCOMPUTADOR & $\begin{array}{l}1 \text { - } \square \text { SIM } 2 \text { - } \square \text { NÃO } 3-\square \text { SIM MAS } \\
\text { SEM CONDIÇÕES DE USO }\end{array}$ \\
\hline p) & OFTALMOSCÓPIO & $\begin{array}{l}1-\square \text { SIM } 2-\square \text { NÃO } 3-\square \text { SIM MAS } \\
\text { SEM CONDIÇÕES DE USO }\end{array}$ \\
\hline q) & OTOSCÓPIO & $\begin{array}{l}1-\square \text { SIM } 2-\square \text { NÃO } 3-\square \text { SIM MAS } \\
\text { SEM CONDIÇÕES DE USO }\end{array}$ \\
\hline r) & SONAR & $\begin{array}{l}1-\square \text { SIM } 2-\square \text { NÃO } 3-\square \text { SIM MAS } \\
\text { SEM CONDIÇÕES DE USO }\end{array}$ \\
\hline s) & TENSIÔMETRO/ESFIGMOMANÔMETRO & $\begin{array}{l}1-\square \text { SIM } 2 \text { - } \square \text { NÃO } 3-\square \text { SIM MAS } \\
\text { SEM CONDIÇÕES DE USO }\end{array}$ \\
\hline t) & TERMÔMETRO & $\begin{array}{l}1-\square \text { SIM } 2-\square \text { NÃO } 3-\square \text { SIM MAS } \\
\text { SEM CONDIÇÕES DE USO }\end{array}$ \\
\hline u) & FITA MÉTRICA & $\begin{array}{l}1 \text { - } \square \text { SIM } 2 \text { - } \square \text { NÃO } 3-\square \text { SIM MAS } \\
\text { SEM CONDIÇÕES DE USO }\end{array}$ \\
\hline v) & RÉGUA ANTROPOMÉTRICA & $\begin{array}{l}1-\square \text { SIM } 2 \text { - } \square \text { NÃO } 3-\square \text { SIM MAS } \\
\text { SEM CONDIÇÕES DE USO }\end{array}$ \\
\hline
\end{tabular}

3.5 - Nesta questão o entrevistador deverá assinalar se há ou não a disponibilidade dos itens farmacêuticos listados. O entrevistador deverá verificar in loco a presença ou não dos itens farmacêuticos listados mesmo nas situações em que a dispensação é feita fora da unidade de saúde onde a ESF atua.

Deve-se assinalar a presença do item apenas se no momento da visita ele estiver presente e não se a equipe ou o gestor referirem a disponibilidade em outros períodos de tempo. Considere SIM mesmo quando houver pouca quantidade do item. 
Não deverá ser considerada a dispensação feita em farmácia privada, casa de lideres comunitários, vereadores ou qualquer outra autoridade local. Não serão consideradas também amostras grátis.

\begin{tabular}{|c|c|c|}
\hline \multicolumn{3}{|c|}{$\begin{array}{l}3.5 \text { - Os itens farmacêuticos listados abaixo foram verificados para dispensação à } \\
\text { população atendida pela ESF? }\end{array}$} \\
\hline a) AMOXACILINA CAPS 500MG & $1-\square \operatorname{SIM}$ & 2 - $\square$ NÃO \\
\hline $\begin{array}{l}\text { b) BENZILPENICILINA BENZATINA } \\
1.200 .000 \mathrm{UI}\end{array}$ & $1-\square \operatorname{SIM}$ & $2-\square$ NÃO \\
\hline c) CAPTOPRIL COMP $25 \mathrm{MG}$ & $1-\square \operatorname{SIM}$ & $2-\square N A ̃ O$ \\
\hline d) CARBAMAZEPINA COMP 200 MG & $1-\square \operatorname{SIM}$ & $2-\square N A ̃ O$ \\
\hline e) DIGOXINA COMP 0,25 MG & $1-\square \operatorname{SIM}$ & $2-\square N A ̃ O$ \\
\hline f) FENOBARBITAL COMP $100 \mathrm{MG}$ & $1-\square \operatorname{SIM}$ & $2-\square$ NÃO \\
\hline g) METRONIDADAZOL COMP 250 MG & $1-\square \operatorname{SIM}$ & $2-\square N A ̃ O$ \\
\hline h) NISTATINA CREME VAGINAL & $1-\square \operatorname{SIM}$ & $2-\square N A ̃ O$ \\
\hline $\begin{array}{l}\text { i) ÁCIDO ACETIL SALICÍLICO COMP } 100 \\
\text { MG }\end{array}$ & $1-\square \operatorname{SIM}$ & $2-\square N A ̃ O$ \\
\hline j) AMINOFILINA COMP 100 MG & $1-\square \operatorname{SIM}$ & $2-\square N A ̃ O$ \\
\hline k) AMPICILINA COMP 500 MG & $1-\square \operatorname{SIM}$ & $2-\square N A ̃ O$ \\
\hline I) CIMETIDINA COMP 200 MG & $1-\square \operatorname{SIM}$ & $2-\square N A ̃ O$ \\
\hline m) DEXAMETASONA POMADA & $1-\square \operatorname{SIM}$ & $2-\square N A ̃ O$ \\
\hline $\begin{array}{l}\text { n) DICLOFENACO POTÁSSICO COMP } 50 \\
\text { MG }\end{array}$ & $1-\square \operatorname{SIM}$ & $2-\square N A ̃ O$ \\
\hline o) FUROSEMIDA COMP 40 MG & $1-\square \operatorname{SIM}$ & $2-\square N A ̃ O$ \\
\hline p) METRONIDAZOL GELÉIA VAGINAL & $1-\square \operatorname{SIM}$ & $2-\square N A ̃ O$ \\
\hline q) NEOMICINA + BACITRACINA POMADA & $1-\square \operatorname{SIM}$ & $2-\square N A ̃ O$ \\
\hline
\end{tabular}

3.6 - Nesta questão o entrevistador deverá assinalar se a maioria dos medicamentos disponíveis é dispensada na própria unidade de saúde onde a equipe de saúde atende ou são distribuídos em outro local. Se a equipe transportar os medicamentos consigo quando se desloca para comunidades mais distantes, considerar que dispensa no local de atendimento. 
3.6.1 - Nesta questão o entrevistador deverá assinalar se os medicamentos acima relacionados são recebidos geralmente dentro do planejado ou se há descontinuidade no seu recebimento.

3.6.2 - O entrevistador deverá assinalar se os medicamentos acima relacionados são suficientes para as necessidades da população coberta pela equipe, não considerar, portanto, as necessidades das pessoas fora da área.

\begin{tabular}{|llc|}
\hline $\begin{array}{l}\text { 3.6 - Os medicamentos são dispensados no local de } \\
\text { atendimento da ESF? }\end{array}$ & 1 - $\square \mathrm{SIM}$ & 2 - $\square$ NÃO \\
\hline $\begin{array}{l}\text { 3.6.1 - Há problemas relacionados regularidade no } \\
\text { recebimento dos medicamentos? }\end{array}$ & 1 - $\square \mathrm{SIM}$ & 2 - $\square$ NÃO \\
\hline $\begin{array}{l}\text { 3.6.2 - Há problemas relacionados a quantidade de } \\
\text { medicamentos recebidos? }\end{array}$ & 1 - $\square \mathrm{SIM}$ & 2 - $\square$ NÃO \\
\hline
\end{tabular}

3.7 - Nesta questão devem ser assinaladas as opções abaixo. O entrevistador deverá investigar a realização de vacinas naquela unidade de saúde in loco e questionar a equipe se todas as vacinas do calendário do PNI são realizadas. Se a resposta à pergunta 3.1 for 2 - Não, pular esta questão.

As vacinas são: BCG, contra Hepatite B, contra Poliomielite, contra Sarampo, Dupla adulto, Tríplice viral, DPT, contra Haemophilus influenzae B (crianças), Dupla viral ou contra Rubéola, contra Raiva Humana e contra Febre Amarela. Se na unidade não forem aplicadas todas as vacinas, o entrevistador deverá assinalar a opção 2 - Não. (Observar a determinação pelo Estado quanto à rotina das vacinas contra Raiva e Febre Amarela.).

No caso da equipe referir que realiza a vacinação de rotina, mas o observador não observar presença de geladeira para este fim, questionar como a equipe organiza as ações de vacinação. Neste caso vale o trabalho feito por equipe em unidade móvel. 
Esta questão não diz respeito à infra-estrutura e sim ao processo de trabalho da equipe. Mesmo que a ESF relate que faz determinada vacina de rotina, mas que está havendo problemas com relação ao repasse do insumo por parte da SES, a equipe deverá marcar sim como resposta. Quanto a BCG, ela pode ser realizada em maternidades, mas o entrevistador deverá saber se a equipe tem condição de realizá-la se necessário, em caso de doses de reforço e partos domiciliares.

\section{7 - Rotineiramente todas vacinas do calendário básico de Programa Nacional de Imunização (PNI) são $\quad 1$ - $\square$ SIM $\quad 2$ - $\square$ NÃO realizadas nesta unidade?}

3.8 - Nesta questão o entrevistador deverá perguntar à equipe se ela dispõe do material citado para a realização de suas atividades, se em quantidade suficiente para o atendimento de todos os usuários que precisarem e, de acordo com a informação prestada, deverão ser assinaladas as opções abaixo.

O entrevistador deverá utilizar os seguintes critérios quanto à disponibilidade dos materiais:

- Suficiente: disponível para todas situações/pacientes quando foram necessários;

- Insuficiente: disponível em quantidade não adequada para atender as necessidades.

3.8 - Assinale a situação de abastecimento de materiais e insumos relacionados conforme as condições definidas a seguir de acordo com informação da equipe:

\begin{tabular}{lllcc|} 
a) AGULHAS DESCARTÁVEIS & $\begin{array}{l}1-\square \text { NÃO HÁ } \\
\text { INSUFICIENTE }\end{array}$ & $2-\square$ SUFICIENTE & $3-\square$ \\
\hline b) ALGODÃO & $\begin{array}{l}1-\square \text { NÃO HÁ } \\
\text { INSUFICIENTE }\end{array}$ & $2-\square$ SUFICIENTE & $3-\square$ \\
\hline c) BLOCO DE RECEITUÁRIO & $\begin{array}{l}1-\square \text { NÃO HÁ } \\
\text { INSUFICIENTE }\end{array}$ & $2-\square$ SUFICIENTE & $3-\square$ \\
\hline
\end{tabular}




\begin{tabular}{|c|c|c|c|c|}
\hline d) & CARTÃO DA CRIANÇA & $\begin{array}{l}1 \text { - } \square \text { NÃO HÁ } \\
\text { INSUFICIENTE }\end{array}$ & 2 - $\square$ SUFICIENTE & $3-\square$ \\
\hline e) & CARTÃO DA GESTANTE & $\begin{array}{l}1-\square \text { NÃO HÁ } \\
\text { INSUFICIENTE }\end{array}$ & 2 - $\square$ SUFICIENTE & $3-\square$ \\
\hline f) & ESPARADRAPO & $\begin{array}{l}1 \text { - } \square \text { NÃO HÁ } \\
\text { INSUFICIENTE }\end{array}$ & 2 - $\square$ SUFICIENTE & $3-\square$ \\
\hline g) & $\begin{array}{l}\text { FICHAS DE CADASTRO } \\
\text { FAMILIAR (FICHA A OU } \\
\text { SIMILAR) }\end{array}$ & $\begin{array}{l}1-\square \text { NÃO HÁ } \\
\text { INSUFICIENTE }\end{array}$ & 2 - $\square$ SUFICIENTE & $3-\square$ \\
\hline h) & $\begin{array}{l}\text { FICHAS DO SIAB OU DE } \\
\text { SISTEMA SIMILAR }\end{array}$ & $\begin{array}{l}1 \text { - } \square \text { NÃO HÁ } \\
\text { INSUFICIENTE }\end{array}$ & 2 - $\square$ SUFICIENTE & $3-\square$ \\
\hline i) & FIO DE SUTURA & $\begin{array}{l}1 \text { - } \square \text { NÃO HÁ } \\
\text { INSUFICIENTE }\end{array}$ & 2 - $\square$ SUFICIENTE & $3-\square$ \\
\hline j) & GAZE & $\begin{array}{l}1-\square \text { NÃO HÁ } \\
\text { INSUFICIENTE }\end{array}$ & 2 - $\square$ SUFICIENTE & $3-\square$ \\
\hline k) & $\begin{array}{l}\text { LUVAS PARA } \\
\text { PROCEDIMENTOS }\end{array}$ & $\begin{array}{l}1-\square \text { NÃO HÁ } \\
\text { INSUFICIENTE }\end{array}$ & 2 - $\square$ SUFICIENTE & $3-\square$ \\
\hline l) & $\begin{array}{l}\text { SERINGAS } \\
\text { DESCARTÁVEIS }\end{array}$ & $\begin{array}{l}1 \text { - } \square \text { NÃO HÁ } \\
\text { INSUFICIENTE }\end{array}$ & 2 - $\square$ SUFICIENTE & $3-\square$ \\
\hline
\end{tabular}

3.9 - O entrevistador deverá saber se a equipe necessita de veículo para seu deslocamento para realizar suas atividades. Se não, marcar diretamente o código 3 . Se a equipe necessita de veículo, o entrevistador deverá saber se este veículo está disponível ou não para a equipe, ou seja, se a falta de veículo é empecilho para a realização das atividades da equipe. Se a agenda/escala de trabalho da equipe ficar prejudicada pela falta de transporte, assinalar a opção 2) Não, que significará que o veículo não está disponível.

O tipo de veículo não é o mais importante, o importante é a garantia de transporte para a equipe.

3.9 - A ESF tem veículo para o deslocamento para a realização das suas atividades?

$1-\square \operatorname{SIM}_{\text {NECESSÁRIO }} 2-\square$ NÃO $3-\square$ NÃO É
-


3.10 - Nesta questão o entrevistador deverá saber se a equipe de saúde da família recebeu o uniforme que foi enviado pelo Ministério da Saúde (composto por jalecos, coletes, mochilas, etc.).

\begin{tabular}{|c|c|c|}
\hline $\begin{array}{l}3.10 \text { - A ESF recebeu o uniforme enviado } \\
\text { pelo MS? }\end{array}$ & $1-\square \operatorname{SIM}$ & 2 - $\square$ NÃO \\
\hline
\end{tabular}

3.11 - Nesta questão o entrevistador deverá saber se a equipe de saúde da família, ou pelo menos a maioria dos membros presentes na entrevista estavam utilizando o uniforme citado acima. Se a equipe recebeu o uniforme, mas não estava usando, registrar o motivo nas observações finais.

\subsection{1 - A ESF estava usando o uniforme enviado pelo MS durante a entrevista? \\ $1-\square \operatorname{SIM} \quad 2-\square$ NÃO}

\section{Parte 4 - Processo de Trabalho das Equipes}

Este bloco se destina a avaliar o processo de trabalho da ESF e se o mesmo atende as recomendações do Ministério da Saúde para o funcionamento do PSF, visando a efetiva mudança no modelo assistencial.

4.1 - Nesta questão, o entrevistador deverá assinalar, para cada profissional que compõe a ESF, se o mesmo realiza ou participa das atividades listadas. 
Na ação ATENDIMENTO CLÍNICO NAS CLÍNICAS BÁSICAS é importante que o entrevistador procure identificar se o médico e enfermeiro realmente atendem em todas as áreas ou se a assistência é dividida entre as diversas equipes ou ainda com outros profissionais ou especialistas. Procurar verificar o tipo de clientela que se encontra na sala de espera da unidade de saúde, abordar as necessidades de capacitação do médico e enfermeiro e suas habilidades com relação as ações clínicas.

As questões específicas sobre atendimento médico e de enfermagem de pediatria, clinica médica e ginecologia e obstetrícia, visam complementar a primeira questão (item "a" sobre o atendimento clínico) identificando os pontos mais necessários para capacitação dos profissionais.

Procurar, caso exista na UBS, dirimir dúvidas com relação a referência de pacientes para especialistas.

Nas ações VISITA DOMICILIAR, REUNIÃO COM A COMUNIDADE, REUNIÃO DA EQUIPE e ATIVIDADE EDUCATIVA EM GRUPO, deve-se assinalar a opção 1 - Sim, se o profissional realiza a ação independente da periodicidade. Se ele participa da ação juntamente com outros componentes da equipe, ainda assim a opção será a 1 - Sim. 
Para o enfermeiro, foram incluídos ainda os itens TREINAMENTO DOS AUXILIARES DE ENFERMAGEM e DOS AGENTES COMUNITÁRIOS DE SAÚDE. Se estes estiverem presentes à entrevista, perguntar também aos mesmos para checar as informações prestadas pelo enfermeiro.

No ultimo item quantificar o número de períodos semanais planejados para atendimento clinico médico e de enfermagem.

\section{1 - Registre se as ações listadas abaixo são desenvolvidas pelos componentes da} ESF

4.1.1 - Médico

a) ATENDIMENTO CLÍNICO EM CLÍNICA MÉDICA, PEDIATRIA E GINECOOBSTETRÍCIA

b) VISITA DOMICILIAR $1-\square$ SIM $2-\square$ NÃO

c) REUNIÃO COM A COMUNIDADE $\quad 1-\square$ SIM 2 - $\square$ NÃO

d) REUNIÃO DA EQUIPE $1-\square$ SIM 2 - $\square$ NÃO

e) ATIVIDADE EDUCATIVA EM GRUPO 1 - $\square$ SIM 2 - $\square$ NÃO

f) ATENDIMENTO EM CLÍNICA MÉDICA $1-\square$ SIM 2 - $\square$ NÃO

g) ATENDIMENTO EM PEDIATRIA $1-\square$ SIM 2 - $\square$ NÃO

h) ATENDIMENTO EM GINECO-OBSTETRÍCIA 1 - $\square$ SIM 2 - $\square$ NÃO

i) QUANTOS PERIODOS POR SEMANA SÃO RESERVADOS PARA O ATENDIMENTO PERÍODOS CLINICO

\subsection{2 - Enfermeiro}

a) ATENDIMENTO CLÍNICO EM CLÍNICA MÉDICA, PEDIATRIA E GINECOOBSTETRÍCIA

\begin{tabular}{|c|c|c|c|}
\hline b) & VISITA DOMICILIAR & $1-\square \operatorname{SIM}$ & $2-\square N A ̃ O$ \\
\hline c) & REUNIÃO COM A COMUNIDADE & $1-\square$ SIM & $2-\square$ NÃO \\
\hline d) & REUNIÃO DA EQUIPE & $1-\square \operatorname{SIM}$ & $2-\square$ NÃO \\
\hline e) & ATIVIDADE EDUCATIVA EM GRUPO & $1-\square \operatorname{SIM}$ & $2-\square$ NÃO \\
\hline f) & $\begin{array}{l}\text { TREINAMENTO DO AUXILIAR DE } \\
\text { ENFERMAGEM }\end{array}$ & $1-\square \operatorname{SIM}$ & $2-\square$ NÃO \\
\hline g) & TREINAMENTO DO ACS & $1-\square \operatorname{SIM}$ & $2-\square$ NÃO \\
\hline h) & ATENDIMENTO EM CLÍNICA MÉDICA & $1-\square \operatorname{SIM}$ & $2-\square \mathrm{NÃO}$ \\
\hline i) & ATENDIMENTO EM PEDIATRIA & $1-\square \operatorname{SIM}$ & $2-\square \mathrm{NÃO}$ \\
\hline & ATENDIMENTO EM GINECO-OBSTETRÍCIA & $1-\square \operatorname{SIM}$ & $2-\square \mathrm{NÃO}$ \\
\hline
\end{tabular}




\begin{tabular}{|c|c|c|}
\hline $\begin{array}{l}\text { k) QUANTOS PERIODOS POR SEMANA SÃO } \\
\text { RESERVADOS PARA O ATENDIMENTO } \\
\text { CLINICO }\end{array}$ & - PEl & \\
\hline 4.1.3 - Auxiliar de enfermagem & & \\
\hline a) VISITA DOMICILIAR & $1-\square \operatorname{SIM}$ & $2-\square \mathrm{NÃO}$ \\
\hline b) REUNIÃO COM A COMUNIDADE & $1-\bar{\square} \operatorname{SIM}$ & $2-\bar{\square} \mathrm{NÃO}$ \\
\hline c) REUNIÃO DA EQUIPE & $1-\square \operatorname{SIM}$ & $2-\square \mathrm{NÃO}$ \\
\hline d) ATIVIDADE EDUCATIVA EM GRUPO & $1-\square \operatorname{SIM}$ & $2-\square \mathrm{NÃO}$ \\
\hline 4.1.4 - Agente Comunitário de Saúde & & \\
\hline a) VISITA DOMICILIAR & $1-\square \operatorname{SIM}$ & $2-\square$ NÃO \\
\hline REUNIÃO COM A COMUNIDADE & $1-\square \operatorname{SIM}$ & $2-\square$ NÃO \\
\hline c) REUNIÃO DA EQUIPE & $1-\bar{\square} \operatorname{SIM}$ & $2-\bar{\square} \mathrm{NÃO}$ \\
\hline d) ATIVIDADE EDUCATIVA EM GRUPO & $1-\square \operatorname{SIM}$ & $2-\bar{\square} \mathrm{N} \tilde{O}$ \\
\hline
\end{tabular}

4.2 - Nesta questão, o entrevistador deverá assinalar se a ESF realiza as ações listadas abaixo. Nos itens ELIMINAÇÃO DA HANSENÍASE (TRATAMENTO), ELIMINAÇÃO DA haNSENÍAse (DISPENSAÇÃO DE MEDICAMENTOS), CONTROLE DA TUBERCULOSE (TRATAMENTO), CONTROLE DA TUBERCULOSE (TRATAMENTO SUPERVISIONADO) e CONTROLE DA TUBERCULOSE (DISPENSAÇÃO DE MEDICAMENTOS) há a alternativa 3 - Não se aplica. Esta alternativa deverá ser assinalada somente se no município ou área onde a ESF atua não houver casos de Hanseníase ou Tuberculose. Nestes casos, conseqüentemente, a equipe não estará realizando tratamento e dispensação de medicamentos, mesmo se estiver capacitada a fazê-lo.

Para as doenças prevalentes na infância não considerar apenas o AIDPI.

Para os casos de Hansen e TB e Saúde mental, procurar saber se a ESF atende algum paciente ou se os mesmos estão cadastrados na UBS. 
Para o tratamento de DST considerar a se há prescrição e acompanhamento do usuário. Se há ou não a dispensação do medicamento pela Secretaria Municipal de Saúde, não é o importante neste momento.

No item VIGILÂNCIA EPIDEMIOLÓGICA (AÇÕES DE CONTROLE DE CASOS E SURTOS), considerar vacinação de bloqueio, quimioprofilaxia, entre outros.

No item INVESTIGAÇÃO DE ÓBITOS, considerar qualquer tipo de óbito.

No item INVESTIGAÇÃO DE INTERNAÇÕES HOSPITALARES, considerar qualquer tipo de internação.

No item ACOMPANHAMENTO EM SAÚDE MENTAL, investigar se a ESF conhece portadores de sofrimento mental na sua área e se faz algum tipo de acompanhamento do mesmo.

4.2 - Assinale se a ESF realiza as seguintes ações:

\begin{tabular}{|c|c|c|c|}
\hline & PRÉ-NATAL (CONSULTA MÉDICA) & $1-\square \operatorname{SIM}$ & $2-\square$ NÃO \\
\hline 2. & PRÉ-NATAL (CONSULTA DE ENFERMAGEM) & $1-\square \operatorname{SIM}$ & $2-\square N A ̃ O$ \\
\hline 3. & $\begin{array}{l}\text { PREVENÇÃO DO CÂNCER DE COLO DE } \\
\text { ÚTERO (COLETA DE MATERIAL) }\end{array}$ & $1-\square \operatorname{SIM}$ & 2 - $\square$ NÃO \\
\hline 4. & $\begin{array}{l}\text { PLANEJAMENTO FAMILIAR (AÇÃOO } \\
\text { EDUCATIVA) }\end{array}$ & $1-\square \operatorname{SIM}$ & 2 - $\square$ NÃO \\
\hline 5. & $\begin{array}{l}\text { PLANEJAMENTO FAMILIAR (OFERTA DE } \\
\text { MÉTODOS) }\end{array}$ & $1-\square \operatorname{SIM}$ & $2-\square$ NÃO \\
\hline
\end{tabular}




\begin{tabular}{|c|c|c|}
\hline 6. TRATAMENTO DE CORRIMENTO VAGINAL & $1-\square \operatorname{SIM}$ & $2-\square$ NÃO \\
\hline $\begin{array}{l}\text { 7. ACOMPANHAMENTO DO CRESCIMENTO E } \\
\text { DESENVOLVIMENTO < } 2 \text { ANOS (CONSULTA } \\
\text { MÉDICA) }\end{array}$ & $1-\square \operatorname{SIM}$ & $2-\square N A ̃ O$ \\
\hline $\begin{array}{ll}\text { 8. } & \text { ACOMPANHAMENTO DO CRESCIMENTO E } \\
\text { DESENVOLVIMENTO < } 2 \text { ANOS (CONS } \\
\text { ENFERMAGEM) }\end{array}$ & $1-\square \operatorname{SIM}$ & $2-\square N A ̃ O$ \\
\hline $\begin{array}{l}\text { 9. ASSISTÊNCIA ÀS DOENÇAS PREVALENTES } \\
\text { NA INFÂNCIA (CONSULTA MÉDICA) }\end{array}$ & $1-\square \operatorname{SIM}$ & $2-\square N A ̃ O$ \\
\hline $\begin{array}{l}\text { 10. ASSISTÊNCIA ÀS DOENÇAS PREVALENTES } \\
\text { NA INFÂNCIA (CONS. ENFERMAGEM) }\end{array}$ & $1-\square \operatorname{SIM}$ & $2-\square N A ̃ O$ \\
\hline $\begin{array}{l}\text { 11. ASSISTÊNCIA ÀS DOENÇAS PREVALENTES } \\
\text { NA INFÂNCIA (TRO) }\end{array}$ & $1-\square \operatorname{SIM}$ & $2-\square N A ̃ O$ \\
\hline $\begin{array}{l}\text { 12. VIGILÂNCIA NUTRICIONAL - PCCN } \\
\text { (IDENTIFICAÇÃO DOS CASOS) }\end{array}$ & $1-\square \operatorname{SIM}$ & $2-\square N A ̃ O$ \\
\hline $\begin{array}{l}\text { 13. VIGILÂNCIA NUTRICIONAL - PCCN } \\
\text { (CONSULTA MÉDICA) }\end{array}$ & $1-\square \operatorname{SIM}$ & $2-\square$ NÃO \\
\hline $\begin{array}{l}\text { 14. VIGILÂNCIA NUTRICIONAL - PCCN } \\
\text { (SUPLEMENTAÇÃO ALIMENTAR) }\end{array}$ & $1-\square \operatorname{SIM}$ & $2-\square N A ̃ O$ \\
\hline 15. CONTROLE DO DIABETES (DIAGNÓSTICO) & $1-\square \operatorname{SIM}$ & $2-\square N A ̃ O$ \\
\hline $\begin{array}{l}\text { 16. CONTROLE DO DIABETES (GLICEMIA } \\
\text { CAPILAR) }\end{array}$ & $1-\square \operatorname{SIM}$ & $2-\square$ NÃO \\
\hline 17. CONTROLE DO DIABETES (TRATAMENTO) & $1-\square \operatorname{SIM}$ & $2-\square \mathrm{NÃO}$ \\
\hline $\begin{array}{l}\text { 18. CONTROLE DA HIPERTENSÃO } \\
\text { (DIAGNÓSTICO) }\end{array}$ & $1-\square \operatorname{SIM}$ & $2-\square$ NÃO \\
\hline $\begin{array}{l}\text { 19. CONTROLE DA HIPERTENSÃO } \\
\text { (TRATAMENTO) }\end{array}$ & $1-\square \operatorname{SIM}$ & $2-\square$ NÃO \\
\hline $\begin{array}{l}\text { 20. ELIMINAÇÃO DA HANSENÍASE } \\
\text { (DIAGNÓSTICO) }\end{array}$ & $1-\square \operatorname{SIM}$ & $2-\square N A ̃ O$ \\
\hline 21. ELIMINAÇÃO DA HANSENÍASE (TRATAMENTO) & $\begin{array}{l}1-\square \text { SIM } 2-\square \\
\text { NÃO SE APLICA }\end{array}$ & INÃO $3-\square$ \\
\hline $\begin{array}{l}\text { 22. ELIMINAÇÃO DA HANSENÍASE (DISPENSAÇÃO } \\
\text { DE MEDICAMENTOS) }\end{array}$ & $\begin{array}{l}1-\square \text { SIM } 2-\square \\
\text { NÃO SE APLICA }\end{array}$ & 1 NÃO $3-\square$ \\
\hline $\begin{array}{l}\text { 23. CONTROLE DA TUBERCULOSE } \\
\text { (DIAGNÓSTICO) }\end{array}$ & $1-\square \operatorname{sIM}$ & $2-\square N A ̃ O$ \\
\hline $\begin{array}{l}\text { 24. CONTROLE DA TUBERCULOSE } \\
\text { (TRATAMENTO) }\end{array}$ & $\begin{array}{l}1-\square \text { SIM } 2-\square \\
\text { NÃO SE APLICA }\end{array}$ & NÃO $3-\square$ \\
\hline $\begin{array}{l}\text { 25. CONTROLE DA TUBERCULOSE } \\
\text { (TRATAMENTO SUPERVISIONADO) }\end{array}$ & $\begin{array}{l}1-\square \text { SIM } 2-\square \\
\text { NÃO SE APLICA }\end{array}$ & INÃO $3-\square$ \\
\hline $\begin{array}{l}\text { 26. CONTROLE DA TUBERCULOSE } \\
\text { (DISPENSAÇÃO DE MEDICAMENTOS) }\end{array}$ & $\begin{array}{l}1-\square \text { SIM } 2-\square \\
\text { NÃO SE APLICA }\end{array}$ & INÃO $3-\square$ \\
\hline 27. DST (DIAGNÓSTICO) & $1-\square \operatorname{SIM}$ & $2-\square N A ̃ O$ \\
\hline 28. DST (TRATAMENTO) & $1-\square \operatorname{SIM}$ & $2-\square \mathrm{NÃO}$ \\
\hline $\begin{array}{l}\text { 29. VIGILÂNCIA EPIDEMIOLÓGICA (NOTIFICAÇÃO } \\
\text { DE DNC) }\end{array}$ & $1-\square \operatorname{SIM}$ & $2-\square N A ̃ O$ \\
\hline $\begin{array}{l}\text { 30. VIGILÂNCIA EPIDEMIOLÓGICA } \\
\text { (INVESTIGAÇÃO DOS CASOS DE DNC) }\end{array}$ & $1-\square \operatorname{SIM}$ & $2-\square$ NÃO \\
\hline $\begin{array}{l}\text { 31. VIGILÂNCIA EPIDEMIOLÓGICA (AÇÕES DE } \\
\text { CONTROLE DE CASOS E SURTOS) }\end{array}$ & $1-\square \operatorname{SIM}$ & $2-\square$ NÃO \\
\hline 32. INVESTIGAÇÃO DE ÓBITOS & $1-\square \operatorname{SIM}$ & $2-\square \mathrm{NÃO}$ \\
\hline $\begin{array}{l}\text { 33. INVESTIGAÇÃO DE INTERNAÇÕES } \\
\text { HOSPITALARES }\end{array}$ & $1-\square \operatorname{SIM}$ & $2-\square N A ̃ O$ \\
\hline 34. ACOMPANHAMENTO EM SAÚDE MENTAL & $1-\square \operatorname{SIM}$ & $2-\square N A ̃ O$ \\
\hline
\end{tabular}


4.3 - Nesta questão, o entrevistador deverá assinalar se a ESF realiza atividades educativas continuadas para os grupos populacionais listados. A periodicidade da ação não é a informação mais importante neste momento, mas sim se a ação tem um caráter continuado. Se a equipe referir a realização de alguma atividade apenas eventual, com os grupos citados assinalar a opção 2 - Não.

\begin{tabular}{|c|c|c|c|}
\hline & $\begin{array}{l}\text { - Em quais grupos populacionais a ESF realiza at } \\
\text { tinuadas: }\end{array}$ & vidades edu & \\
\hline a) & GESTANTES & $1-\square \operatorname{SIM}$ & $2-\square N A \tilde{O}$ \\
\hline b) & $\begin{array}{l}\text { MENORES DE } 2 \text { ANOS PARA MONITORAMENTO } \\
\text { DE CRESCIMENTO E DESENVOLVIMENTO }\end{array}$ & $1-\square \operatorname{SIM}$ & $2-\square$ NÃO \\
\hline c) & DESNUTRIDOS & $1-\square \operatorname{SIM}$ & $2-\square$ NÃO \\
\hline d) & ESCOLARES & $1-\square \operatorname{SIM}$ & $2-\square \mathrm{NÃO}$ \\
\hline & DIABÉTICOS & $1-\square \operatorname{SIM}$ & $2-\square \mathrm{NÃO}$ \\
\hline f) & HIPERTENSOS & $1-\square \operatorname{SIM}$ & $2-\square \mathrm{NÃO}$ \\
\hline & ADOLESCENTES & $1-\bar{\square} \operatorname{SIM}$ & $2-\bar{\square} \mathrm{NÃO}$ \\
\hline & IDOSOS & $1-\square \operatorname{SIM}$ & $2-\square \mathrm{NÃO}$ \\
\hline
\end{tabular}

4.4 - Nesta questão deverá ser investigada a utilização de prontuários pela ESF, podendo ser individual ou de família.

A questões a seguir são relativas à organização do prontuário na unidade.

4.4.1 - Nesta questão o pesquisador deverá anotar se os dados clínicos individuais dos pacientes são descritos no prontuário, independente da qualidade e legibilidade da anotação.

4.4.2 - Nesta questão deverá ser investigado se os resultados dos exames estão incluídos (ou anotados) nos prontuários, ou se são guardados em outro local e não anotados no prontuário.

4.4.3 e 4.4.4 - Nestas questões o pesquisador deverá questionar se as informações colhidas pelos ACS, que estão descritas na ficha $\mathrm{B}$ e $\mathrm{C}$, são incluídas no prontuário independentemente se for individual ou familiar. Responder sim se os dados das fichas $B$ e/ou C são transcritos no prontuário ou se as próprias fichas B ou C estiverem anexadas no prontuário. 
4.4.5 - Nesta questão o entrevistador assinalará sim se a unidade usar prontuário familiar. Se a unidade não utilizar prontuário familiar o entrevistador pode pular para a questão 4.5

4.4.6. - Responder sim se o prontuário familiar inclui os prontuários individuais dos membros da família.

4.4.7 e 4.4.8 - Estas questões exploram a composição da prontuário familiar. Se informações de caráter mais geral da família ou coletivo são incluídos no prontuário familiar.

4.4.7 - Assinalar sim se as informações da família contidas na ficha A ou, se a própria ficha A, compõe o prontuário família.

4.4.8. - Assinalar se outras informações, além da ficha A, importantes para a saúde da família, como situações de risco (desemprego, violência, drogas, morte) ou da dinâmica familiar, são descritas no prontuário família.

\begin{tabular}{|c|c|c|}
\hline 4.4 - A ESF utiliza prontuário? & $1-\square \operatorname{SIM}$ & $2-\square \mathrm{NÃO}$ \\
\hline $\begin{array}{l}\text { 4.4.1 - O prontuário inclui as fichas clínicas } \\
\text { individuais dos membros da família? }\end{array}$ & $1-\square \operatorname{SIM}$ & $2-\square N A ̃ O$ \\
\hline 4.4.2 - O prontuário inclui os resultados de exames? & $1-\square \mathrm{SIM}$ & $2-\square \mathrm{NÃO}$ \\
\hline $\begin{array}{l}\text { 4.4.3 - O prontuário inclui a ficha "B" do SIAB ou os } \\
\text { dados coletados pelos agentes e descritos na ficha } \\
\text { B? }\end{array}$ & $1-\square \mathrm{SIM}$ & $2-\square \mathrm{NÃO}$ \\
\hline $\begin{array}{l}\text { 4.4.4 - O prontuário inclui a ficha "C" do SIAB ou os } \\
\text { dados da ficha C? }\end{array}$ & $1-\square \operatorname{SIM}$ & $2-\square N A ̃ O$ \\
\hline 4.4.5 - A ESF tem prontuário familiar? & $1-\square \operatorname{SIM}$ & $2-\square \mathrm{NÃO}$ \\
\hline $\begin{array}{l}\text { 4.4.6 - O prontuário familiar inclui os prontuários } \\
\text { individuais? }\end{array}$ & $1-\square \mathrm{SIM}$ & $2-\square \mathrm{NÃO}$ \\
\hline $\begin{array}{l}\text { 4.4.7 - O prontuário familiar inclui a ficha " } A \text { " do } \\
\text { SIAB ou os dados sociais e ambientais descritos na } \\
\text { ficha A? }\end{array}$ & $1-\square \mathrm{SIM}$ & $2-\square \mathrm{NÃO}$ \\
\hline $\begin{array}{l}\text { 4.4.8 - O prontuário familiar inclui outras informações } \\
\text { de situações de risco familiar ou da dinâmica da } \\
\text { família? }\end{array}$ & $1-\square \mathrm{SIM}$ & $2-\square \mathrm{NÃO}$ \\
\hline
\end{tabular}

4.5 - Nesta questão deverão ser assinaladas as alternativas 1 ou 2 conforme descrição abaixo. O entrevistador deverá perguntar qual utilização a equipe faz dos dados do SIAB e se os mesmos são apropriados pela equipe ou não para realizar a programação e o planejamento das atividades. 
Nas questões 4.5.1 a 4.5.4 responder a alternativa referida pela equipe. Caso haja mais de uma resposta, perguntar quem, com maior freqüência, realiza estas ações.

\begin{tabular}{|c|c|}
\hline $\begin{array}{l}\text { 4.5 - A ESF utiliza as informações contidas no } \\
\text { SIAB para programar as suas ações? }\end{array}$ & $1-\square \operatorname{SIM}$ \\
\hline 4.5.1 - Quem geralmente consolida o SIAB? & $\begin{array}{l}1 \text { - } \square \text { O MÉDICO } \\
2 \text { - } \square \text { O ENFERMEIRO } \\
3 \text { - } \square \text { O AUXILIAR DE } \\
\text { ENFERMAGEM } \\
4 \text { - } \square \text { O AGENTE COMUNITÁRIO } \\
\text { DE SAÚDE }\end{array}$ \\
\hline 4.5.2 - Quem digita o SIAB? & $\begin{array}{l}1 \text { - } \square \text { O MÉDICO } \\
2 \text { - } \square \text { O ENFERMEIRO } \\
3 \text { - } \square \text { O AUXILIAR DE } \\
\text { ENFERMAGEM } \\
4 \text { - } \square \text { O AGENTE COMUNITÁRIO } \\
\text { DE SAÚDE } \\
5 \text { - } \square \text { OUTROS }\end{array}$ \\
\hline 4.5.3 - Onde é digitado o SIAB? & $\begin{array}{l}1-\square \text { USF } \\
2-\square \text { SECRETARIA MUNICIPAL DE } \\
\text { SAUUDE } \\
3-\square \text { OUTROS }\end{array}$ \\
\hline $\begin{array}{l}\text { 4.5.4 - A quem a ESF recorre com maior } \\
\text { freqüência quando tem problemas com o SIAB? }\end{array}$ & $\begin{array}{l}1-\square \text { SECRETARIA MUNICIPAL DE } \\
\text { SAUUDE } \\
2-\square \text { DIR } \\
3-\square \text { COORD. ESTADUAL } \\
\text { PACS/PSF } \\
4-\square \text { OUTRAS USF }\end{array}$ \\
\hline
\end{tabular}

4.6 - Nesta questão deverão ser assinaladas as alternativas 1 ou 2 conforme descrição abaixo. Se um ou mais membros da equipe participam regularmente das reuniões do Conselho Municipal/Comissão Local de Saúde, assinalar a opção 1 - Sim. O(s) componente(s) da equipe não necessita(m) fazer parte do Conselho/Comissão de Saúde para considerar a afirmativa como positiva.

\begin{tabular}{l}
$\begin{array}{l}\text { 4.6 - Algum membro da equipe participa das reuniões do } \\
\text { Conselho Municipal/Comissão Local de Saúde } \\
\text { regularmente? }\end{array} \quad 1-\square$ SIM 2 - $\square$ NÃO \\
\hline
\end{tabular}


4.7 - Nesta questão assinalar sim ou não conforma a existência de um cronograma semanal para principais atividades dos membros das equipes.

\begin{tabular}{|lll|}
\hline 4.7 Existe cronograma semanal das principais atividades da ESF para : \\
\hline a) para médicos & {$[$ ] 1-sim } & [ ] 2-não \\
\hline b) para enfermeiros & [ ] 1-sim & [ ] 2-não \\
\hline c) para aux. de enfermagem & {$[$ ] 1-sim } & [ ] 2-não \\
\hline d) para ACS & [ ] 1-sim & [ ] 2-não \\
\hline
\end{tabular}

\section{Parte 5 - Acesso à Serviços e Procedimentos}

Este bloco se destina a avaliar se o sistema de referência e contra-referência do município ou região está ou não atendendo às necessidades das ESF, garantindo a resolutividade do sistema de saúde.

5.1 - Nesta questão deverão ser utilizados os códigos 1, 2, 3 ou 4 para cada item conforme descrição abaixo. O entrevistador deverá perguntar à equipe se estão disponíveis os exames e serviços citados abaixo para a população adstrita. A rede SUS a que se refere a questão pode ser a própria ou contratada e os exames/serviços podem ser realizados dentro ou fora do município. Poderá ser considerado existente, se a prefeitura paga o exame, mesmo não havendo convênio formal com o SUS, mas o usuário conta com este exame gratuitamente.

Se o exame for regularmente realizado pelo município, mas não estiver disponível no período do estudo, assinalar a opção 2 - Não. 
- A opção 1- Sim, deverá ser utilizada quando o exame é realizado sempre que solicitado, em tempo hábil.

- A opção 2- Não, deverá ser utilizada se não há disponibilidade na rede SUS do exame citado.

- A opção 3- Insuficiente, se nem todos os usuários para os quais são solicitados os determinados exames conseguem realizá-lo.

- A opção 4- Não sabe, se o informante não souber se há ou não a disponibilidade do exame.

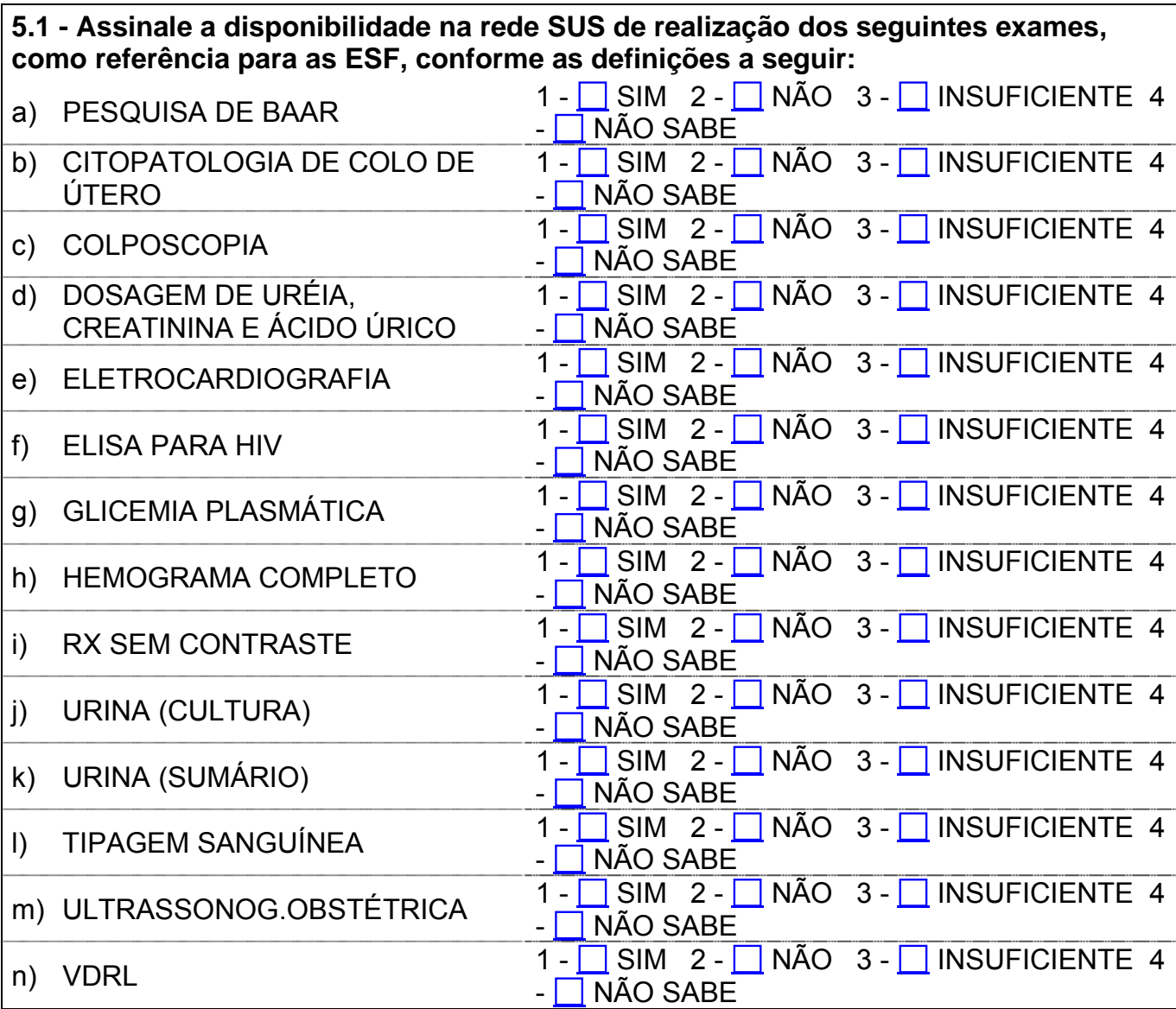

5.2 - Nesta questão deverão ser assinaladas as opções 1, 2, 3 ou 4 para cada item conforme descrição abaixo. $O$ entrevistador deverá perguntar à equipe se estão disponíveis para os usuários cadastrados na ESF os serviços citados abaixo, realizados em unidades dentro ou fora do município. 
- A opção 1 - Sim, deverá ser utilizada se sempre que a equipe encaminha os usuários adstritos a ela, que necessitem dos serviços citados, os mesmos são atendidos.

- A opção 2 - Não, deverá ser utilizada se não há disponibilidade na rede SUS dos serviços citados.

- A opção 3 - Insuficiente, se nem todos os usuários encaminhados para este serviço de referência são atendidos.

- A opção 4 - Não sabe, se o informante não souber se há ou não a disponibilidade do serviço citado.

No item INTERNAÇÃO HOSPITALAR NAS CLÍNICAS BÁSICAS, deve ser considerado existente se há a disponibilidade de internações nas clínicas médica, pediátrica e gineco-obstétrica.

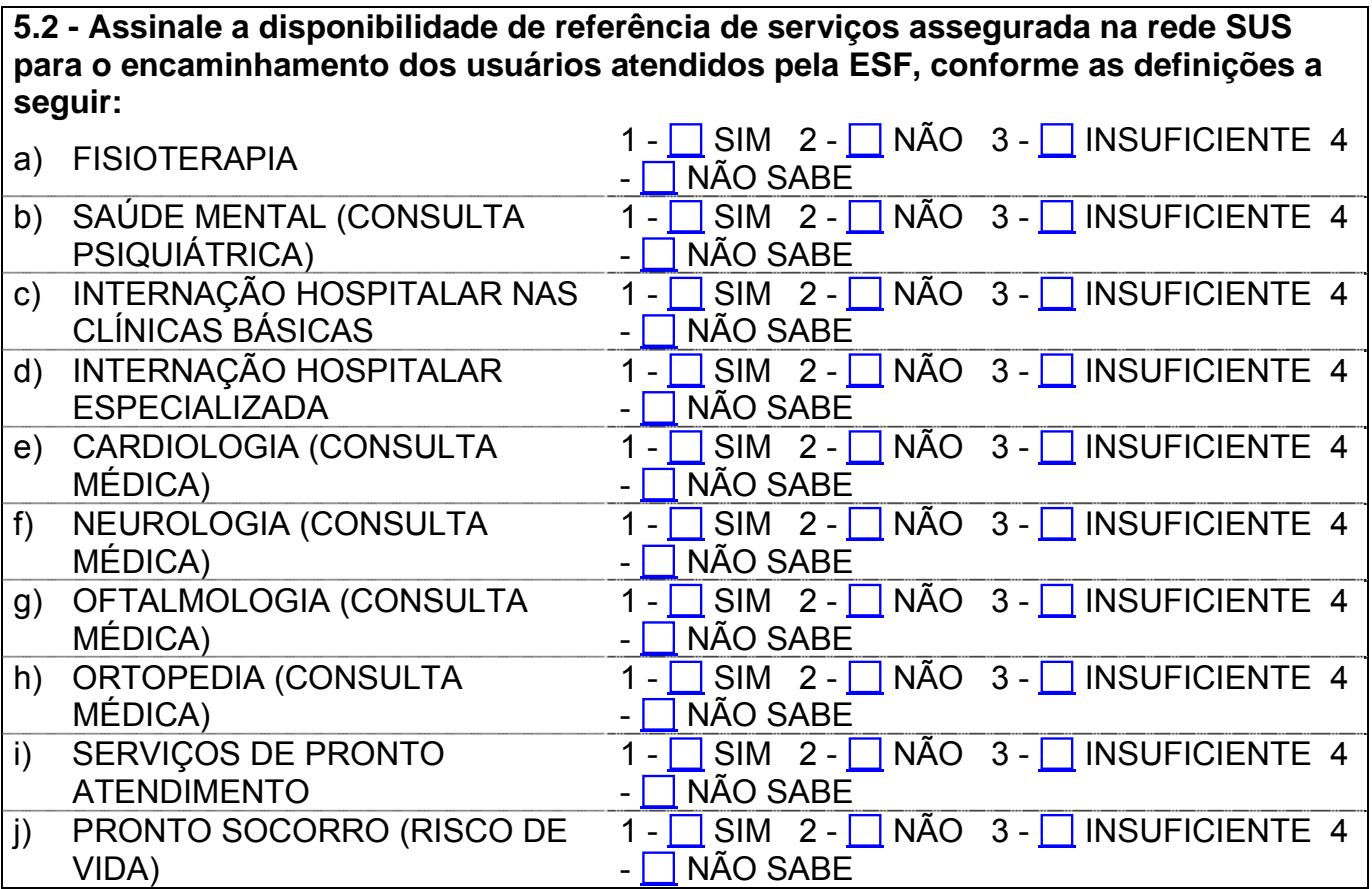

Nas do item 5.3 são relacionadas a organização da assistência. 
5.3.1 - anotar o profissional que geralmente recebe os clientes na unidade.

As questões seguintes assinalar a opção que for mais de acordo com a pratica na unidade. Todas as questões são referentes ao atendimento dos pacientes não agendados que procuram a unidade.

5.3.3 - assinalar a conduta mais freqüente da equipe no caso de algum paciente da área não agendado procurar atendimento. Observar que há um erro a pergunta correta é: No caso de um paciente não agendado qual é o procedimento mais freqüente da equipe nesses casos.

5.3.4 - assinalar o número de vagas reservadas para pacientes não agendados por período de atendimento clínico.

\section{3 - Questões relacionadas com o modelo de assistência.}

\begin{tabular}{|c|c|}
\hline $\begin{array}{l}\text { 5.3.1 - Quem é o primeiro contato do cliente na } \\
\text { ESF? }\end{array}$ & $\begin{array}{l}1 \text { - }-\square \text { O MÉDICO } \\
2 \text { - } \square \text { O ENFERMEIRO } \\
3-\square \text { O AUXILIAR DE } \\
\text { ENFERMAGEM } \\
4-\square \text { O AGENTE COMUNITÁRIO } \\
\text { DE SAÚDE } \\
5 \text { - } \square \text { OUTROS }\end{array}$ \\
\hline 5.3.2 - A ESF atende pacientes não agendados? & $1-\square S I M \quad 2-\square N$ ÃO \\
\hline $\begin{array}{l}5.3 .3 \text { - No caso do paciente não agendado, como é } \\
\text { o procedimento mais freqüente da equipe nesses } \\
\text { casos? }\end{array}$ & $\begin{array}{l}1 \text { - - } \square \text { SÓ ATENDE AGENDADOS } \\
2 \text { - } \square \text { ENCAMINHA PARA O PA } \\
3 \text { - } \square \text { AVALIA, SER FOR } \\
\text { URGENCIA ATENDE, SE } \\
\text { NÃO AGENDA } \\
\text { - }-\square \text { ATENDE A TODAS AS } \\
\text { PESSOAS QUE PROCURAM A }\end{array}$ \\
\hline
\end{tabular}




\begin{tabular}{|l|l|}
\hline & \\
& \\
\hline $\begin{array}{l}\text { 5.3.4- Caso a ESF atenda não agendados, há um } \\
\text { número de vagas por período reservadas para } \\
\text { estes casos? }\end{array}$ & $\begin{array}{l}\text { 1- } \square \text { SIM QUANTAS? } \\
\text { Q }-\square \text { NÃ }\end{array}$ \\
\hline
\end{tabular}

\section{Parte 6 - Recursos Humanos}

Este último bloco se destina a avaliar a situação de recursos humanos da ESF e se a sua composição e funcionamento atende as recomendações do Ministério da Saúde para o PSF, visando a efetiva mudança no modelo assistencial.

6.1 - Nesta questão, para cada categoria profissional há cinco itens a serem respondidos.

No item a) o entrevistador deverá assinalar a alternativa que indique quantos profissionais daquela categoria atuam naquela equipe. Este item visa identificar equipes que possuem mais de um médico e enfermeiro. Visa ainda verificar se as equipes estão sem estes profissionais e há quanto tempo. Em relação aos agentes comunitários de saúde, a quantidade foi agrupada de forma diferente das demais já que as equipes possuem este profissional em maior número. Assinalar, portanto, a alternativa mais adequada. No caso da resposta ser nenhum verificar a situação e registrar nas observações (licença, doenças, desligamento, entre outros).

No item b), o entrevistador deverá assinalar a opção mais adequada para a carga horária prevista no contrato entre a instituição empregadora e o profissional. Mesmo que 
não haja contrato formal, o entrevistador deverá procurar saber quantas horas estão previstas no contrato verbal firmado entre o gestor e o profissional. No caso de a resposta não se enquadrar nas categorias listadas, marcar a opção 4) outra e anotar a carga horária contratada.

No item c), o entrevistador deverá assinalar a opção mais adequada para a carga horária efetivamente cumprida pelo profissional, principalmente do médico e do enfermeiro. Esta questão visa identificar os casos em que o profissional é contratado para uma jornada de 40 horas semanais, mas existem acordos com o gestor ou gerente da saúde da família para cumprimento de jornada menor, através de folgas, liberação para plantão, etc. e o profissional acaba não dedicando para o programa de saúde da família a carga horária necessária. No caso de a resposta não se enquadrar nas categorias listadas, marcar a opção 4) outra e anotar a carga horária cumprida. A questão carga horária não deve ser apenas assinalada tomando como base a resposta verbal, os entrevistadores devem ter a habilidade de identificar distorções ou incoerências, caso existam, nas afirmações referentes as cargas horárias.

No item d), o entrevistador deverá assinalar qual o vínculo contratual do profissional, conforme as opções apresentadas. No caso de a resposta não se enquadrar nas categorias listadas, marcar a opção 9) Outros e anotar qual a forma de contratação adequada. Se o profissional for cedido ou for contratado por ONGs, assinalar a forma de contratação do mesmo pela entidade em questão e explicitar esta situação no espaço aberto da opção 9). 
É importante destacar que não há possibilidade de marcar mais de uma opção nos itens a), b), c) e e). $O$ item d) permite que seja marcada mais de uma opção desde que uma delas seja a opção 9 - outros.

No item e), o entrevistador deverá assinalar há quanto tempo os profissionais estão trabalhando naquela equipe daquele município. Esta questão visa detectar a rotatividade dos médicos, enfermeiros e auxiliares de enfermagem.

Se forem encontrados mais de um profissional médico e enfermeiro na equipe, usar as informações referentes àquele que se encontra cadastrado no SIAB.

Se houver mais de um auxiliar de enfermagem na equipe, usar as informações referentes àquele que dedica maior parte da sua carga horária exclusivamente para o programa de saúde da família. Se for igual, registrar as informações referentes àquele que está há mais tempo na equipe.

No caso dos agentes comunitários de saúde, se foram encontradas situações diferentes entre eles em relação à carga horária e vínculo profissional, assinalar as alternativas que reflitam a situação da maioria deles. 
No último item, sobre o salário bruto de cada categoria, se entrevistador identificar situações em que esta pergunta for constrangedora para os entrevistados, poderá fazê-la individualmente aos membros da equipe.

\section{1 - Registre a situação dos profissionais da ESF para as seguintes informações:}

\subsection{1 - Médico}

a)

$\begin{aligned} \text { QUANTIDADE } & 30 \text { DIAS } \\ & 2-\square \text { NENHUM DE } 30 \text { A } 60 \text { DIAS } \\ & 3-\square \text { NENHUM HÁ MAIS DE } 60 \\ & \text { DIAS }\end{aligned}$

$4-\square$ UM

$5-\square$ DOIS

6 - $\square$ TRÊS OU MAIS

b) CARGA HORÁRIA

CONTRATADA $2-\square 30 \mathrm{HS}$

$1-\square 20 \mathrm{HS}$

$3-\square 40 \mathrm{HS}$

4 - $\square$ OUTRA

c) CARGA HORÁRIA $1-\square 20 \mathrm{HS}$

CUMPRIDA $2-\square 30 \mathrm{HS}$

3 - $40 \mathrm{HS}$

4 - $\square$ OUTRA

d) VÍNCULO CONTRATUAL 1 - $\square$ ESTATUTÁRIO

$2-\square \mathrm{CLT}$

3 - $\square$ CONTRATO TEMPORÁRIO

4 - $\square$ CARGO COMISSIONADO

5 - $\square$ BOLSA

6 - $\square$ PRESTAÇÃO DE SERVIÇOS

7 - $\square$ COOPERADO

8 - $\square$ CONTRATO INFORMAL

9 - $\square$ OUTROS

e) TEMPO NA EQUIPE $1-\square$ MENOS DE 1 MÊS

2 - D DE 1 A 3 MESES

3 - $\square$ DE 4 A 6 MESES

4 - $\square$ DE 7 MESES A 1 ANO

5 - $\square$ DE 1 ANO A 1 ANO E MEIO

6 - $\square$ DE 1 ANO E MEIO A 2 ANOS

7 - $\square$ DE 2 A 3 ANOS

8 - $\square$ HÁ MAIS DE 3 ANOS

f) Qual o salário bruto

$\mathrm{R} \$$

\subsection{2 - Enfermeiro}

a) 1 - $\square$ NENHUM HÁ MENOS DE QUANTIDADE 30 DIAS

2 - $\square$ NENHUM DE 30 A 60 DIAS

3 - $\square$ NENHUM HÁ MAIS DE 60

4 - $\square$ UM

5 - $\square$ DOIS

DIAS

b) CARGA HORÁRIA CONTRATADA

$1-\square 20 \mathrm{HS}$
$2-\square 30 \mathrm{HS}$
$3-\square$ 40 HS
$4-\square$ OUTRA




\begin{tabular}{|c|c|c|}
\hline $\begin{array}{l}\text { c) CARGA HORÁRIA } \\
\text { CUMPRIDA }\end{array}$ & \multicolumn{2}{|l|}{$\begin{array}{l}2 \text { - }-\bar{\square} 30 \mathrm{HS} \\
3 \text { - } 40 \text { HS } \\
4 \text { - } 1 \text { OUTRA }\end{array}$} \\
\hline d) VÍNCULO CONTRATUAL & $\begin{array}{l}1-\bar{\square} \text { ESTATUTA } \\
2-\square \text { CLT } \\
3-\square \text { CONTRAT } \\
4-\square \text { CARGO C } \\
5-\square \text { BOLSA } \\
6-\square \text { PRESTAÇ } \\
7-\square \text { COOPERA } \\
8-\square \text { CONTRAT } \\
9-\square \text { OUTROS }\end{array}$ & $\begin{array}{l}\text { RIO } \\
\text { TEMPORÁRIO } \\
\text { MISSIONADO } \\
\text { O DE SERVIÇOS } \\
\text { INFORMAL }\end{array}$ \\
\hline e) TEMPO NA EQUIPE & \multicolumn{2}{|c|}{$\begin{array}{l}-\square \text { MENOS DE } 1 \text { MÊS } \\
\text { - } \square \text { DE } 1 \text { A } 3 \text { MESES } \\
\text { - } \square \text { DE } 4 \text { A } 6 \text { MESES } \\
\text { - } \square \text { DE } 7 \text { MESES A } 1 \text { ANO } \\
\text { - } \square \text { DE } 1 \text { ANO A } 1 \text { ANO E MEIO } \\
\text { - } \square \text { DE } 1 \text { ANO E MEIO A } 2 \text { ANOS } \\
\text { - } \square \text { DE } 2 \text { A } 3 \text { ANOS } \\
\text { - } \\
\text { HÁ MAIS DE } 3 \text { ANOS }\end{array}$} \\
\hline f) Qual o salário bruto & \multicolumn{2}{|l|}{$\mathbf{R} \mathbf{.}$} \\
\hline \multicolumn{3}{|c|}{ 6.1.3 - Auxiliar de Enfermagem } \\
\hline \multicolumn{2}{|c|}{$\begin{array}{ll}\text { a) } & 1-\square \text { NENHUM HÁ MENOS DE } \\
\text { QUANTIDADE } & 30 \text { DIAS } \\
& 2-\square \text { NENHUM DE } 30 \text { A } 60 \text { DIAS } \\
& 3-\square \text { NENHUM HÁ MAIS DE } 60 \\
& \text { DIAS }\end{array}$} & $\begin{array}{l}4-\square \text { UM } \\
5-\square \text { DOIS } \\
6-\square \text { TRÊS OU MAIS }\end{array}$ \\
\hline $\begin{array}{l}\text { b) CARGA HORÁRIA } \\
\text { CONTRATADA }\end{array}$ & $\begin{array}{l}1-\square 20 \text { HS } \\
2-\square 30 \text { HS } \\
3-\square 40 \text { HS } \\
4-\square \text { OUTRA }\end{array}$ & \\
\hline $\begin{array}{l}\text { c) CARGA HORÁRIA } \\
\text { CUMPRIDA }\end{array}$ & $\begin{array}{l}1-\bar{\square} 20 \mathrm{HS} \\
2-\bar{\square} 30 \mathrm{HS} \\
3-\bar{\square} \text { 40 HS } \\
4-\bar{\square} \text { OUTRA }\end{array}$ & \\
\hline d) VÍNCULO CONTRATUAL & \multicolumn{2}{|c|}{ 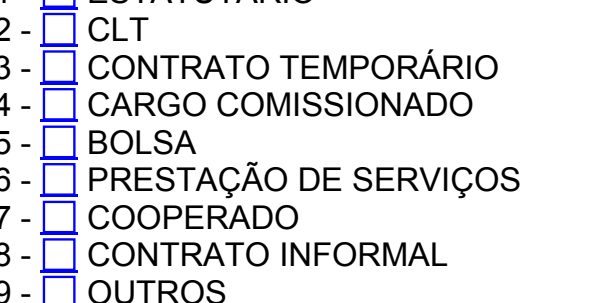 } \\
\hline e) TEMPO NA EQUIPE & \multicolumn{2}{|c|}{$\begin{array}{l}1 \text { - } \text { MENOS DE } 1 \text { MESS } \\
\text { - }-\square \text { DE } 1 \text { A } 3 \text { MESES } \\
\text { - } \square \text { DE } 4 \text { A } 6 \text { MESES } \\
\text { - } \square \text { DE } 7 \text { MESES A } 1 \text { ANO } \\
\text { - } \square \text { DE } 1 \text { ANO A } 1 \text { ANO E MEIO } \\
\text { - } \square \text { DE } 1 \text { ANO E MEIO A } 2 \text { ANOS } \\
\text { - } \square \text { DE } 2 \text { A } 3 \text { ANOS } \\
\text { - } \text { HÁ MAIS DE } 3 \text { ANOS }\end{array}$} \\
\hline f) Qual o salário bruto & \multicolumn{2}{|l|}{$\mathrm{R} \$$} \\
\hline
\end{tabular}


6.1.4 - Agente Comunitário de Saúde:

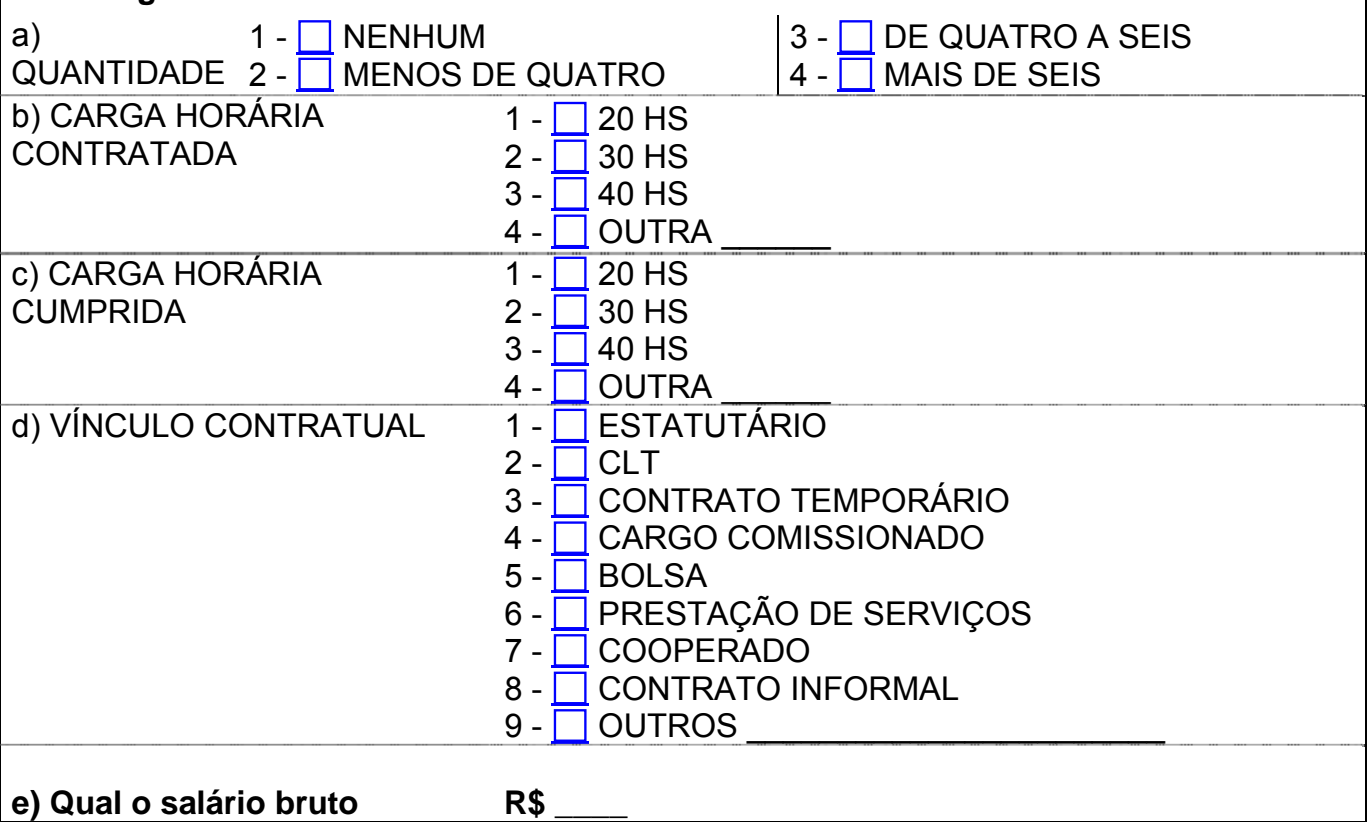

6.2 - Nesta questão, o entrevistador deverá assinalar, para cada categoria profissional, de quais treinamentos o profissional participou. Devem ser considerados todos os treinamentos aos quais se submeteram os profissionais, independente da instituição que realizou e da carga horária. É importante ressaltar que devem ser considerados os treinamentos realizados após o ingresso no programa de saúde da família, mesmo se tivesse atuando em outro município.

Como deve haver mais de um agente comunitário de saúde e pode haver mais de um auxiliar de enfermagem, assinalar as informações que retratem a realidade da maioria destes profissionais.

6.2 - Marcar se os componentes da ESF foram submetidos a capacitações nas seguintes áreas: 
6.2.1 - Médico

\begin{tabular}{|c|c|c|c|}
\hline a) & AIDPI & $1-\square \operatorname{SIM}$ & 2 - $\square$ NÃO \\
\hline b) & DIABETES & $1-\square$ SIM & $2-\square \mathrm{NÃO}$ \\
\hline c) & HIPERTENSÃO & $1-\square \operatorname{SIM}$ & 2 - $\square$ NÃO \\
\hline d) & DST/AIDS & $1-\square$ SIM & $2-\square$ NÃO \\
\hline e) & HANSENÍASE & $1-\square \operatorname{SIM}$ & $2-\square N A ̃ C$ \\
\hline f) & IMUNIZAÇÃO & $1-\square \operatorname{SIM}$ & $2-\square$ NÃO \\
\hline g) & SAÚDE DA MULHER & $1-\square \operatorname{SIM}$ & 2 - $\square$ NÃO \\
\hline h) & TREINAMENTO INTRODUTÓRIO & $1-\square \operatorname{SIM}$ & $2-\square$ NÃO \\
\hline i) & $\begin{array}{l}\text { TREINAMENTO PARA O } \\
\text { PREENCHIMENTO DO SIAB }\end{array}$ & $1-\square \operatorname{SIM}$ & 2 - $\square$ NÃO \\
\hline j) & TUBERCULOSE & $1-\square \operatorname{SIM}$ & $2-\square N A \tilde{C}$ \\
\hline k) & OUTROS & $1-\square$ SIM & $2-$ \\
\hline
\end{tabular}

6.2.2 Enfermeiro

\begin{tabular}{llll} 
a) & AIDPI & $1-\square \mathrm{SIM}$ & $2-\square$ NÃO \\
b) & DIABETES & $1-\square \mathrm{SIM}$ & $2-\square$ NÃO \\
\hline c) & HIPERTENSÃO & $1-\square \mathrm{SIM}$ & $2-\square$ NÃO \\
\hline d) & DST/AIDS & $1-\square \mathrm{SIM}$ & $2-\square$ NÃO \\
\hline e) & HANSENÍASE & $1-\square \mathrm{SIM}$ & $2-\square$ NÃO \\
\hline f) & IMUNIZAÇÃO & $1-\square \mathrm{SIM}$ & $2-\square$ NÃO \\
\hline g) & SAÚDE DA MULHER & $1-\square \mathrm{SIM}$ & $2-\square$ NÃO \\
\hline h) & TREINAMENTO INTRODUTÓRIO & $1-\square \mathrm{SIM}$ & $2-\square$ NÃO \\
\hline i) & TREINAMENTO PARA O & $1-\square \mathrm{SIM}$ & $2-\square$ NÃO \\
& PREENCHIMENTO DO SIAB & $1-\square \mathrm{SIM}$ & $2-\square$ NÃO \\
j) & TUBERCULOSE & $1-\square \mathrm{SIM}$ & $2-\square$ NÃO \\
\hline k) & OUTROS & $1-\square$
\end{tabular}

6.2.3 Auxiliar de Enfermagem
a) AIDPI
$1-\square \operatorname{SIM}$
2 - $\square$ NÃO
b) DIABETES
$1-\square$ SIM
2 - $\square$ NÃO
c) HIPERTENSÃO
$1-\square$ SIM
2 - $\square$ NÃO
d) DST/AIDS
$1-\square$ SIM
2 - $\square$ NÃO
e) HANSENÍASE
$1-\square$ SIM
2 - $\square$ NÃO
f) IMUNIZAÇÃO
$1-\square$ SIM
$2-\square$ NÃO
g) SAÚDE DA MULHER
$1-\square \operatorname{SIM}$
2 - $\square$ NÃO
h) TREINAMENTO INTRODUTÓRIO
$1-\square \operatorname{SIM}$
2 - $\square$ NÃO
i) TREINAMENTO PARA O PREENCHIMENTO DO SIAB
$1-\square \operatorname{SIM}$
2 - $\square$ NÃO
j) TUBERCULOSE
$1-\square \operatorname{SIM}$
2 - $\square$ NÃO
k) OUTROS

$1-\square \operatorname{SIM} \quad 2-\square$ NÃO

6.2.4. Agente Comunitário de Saúde
a) AIDPI
$1-\square \operatorname{SIM}$
$2-\square$ NÃO
b) DIABETES
$1-\square$ SIM
2 - $\square$ NÃO 


\begin{tabular}{|c|c|c|c|}
\hline c) & HIPERTENSÃO & $1-\square \operatorname{SIM}$ & $2-\square N A ̃ O$ \\
\hline d) & DST/AIDS & $1-\bar{\square} \operatorname{SIM}$ & $2-\vec{\square} N A ̃ O$ \\
\hline e) & HANSENÍASE & $1-\square \operatorname{SIM}$ & $2-\bar{\square} N \tilde{O} O$ \\
\hline f) & IMUNIZAÇÃO & $1-\square \operatorname{SIM}$ & $2-\square N A ̃ O$ \\
\hline g) & SAÚDE DA MULHER & $1-\square \operatorname{SIM}$ & $2-\square$ NÃO \\
\hline h) & TREINAMENTO INTRODUTÓRIO & $1-\square \operatorname{SIM}$ & $2-\square$ NÃO \\
\hline i) & $\begin{array}{l}\text { TREINAMENTO PARA O } \\
\text { PREENCHIMENTO DO SIAB }\end{array}$ & $1-\square \operatorname{SIM}$ & $2-\square N A ̃ O$ \\
\hline j) & TUBERCULOSE & $1-\square \operatorname{SIM}$ & $2-\square N A ̃ O$ \\
\hline k) & OUTROS & $1-\square \operatorname{SIM}$ & $2-\square N \tilde{N O}$ \\
\hline
\end{tabular}

6.3 - Nesta questão, o entrevistador deverá identificar se a equipe teve acesso, na unidade de saúde, às publicações listadas. O entrevistador não precisa solicitar as publicações para verificar se as mesmas realmente estão disponíveis, mas deverá identificar se a equipe teve acesso no próprio local de trabalho. Caso o acesso às publicações listadas tenha sido por meio de veículos como eventos, congressos, Internet, etc assinalar a opção 2 - Não.

\section{3 - A ESF teve acesso na unidade de saúde às seguintes publicações do MS?}

\begin{tabular}{|c|c|c|c|c|}
\hline & REVISTA BRASILEIRA SAÚDE DA FAMÍLIA & $\begin{array}{l}1-\square \text { SIM } \\
\square \text { NÃO SABE }\end{array}$ & $2-\square$ NÃO & \\
\hline & $\begin{array}{l}\text { INFORME DA ATENÇÃO BÁSICA - No } 4 \text { - } \\
\text { TUBERCULOSE - DEZ/2000 }\end{array}$ & $\begin{array}{l}1-\square \text { SIM } \\
\square \text { NÃO SABE }\end{array}$ & $2-\square \mathrm{NÃO}$ & 3 - \\
\hline C) & $\begin{array}{l}\text { INFORME DA ATENÇÃO BÁSICA - N } 5 \text { - } \\
\text { ASSISTÊNCIA FARMACÊUTICA - JAN/2001 }\end{array}$ & $\begin{array}{l}1-\square \text { SIM } \\
\square \text { NÃO SABE }\end{array}$ & NÃO & $3-$ \\
\hline D) & $\begin{array}{l}\text { INFORME DA ATENÇÃO BÁSICA - N } 6 \text { - } \\
\text { DIABETES - FEV/2001 }\end{array}$ & $\begin{array}{l}1-\square \operatorname{SIM} \\
\square \text { NÃO SABE }\end{array}$ & NÃO & $3-$ \\
\hline E) & $\begin{array}{l}\text { INFORME DA ATENÇÃO BÁSICA - Nº } 7 \text { - SAÚDE } \\
\text { BUCAL - MAR/2001 }\end{array}$ & $1-\square$ SIM & NÃO & $3-$ \\
\hline F) & $\begin{array}{l}\text { MANUAL DO SISTEMA DE INFORMAÇÃO DA } \\
\text { ATENÇÃO BÁSICA }\end{array}$ & $\begin{array}{l}1-\square \text { SIM } \\
\square \text { NÃO SABE }\end{array}$ & NÃO & $3-$ \\
\hline G) & $\begin{array}{l}\text { MANUAL: O TRABALHO DO AGENTE } \\
\text { COMUNITÁRIO DE SAÚDE }\end{array}$ & $1-\square$ SIM & & \\
\hline H) & $\begin{array}{l}\text { CADERNOS DE ATENÇÃO BÁSICA No } N^{\circ} 7- \\
\text { HIPERTENSÃO E DIABETES - } 2001\end{array}$ & $\begin{array}{l}1-\square \text { SIM } \\
\square \text { NÂO SABE }\end{array}$ & $2-\square$ NÃO & $3-$ \\
\hline
\end{tabular}


O item 6.4 o entrevistador identificará a existência um programa sistemático de educação continuado para cada categoria da equipe.

\begin{tabular}{|c|c|c|}
\hline 6.4 - Existe um programa sistemático $d$ & :ontinuada & ra os profis \\
\hline MÉDICO & $1-\square S I M$ & $2-\square N \tilde{A} O$ \\
\hline b) ENFERMEIRO & $1-\square S I M$ & $2-\square N \tilde{A} O$ \\
\hline c) AUXILIAR DE ENFERMAGEM & $1-\square S I M$ & $2-\square N \tilde{A} O$ \\
\hline d) AGENTE COMUNITÁRIO DE SAÚDE & $1-\square S I M$ & $2-\square N \tilde{A} O$ \\
\hline
\end{tabular}

\section{Parte 7 - Observações gerais}

O item a seguir, deve ser preenchido com o nome e categoria do principal informante. Mesmo que vários profissionais estejam presentes durante o preenchimento do roteiro de observações, colocar o nome daquele que se apresentou como informante mais importante.

Principal informante (nome e categoria):

O campo OBSERVAÇÕES é destinado para o registro de eventuais observações feitas pelo entrevistador que mereçam análise da comissão organizadora e de excepcionalidades encontradas.

\section{Observações:}


Ao final do dia, os entrevistadores devem revisar todos os roteiros de observações e reescrevê-los à tinta. Observar atentamente a existência de questões em branco sem justificativa, ou questões respondidas duplamente.

Em seguida, o entrevistador deverá assinalar a situação do roteiro de observações (Item 1).

- Será considerado completo o roteiro de observações que apresentar todas as questões devidamente assinaladas e sem erros.

- Será considerado incompleto o roteiro de observações que foi aplicado a algum informante e no qual alguma questão ficou sem resposta ou com resposta inválida.

- A situação "não respondido" deverá ser assinalada nos casos em que o entrevistador não conseguir obter respostas de nenhum informante.

Na seqüência o entrevistador deverá assinalar o motivo da situação do roteiro de observações (Item 2), principalmente nos casos em que o roteiro de observações estiver incompleto ou não respondido. Se ocorrer a situação do roteiro de observações se encontrar completo, mas não tiver sido aplicado ao médico ou enfermeiro da equipe, assinalar o motivo neste item.

A única situação em que não há marcação de motivo é a do roteiro de observações completo e aplicado ao profissional médico ou enfermeiro da equipe observada.

Não existe a possibilidade de marcação de mais de um motivo da situação do questionário. 


\section{Saúde Bucal}

Instruções para preenchimento do roteiro de observações a ser aplicado à equipe de saúde bucal:

Roteiro de observações no.

O coordenador local será responsável pela numeração destes roteiros de observações. Se algum roteiro de observações for invalidado, repetir a numeração num roteiro de observações em branco e escrever na primeira folha ocupando toda a página que o mesmo foi cancelado.

No caso dos entrevistadores encontrarem equipes que não estavam na programação, utilizar os roteiros de observações sobressalentes e deixar este item em branco.

A primeira página do roteiro de observações deverá sempre ser toda preenchida. O primeiro quadro apresentado deverá ser preenchido pelo entrevistador ao final do dia, após a conferência do roteiro de observações. As instruções quanto a este campo estão no fim do manual. 


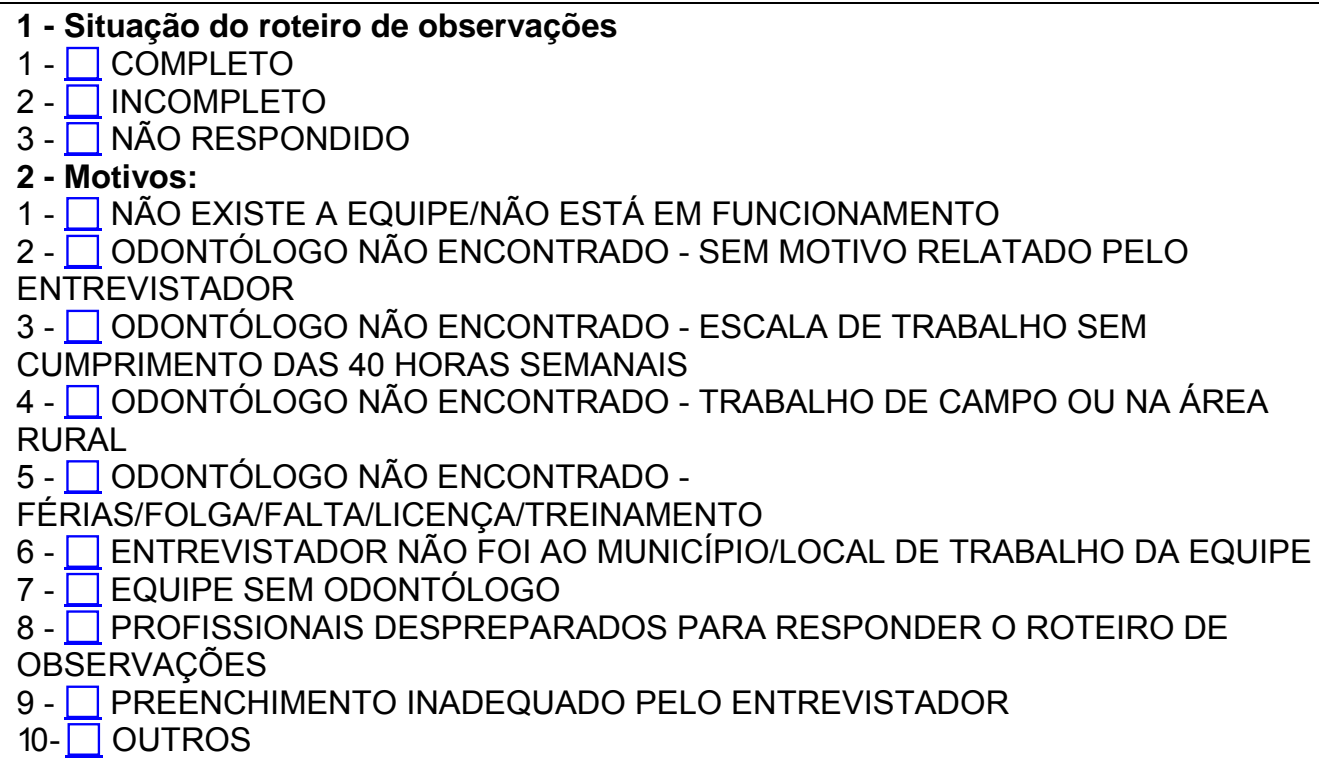

Preencher com o nome completo do entrevistador e data da entrevista

\section{Entrevistador(a):}

Data da Entrevista: $\quad l \quad I 2001$

\section{Parte 1 - Caracterização da ESB}

Neste bloco, serão registrados os dados gerais de identificação do estado, município e equipe. Os itens que não estão numerados não comporão o banco de dados, mas são importantes instrumentos de verificação da composição da equipe.

\begin{tabular}{|l|}
\hline 1.1 - UF: SÃO PAULO (Este campo estará previamente preenchido) \\
\hline $\begin{array}{l}\text { 1.2 - Município: (Neste campo, o entrevistador deverá anotar o nome do município } \\
\text { estudado) }\end{array}$ \\
\hline
\end{tabular}


Neste campo, o entrevistador deverá anotar o nome ou o código com o qual a equipe é identificada. No caso da ESB, a identificação dela pode ser a das duas ESF às quais ela está vinculada. Registrar também o código da unidade de saúde que funciona como sede da equipe de saúde bucal.

Nome da ESB: (Neste campo, o entrevistador deverá anotar o nome ou o código com o qual a equipe é identificada)

Neste campo o entrevistador deverá assinalar em qual modalidade de habilitação está cadastrada a equipe de saúde bucal, de acordo com a Portaria $n^{\circ} 1444$ de 28 de dezembro de 2000. Na modalidade 1, a equipe é composta pelo Cirurgião-dentista e pelo Auxiliar de Consultório Dentário e na modalidade 2, a equipe é composta pelo Cirurgiãodentista, pelo Técnico de Higiene Dental e pelo Auxiliar de Consultório Dentário.

\begin{tabular}{|lc|l|}
\hline $\begin{array}{l}1.3 \text { - Modalidade de Habilitação: } \\
\square-\square\end{array}$ & 1 - & $\begin{array}{l}\text { Código da unidade de saúde: } \\
\text { (Código SIA/SUS da unidade de saúde) }\end{array}$ \\
\hline
\end{tabular}

Componentes da ESB: (Neste campo o entrevistador deverá anotar o nome por extenso e o número do registro profissional)

Dentista: CRO/UF:

THD:

ACD:

\section{Parte 2 - Implantação da Equipe de Saúde Bucal}

O primeiro bloco do instrumento agrupa questões que pretendem avaliar características e o processo de implantação da ESB. 
2.1 - Nesta questão, o entrevistador deverá perguntar à equipe há quanto tempo a mesma está em funcionamento. Caso nenhum componente da equipe saiba informar, preencher com a informação prestada pelo gestor municipal.

\section{1 - Esta ESB está em funcionamento há quanto tempo?}

1 - $\square$ MAIS DE 6 MESES $\quad 3$ - $\square$ DE 1 A 3 MESES

2 - $\square$ DE 4 A 6 MESES $4-\square$ MENOS DE 30 DIAS

2.2 - Nesta questão o entrevistador deverá marcar a opção adequada conforme a informação prestada pela equipe.

2.2 - A ESB atua em zona:

$1-\square$ URBANA $2-\square$ RURAL $3-\square$ EM AMBAS

2.3 - A recomendação da Portaria nº 267 de 6 de março de 2001 é que haja uma equipe de saúde bucal para cada duas equipes de saúde da família, mas podem ser encontradas situações nas quais o município não estará cumprindo as recomendações da portaria. Registrar, portanto, a quantas equipes de saúde da família está ligada a equipe de saúde bucal entrevistada.

2.3 - A quantas ESF está ligada esta ESB?

1 - $\square$ UMA 2 - $\square$ DUAS 3 - $\square$ TRÊS OU MAIS 
2.4 - Registrar os nomes ou códigos das equipes de saúde da família às quais estão ligadas as equipes de saúde bucal de acordo com os roteiros de observações das equipes de saúde da família.

\section{4 - Identificação das ESF:}

2.5 - Nesta questão o entrevistador deverá assinalar as opções abaixo, conforme a categoria populacional. O entrevistador deverá perguntar a ESB qual a população adstrita a ela. Esta questão deverá ser de fato preenchida com a informação prestada pela ESB mesmo que seja estimada. Se a equipe de saúde bucal não souber informar, assinalar a opção 4 - Não sabe informar.

\begin{tabular}{ll} 
& $1-\square$ MENOS DE 4.800 PESSOAS \\
& $2-\square$ DE 4.800 A 6.900 PESSOAS \\
2.5 - População acompanhada por esta & $3-\square$ MAIS DE 6.900 PESSOAS \\
ESB: & $4-\square$ NÃO SABE INFORMAR \\
\hline
\end{tabular}

2.6 - Nesta questão o entrevistador deverá assinalar as opções abaixo, conforme a existência ou não de área de abrangência definida para a equipe de saúde bucal. $O$ entrevistador deverá perguntar a ESB se há área de abrangência definida para a mesma. Observar qual instrumento possibilita à equipe a identificação da área pela qual a mesma tem responsabilidade sanitária. Estes instrumentos poderão ser mapa da área, lista dos bairros ou das ruas que limitam as áreas, algum documento da secretaria de saúde que aponte as áreas por equipe, etc. Se a equipe não souber informar, marcar a opção 2 - Não. 
2.6 Existe área de abrangência definida para a equipe de saúde Bucal?

\section{$1-\square \operatorname{SIM} \quad 2-\square$ NÃO}

2.7 - Nesta questão o entrevistador deverá assinalar as opções abaixo. O entrevistador deverá perguntar a ESB se há mapa da área de abrangência disponível para o seu uso na unidade de saúde e solicitá-lo para verificação. Se a equipe não souber informar, marcar a opção 2 - Não.

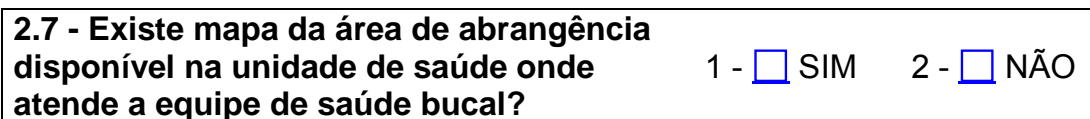

atende a equipe de saúde bucal?

Parte 3 - Infra-estrutura da Unidade Básica de Saúde

Este segundo bloco se destina a avaliar em que condições estruturais têm se dado o trabalho da ESB e se a infra-estrutura local atende as recomendações do Ministério da Saúde para o funcionamento desta equipe no município.

3.1 - O entrevistador deverá verificar a unidade de saúde in loco para o preenchimento desta questão, não devendo coletar apenas informações da ESB ou do gestor local.

- Se a ESB atua em uma ou mais unidades de saúde junto com as ESF ligadas a ela, colocar o código 1. Estão incluídas nesta categoria prédios próprios ou alugados, desde que configurados como unidade de saúde.

- Se a ESB atende em consultório odontológico que fica localizado em clínica ou unidade de saúde diferente da que a ESF atende, usar o código 2. 
- Se a ESB atende exclusivamente em consultório localizado em escola, usar o código 3.

- Se a ESB atende exclusivamente em locais comunitários emprestados ou alugados, mas diferentes daquele onde a equipe de saúde da família atende, assinalar a opção 4.

- Se não há consultório odontológico disponível para a equipe realizar os atendimentos, assinalar a opção 5.

O equipamento odontológico deverá ser considerado aquele onde a equipe atende a maior parte do tempo, mesmo que esteja fora da área de abrangência da equipe. Se a equipe atender em unidade móvel, considerar o item 2). Se for marcada a opção 5 - NÃO HÁ CONSULTÓRIO ODONTOLÓGICO, responder apenas as questões 3.5 e 3.6 desta parte.

\section{1 - Qual o local onde está localizado o equipamento odontológico utilizado pela} ESB?

$\begin{array}{ll}1-\square \text { US } & 4-\square \text { PRÉDIOS COMUNITÁRIOS } \\ 2-\square \text { CLÍNICA ODONTOLÓGICA } & 5 \text { - } \square \text { NÃO HÁ CONSULTÓRIO } \\ \text { SEPARADA DA USF } & \text { ODONTOLÓGICO }\end{array}$

$3-\square$ ESCOLA

3.2 - Nesta questão o entrevistador deverá perguntar quantas ESB atendem na unidade de saúde onde trabalha a ESB entrevistada, incluindo a mesma, e colocar este número no espaço em branco. Se a opção marcada na questão 3.1 tiver sido a 5 , o entrevistador deverá pular esta questão.

3.2 - Quantas ESB atendem no local citado acima?

3.3 - Nesta questão o entrevistador deverá verificar se o consultório odontológico onde a equipe de saúde bucal atende a sua população adstrita está localizado dentro da área de abrangência da mesma. Como a implantação é recente, pode ser que ainda não 
haja infra-estrutura adequada no município e a ESB atenda em unidades fora da sua área de abrangência. Se a opção marcada na questão 3.1 tiver sido a 5, o entrevistador deverá pular esta questão.

3.3 - O equipamento odontológico está localizado dentro da área de abrangência da ESB?

\section{1 - $\square$ SIM 2 - $\square$ NÃO $3-\square$ NÃO} SABE / IGNORADO

3.4 - Nesta questão o entrevistador deverá assinalar se estão ou não presentes na unidade de saúde onde a ESB atende os materiais e equipamentos listados. O entrevistador deverá verificar in loco a presença dos mesmos e marcar que estão disponíveis somente quando estiverem em condições de uso no momento.

- Se os equipamentos estiverem disponíveis, mas sem condições de uso no momento, assinalar a opção 3.

- Se o equipamento não pertencer ao sistema de saúde e for de propriedade do profissional, a alternativa assinalada deverá ser a 2 - Não.

Se a opção marcada na questão 3.1 tiver sido a 5, o entrevistador deverá pular esta questão.

3.4 - A ESB dispõe, em sua unidade de saúde, dos seguintes materiais e equipamentos para atendimento da população?
a) APARELHO
1 - $\square$ SIM 2 - $\square$ NÃO
3 - $\square$ SIM MAS SEM
FOTOPOLIMERIZADOR CONDIÇÕES DE USO
b) CADEIRA ODONTOLÓGICA $\begin{array}{ll}1-\square \text { SIM } & 2-\square \text { CONDIÇÕES DE USO }\end{array}$ 


\begin{tabular}{|c|c|c|}
\hline c) COMPRESSOR & $\begin{array}{l}1-\square \text { SIM } 2 \text { - } \square \text { NÃO } \\
\text { CONDIÇÕES DE USO }\end{array}$ & 3 - $\square$ SIM MAS SEM \\
\hline $\begin{array}{l}\text { d) EQUIPO ODONTOLÓGICO } \\
\text { (INCLUINDO ALTA E BAIXA } \\
\text { ROTAÇÃO) }\end{array}$ & $\begin{array}{l}1-\square \text { SIM } 2-\square \text { NÃO } \\
\text { CONDIÇÕES DE USO }\end{array}$ & 3 - $\square$ SIM MAS SEM \\
\hline e) ESTUFA OU AUTOCLAVE & $\begin{array}{l}1-\square \text { SIM } 2-\square \text { NÃO } \\
\text { CONDIÇÕES DE USO }\end{array}$ & 3 - $\square$ SIM MAS SEM \\
\hline f) $\mathrm{MOCHO}$ & $\begin{array}{l}1-\square \text { SIM } 2-\square \text { NÃO } \\
\text { CONDIÇÕES DE USO }\end{array}$ & 3 - $\square$ SIM MAS SEM \\
\hline g) REFLETOR & $\begin{array}{l}1-\square \text { SIM } 2-\square \text { NÃO } \\
\text { CONDIÇÕES DE USO }\end{array}$ & 3 - $\square$ SIM MAS SEM \\
\hline h) UNIDADE AUXILIAR & $\begin{array}{l}1-\square \text { SIM } 2-\square \text { NÃO } \\
\text { CONDIÇÕES DE USO }\end{array}$ & 3 - $\square$ SIM MAS SEM \\
\hline
\end{tabular}

3.5 - Nesta questão o entrevistador deverá perguntar à ESB se ela dispõe do material citado para a realização de suas atividades, se em quantidade suficiente para o atendimento de todos os usuários que precisarem e, de acordo com a informação prestada, deverão ser assinaladas as opções abaixo.

O entrevistador deverá utilizar os seguintes critérios quanto à disponibilidade dos materiais:

- Suficiente: disponível para todas situações/pacientes quando foram necessários;

- Insuficiente: disponível em quantidade não adequada para atender as necessidades.

3.5 - A ESB dispõe do seguinte instrumental para atendimento da população?

\begin{tabular}{|c|c|c|c|c|}
\hline a) & $\begin{array}{l}\text { INSTRUMENTAL PARA EXAME } \\
\text { CLÍNICO }\end{array}$ & $\begin{array}{l}1-\square \text { NÃO HÁ } \\
\text { INSUFICIENTE }\end{array}$ & 2 - $\square$ SUFICIENTE & $3-\square$ \\
\hline b) & INSTRUMENTAL PARA DENTÍSTICA & $\begin{array}{l}1-\square \text { NÃO HÁ } \\
\text { INSUFICIENTE }\end{array}$ & 2 - $\square$ SUFICIENTE & $3-\square$ \\
\hline c) & $\begin{array}{l}\text { INSTRUMENTAL PERIODONTAL } \\
\text { BÁSICO }\end{array}$ & $\begin{array}{l}1-\square \text { NÃO HÁ } \\
\text { INSUFICIENTE }\end{array}$ & 2 - $\square$ SUFICIENTE & $3-\square$ \\
\hline d) & $\begin{array}{l}\text { INSTRUMENTAL CIRÚRGICO } \\
\text { BÁSICO }\end{array}$ & $\begin{array}{l}1-\square \text { NÃO HÁ } \\
\text { INSUFICIENTE }\end{array}$ & $2-\square$ SUFICIENTE & $3-\square$ \\
\hline
\end{tabular}




\begin{tabular}{lll}
\hline e) INSTRUMENTAL PARA URGÊNCIAS & $1-\square$ NÃO HÁ & $2-\square$ SUFICIENTE \\
ODONTOLÓGICAS (BÁSICO) & INSUFICIENTE
\end{tabular}

3.6 - Nesta questão o entrevistador deverá perguntar à ESB se ela dispõe do material citado para a realização de suas atividades, se em quantidade suficiente para o atendimento de todos os usuários que precisarem e, de acordo com a informação prestada, deverão ser assinaladas as opções abaixo.

O entrevistador deverá utilizar os seguintes critérios quanto à disponibilidade dos materiais:

- Suficiente: disponível para todas situações/pacientes quando foram necessários;

- Insuficiente: disponível em quantidade não adequada para atender as necessidades.

3.6 - Assinale a situação de abastecimento de materiais e insumos relacionados conforme as condições definidas a seguir de acordo com informação da equipe:

\begin{tabular}{|c|c|c|c|c|c|c|c|}
\hline a) & $\begin{array}{l}\text { EPI E } \\
\text { BIOSEGURAI }\end{array}$ & NÇA ${ }^{\text {MATERI }}$ & & DE & $\begin{array}{l}1 \text { - } \square \text { NÃO HÁ } \\
\text { INSUFICIENTE }\end{array}$ & 2 - $\square$ SUFICIENTE & $3-\square$ \\
\hline b) & $\begin{array}{l}\text { MATERIAL } \\
\text { CONSUMO }\end{array}$ & ODONTOLÓ & $\mathrm{GICO}$ & DE & $\begin{array}{l}1 \text { - } \square \text { NÃO HÁ } \\
\text { INSUFICIENTE }\end{array}$ & 2 - $\square$ SUFICIENTE & $3-\square$ \\
\hline c) & $\begin{array}{l}\text { MATERIAL } \\
\text { POPULAÇÃO }\end{array}$ & EDUCATIVO & PARA & A & $\begin{array}{l}1 \text { - } \square \text { NÃO HÁ } \\
\text { INSUFICIENTE }\end{array}$ & 2 - $\square$ SUFICIENTE & $3-\square$ \\
\hline d) & $\begin{array}{l}\text { FORMULÁRIC } \\
\text { ATENDIMENT }\end{array}$ & $\begin{array}{l}\text { OS } \\
\text { TO }\end{array}$ & HAS & DE & $\begin{array}{l}1-\square \text { NÃO HÁ } \\
\text { INSUFICIENTE }\end{array}$ & 2 - $\square$ SUFICIENTE & $3-\square$ \\
\hline
\end{tabular}


Este bloco se destina a avaliar o processo de trabalho da ESB e se o mesmo atende as recomendações do Ministério da Saúde para o funcionamento do PSF, visando a efetiva mudança no modelo assistencial.

4.1 - Nesta questão, o entrevistador deverá identificar se a equipe de saúde bucal participa das discussões para planejamento das atividades em conjunto com os demais componentes da equipe de saúde da família. Se os profissionais relatarem que participam das reuniões, questionar se é somente quando são discutidos assuntos relativos à saúde bucal, e assinale a opção 4 . Se os profissionais responderem que não, saber se é porque a equipe de saúde da família não se reúne, se for o caso, assinalar a opção 3 . Ainda, se os profissionais relatarem que nem todos os componentes da equipe de saúde bucal participam das reuniões, assinalar a opção 1 - Sim.

\section{1 - A ESB participa de reuniões de planejamento/avaliação junto com os demais membros da ESF? \\ $1-\square$ SIM \\ $2-\square N A \tilde{O}$ \\ 3 - $\square$ NÃO HÁ REUNIÕES DE PLANEJAMENTO \\ 4 - $\square$ SOMENTE QUANDO SÃO TRATADOS ASSUNTOS RELACIONADOS À SAÚDE BUCAL}

4.2 - Nesta questão, o entrevistador deve perguntar à equipe se a mesma registra suas ações em algum formulário específico para a equipe de saúde bucal do PSF. Se a equipe relatar que utiliza os mesmos formulários da rede de saúde para a saúde bucal, assinalar a opção 2 - Não. 
4.2 - A ESB conta com formulários específicos para controle e avaliação das suas atividades?

$1-\square \operatorname{SIM} 2-\square$ NÃO

4.3 - Assinalar se as técnicas listadas foram utilizadas pela ESB para o conhecimento do perfil epidemiológico da população adstrita. Podem ser considerados levantamentos realizados antes da implantação da equipe, desde que a mesma relate que se apropriou das informações para o planejamento e desenvolvimento das atividades.

4.3 - As ferramentas listadas abaixo foram utilizadas pela ESB para conhecimento do perfil epidemiológico relativo à saúde bucal da população da sua área de abrangência?

\begin{tabular}{llll|} 
a) & INQUÉRITO EPIDEMIOLÓGICO EM ESCOLARES & $1-\square$ SIM & $2-\square$ NÃO \\
\hline b) & $\begin{array}{l}\text { INQUÉRITO EPIDEMIOLÓGICO NA POPULAÇÃO } \\
\text { EM GERAL }\end{array}$ & $1-\square$ SIM & $2-\square$ NÃO \\
\hline c) & $\begin{array}{l}\text { LEVANTAMENTO DE NECESSIDADES EM } \\
\text { INSTITUIÇÕES }\end{array}$ & $1-\square$ SIM & $2-\square$ NÃO \\
\hline d) & $\begin{array}{l}\text { LEVANTAMENTO DE NECESSIDADES DA } \\
\text { POPULAÇÃO EM GERAL }\end{array}$ & $1-\square$ SIM & $2-\square$ NÃO \\
\hline e) & ESTUDO DE DEMANDA NAS US & $1-\square$ SIM & $2-\square$ NÃO \\
\hline
\end{tabular}

4.4 - Nesta questão o entrevistador deverá perguntar à equipe como se dá o acesso da população ao atendimento odontológico e assinalar as opções mais adequadas à resposta obtida.

4.4 - Assinale se a equipe utiliza as seguintes formas de acesso da população ao atendimento odontológico:

\begin{tabular}{|c|c|c|c|}
\hline a) & $\begin{array}{l}\text { INSCRIÇÃO E LISTA DE ESPERA SEM } \\
\text { CLASSIFICAÇÃO DE NECESSIDADES }\end{array}$ & $1-\square$ SIM & $2-\square$ NÃO \\
\hline b) & $\begin{array}{l}\text { INSCRIÇÃO E LISTA DE ESPERA COM } \\
\text { CLASSIFICAÇÃO DE NECESSIDADES }\end{array}$ & $1-\square$ SIM & $2-\square$ NÃO \\
\hline c) & FICHA NA US & $1-\square \operatorname{SIM}$ & $2-\square$ NÃO \\
\hline
\end{tabular}




\begin{tabular}{|llll|}
\hline d) & DEMANDA PROGRAMADA PARA INSTITUIÇÕES & $1-\square \mathrm{SIM}$ & 2 - $\square$ NÃO \\
\hline e) & DEMANDA PROGRAMADA PARA GRUPOS \\
PRIORITÁRIOS & $1-\square \mathrm{SIM}$ & $2-\square$ NÃO \\
\hline f) & ATENDIMENTO DE URGÊNCIA & $1-\square \mathrm{SIM}$ & 2 - $\square$ NÃO \\
\hline g) & SÓ ATENDE ESCOLARES & $1-\square \mathrm{SIM}$ & $2-\square$ NÃO \\
\hline
\end{tabular}

\section{Parte 5 - Acesso aos serviços e procedimentos}

Este bloco se destina a avaliar se o sistema de referência e contra-referência do município ou região está ou não atendendo às necessidades das ESB, garantindo a resolutividade do sistema de saúde.

5.1 - Nesta questão deverão ser assinaladas as opções 1, 2, 3 ou 4 para cada item conforme descrição abaixo. O entrevistador deverá perguntar à equipe se estão disponíveis para os usuários cadastrados na ESB os serviços citados abaixo, realizados em unidades dentro ou fora do município.

- A opção 1 - Sim, deverá ser utilizada sempre que todos os usuários encaminhados aos serviços especializados listados são atendidos.

- A opção 2 - Não, deverá ser utilizada se não há disponibilidade na rede SUS dos serviços citados.

- A opção 3 - Insuficiente, se nem todos os usuários encaminhados para este serviço de referência são atendidos.

- Se o informante não souber se há ou não a disponibilidade do serviço citado, assinalar a opção 4 - Não sabe.

5.1 - Assinale se estão disponíveis para encaminhamento de pacientes que necessitem de tratamento especializado atendidos pela ESB os seguintes serviços:
a) TRATAMENTO
$1-\square \operatorname{SIM} 2$ -
NÃO 3 - $\square$ INSUFICIENTE 4 -

ENDODÔNTICO NÃO SABE 


\begin{tabular}{|c|c|}
\hline $\begin{array}{l}\text { b) SERVIÇOS DE } \\
\text { REABILITAÇÃO (PRÓTESE) }\end{array}$ & $\begin{array}{l}1-\square \text { SIM } 2 \text { - } \square \text { NÃO } 3 \text { - } \square \text { INSUFICIENTE } 4 \text { - } \\
\square \text { NÃO SABE }\end{array}$ \\
\hline $\begin{array}{l}\text { c) SERVIÇOS ESPECIALIZADOS } \\
\text { DE PERIODONTIA }\end{array}$ & $\begin{array}{l}1-\square \text { SIM } 2 \text { - } \square \text { NÃO } 3 \text { - } \square \text { INSUFICIENTE } 4 \text { - } \\
\square \text { NÃO SABE }\end{array}$ \\
\hline d) ORTODONTIA PREVENTIVA & $\begin{array}{l}1-\square \text { SIM } 2 \text { - } \square \text { NÃO } 3 \text { - } \square \text { INSUFICIENTE } 4 \text { - } \\
\square \text { NÃO SABE }\end{array}$ \\
\hline $\begin{array}{l}\text { e) SERVIÇOS DE URGÊNCIA E } \\
\text { EMERGÊNCIA }\end{array}$ & $\begin{array}{l}1-\square \text { SIM } 2-\square \text { NÃO } 3-\square \text { INSUFICIENTE } 4 \text { - } \\
\square \text { NÃO SABE }\end{array}$ \\
\hline
\end{tabular}

Parte 6 - Recursos Humanos

Este último bloco se destina a avaliar a situação de recursos humanos da ESB e se a sua composição e funcionamento atende as recomendações do Ministério da Saúde para o PSF, visando a efetiva mudança no modelo assistencial.

6. 1 - Nesta questão, para cada categoria profissional há quatro itens a serem respondidos.

- No item a) o entrevistador deverá assinalar a alternativa que indique quantos profissionais daquela categoria atuam naquela equipe. Este item visa identificar equipes que possuem mais de um cirurgião-dentista, THD ou ACD. Visa ainda verificar se as equipes estão sem estes profissionais e há quanto tempo. Assinalar, portanto, a alternativa mais adequada. No caso da resposta ser nenhum verificar a situação e registrar nas observações (licença, doenças, desligamento, entre outros).

- No item b), o entrevistador deverá assinalar a opção mais adequada para a carga horária prevista no contrato entre a instituição empregadora e o profissional. Mesmo que não haja contrato formal, o entrevistador deverá procurar saber quantas horas estão prevista no contrato verbal firmado entre o gestor e o profissional. No caso de a resposta não se enquadrar nas categorias listadas, marcar a opção 4) outra e anotar a carga horária contratada.

- No item c) o entrevistador deverá assinalar a opção mais adequada para a carga horária efetivamente cumprida pelo profissional. Esta questão visa identificar os casos em que o profissional é contratado para uma jornada de 40 horas semanais, mas existem acordos com o gestor ou gerente do saúde da família para cumprimento de jornada menor, através de folgas, liberação para plantão, etc. e o profissional acaba não dedicando para o programa de saúde da família a carga horária necessária. No caso de a resposta 
não se enquadrar nas categorias listadas, marcar a opção 4) outra e anotar a carga horária cumprida.

- No item d) o entrevistador deverá assinalar qual o vínculo contratual do profissional, conforme as opções apresentadas. No caso de a resposta não se enquadrar nas categorias listadas, marcar a opção 9) Outros e anotar qual a forma de contratação adequada. Se o profissional for cedido ou for contratado por ONGs, assinalar a forma de contratação do mesmo pela entidade em questão e explicitar esta situação no espaço aberto da opção 9).

- No item e), o entrevistador deverá assinalar há quanto tempo os profissionais estão trabalhando naquela equipe daquele município. Esta questão visa detectar a rotatividade dos odontólogos, técnicos de higiene dental e auxiliares de consultório dentário.

- Se forem encontrados mais de um profissional na equipe, usar as informações referentes àquele que se encontra cadastrado no SIAB.

É importante destacar que não há possibilidade de marcar mais de uma opção nos itens a), b), c) e e). O item d) permite que seja marcada mais de uma opção desde que uma delas seja a opção 9 - outros.

Se houver mais de um auxiliar de consultório dentário na equipe, usar as informações referentes àquele que dedica maior parte da sua carga horária exclusivamente para o programa de saúde da família. Se for igual, registrar as informações referentes àquele que está há mais tempo na equipe.

6.1 - Registre a situação dos profissionais da ESB para as seguintes informações:

6.1.1 - Cirurgião-dentista

a) $\quad 1$ - $\square$ NENHUM HÁ MENOS DE

QUANTIDADE 30 DIAS

2 - $\square$ NENHUM DE 30 A 60 DIAS 5 - $\square$ DOIS

$3-\square$ NENHUM HÁ MAIS DE $60 \quad 6-\square$ TRÊS OU MAIS

b) CARGA HORÁRIA

$1-\square 20 \mathrm{HS}$

CONTRATADA $2-\square 30 \mathrm{HS}$

$3-\square 40 \mathrm{HS}$

4 - $\square$ OUTRA 


\begin{tabular}{|c|c|c|}
\hline $\begin{array}{l}\text { c) CARGA HORÁRIA } \\
\text { CUMPRIDA }\end{array}$ & \multicolumn{2}{|l|}{$\begin{array}{l}1-\square 20 \mathrm{HS} \\
2-\square 30 \mathrm{HS} \\
3-\square 40 \mathrm{HS} \\
4-\square \text { OUTRA }\end{array}$} \\
\hline d) VÍNCULO CONTRATUAL & \multicolumn{2}{|c|}{$\begin{array}{l}1-\bar{\square} \text { ESTATUTÁRIO } \\
2-\bar{\square} \text { CLT } \\
3-\bar{\square} \text { CONTRATO TEMPORÁRIO } \\
4-\square \text { CARGO COMISSIONADO } \\
5-\bar{\square} \text { BOLSA } \\
6 \text { - } \bar{\square} \text { PRESTAÇÃO DE SERVIÇOS } \\
7-\square \text { COOPERADO } \\
8-\bar{\square} \text { CONTRATO INFORMAL } \\
9-\square \text { OUTROS }\end{array}$} \\
\hline e) TEMPO NA EQUIPE & \multicolumn{2}{|c|}{$\begin{array}{l}\square \text { Mais de seis meses } \\
-\square \text { De } 4 \text { a } 6 \text { meses } \\
-\square \text { De } 1 \text { a } 3 \text { meses } \\
-\square \text { Menos de } 30 \text { dias }\end{array}$} \\
\hline \multicolumn{3}{|c|}{ 6.1.2 - Técnico de Higiene Dental (apenas para a modalidade 2) } \\
\hline $\begin{array}{ll}\text { a) } & 1-\square \text { NENH } \\
\text { QUANTIDADE } & 30 \text { DIAS } \\
& 2-\square \text { NENH } \\
& 3-\square \text { NENH } \\
& \text { DIAS }\end{array}$ & $\begin{array}{l}\text { HÁ MENOS DE } \\
\text { DE } 30 \text { A } 60 \text { DIAS } \\
\text { HÁ MAIS DE } 60\end{array}$ & $\begin{array}{l}4-\square \text { UM } \\
5-\square \text { DOIS } \\
6-\square \text { TRÊS OU MAIS }\end{array}$ \\
\hline $\begin{array}{l}\text { b) CARGA HORÁRIA } \\
\text { CONTRATADA }\end{array}$ & \multicolumn{2}{|l|}{$\begin{array}{l}1-\square 20 \mathrm{HS} \\
2-\square 30 \mathrm{HS} \\
3-\square 40 \mathrm{HS} \\
4-\square \text { OUTRA }\end{array}$} \\
\hline $\begin{array}{l}\text { c) CARGA HORÁRIA } \\
\text { CUMPRIDA }\end{array}$ & \multicolumn{2}{|c|}{$\begin{array}{l}1-\square 20 \text { HS } \\
2-\square 30 \text { HS } \\
3-\square \text { 40 HS } \\
4-\square \text { OUTRA }\end{array}$} \\
\hline d) VÍNCULO CONTRATUAL & \multicolumn{2}{|c|}{$\begin{array}{l}1-\bar{\square} \text { ESTATUTÁRIO } \\
2-\bar{\square} \text { CLT } \\
3-\bar{\square} \text { CONTRATO TEMPORÁRIO } \\
4-\bar{\square} \text { CARGO COMISSIONADO } \\
5-\bar{\square} \text { BOLSA } \\
6 \text { - } \\
7 \text { - PRESTAÇÃO DE SERVIÇOS } \\
8 \text { - } \text { COOPERADO } \\
9 \text { - } \text { CONTRATO INFORMAL } \\
\end{array}$} \\
\hline e) TEMPO NA EQUIPE & \multicolumn{2}{|c|}{$\begin{array}{l}1-\square \text { Mais de seis meses } \\
2-\square \text { De } 4 \text { a } 6 \text { meses } \\
3-\square \text { De } 1 \text { a } 3 \text { meses } \\
4-\square \text { Menos de } 30 \text { dias }\end{array}$} \\
\hline \multicolumn{3}{|c|}{ 6.1.3 - Auxiliar de Consultório Dentário } \\
\hline \multicolumn{3}{|c|}{$\begin{array}{ll}\text { a) } & 1-\square \text { NENHUM HÁ MENOS DE } \\
\text { QUANTIDADE } & 30 \text { DIAS } \\
& 2-\square \text { NENHUM DE } 30 \text { A } 60 \text { DIAS } \\
& 3-\square \text { NENHUM HÁ MAIS DE } 60 \\
& \text { DIAS }\end{array}$} \\
\hline $\begin{array}{l}\text { b) CARGA HORÁRIA } \\
\text { CONTRATADA }\end{array}$ & $\begin{array}{l}1-\square 20 \mathrm{HS} \\
2-\square 30 \mathrm{HS} \\
3-\square 40 \mathrm{HS} \\
4-\square \text { OUTRA }\end{array}$ & \\
\hline
\end{tabular}




\begin{tabular}{|ll|}
\hline C) CARGA HORÁRIA & $1-\square$ 20 HS \\
CUMPRIDA & $2-\square$ 30 HS \\
& $3-\square$ 40 HS \\
& $4-\square$ OUTRA \\
\hline d) VÍNCULO CONTRATUAL & $1-\square$ ESTATUTÁRIO \\
& $2-\square$ CLT \\
& $3-\square$ CONTRATO TEMPORÁRIO \\
& $4-\square$ CARGO COMISSIONADO \\
& $5-\square$ BOLSA \\
& $6-\square$ PRESTAÇÃO DE SERVIÇOS \\
& $7-\square$ COOPERADO \\
& $8-\square$ CONTRATO INFORMAL \\
& $9-\square$ OUTROS \\
& $1-\square$ Mais de seis meses \\
& $2-\square$ De 4 a 6 meses \\
& $3-\square$ De 1 a 3 meses \\
& $4-\square$ Menos de 30 dias \\
\hline e) TEMPO NA EQUIPE &
\end{tabular}

\section{Parte 7 - Observações gerais}

O item a seguir, deve ser preenchido com o nome e categoria do principal informante. Mesmo que vários profissionais estejam presentes durante o preenchimento do roteiro de observações, colocar o nome daquele que se apresentou como informante mais importante.

Principal informante (nome e categoria):

O campo OBSERVAÇÕES é destinado para o registro de eventuais observações feitas pelo entrevistador que mereçam análise da comissão organizadora e de excepcionalidades encontradas.

\section{Observações:}


Ao final do dia, os entrevistadores devem revisar todos os roteiros de observações. Observar atentamente a existência de questões em branco sem justificativa, ou questões respondidas duplamente.

Em seguida, o entrevistador deverá assinalar a situação do roteiro de observações (Item 1).

- Será considerado completo o roteiro de observações que apresentar todas as questões devidamente assinaladas e sem erros.

- Será considerado incompleto o roteiro de observações que foi respondido por algum informante e no qual alguma questão ficou sem resposta ou com resposta inválida.

- A situação "não respondido" deverá ser assinalada nos casos em que o entrevistador não conseguir obter respostas de nenhum informante.

Na seqüência o entrevistador deverá assinalar o motivo da situação do roteiro de observações (Item 2), principalmente nos casos em que o roteiro de observações estiver incompleto ou não respondido. Se ocorrer a situação do roteiro de observações se encontrar completo, mas não tiver sido aplicado ao odontólogo da equipe, assinalar o motivo neste item.

A única situação em que não há marcação de motivo é a do roteiro de observações completo e aplicado ao profissional odontólogo da equipe observada.

Não existe a possibilidade de marcação de mais de um motivo da situação do questionário. 